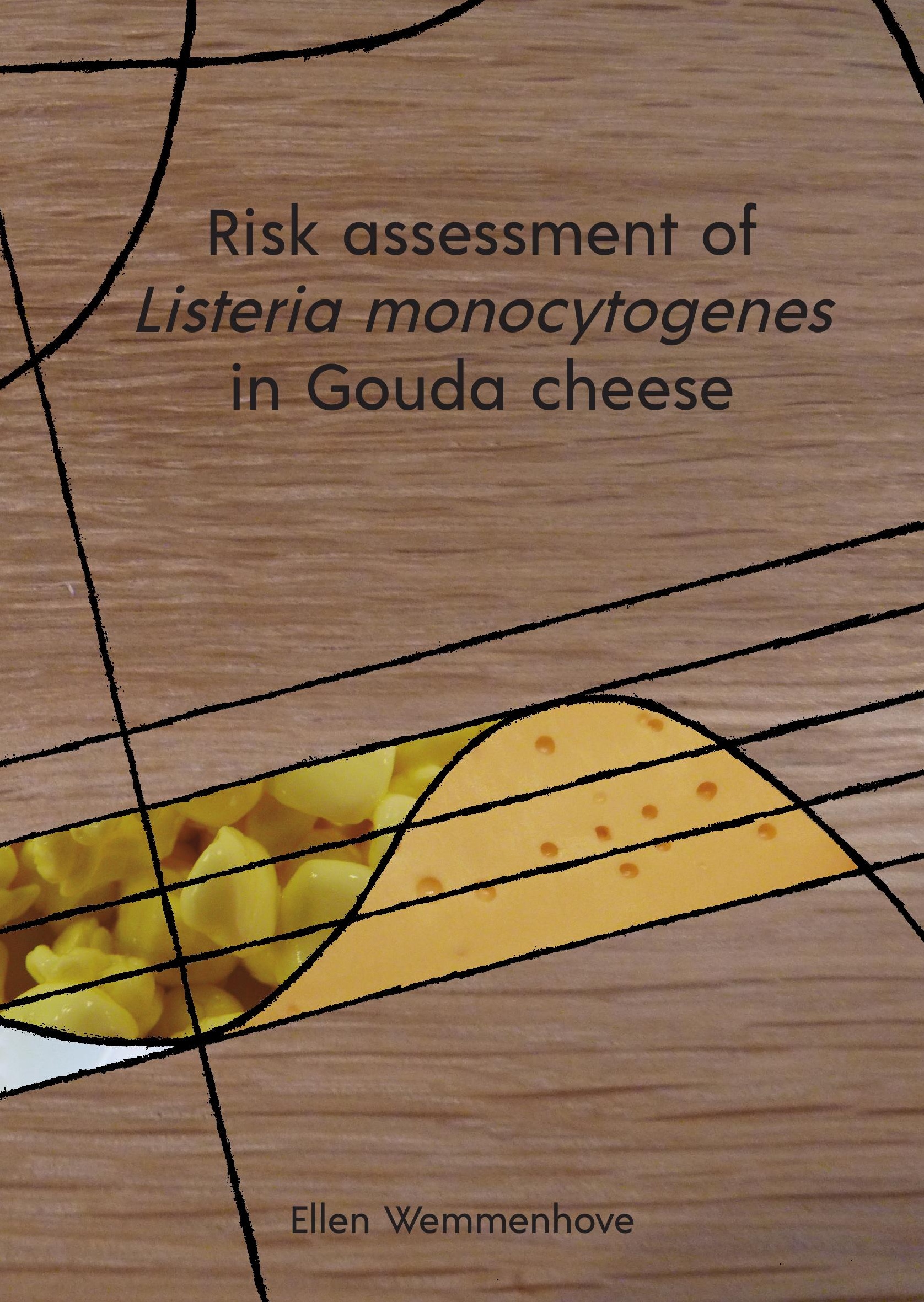





\section{Risk assessment of Listeria monocytogenes in Gouda cheese}




\section{Thesis committee}

\section{Promotors}

Prof. Dr M.H. Zwietering

Professor of Food Microbiology

Wageningen University \& Research

Prof. Dr A.C.M. van Hooijdonk

Emeritus Professor of Dairy Science

Wageningen University \& Research

\section{Co-promotor}

Dr M.H.J. Wells-Bennik

Principle Scientist

NIZO food research, Ede

\section{Other members}

Prof. Dr M. Kleerebezem, Wageningen University \& Research

Prof. Dr B.H. ter Kuile, University of Amsterdam

Prof. Dr J.C. Augustin, National Veterinary School of Alfort, France

Dr M.H. Bonestroo, Royal FrieslandCampina, Wageningen 


\title{
Risk assessment of Listeria monocytogenes in Gouda cheese
}

\author{
Ellen Wemmenhove
}

Thesis

submitted in fulfilment of the requirements for the degree of doctor at Wageningen University

by the authority of the Rector Magnificus,

Prof. Dr A.P.J. Mol, in the presence of the

Thesis Committee appointed by the Academic Board to be defended in public on Friday 1 February 2019 at $1: 30$ p.m. in the Aula. 
Ellen Wemmenhove

Risk assessment of Listeria monocytogenes in Gouda cheese, 180 pages.

PhD thesis, Wageningen University, Wageningen, the Netherlands (2019) With references, with summary in English

ISBN 978-94-6343-562-8

DOI https://doi.org/10.18174/466848 


\section{Table of contents}

$\begin{array}{ll}\text { Abstract } & 6\end{array}$

Chapter $1 \quad$ General introduction 9

Chapter 2 Fate of Listeria monocytogenes in Gouda microcheese: 35

no growth, and substantial inactivation after extended

ripening times

Chapter 3 The fate of Listeria monocytogenes in brine and on

Gouda cheese following artificial contamination during brining

Chapter $4 \quad$ How $\mathrm{NaCl}$ and water content determine water activity

during ripening of Gouda cheese, and the predicted

effect on inhibition of Listeria monocytogenes

Chapter 5

Minimal inhibitory concentrations of undissociated lactic,

acetic, citric and propionic acid for Listeria

monocytogenes under conditions relevant to cheese

Chapter 6 Factors that inhibit growth of Listeria monocytogenes in

nature-ripened Gouda cheese: A major role for

undissociated lactic acid

Chapter 7

General discussion

Summary

Acknowledgements

List of publications

Curriculum vitae

VLAG graduate school activities 


\section{Abstract}

In this PhD thesis, the potential of outgrowth of L. monocytogenes was assessed in Dutchtype Gouda cheese. It was demonstrated that L. monocytogenes, which can cause listeriosis, is not able to grow in or on Dutch-type Gouda. The factors present in Gouda cheese that can lead to full inhibition of growth of L. monocytogenes were identified and safety criteria aiming for complete inhibition of growth of L. monocytogenes in Dutch-type Gouda cheese are suggested.

Dutch-type Gouda cheese is a semi-hard cheese made from bovine milk that is pasteurized when produced at an industrial scale. It is a ready-to-eat food with a $\mathrm{pH}>5.0$ and water activity $a_{w}>0.94$. In absence of scientific evidence that this product does not support growth, Dutch-type Gouda is classified by the European legislation as a ready-to-eat food product able to support growth of L. monocytogenes.

In two challenge studies described in this thesis, it was demonstrated that Dutch-type Gouda cheese does not support growth of L. monocytogenes when inoculated in and on the product. During the cheese making process, entrapment but no growth of L. monocytogenes in the curd was observed. During subsequent ripening of the cheeses, no growth was observed, and upon prolonged ripening periods ( $>2$ months) inactivation was found. In the second challenge study, a limited transfer of L. monocytogenes from brine to the outer layers of cheeses was observed, and during brining and ripening viable numbers of $L$. monocytogenes did not increase.

The variation in $\mathrm{a}_{\mathrm{w}}$ inside Gouda cheese was assessed by determining the profiles of water and $\mathrm{NaCl}$ and the resulting $\mathrm{a}_{\mathrm{w}}$ in nature-ripened and foil-ripened Gouda cheese during brining and ripening. An empirical model was derived for Gouda cheese in which $a_{w}$ is expressed as a function of the $\mathrm{NaCl}$-in-moisture content.

Dutch-type cheeses contain organic acids that are known to have potential inhibitory effects on L. monocytogenes. The MICs of organic acids for 6 different L. monocytogenes strains were established at $\mathrm{pH}$ values that are relevant to Dutch-type Gouda. The MICs were established for lactic acid (which is the main organic acid in Gouda), acetic acid, propionic acid, and citric acid. Variations in MICs between strains were observed.

In an overall review of the factors present in Gouda cheese that are relevant to growth inhibition of L. monocytogenes, undissociated lactic acid was evaluated as the primary growth-inhibiting factor that can lead to full growth inhibition in Gouda. Additionally, low $a_{w}$ in the cheese rind and after prolonged ripening times can cause full growth inhibition. 
This thesis lends support to categorizing Gouda as a ready-to-eat food product that does not support growth of L. monocytogenes. Furthermore, it is justifiable to include undissociated lactic acid (together with $\mathrm{pH}$ and $\mathrm{a}_{\mathrm{w}}$ ) in future food safety criteria for readyto-eat products related to absence of growth of L. monocytogenes. 
Chapter 1

General introduction 


\subsection{Food safety management}

Food safety is critical to assure that food will not cause harm to the consumer when it is prepared and/or eaten according to its intended use (CAC, 2003). In the European general food law EC 178/2002 it is stated that free movement of safe and wholesome food is an essential aspect of the internal European market, and that it contributes significantly to the health and well-being of citizens, and to their social and economic interests. Consumers must be able to rely on the fact that the foods purchased and consumed will be safe and of high quality.

Food safety management systems are implemented to control foodborne hazards and thereby prevent foodborne illnesses (Meng \& Doyle, 2002). Ensuring food safety is important to maintain the trust of consumers (Raspor, Smozina \& Ambrožič, 2014). A food safety system comprises a combination of external (legal and governmental) and internal (food producer) requirements and procedures that are integrated in management and control systems. Risk management decisions should be taken based on technical and scientific input. The international ISO 22000 standard sets out the requirements for a food safety management system and maps out what an organization needs to do to demonstrate its ability to control food safety hazards and ensure that food is safe (ISO, 2005). Food safety management systems in the food industry include hazard analysis and critical control points (HACCP) approaches. Such approaches are suitable to analyse potential risks related to complex manufacturing processes and constitute a more costeffective and reliable way of assuring food safety than traditional inspection and endproduct testing. HACCP as a food safety management system is recommended by the Codex Alimentarius (van Schothorst, 2004). The aim of an HACCP analysis is to identify, evaluate and control hazards which are significant for food safety (CAC, 2003) wherein good manufacturing practice (GMP) and good hygiene practice (GHP) are prerequisites. Using an HACCP approach, it is possible to assess the likelihood of the occurrence of hazards in foods during the manufacturing, distribution and use of a food product, and to define measures for adequate control of hazards. Hazards may originate from different sources throughout the entire food production chain, for instance from the raw materials produced by farmers, from processing and production environments of food products, and from handling and storage at the level of retail, food service and consumer. Hazard analysis is the procedure to identify significant potential hazards and the conditions that lead to the presence thereof in food. It evaluates the likelihood of the hazard being present and the severity of an adverse health effect when it occurs, in order to determine whether the hazard is significant to threaten food safety. A critical control point is a raw material, location, practice, formulation or process where measures can be applied to prevent or minimize the likelihood of the presence of hazards at unacceptable levels. Specific aspects of GMP are essential for food safety and have to be singled out as CCP. Monitoring is 
checking the conformity of the control at a CCP and consists of systematic observation, measurement, recording and evaluation. Corrective actions need to be taken when monitoring indicates loss of control (van Schothorst, 2004). Examples of corrective actions are re-pasteurization and adjustment of the processing conditions. By such corrective actions, the likelihood of exposure to biological hazards such as pathogenic bacteria, viruses and mycotoxin-producing moulds can be reduced.

\subsection{Listeria monocytogenes causing listeriosis}

Listeria monocytogenes is known as an important bacterial foodborne pathogen (Table 1.1) and is the causative agent of foodborne listeriosis. Listeriosis is an illness that may have a severe outcome with a high case-fatality rate (Swaminathan \& Gerner-Smidt, 2007). It can be contracted after consumption of food that is contaminated with L. monocytogenes. L. monocytogenes is specifically a problem for the food industry, being a robust pathogen that can be present in food ingredients and in food processing facilities due to its ability to survive in highly acidic, salty and low-temperature environments and due to its ability to form biofilms. Cases of foodborne listeriosis are often related to consumption of readyto-eat products (i.e. products that are not heat-treated before consumption), including meat, seafood and dairy products. Specific microbiological criteria for L. monocytogenes in RTE foods have been set for these foods in regulation (EC) No 2073/2005. Different categories of RTE foods are defined therein, based on intended use and on the ability of L. monocytogenes to grow in or on the RTE food. Foodborne transmission of listeriosis has only been known since 1981, after an outbreak in Canada that was associated with consumption of contaminated coleslaw. The probability that a food product leads to listeriosis depends on the virulence of the strain, (human) host susceptibility and the level of exposure (WHO/FAO, 2004). The time between ingestion of contaminated food and the onset of listeriosis symptoms is eight days on average, but can be as long as two months. A long incubation period between the time of consumption and manifestation of disease symptoms can make it extremely difficult to trace the food product that contained the pathogen and it hampers an accurate assessment of the dose that led to the disease (Buchanan, Gorris, Hayman, Jackson \& Whiting, 2017).

Listeriosis may manifest as a range of symptoms. Non-invasive listeriosis can occur in any person after consumption of a high concentration of L. monocytogenes. This type of listeriosis usually manifests as mild gastroenteritis (Ooi \& Lorber, 2005). Invasive listeriosis manifests as an infection of the central nervous system and a systemic infection, leading to the high case-fatality rate of listeriosis (Low \& Donachie, 1997). In such cases, L. monocytogenes spreads from the intestines to the blood stream and from there to other organs. L. monocytogenes can cross the intestinal barrier, placental barrier and the blood- 
brain barrier. It enters, survives and multiplies in both phagocytic and non-phagocytic cells (Cossart, Pizarro-Cerda \& Lecuit, 2003). Listeriosis is mainly a risk for people with a weak immune system, such as pregnant women, newborns and people older than 65 years (Ramaswamy et al., 2007).

Table 1.1 Overview of microbial pathogens associated with foodborne outbreaks, and the proportion of food classes associated with outbreaks by that pathogen. The table was extracted from Greig \& Ravel (2009) who created a foods and aetiology cross tabulation based on 4093 foodborne outbreaks that occurred globally between 1988 and 2007 (Greig \& Ravel, 2009)

\begin{tabular}{|c|c|c|c|c|c|c|}
\hline \multirow[b]{2}{*}{ Microbial pathogen } & \multicolumn{6}{|c|}{$\%$ of food class associated with outbreak } \\
\hline & $\begin{array}{l}\text { Number of } \\
\text { outbreaks }\end{array}$ & Dairy & Seafood & Meat & $\begin{array}{l}\text { Multi- } \\
\text { ingredient }\end{array}$ & Other \\
\hline Bacillus cereus & 74 & 4.1 & 4.1 & 22.9 & 56.8 & 12.3 \\
\hline Campylobacterspp. & 191 & 34.6 & 2.6 & 41.8 & 14.1 & 6.8 \\
\hline Clostridium botulinum & 108 & 3.7 & 25 & 26.8 & 0.9 & 43.5 \\
\hline Clostridium perfringens & 248 & 0.4 & 2 & 74.6 & 20.2 & 2.8 \\
\hline Escherichia coli & 389 & 9.8 & 0.5 & 52.9 & 11.8 & 24.9 \\
\hline Listeria monocytogenes & 53 & 41.5 & 11.3 & 39.7 & 5.7 & 1.9 \\
\hline \multicolumn{7}{|l|}{ Salmonella enterica serovar } \\
\hline Enteritidis & 991 & 6.4 & 4.2 & 18.9 & 10.1 & 60.4 \\
\hline \multicolumn{7}{|l|}{ Salmonella enterica serovar } \\
\hline Typhimurium & 270 & 11.9 & 4.8 & 34.5 & 10.7 & 38.1 \\
\hline Other Salmonella enterica & 657 & 6.2 & 2.6 & 36.9 & 13.9 & 40.6 \\
\hline Shigella spp. & 83 & 14.5 & 9.6 & 14.4 & 30.1 & 31.3 \\
\hline Staphylococcus aureus & 182 & 11 & 3.3 & 51 & 22 & 12.9 \\
\hline
\end{tabular}

The number of reported cases of human listeriosis was $0.25-0.32$ per 100,000 population in the US between 2004 and 2009 (Cartwright et al., 2013) and 0.44 per 100,000 population in the EU in 2013 (EFSA, 2015). Hospitalization rates in the case of listeriosis may be as high as 94\% (Melo, Andrew \& Faleiro, 2015) and fatality rates as high as 20-30\% (Swaminathan \& Gerner-Smidt, 2007) and 15.6\% (EFSA, 2015). Leclercq, Charlier \& Lecuit (2014) assessed the global disease burden of listeriosis in 2010 and estimated that 23,150 cases related to listeriosis occurred worldwide, resulting in 5,463 deaths (case-fatality rate of 23.6\%) and 172,823 Disability Adjusted Life Years (DALYs) (Leclercq et al., 2014). L. monocytogenes was the third most costly foodborne pathogen per case in the US in 2010, due to the high hospitalization costs for listeriosis (Scharff, 2012). Listeriosis not only has negative consequences for public health, but also for the economy. When excluding medical costs, the total costs of food safety incidents in the US are around 7 billion USD per year (Hussain \& Dawson, 2013). Thomas et al. (2015) estimated the total costs of an outbreak with L. monocytogenes in a meat processing plant at nearly 242 million Canadian dollars, while the medical costs were 2.8 million Canadian dollars. 
L. monocytogenes is subdivided into 12 serotypes, of which serotype $1 / 2$ strains (especially $1 / 2 \mathrm{a}$ and $1 / 2 \mathrm{~b}$ ) account for more than $50 \%$ of the isolates from foods and food environments. Serotype 4b, however, is most often related to listeriosis (Cartwright et al., 2013; Nho, Abdelhamed, Reddy, Karsj \& Lawrence, 2015). The pathogen is rod-shaped, Gram-positive and facultative anaerobic. It belongs to the Firmicutes, but cannot form spores, and depending on the temperature, this bacterium can show motility by means of flagellae (Kathariou, Kanenaka, Allen, Kok \& Mizomoto, 1995; Lemon, Higgins \& Kolter, 2007; O'Neil \& Marquis, 2006). L. monocytogenes is ubiquitous in the environment where it can be very persistent (Farber \& Peterkin, 1991), and it is able to grow at a low $\mathrm{pH}$, low temperatures, and high salinity levels (Table 1.2). Also, the bacterium can form biofilms (Borucki, Peppin, White, Loge \& Call, 2003; Cossart et al. 2003; Carpentier \& Cerf, 2011) and is known for its proteolytic activity (Verheul, Rombouts \& Abee, 1998). The heat resistance of $L$. monocytogenes can vary per strain and food product (Aryani, Zwietering \& den Besten, 2016; van Lieverloo, de Roode, Fox, Zwietering \& Wells-Bennik, 2013).

Table 1.2 Temperature $(\tau)$, salt, $\mathrm{a}_{\mathrm{w}}, \mathrm{pH}$ limits for growth of L. monocytogenes, as obtained from ICMSF (1996)

\begin{tabular}{llc}
\hline Factor & Minimum & Limit \\
& -0.4 & Maximum \\
\hline$\tau\left({ }^{\circ} \mathrm{C}\right)$ & $<0.5$ & $\sim 45$ \\
\hline $\begin{array}{l}\text { Salt }(\% \mathrm{NaCl} \text { in water } \\
\text { phase) }\end{array}$ & and $>0.997$ & $13-16$ \\
$\quad$ and concomitant $\mathrm{a}_{\mathrm{w}}$ & & and 0.92 (minimum a growth limit) \\
\hline $\mathrm{pH}$ (using $\mathrm{HCl}$ ) & 4.39 & $9.4-9.5$ \\
\hline
\end{tabular}

\subsection{Detection and identification of L. monocytogenes}

The international standard for the method for detection of L. monocytogenes is described in ISO 11290, with part 1: detection and part 2: enumeration (ISO, 2017a;b). Enumeration of $L$. monocytogenes in positive food samples is performed on representative samples by colony count on L. monocytogenes differential selective agars in conjunction with MPN enumeration using selective enrichment in Buffered Listeria Enrichment Broth (BLEB) with subsequent plating on L. monocytogenes differential selective agars (Hitchins, Jinneman \& Chen, 2016). L. monocytogenes can be detected and identified using traditional phenotypic subtyping methods and by using molecular subtyping methods. Brain Heart Infusion (BHI) broth or $\mathrm{BHI}$ agar is the most commonly used non-selective medium for cultivation of Listeria species (Jones \& D'Orazio, 2013), but chemically defined minimal media supporting growth of L. monocytogenes are also available (Premaratne, Lin \& Johnson, 1991). There is a wide range of selective media available for L. monocytogenes, including Oxford medium, Palcam agar, ALOA agar and Rapid L'mono (Hitchins et al., 2016). Molecular subtyping methods can discriminate L. monocytogenes in a more 
sensitive way than traditional phenotyping (Wiedmann, 2015). Different methods are available: banding pattern-based methods such as pulsed field gel electrophoresis (PFGE), ribotyping, repetitive extragenic palindromic sequence analysis and sequence-based subtyping. Whole-genome sequencing (WGS) reveals the complete DNA sequence of a microorganism. WGS is currently considered as a key method to identify variation between L. monocytogenes strains, and is increasingly used to link clinical isolates from patients with contaminated foods (Wiedmann, 2015; FDA, 2016b).

\subsection{L. monocytogenes, a hazard for the dairy industry}

The dairy industry considers L. monocytogenes as a microbial hazard. The pathogen may be present in raw milk and may reside in the processing environment. Multiple reported cases of foodborne listeriosis outbreaks are related to the consumption of dairy products (Table 1.1) including raw milk cheeses and cottage cheeses (Greig \& Ravel, 2009; MartinezRios \& Dalgaard, 2018). The first recognized foodborne listeriosis outbreak that was related to consumption of dairy occurred in 1983 and was associated with pasteurized milk that was contaminated post-processing (Fleming et al., 1985).

Table 1.3 Prevalence of L. monocytogenes in raw milk based on presence/absence of L. monocytogenes detected in $25 \mathrm{~g}$ or $\mathrm{ml}$

\begin{tabular}{lllll}
\hline $\begin{array}{l}\text { Total } \\
\text { samples } \\
\text { (n) }\end{array}$ & $\begin{array}{l}\text { Amount of } \\
\text { positive } \\
\text { samples }\end{array}$ & $\begin{array}{l}\text { Prevalence } \\
\mathbf{( \% )}\end{array}$ & Country of origin & References \\
\hline 137 & 6 & 4.4 & The Netherlands & $\begin{array}{l}\text { Beckers, Soentoro \& Delgou-van Asch } \\
(1987)\end{array}$ \\
\hline 176 & 27 & 15.6 & Northern Ireland & Harvey \& Gilmour (1992) \\
\hline 589 & 29 & 4.9 & Ireland & Rea, Cogan \& Tobin (1992) \\
\hline 774 & 28 & 3.6 & Spain & Gaya, Sanchez, Medina \& Nuñez (1998) \\
\hline 295 & 58 & 19.7 & Sweden & Waak, Tham \& Danielsson-Tham (2002) \\
\hline 143 & 9 & 6.3 & Belgium & De Reu, Grijspeerdt \& Herman (2004) \\
\hline 24 & 1 & 4.2 & Ireland & Fox et al. (2009) \\
\hline 230 & 0 & 0 & Austria & Schoder et al. (2011) \\
\hline 297 & 2 & 0.7 & New Zealand & Hill, Smythe, Lindsay \& Shepherd (2012) \\
\hline 446 & 97 & 21.7 & Iran & Jamali, Radmehr \& Thong (2013) \\
\hline 468 & 11 & 2.4 & France & $\begin{array}{l}\text { Meyer-Broseta, Diot, Bastian, Rivière \& } \\
\text { Cerf (2003) }\end{array}$ \\
\hline 182 & 10 & 5.5 & Finland & Ruusunen et al. (2013) \\
\hline
\end{tabular}

Cheese may get contaminated with L. monocytogenes via the raw milk, or after pasteurization via the manufacturing environment and through the addition of additional ingredients (Lomonaco et al., 2009). The prevalence of L. monocytogenes in raw milk varies 
from 0 to $21.7 \%$ worldwide, as follows from the overview of studies shown in Table 1.3. Pasteurization leads to a reduction in viable numbers of $L$. monocytogenes in milk by 10.4 $\log$ cfu $\mathrm{g}^{-1}$ based on an average $D$ value and by 2.7 log cfu $\mathrm{g}^{-1}$ based on a $95 \%$ upper confidence interval for the $D$ value (den Besten \& Zwietering, 2012). Recontamination of the cheese milk, cheese curd or pressed cheese may occur after pasteurization, for instance via contact surfaces. L. monocytogenes has for instance been detected on cheese shelves (Notermans, 1994) and from machines used to turn cheeses during ripening (Yde et al., 2012). Raw milk (and thus raw milk cheeses) may contain L. monocytogenes through contamination of the milk at the farm level. For cheese made from pasteurized milk, the cheese milk usually undergoes a heat treatment of $72{ }^{\circ} \mathrm{C}$ for $15 \mathrm{~s}$ to inactivate microbes, including L. monocytogenes. However, if such products are contaminated later in the process with the pathogen and those support the growth of L. monocytogenes, then consumers may be exposed to the pathogen as these are ready-to-eat products that do not undergo heating prior to consumption.

Listeriosis outbreaks with cheese are often related to the consumption of contaminated soft cheeses (Melo et al., 2015), but in one case also to hard Mimolette cheese containing mites at the surface (Yde et al., 2012). Table 1.4 presents an overview of reported listeriosis outbreaks in the EU and the USA that were linked to cheese since 1983. Several cheese companies were closed after recalls or outbreaks related to cheeses contaminated with L. monocytogenes. An US company was shut down after a large outbreak of listeriosis in 1985 that was related to its Mexican-style cheese (Flynn, 2011). More recently, the Food and Drug Authority (FDA) enforced the shutdown of several US companies producing Mexican-style cheese (FDA, 2012; FDA, 2013).

Table 1.4 Overview of listeriosis outbreaks in 1983-2017 that were related to consumption of cheese. Compiled from EFSA reports (Eurosurveillance), CDC reports and a general search in Web of Science and Scopus (keywords 'listeriosis' and 'cheese', or 'Listeria', 'outbreak' and 'cheese', sorted on relevance, first 300 hits)

\begin{tabular}{lllll}
\hline $\begin{array}{l}\text { Year of } \\
\text { outbreak }\end{array}$ & Cheese group & Cases & $\begin{array}{l}\text { Morta- } \\
\text { lity } \\
\mathbf{( \% )}\end{array}$ & Reference \\
\hline $1983-1987$ & Soft cheese made from raw milk & 122 & 27 & Bula, Bille \& Glauser (1995) \\
\hline 1985 & Mexican-style soft cheeses & 142 & 34 & Linnan et al. (1988) \\
\hline 1989 & Camembert & 2 & 0 & Ries, Dicato, Hemmer \& Arendt (1990) \\
\hline $1989 / 1990$ & Blue cheese & 26 & 23 & $\begin{array}{l}\text { Jensen, Frederiksen \& Gerner-Smidt } \\
\text { (1994) }\end{array}$ \\
\hline 1995 & Brie de Meaux & NR & NR & Goulet et al. (1995) \\
\hline 1995 & Soft cheese & 37 & 30 & $\begin{array}{l}\text { Vaillant, Maillot, Charley \& Stainer } \\
\text { (1998) }\end{array}$ \\
\hline 1997 & Soft cheese & 14 & 0 & $\begin{array}{l}\text { Jacquet, Brouillé, Saint-Cloment, } \\
\text { Catimel \& Rocourt (1999) }\end{array}$ \\
\hline 1997 & Soft cheese & NR & NR & RNSP (1997)
\end{tabular}


Table 1.4 (continued)

\begin{tabular}{|c|c|c|c|c|}
\hline 2000 & Mexican-style cheese & 13 & 0 & Cartwright et al. (2013) \\
\hline 2001 & Soft cheese & 33 & 0 & Carrique-Mas et al. (2003) \\
\hline 2001 & Soft cheese & 120 & NR & Danielsson-Tham et al. (2004) \\
\hline 2001 & Cheese & 19 & 0 & Makino et al. (2005) \\
\hline 2002 & Cheese made from pasteurized milk & 86 & 0 & Pagotto, Ng, Clark \& Farber (2006) \\
\hline 2003 & Soft cheese from raw milk & 17 & 0 & $\begin{array}{l}\text { Gaulin, Ramsay, Ringuette \& Ismail } \\
\text { (2003) }\end{array}$ \\
\hline 2005 & Mexican-style cheese & 23 & 22 & MacDonald et al. (2005) \\
\hline 2005 & Queso fresco & 9 & NR & FIOD (2005) \\
\hline 2005 & Tomme cheese & 10 & 50 & Bille et al. (2006) \\
\hline 2006 & Soft cheese & 189 & 14 & Koch et al. (2010) \\
\hline 2006 & Soft cheese & 78 & 17 & EFSA (2007) \\
\hline 2007 & Camembert cheese & 17 & 18 & $\begin{array}{l}\text { Johnsen, Lingaas, Torfoss, Strom \& } \\
\text { Nordoy (2010) }\end{array}$ \\
\hline 2007 & Mature cheese & NR & NR & Vít et al. (2007) \\
\hline 2008 & Cheese & 92 & NR & $\begin{array}{l}\text { Taillefer, Boucher, Laferriere \& Morin } \\
(2010)\end{array}$ \\
\hline 2008 & Brie cheese & 91 & 5 & ProMed (2008) \\
\hline 2008 & Mexican-style cheese & 8 & 0 & Cartwright et al. (2013) \\
\hline 2009-2012 & Queso fresco & 30 & 37 & Magalhaes et al. (2015) \\
\hline 2010 & $\begin{array}{l}\text { Soft cheese (Panela, Queso fresco, } \\
\text { Requeson) }\end{array}$ & 5 & 0 & FIOD (2010) \\
\hline 2010 & Soft cheese & 28 & 11 & FIOD (2015) \\
\hline 2010 & Acid-curd cheese (Quargel) & 14 & 36 & Fretz et al. (2010) \\
\hline 2011 & Fresh cheese (chives) & 2 & NR & FIOD (2011) \\
\hline 2011 & Mexican-style cheese & 7 & 29 & Jackson et al. (2011) \\
\hline 2011 & $\begin{array}{l}\text { Pave de Nord (Mimolette-type } \\
\text { cheese made from pasteurized milk) }\end{array}$ & 12 & 33 & Yde et al. (2012) \\
\hline 2012 & $\begin{array}{l}\text { Latin-style fresh cheese (pasteurized } \\
\text { milk) }\end{array}$ & 2 & 0 & De Castro et al. (2012) \\
\hline 2012 & Ricotta cheese & 22 & 18 & CDC (2012) \\
\hline 2013 & Camembert / Brie & 18 & 17 & Newsdesk (2013b) \\
\hline 2014 & Fresh cheese & 1 & 14 & FIOD (2014) \\
\hline 2014 & Soft cheese & 5 & 20 & CDC (2014) \\
\hline 2015 & $\begin{array}{l}\text { Cheese made from unpasteurized } \\
\text { milk }\end{array}$ & 2 & 0 & $\begin{array}{l}\text { Del-Valdivia-Tapia, Pinelo-Chumbe \& } \\
\text { Carreazo (2015) }\end{array}$ \\
\hline 2015 & Fresh cheese & 3 & 33 & FIOD (2015) \\
\hline 2017 & Smear cheese & 8 & 25 & CDC (2017) \\
\hline
\end{tabular}

NR: Not reported

In the EU, $0.3 \%$ of hard, semi-soft and soft cheeses made from pasteurized milk tested positive for L. monocytogenes in 2013 (EFSA, 2015). In 2009, L. monocytogenes was detected in Dutch-type Gouda cheese exported to the USA following sampling by the FDA (FDA, 2016a), but this Gouda cheese was not linked to listeriosis, and it was unclear whether the Gouda cheese in question was made from pasteurized or unpasteurized milk, nor was information available on concentrations of L. monocytogenes in this cheese. 


\subsection{Dutch-type Gouda cheese and L. monocytogenes}

Dutch-type cheeses are semi-hard cheeses that are made from bovine milk that is pasteurized when produced at an industrial scale. In 2017, 865 million kg of cheese was produced in The Netherlands (ZuivelNL, 2017), the majority of which being Gouda cheese. Gouda Holland cheese has the protected designation of origin (PDO) status. The first production of Gouda cheese was recorded in the 17th century (Fox \& McSweeney, 2004).

A global overview of the production process of Dutch-type Gouda cheese is presented in Fig. 1.1. Upon receipt of the raw milk, the milk is thermized. After thermization, cream is removed and the skimmed milk is optionally bactofugated to reduce the concentrations of bacterial spores of Clostridium tyrobutyricum, thereby improving the final quality of the cheese and whey. Subsequently, the milk is standardized by adding pasteurized cream, therewith obtaining cheese milk with a protein content $(\sim 3.4 \%)$ and fat content $(\sim 3.7 \%)$ for a Dutch-type Gouda cheese with $48 \%$ w/w fat in dry matter. The standardized cheese milk is then pasteurized (min. $72{ }^{\circ} \mathrm{C}$ for $15 \mathrm{~s}$ ) and cooled to $\sim 31{ }^{\circ} \mathrm{C}$. At this stage, $\mathrm{CaCl}_{2}$ $(\sim 0.02 \%)$ is added to the cheese milk, followed by a starter culture consisting of $\sim 0.5-1.0 \%$ mesophilic lactic acid bacteria (primarily of Lactococcus lactis subsp. cremoris and Lactococcus lactis subsp. lactis, and additionally Leuconostoc and Lactococcus lactis subsp. lactis var. diacetylactis), and rennet ( 0.02\%). Subsequently, the milk is kept for $\sim 20$ minutes at $\sim 31^{\circ} \mathrm{C}$. The resulting curd is cut and the whey is drained from the curd. After drainage, hot water (25-30\% of the initial milk volume) is added to wash the curd and to increase the temperature to $\sim 35^{\circ} \mathrm{C}$. The latter temperature is maintained during stirring, residual heating and drainage of residual whey ( $\sim 50$ minutes). The curd is placed in a cheese mold and pressed. The resulting cheese is demolded after $80-90$ minutes and is soaked for 2-3 days in a brine bath of $\mathrm{pH} 4.4-4.8$ that contains $\sim 18 \% \mathrm{NaCl}$. After brining, the cheese is coated and ripened at $12-13{ }^{\circ} \mathrm{C}$ for $4-48$ weeks depending on age type, resulting in nature-ripened cheese (van den Berg, Meijer, Düsterhöft \& Smit, 2004). For foil-ripened cheese, the brined cheese is packed in foil before ripening.

HACCP plans have been established for Dutch cheese factories to monitor and to prevent recontamination of the cheese with L. monocytogenes after pasteurization of the milk and during processing, with procedures in place that focus on prevention of occurrence of L. monocytogenes in the cheese product (raw and pasteurized milk, curd, cheese) and cheese processing facilities (e.g. brine baths, waste pits, floors). 


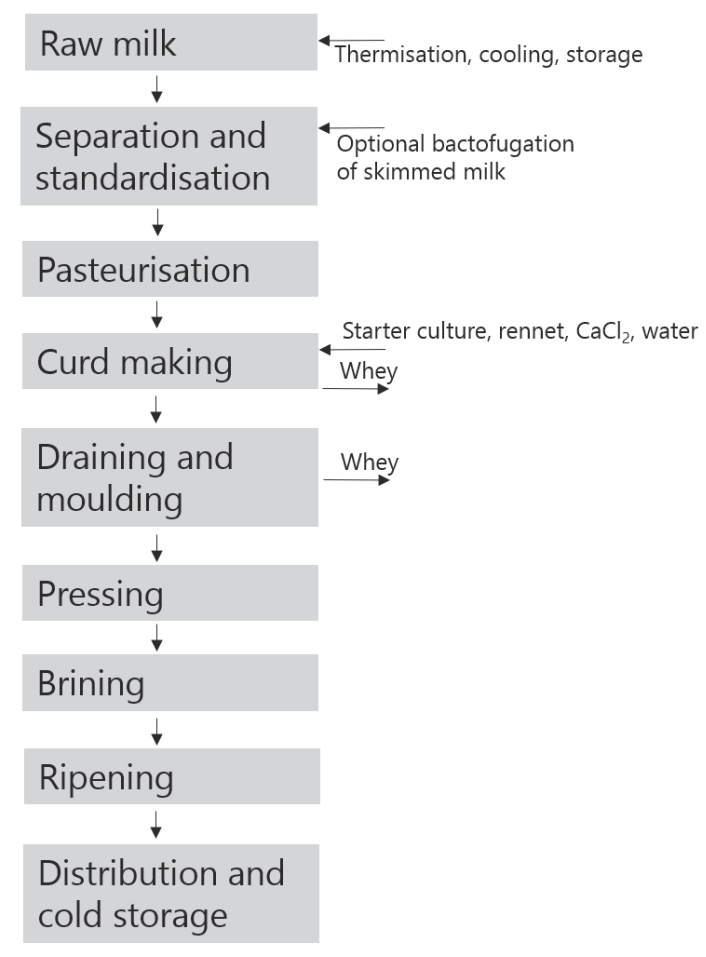

Fig. 1.1 Overview of production process of Gouda cheese.

\subsection{Dutch-type Gouda cheese and legislation with regard to L. monocytogenes}

Dutch-type Gouda cheese is a ready-to-eat food product (RTE food) as it does not undergo a heat treatment prior to consumption. Good manufacturing practices (GMP), in compliance with criteria established by food authorities, are required for manufacturing and selling of food. Sampling procedures must be established to estimate contamination levels in food products and processing environments.

Measures are implemented by cheese producers to prevent contamination of cheese with L. monocytogenes, thereby ultimately preventing the occurrence of listeriosis cases due to the consumption of contaminated cheese.

The EU criteria for RTE foods rely on concentrations of L. monocytogenes (maximum of $100 \mathrm{cfu} \mathrm{g}^{-1}$ at the moment of consumption and/or absence in $25 \mathrm{~g}$ ). An overview of the European food safety criteria in RTE foods defined in EC 2073/2005 is presented in Fig. 1.2. According to those criteria, RTE foods are divided into three categories. 
Category 1.1 RTE foods intended for infants and RTE foods for special medical purposes*;

Category 1.2 RTE foods able to support growth of L. monocytogenes, other than those intended for infants and for special medical purposes;

Category 1.3 RTE foods unable to support growth of L. monocytogenes, other than those intended for infants and for special medical purposes*.

RTE foods intended for infants and for special medical purposes fall within category 1.1 and these foods have to be monitored for the absence of L. monocytogenes (absence in 10 samples of $25 \mathrm{~g})$. Other RTE foods that are very acidic ( $\mathrm{pH} \leq 4.4)$, very salty and/or dry ( $\mathrm{a}_{\mathrm{w}} \leq 0.92$, which corresponds with $\sim 13 \%$ (or $2.2 \mathrm{M}$ ) NaCl in liquid food), or acidic as well as salty $\left(\mathrm{pH} \leq 5.0\right.$ and $\mathrm{a}_{\mathrm{w}} \leq 0.94$, with the latter corresponding with $\sim 10 \%$ (or $1.7 \mathrm{M}$ ) NaCl in liquid food) fall within category 1.3 of 'foods unable to support growth'. Other foods can also belong to category 1.3 if scientific evidence of non-growth of L. monocytogenes is available (Fig. 1.2). Such scientific evidence can consist of predictive mathematical modelling, durability tests and/or challenge tests.

\footnotetext{
* As described in EC 2073/2005, regular testing against the criterion applicable to category 1.1 and 1.3 foods is normally unnecessary for RTE foods that are heat-treated or processed effectively to eliminate L. monocytogenes and for which recontamination is not possible. This also applies to fresh, uncut and unprocessed vegetables and fruits excluding sprouted seeds, for bread, biscuits and similar products, for bottled or packed waters, soft drinks, beer, cider, wine and similar products, for sugar, honey and confectionary products, and for live bivalve molluscs. In EC 365/2010 amending EC 2073/2005, food-grade salt is added to the list of RTE foods for which regular testing against the criterion of category 1.1 and 1.3 is normally unnecessary. Although not described in EC 2073/2005 and/or EC 365/2010, this unnecessary regular testing can also apply to category 1.2 foods.
} 


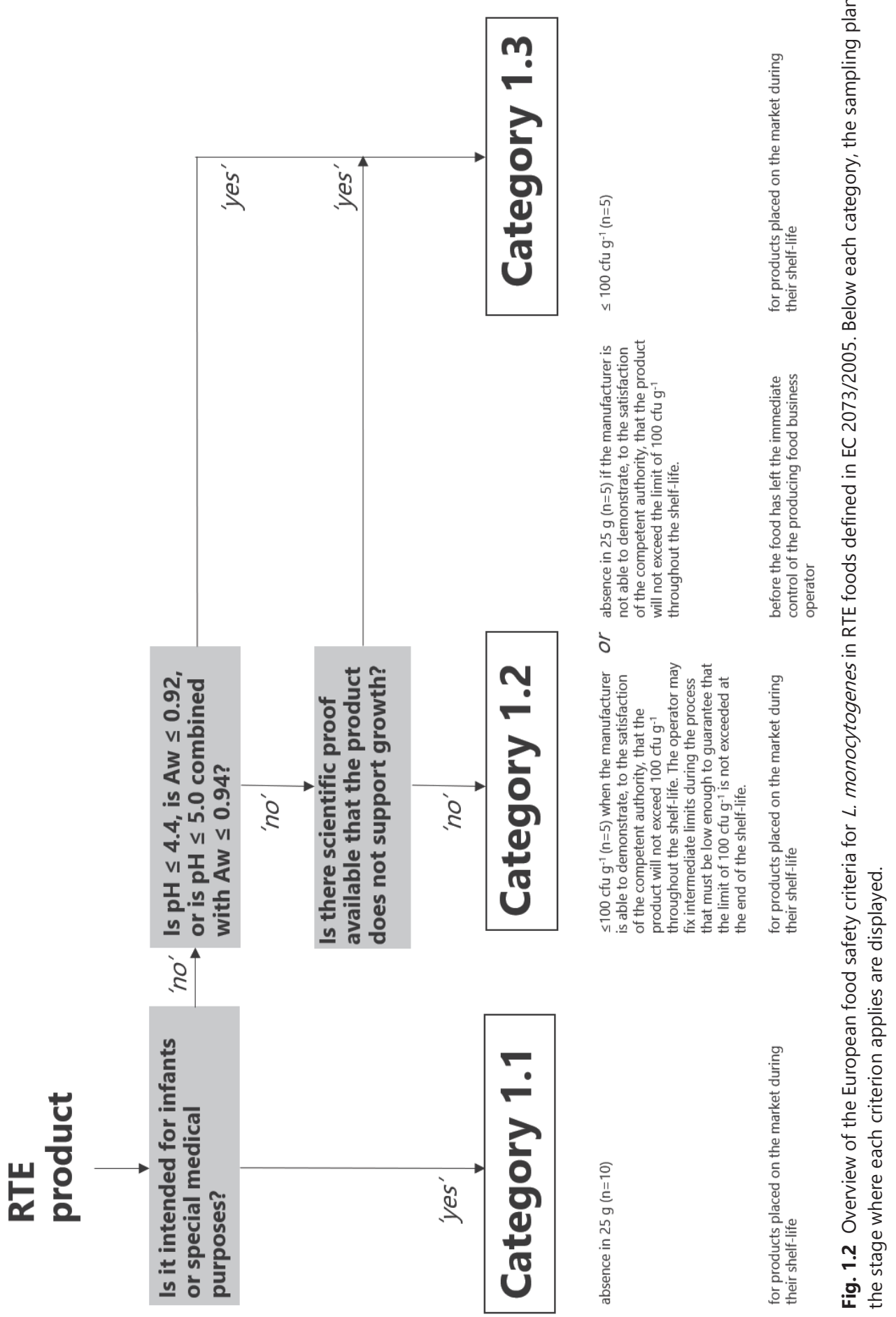


The fate of L. monocytogenes in a food product can be experimentally determined in two different ways: by durability testing or by challenge testing (Fig. 1.3). According to the most recent draft technical guidelines for such studies in RTE foods (Beaufort, Bergis \& Lardeux, 2014), durability studies allow for an assessment of the shelf-life of the food regarding L. monocytogenes in a naturally contaminated food during its storage, according to reasonably foreseeable conditions. A challenge test assesses the growth potential or the maximum growth rate of $L$. monocytogenes, simulating as closely as possible the likely storage conditions of the product. In challenge studies, the contamination is artificial. Results generated in durability studies may be more realistic, but may be more difficult to interpret because the prevalence of the initial contamination is often low and the initial contamination levels may be unevenly distributed (Spanu et al., 2014). Challenge studies seem more suitable for Dutch-type Gouda cheese, as absence of L. monocytogenes is expected in a standard Gouda made from pasteurized milk.

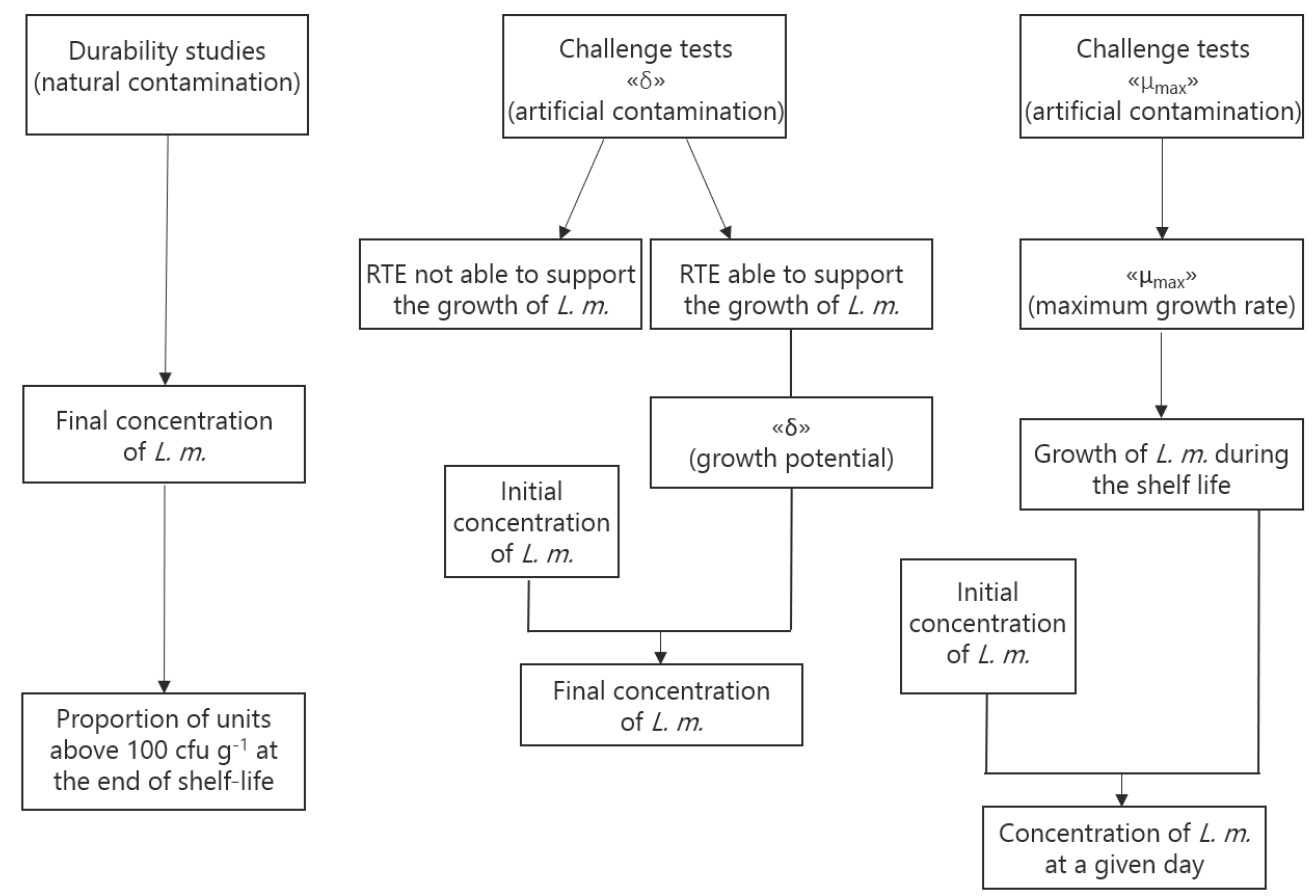

Fig. 1.3 Microbiological procedures for determining the growth of L. monocytogenes in RTE foods using durability and challenge tests. Obtained from the draft Technical guidance document for conducting shelflife studies on L. monocytogenes in RTE foods of Beaufort et al. (2014).

Currently, Dutch-type Gouda cheese can be categorized based on EC 2073/2005 as a category 1.2 food. When the manufacturer has not demonstrated to the satisfaction of the competent authority that the product will not exceed $100 \mathrm{cfu} \mathrm{g}^{-1}$ throughout the shelf-life, L. monocytogenes must be absent in $25 \mathrm{~g}(\mathrm{n}=5)$ before the food has left the immediate control of the food business operator, who has produced it. Gouda is a food with $\mathrm{pH}>5.0$ 
and $\mathrm{a}_{\mathrm{w}}>0.94$ and merely based on $\mathrm{pH}$ and $\mathrm{a}_{\mathrm{w}}$ criteria, growth of L. monocytogenes may not be excluded. There is evidence that Dutch-type Gouda cheese does not support growth of $L$. monocytogenes and the product has never been linked with listeriosis. Therefore, the Dutch dairy industry would like to investigate if Dutch-type Gouda cheese made from pasteurized milk could classify for the sampling plan of $<100 \mathrm{cfu} \mathrm{g}^{-1}(\mathrm{n}=5)$ for products placed on the market during their shelf-life. There are two cases in which L. monocytogenes has been isolated from US-type Gouda cheese, leading to recalls (Newsdesk, 2013a; 2014), but it was unclear if those recalls involved cheeses made from raw or pasteurized milk.

The published challenge study by Northolt et al. (1988) for Dutch-type Gouda cheese showed no growth, only survival of L. monocytogenes during six weeks of ripening. More insight in the most important production and product parameters that determine growth/no growth of L. monocytogenes in Dutch-type Gouda cheeses can be obtained by studying the fate of $L$. monocytogenes in the cheese. The impact of the factors determining this fate can be studied using a predictive modelling approach.

\subsection{Predictive modelling}

Predictive modelling is a technique with which the behavior as a response to environmental conditions can be systematically captured and converted into predictions using mathematics. It relies on the concept that responses are reproducible.

Predictive models for microorganisms in foods are constructed to describe their fate in those foods. The fate of bacteria in food can either be growth, survival or inactivation. Models can either be probabilistic, modelling the likelihood of growth or inactivation, or they can be kinetic, modelling the growth or inactivation rate and concentration of microorganisms (Ross \& McMeekin, 1994). There are three types of predictive models describing bacterial behavior: primary, secondary and tertiary models (Whiting \& Buchanan, 1993).

Primary models describe the change in microbial populations (bacterial growth of death) as a function of time. Gibson, Bratchell \& Roberts (1987) established the Gompertz equation to describe the bacterial growth curve. Zwietering, Jongenburger, Rombouts \& van 't Riet (1990) adapted this equation to the modified Gompertz equation, which is currently the most widely used primary model to describe bacterial growth.

Secondary models describe the effect of environmental factors on growth or starvation parameters, by describing the response of primary parameters to intrinsic and extrinsic parameters. Such intrinsic or extrinsic parameters often include $\mathrm{pH}$, water activity $\left(\mathrm{a}_{\mathrm{w}}\right)$ and 
temperature $(\mathrm{T})$, but can also include other factors such as $\mathrm{CO}_{2}$, organic acids and nitrite (Baranyi \& Roberts, 1994; Farber, Cai \& Ross, 1996; Mejlholm \& Dalgaard, 2009). Several types of secondary models are available to describe the growth of bacteria. Polynomial models have been developed as a technique for empirical curve fitting (Gibson, Bratchell \& Roberts, 1988; Buchanan \& Phillips, 1990). Ratkowsky, Lowry, McMeekin, Stokes \& Chandler (1983) developed a square-root model to model the inhibiting effect of temperature on growth of bacteria at temperatures lower than the optimum growth temperature. This square-root model was extended with other growth-inhibiting factors such as $\mathrm{a}_{\mathrm{w}}$ and $\mathrm{pH}$ (Presser, Ratkowsky \& Ross, 1997; Presser, Ross \& Ratkowsky, 1998). Zwietering, Wijtzes, de Wit \& van 't Riet (1992) established the Gamma model following a multiplicative approach to evaluate the effect of single factors in various combinations by multiplication of the effects. The Gamma model assumes that there are no interactions between the growth-inhibiting parameters; therewith it models the growth-inhibiting effects of individual factors. The model allows inclusion of several datasets for each hurdle. These datasets can be less extensive in comparison to datasets required for polynomial models. The Gamma hypothesis is defined as follows:

$$
\mu_{\max }(x, y)=\mu_{o p t} \cdot \gamma(x) \cdot \gamma(y)
$$

stating that the maximum specific growth rate of a bacterium in a food product $\mu_{\max }$ is dependent on the growth rate of that bacterium at optimal conditions $\mu_{\mathrm{opt}}$ and the growth-inhibiting effects of the intrinsic and extrinsic factors that are present $\gamma(x)$ and $\gamma(y)$. Equations representing the effects of the intrinsic and extrinsic factors can be described by the cardinal model from Rosso, Lobry, Bajard \& Flandrois (1995).

Le Marc et al. (2002) used the multiplicative approach with $\tau, \mathrm{pH}$ and organic acids as growth-inhibiting factors, but expanded the Gamma model with a synergy factor $\zeta(x, y)$ to describe interaction between factors at the growth limits:

$$
\mu_{\max }(x, y)=\mu_{o p t} \cdot \gamma(x) \cdot \gamma(y) \cdot \zeta(x, y)
$$

Augustin \& Carlier (2000a; 2000b) also proposed a secondary model to describe the global

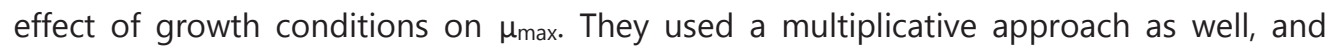
assumed that $\mathrm{T}, \mathrm{pH}, \mathrm{a}_{\mathrm{w}}$ inhibitory substances $c_{i}$ and qualitative factors $k_{j l}$ have independent effects on $\mu_{\max }$ :

$$
\mu_{\max }=\mu_{o p t} \cdot \tau(T) \cdot \rho(p H) \cdot \alpha\left(a_{w}\right) \cdot \prod_{i=1}^{n} \gamma\left(c_{i}\right) \cdot \prod_{j=1}^{p} k_{j l}
$$

with $\prod_{i=1}^{n} \gamma\left(c_{i}\right)$ as the sum of inhibitory substances $c_{i}$ and $\prod_{j=1}^{p} k_{j l}$ as the sum of qualitative factors $k_{j l}$.

The minimal growth parameters for the factors determining $\mu_{\max }$ are described by Rosso et al. (1995) and others according to Augustin et al. (2000a). 
Tertiary models are based on software programs that provide an interface between the underlying mathematics and the user, allowing model inputs to be entered and estimates to be observed through simplified graphical outputs (Pérez-Rodríguez \& Valero, 2013). Examples of tertiary models are Combase Predictor (http:/modelling.combase.cc) and a predictive model for L. monocytogenes in Blue-type cheeses (Rosshaug, Detmer, Ingmer \& Larsen, 2012).

At the start of the work described in this thesis, no predictive models had been applied to study the fate of L. monocytogenes in Gouda cheese. In this thesis, the Gamma model without interaction between factors has been applied to Dutch-type Gouda cheese to model growth/no growth of L. monocytogenes, as this model can incorporate the effects of multiple growth-inhibiting factors whilst inclusion of several datasets is allowed.

\subsection{Aim and outline of the thesis}

The aims of this study were to establish if L. monocytogenes can grow in Dutch-type Gouda cheese and to provide insight in the most important factors for inhibition of growth and the variation of these factors inside the cheese and throughout the ripening. An additional aim of this study was to provide data that support decisions with respect to food safety limits for L. monocytogenes in Dutch-type Gouda cheese. Establishing food safety limits requires interactions between academia/research institutes (research), policy makers (categorization and monitoring) and industry (quality management and production). Academia have an advisory role on the food safety limits, policy makers use the limits for categorization and legislation where safety supervisors monitor the conformity to the limits, and industry complies with the set limits to assure food safety throughout production (Fig. 1.4).
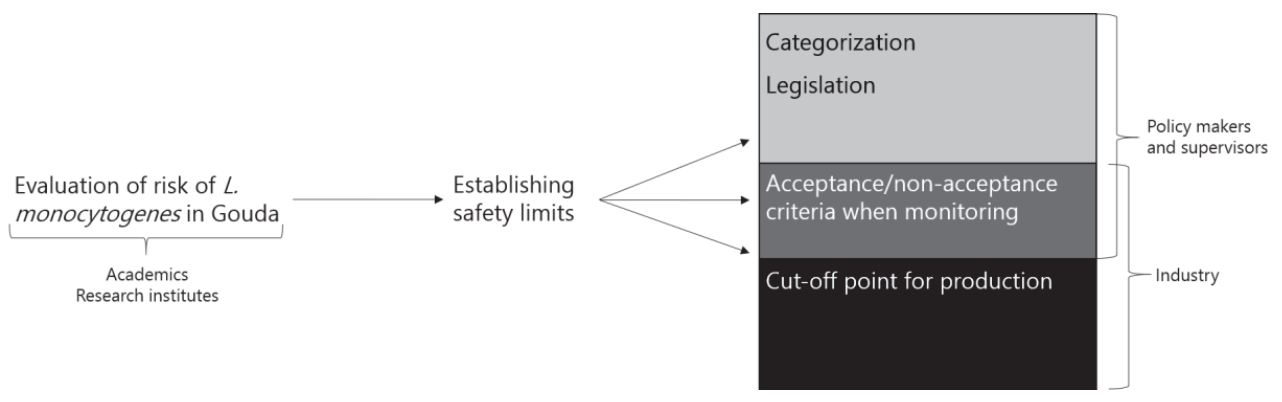

Fig. 1.4 Establishment of food safety limits is an interaction between academia/research institutes, policy makers and supervisors, and the industry. 
The different research topics addressed in this thesis are as follows. The fate of L. monocytogenes in and on Dutch-type Gouda cheese is described in Chapter 2 and Chapter 3, respectively. To improve the estimation of the effect of $\mathrm{a}_{w}$ on growth inhibition of L. monocytogenes, the $\mathrm{NaCl}$ and water content together with the $\mathrm{a}_{\mathrm{w}}$ were established during brining and ripening of Gouda cheese for both foil-ripened and nature-ripened cheese (Chapter 4). In Chapter 5, the sensitivity of L. monocytogenes to organic acids prevalent in Dutch-type cheeses was assessed. In Chapter 6, the individual factors contributing to inhibition of growth of L. monocytogenes in Dutch-type Gouda were evaluated. The actual concentrations of the factors as present in Dutch-type Gouda were determined, as well as their corresponding capacity to inhibit growth of L. monocytogenes. Chapter 7 is the general discussion, including a validation of growth/no growth of L. monocytogenes in RTE cheese when growth/no growth is predicted based on undissociated lactic acid, $\mathrm{pH}, \mathrm{a}_{\mathrm{w}}$ and $\mathrm{T}$ as growth-inhibiting factors, using an existing secondary growth model. In addition, growth/no growth of L. monocytogenes is predicted in the last chapter in other types of soft, semi-hard and hard cheeses. The main results are summarized and discussed, and implications for the dairy industry with regard to L. monocytogenes and Dutch-type Gouda cheese are presented. 


\section{References}

Aryani, D.C., Zwietering, M.H., \& den Besten, H.M.W. (2016). The effect of different matrices on the growth kinetics and heat resistance of Listeria monocytogenes and Lactobacillus plantarum. International Journal of Food Microbiology 238:326-337.

Augustin, J.C., \& Carlier, V. (2000a). Mathematical modelling of the growth rate and lag time for Listeria monocytogenes. International Journal of Food Microbiology 56:29-51.

Augustin, J.C., \& Carlier, V. (2000b). Modelling the growth rate of Listeria monocytogenes with a multiplicative type model including interactions between environmental factors. International Journal of Food Microbiology 56:53-70.

Baranyi, J., \& Roberts, T.A. (1994). A dynamic approach to predicting bacterial growth in food. International Journal of Food Microbiology 23:277-294.

Beaufort, A., Bergis, H., \& Lardeux, A.L. (2014). Technical guidance document for conducting shelf-life studies on L. monocytogenes in RTE foods. ANSES, ed. ANSES, Maisons-Alfort, France.

Beckers, H.J., Soentoro, P.S.S., \& Delgou-van Asch, E.H.M. (1987). The occurrence of Listeria monocytogenes in soft cheeses and raw milk and its resistance to heat. International Journal of Food Microbiology 4:249-256.

Bille, J., Blanc, D.S., Schmid, H., Boubaker, K., Baumgartner, A., Siegrist, H.H., Tritten, M.L., Lienhard, R., Berner, D., Anderau, R., Treboux, M., Ducommun, J.M., Malinverni, R., Genne, D. Erard, P.H., \& Waespi, U. (2006). Outbreak of human listeriosis associated with tomme cheese in northwest Switzerland, 2005. Eurosurveillance 11:91-93.

Borucki, M.K., Peppin, J.D., White, D. Loge, F., \& Call, D.R. (2003). Variation in biofilm formation among strains of Listeria monocytogenes. Applied and Environmental Microbiology 69:7336-7342.

Buchanan, R.L., Gorris, L.G.M., Hayman, M.H., Jackson, T.C., \& Whiting, R.C. (2017). A review of Listeria monocytogenes. An update on outbreaks, virulence, dose-response, ecology, and risk assessments. Food Control 75:1-13.

Buchanan, R.L., \& Phillips, J.G. (1990). Response surface model for predicting the effects of temperature $\mathrm{pH}$, sodium chloride content, sodium nitrite concentration and atmosphere on the growth of Listeria monocytogenes. Journal of Food Protection 53:370-376.

Bula, C.J., Bille, J. \& Glauser, M.P. (1995). An epidemic of food-borne listeriosis in western Switzerland: description of 57 cases involving adults. Clinical Infectious Diseases 20:66-72.

CAC (2003). Recommended international code of practice - general principles of food hygiene. http://www.mhlw.go.jp/english/topics/importedfoods/guideline/dl/04.pdf. Date last accessed: 0209-2018.

Carpentier, B., \& Cerf, O. (2011). Review - Persistence of Listeria monocytogenes in food industry equipment and premises. International Journal of Food Microbiology 145:1-8.

Carrique-Mas, J.J., Hokeberg, I., Andersson, Y., Arneborn, M. Tham, W. Danielsson-Tham, M.L. Osterman, B. Leffler, M. Steen, M. Eriksson, E. Hedin, G., \& Giesecke, J. (2003). Febrile gastroenteritis after eating on-farm manufactured fresh cheese - an outbreak of listeriosis? Epidemiology and Infections 130:79-86. 
Cartwright, E.J., Jackson, K.A., Johnson, S.D., Graves, L.M., Silk, B.J., \& Mahon, B.E. (2013). Listeriosis outbreaks and associated food vehicles, United States, 1998-2008. Emerging Infectious Diseases 19:1-10.

CDC (2012). Multistate outbreak of listeriosis linked to imported Frescolina Marte Brand ricotta salata cheese (final update). http://www.cdc.gov/listeria/outbreaks/cheese-09-

12/index.html?s_cid=fb1807. Date last accessed: 02-09-2018.

CDC (2014). Oasis Brands, Inc. cheese recalls and investigation of human listeriosis cases (final update). http://www.cdc.gov/listeria/outbreaks/cheese-10-14/index.html. Date last accessed: 02-09-2018.

CDC (2015). How food gets contaminated - the food production chain.

https://www.cdc.gov/foodsafety/ outbreaks/investigating-outbreaks/production-chain.html. Date last accessed: 02-09-2018.

CDC (2017). Multistate outbreak of listeriosis linked to soft raw milk cheese made by Vulto creamery (final update). https://www.cdc.gov/listeria/outbreaks/soft-cheese-03-17/index.html. Date last accessed: 02-09-2018.

Cossart, P., Pizarro-Cerda, J., \& Lecuit, M. (2003). Invasion of mammalian cells by Listeria monocytogenes. functional mimicry to subvert cellular functions. Trends in Cell Biology 13:23-31.

Danielsson-Tham, M.L., Eriksson, E., Helmersson, S., Leffler, M., Ludtke, L., Steen, M., Sorgjerd, S., \& Tham, W. (2004). Causes behind a human cheese-borne outbreak of gastrointestinal listeriosis. Foodborne Pathogenic Diseases 1:153-159.

De Castro, V., Escudero, J., Rodriguez, J., Muniozguren, N., Uribarri, J., Saez, D., \& Vazquez, J. (2012). Listeriosis outbreak caused by Latin-style fresh cheese, Bizkaia, Spain, August 2012. Eurosurveillance 17:42.

De Reu, K., Grijspeerdt, K., \& Herman, L. (2004). A Belgian survey of hygiene indicator bacteria and pathogenic bacteria in raw milk and direct marketing of raw milk farm products. Journal of Food Safety 24:17-36.

Del-Valdivia-Tapia, M.C., Pinelo-Chumbe, E., \& Carreazo, N.Y. (2015). Listeria monocytogenes meningitis in immunocompetent children: unpasteurised cheese likely cause of infection. Revista Chilena de Infectologia 32:464-466.

den Besten, H.M.W., \& Zwietering, M.H. (2012). Meta-analysis for quantitative microbiological risk assessments and benchmarking data. Trends in Food Science \& Technology 25:34-39.

EFSA (2007). The community summary report on trends and sources of zoonoses, zoonotic agents, antimicrobial resistance and foodborne outbreaks in the European Union in 2006. EFSA Journal 130:1-352.

EFSA (2015). The European Union summary report on trends and sources of zoonoses, zoonotic agents and food-borne outbreaks in 2013. EFSA Journal 3991:1-165.

Farber, J.M., Cai, Y., \& Ross, W.H. (1996). Predictive modeling of the growth of Listeria monocytogenes in $\mathrm{CO} 2$ environments. International Journal of Food Microbiology 32:133-144.

Farber, J.M., \& Peterkin, P.I. (1991). Listeria monocytogenes, a food-borne pathogen. Microbiological Reviews 55:476-511. 
FDA (2012). FDA warns consumers about Listeria threat in Mexicali Cheese Corp. products. http://www.ibtimes.com/fda-warns-about-listeria-threat-mexicali-cheese-corp-products- 723410. Date last accessed: 02-09-2018.

FDA (2013). Recall - firm press release - Food Co. recalls Gouda cheeses because of possible health risk. https://www.lawampm.com/blog/food-poisioning/2013/06/10/food-co-recalls-goudacheeses-because-of-possible-health-risk. Date last accessed: 02-09-2018.

FDA (2016a). Import alert 12-10. http://www.accessdata.fda.gov/CMS_IA/importalert_9.html. Date last accessed: 02-09-2018.

FDA (2016b). Whole genome sequencing (WGS) program. http://www.fda.gov/Food/ FoodScienceResearch/WholeGenomeSequencingProgramWGS/. Date last accessed: 02-09-2018.

FIOD (2005). Raw, unpasteurized, queso fresco 2005. http://www.outbreakdatabase.com/details/rawunpasteurized-queso-fresco-2005/?organism $=$ Listeria + monocytogenes $\&$ vehicle $=$ cheese\&year $=$ 2005. Date last accessed: 02-09-2018.

FIOD (2010). Queseria bendita fresh cheese 2010. http://www.outbreakdatabase.com/details/queseriabendita-fresh-cheese-2010/?organism=Listeria + monocytogenes \&vehicle=cheese $\& y e a r=2010$. Date last accessed: 02-09-2018.

FIOD (2011). Natural ackawi and chives cheese 2011. Green Cedar Dairy - Harb, Inc. http://www. outbreakdatabase.com /details/green-cedar-dairy-harb-inc.-natural-ackawi-and-chives-cheese2011/?organism=Listeria+monocytogenes\&year=2011. Date last accessed: 02-09-2018.

FIOD (2013). 2013 multistate outbreak of listeriosis linked to Les Freres cheese. http://www. outbreakdatabase.com/details/les-freres-cheese-listeriosis-outbreak-june2013/?organism=Listeria+monocytogenes\&year=2013. Date last accessed: 02-09-2018.

FIOD (2014). 2014 multistate outbreak of listeriosis linked to soft cheese produced by Roos foods. http:// outbreakdatabase.com/details/2013-2014-multistate-outbreak-of-listeriosis-linked-tosoft-cheese-produced-by-roosfoods/?organism $=$ Listeria + monocytogenes \&vehicle=cheese\&year=2013. Date last accessed: $02-$ 09-2018.

FIOD (2015). 2015 Listeria outbreak linked to Queseria Bendita latin-style cheese, Washington State. http://outbreakdatabase.com/details/2015-listeria-outbreak-linked-to-queseria-bendita-latinstyle-cheese-washingtonstate/?organism $=$ Listeria + monocytogenes\&vehicle $=$ cheese\&year $=2015$. Date last accessed: $02-$ 09-2018.

Fleming, D.W., Cochi, S.L., MacDonald, K.L., Brondum, J. Hayes, P.S., Plikaytis, B.D., Holmes, M.B., Audurier, A., Broome, C.V., \& Reingold, A.L. (1985). Pasteurized milk as a vehicle of infection in an outbreak of listeriosis. New England Journal of Medicine 312:404-407.

Flynn, D. (2011). Remembering the sad 1985 listeriosis outbreak. http://www.foodsafetynews.com/2011/11/ remembering-the-sad-1985-listeriosis-outbreak/. Date last accessed: 02-09-2018.

Fox, E., O'Mahony, T. Clancy, M., Dempsey, R., O'Brien, M., \& Jordan, K. (2009). Listeria monocytogenes in the Irish dairy farm environment. Journal of Food Protection 72:1450-1456.

Fox, P.F., \& McSweeney, P.L.H. (2004). Cheese: an overview. Pages 1-18 in Cheese: chemistry, physics and microbiology (3rd ed.). Vol. 1. P.F. Fox, P.L.H. McSweeney, T.M. Cogan, \& T.P. Guinee, ed. Elsevier Ltd., London. 
Fretz, R., Pichler, J., Sagel, U. Much, P., Ruppitsch, W., Pietzka, A.T., Stöger, A. Huhulescu, S., Heuberger, S., Appl, G., Werber, D., Stark, K., Prager, R., Flieger, A., Karpíšková, R., Pfaff, G., \& Allerberger, F. (2010). Update: multinational listeriosis outbreak due to 'Quargel', a sour milk curd cheese, caused by two different L. monocytogenes serotype 1/2a strains, 2009-2010 Eurosurveillance 15:1-2.

Gaulin, C., Ramsay, D., Ringuette, L., \& Ismail, J. (2003). First documented outbreak of Listeria monocytogenes in Quebec, 2002. Canada Communicable Disease report 29:1-6.

Gaya, P., Sanchez, J., Medina, M., \& Nuñez, M. (1998). Incidence of Listeria monocytogenes and other Listeria species in raw milk produced in Spain. Food Microbiology 15:551-555.

Gibson, A.M., Bratchell, N., \& Roberts, T.A. (1987). The effect of sodium chloride and temperature on the rate and extent of growth of Clostridium botulinum type $A$ in pasteurized pork slurry. Journal of Applied Bacteriology 62:479-490.

Gibson, A.M., Bratchell, N., \& Roberts, T.A. (1988). Predicting microbial growth: growth responses of salmonellae in a laboratory medium as affected by $\mathrm{pH}$, sodium chloride and storage temperature. International Journal of Food Microbiology 6:155-178.

Goulet, V., Jacquet, C., Vaillant, V., Rebiere, I., Mouret, E., Lorente, C., Maillot, E. Stainer, F., \& Rocourt, J. (1995). Listeriosis from consumption of raw-milk cheese. Lancet 345:1581-1582.

Greig, J.D., \& Ravel, A. (2009). Analysis of foodborne outbreak data reported internationally for source attribution. International Journal of Food Microbiology 130:77-87.

Harvey, J., \& Gilmour, A. (1992). Occurrence of Listeria species in raw milk and dairy products produced in Northern Ireland. Journal of Applied Bacteriology 72:119-125.

Hill, B., Smythe, B., Lindsay, D., \& Shepherd, J. (2012). Microbiology of raw milk in New Zealand. International Journal of Food Microbiology 157:305-308.

Hitchins, A.D., Jinneman, K., \& Chen, Y. (2016). BAM: Detection and enumeration of Listeria monocytogenes. Chapter 10 Detection and enumeration of Listeria monocytogenes in foods. http://www.fda.gov/Food/FoodScienceResearch/LaboratoryMethods/ucm071400.htm. Date last accessed: 02-09-2018.

Hussain, M., \& Dawson, C. (2013). Economic impact of food safety outbreaks on food businesses. Foods 2:585-589.

ICMSF (1996). Microorganisms in foods, Microbiological specifications of food pathogens. Vol. 5, Blackie, London.

ISO (2005). ISO 22000 - food safety management. https://www.iso.org/iso-22000-food-safetymanagement.html. Date last accessed: 02-09-2018.

ISO (2017a). ISO 11290-1:2017 Microbiology of the food chain - Horizontal method for the detection and enumeration of Listeria monocytogenes and of Listeria spp. - Part 1: Detection method.

ISO (2017b). ISO 11290-2:2017 Microbiology of the food chain - Horizontal method for the detection and enumeration of Listeria monocytogenes and of Listeria spp. - Part 2: Enumeration method.

Jackson, K.A., Biggerstaff, M., Tobin-D'Angelo, M., Sweat, D., Klos, R., Nosari, J., Garrison, O., Boothe, E., Saathoff-Huber, L., Hainstock, L., \& Fagan, R.P. (2011). Multistate outbreak of Listeria monocytogenes associated with Mexican-style cheese made from pasteurized milk among pregnant, Hispanic women. Journal of Food Protection 74:949-953. 
Jacquet, C., Brouillé, F., Saint-Cloment, C., Catimel, B., \& Rocourt, J. (1999). La listériose humaine en France en 1998. Bulletin Epidémiologique Hebdomadaire 37:153-154.

Jamali, H., Radmehr, B., \& Thong, K.L. (2013). Prevalence, characterisation, and antimicrobial resistance of Listeria species and Listeria monocytogenes isolates from raw milk in farm bulk tanks. Food Control 34:121-125.

Jensen, A., Frederiksen, W., \& Gerner-Smidt, P. (1994). Risk factors for listeriosis in Denmark, 19891990. Scandinavian Journal of Infectious Diseases 26:171-178.

Johnsen, B.O., Lingaas, E., Torfoss, D., Strom, E.H., \& Nordoy, I. (2010). A large outbreak of Listeria monocytogenes infection with short incubation period in a tertiary care hospital. Journal of Infection 61:465-470.

Jones, G.S., \& D'Orazio, S.E.F. (2013). Listeria monocytogenes. cultivation and laboratory maintenance. Current Protocols in Microbiology 31:9B.2.1-9B.2.7.

Kathariou, S., Kanenaka, R., Allen, R.D. Kok, A.K., \& Mizumoto, C. (1995). Repression of motility and flagellin production at 37 degrees $C$ is stronger in Listeria monocytogenes than in the nonpathogenic species Listeria innocua. Canadian Journal of Microbiology 41:572-577.

Koch, J., Dworak, R., Prager, R., Becker, B., Brockmann, S., Wicke, A., Wichmann-Schauer, H., Hof, H., Werber, D., \& Stark, K. (2010). Large listeriosis outbreak linked to cheese made from pasteurized milk, Germany, 2006-2007. Foodborne Pathogenic Diseases 7:1581-1584.

Le Marc, Y., Huchet, V., Bourgeois, C.M., Guyonnet, J.P., Mafart, P., \& Thuault, D. (2002). Modelling the growth kinetics of Listeria as a function of temperature, $\mathrm{pH}$ and organic acid concentration. International Journal of Food Microbiology 73:219-237.

Leclercq, A., Charlier, C., \& Lecuit, M. (2014). Global burden of listeriosis: the tip of the iceberg. Lancet Infectious Diseases 14:1027-1028.

Lemon, K.P., Higgins, D.E., \& Kolter, R. (2007). Flagellar motility is critical for Listeria monocytogenes biofilm formation. Journal of Bacteriology 189:4418-4424.

Linnan, M.J., Mascola, L., Lou, X.D., Goulet, V., May, S., Salminen, C., Hird, D.W., Yonekura, M.L., Hayes, P., Weaver, R., Audurier, A., Plikaytis, B.D., Fannin, S.L., Kleks, A., \& Broome, C.V. (1988). Epidemic listeriosis associated with Mexican-style cheese. New England Journal of Medicine 319:823-828.

Lomonaco, S., Decastelli, L., Nucera, D., Gallina, S., Manila Bianchi, D., \& Civera, T. (2009). Listeria monocytogenes in Gorgonzola: Subtypes, diversity and persistence over time. International Journal of Food Microbiology 128:516-520.

Low, J.C., \& Donachie, W. (1997). A review of Listeria monocytogenes and listeriosis. The Veterinary Journal 153:9-29.

MacDonald, P.D., Whitwam, R.E., Boggs, J.D., MacCormack, J.N., Anderson, K.L., Reardon, J.W. J.W., Saah, J.R., Graves, L.M., Hunter, S.B., \& Sobel, J. (2005). Outbreak of listeriosis among Mexican immigrants as a result of consumption of illicitly produced Mexican-style cheese. Clinical Infectious Diseases 40:677-682.

Magalhaes, R., Almeida, G., Ferreira, V., Santos, I., Silva, J., Mendes, M.M., Pita, J. Mariano, G., Mancio, I., Sousa, M.M., Farber, J., Pagotto, F., \& Teixeira, P. (2015). Cheese-related listeriosis outbreak, Portugal, March 2009 to February 2012. Eurosurveillance 20:1-6. 
Makino, S.I., Kawamoto, K., Takeshi, K., Okada, Y., Yamasaki, M., Yamamoto, S., \& Igimi, S. (2005). An outbreak of food-borne listeriosis due to cheese in Japan, during 2001. International Journal of Food Microbiology 104:189-196.

Martinez-Rios, V., \& Dalgaard, P. (2018). Prevalence of Listeria monocytogenes in European cheeses: a systematic review and meta-analysis. Food Control 84:205-214.

Mejlholm, O., \& Dalgaard, P. (2009). Development and validation of an extensive growth and growth boundary model for Listeria monocytogenes in lightly preserved and ready-to-eat shrimp. Journal of Food Protection 72:2132-2143.

Melo, J., Andrew, P.W., \& Faleiro, M.L. (2015). Listeria monocytogenes in cheese and the dairy environment remains a food safety challenge: the role of stress responses. Food Research International 67:75-90.

Meng, J., \& Doyle, M.P. (2002). Introduction. Microbiological food safety. Microbes and Infection 4:395397.

Meyer-Broseta, S., Diot, A., Bastian, S., Rivière, J., \& Cerf, O. (2003). Estimation of low bacterial concentration: Listeria monocytogenes in raw milk. International Journal of Food Microbiology 80:1-15.

Newsdesk (2013a). Finger Lakes recalls Gouda cheese in NY for Listeria risk. http://www.foodsafetynews. com/2013/06/finger-lakes-recalls-gouda-cheese-in-ny-for-listeriarisk/\#.WOfjseRMQqU. Date last accessed: 02-09-2018.

Newsdesk (2013b). Two dead in Australian Listeria outbreak linked to soft cheese. http://www. foodsafetynews.com/2013/01/two-dead-in-australian-listeria-outbreak-linked-to-soft-cheese/ \#.WOfj-eRMQqU. Date last accessed: 02-09-2018.

Newsdesk (2014). Gouda cheese recalled for potential Listeria contamination. http://www.foodsafetynews. com/2014/06/21-wheels-of-gouda-cheese-recalled-for-potentiallisteria-contamination/\#.WOfkG-RMQqU. Date last accessed: 02-09-2018.

Nho, S.W., Abdelhamed, H., Reddy, S., Karsi, A., \& Lawrence, M.L. (2015). Identification of high-risk Listeria monocytogenes serotypes in lineage I (serotype 1/2a, 1/2c, 3a and 3c) using multiplex PCR. Journal of Applied Microbiology 119:845-852.

Northolt, M.D., Beckers, H.J., Vecht, U., Toepoel, L., Soentoro, P.S.S., \& Wisselink, H.J. (1988). Listeria monocytogenes. heat resistance and behaviour during storage of milk and whey and making of Dutch types of cheese. Netherland Milk \& Dairy Journal 42:207-219.

Notermans, S. (1994). The significance of biofouling to the food industry. Food Technology 48:13-14.

O'Neil, H.S., \& Marquis, H. (2006). Listeria monocytogenes flagella are used for motility, not as adhesins, to increase host cell invasion. Infection and Immunity 74:6675-6681.

Ooi, S.T., \& Lorber, B. (2005). Gastroenteritis due to Listeria monocytogenes. Clinical Infectious Diseases 40:1327-1332.

Pagotto, F., Ng, L.K., Clark, C., \& Farber, J. (2006). Canadian listeriosis reference service. Foodborne Pathogens and Disease 3:132-137.

Pérez-Rodríguez, F., \& Valero, A. (2013). Chapter 3. Predictive models: foundation, types and development. Pages 25-55 in Predictive microbiology in foods., Pérez-Rodríguez, F., \& A. Valero. ed. Springer International Publishing AG, Switzerland. 
Premaratne, R.J., Lin, W.J., \& Johnson, E.A. (1991). Development of an improved chemically defined minimal medium for Listeria monocytogenes. Applied and Environmental Microbiology 57:30463048.

Presser, K.A., Ratkowsky, D.A., \& Ross, T. (1997). Modelling the growth rate of Escherichia coli as a function of $\mathrm{pH}$ and lactic acid concentration. Applied and Environmental Microbiology 63:23552360 .

Presser, K.A., Ross, T., \& Ratkowsky, D.A. (1998). Modelling the growth limits (growth/no growth interface) of Escherichia coli as a function of temperature, $\mathrm{pH}$, lactic acid concentration, and water activity. Applied and Environmental Microbiology 64:1773-1779.

ProMed (2008). Listeriosis, fatal - Chile: (Santiago), cheese suspected. request for information. http://www. promedmail.org/post/20081128.3754. Date last accessed: 02-09-2018.

Ramaswamy, V., Cresence, V.M., Rejitha, J.S., Lekshmi, M.U., Dharsana, K.S., Prasad, S.P., \& Vijila, H.M. (2007). Listeria - review of epidemiology and pathogenesis. Journal of Microbiological and Immunological Infections 40:4-13.

Raspor, P., Smozina, S.S., \& Ambrožič, M. (2014). Basic concepts of food microbiology. In Dairy microbiology, a practical approach. ed. Papademas, P. CRC Press, Boca Raton, FL, US.

Ratkowsky, D.A., Lowry, R.K., McMeekin, T.A., Stokes, A.N., \& Chandler, R.E. (1983). Model for bacterial culture growth rate throughout the entire biokinetic temperature range. Journal of Bacteriology 154:1222-1226.

Rea, M.C., Cogan, T.M., \& Tobin, S. (1992). Incidence of pathogenic bacteria in raw milk in Ireland. Journal of Applied Bacteriology 73:331-336.

Ries, F., Dicato, M., Hemmer, R., \& Arendt, F. (1990). Camembert, Listeria and the immunocompromised patient. Bulletin de la Societe des Sciences Medicales du Grand-Duche de Luxembourg 127:41-43.

RNSP (1997). Epidémie de listériose 1997. Reseau National de Santé Publique, France.

Rosshaug, P.S., Detmer, A., Ingmer, H., \& Larsen, M.H. (2012). Modeling the growth of Listeria monocytogenes in soft blue-white cheese. Applied and Environmental Microbiology 78:85088514.

Ross, T., \& McMeekin T.A. (1994). Predictive microbiology. International Journal of Food Microbiology 23:241-264.

Rosso, L., Lobry, J.R., Bajard, S., \& Flandrois, J.P. (1995). Convenient model to describe the combined effects of temperature and $\mathrm{pH}$ on microbial growth. Applied and Environmental Microbiology 61:610-616.

Ruusunen, M., Salonen, M., Pulkkinen, H., Huuskonen, S., Hellström, J., Revez, M., Hänninen, L., Fredriksson-Ahomaa, M., \& Lindström, M. (2013). Pathogenic bacteria in Finnish bulk tank milk. Foodborne Pathogens and Disease 10:99-106.

Scharff, R.L. (2012). Economic burden from health losses due to foodborne illness in the United States. Journal of Food Protection 75:123-131.

Schmid, D., Allerberger, F., Huhulesco, S., Pietzka, A., Amar, C., Kleta, S., Prager, R., Preußel, K., Aichinger, E., \& Mellmann, A. (2014). Whole genome sequencing as a tool to investigate a cluster of seven cases of listeriosis in Austria and Germany, 2011-2013. Clinical Microbiology and Infection 20:431-436. 
Schoder, D., Melzner, D., Schmalwieser, A., Zangana, A., Winter, P., \& Wagner, M. (2011). Important vectors for Listeria monocytogenes transmission at farm dairies manufacturing fresh sheep and goat cheese from raw milk. Journal of Food Protection 74:919-924.

Spanu, C., Scarano, C., Ibba, M., Pala, C., Spanu, V., \& de Santis, E.P.L. (2014). Microbiological challenge testing for Listeria monocytogenes in ready-to-eat food: a practical approach. Italian Journal of Food Safety 3:4518:231-237.

Swaminathan, B., \& Gerner-Smidt, P. (2007). The epidemiology of human listeriosis. Microbes and Infection 9:1236-1243.

Taillefer, C., Boucher, M., Laferriere, C., \& Morin, L. (2010). Perinatal listeriosis: Canada's 2008 outbreaks. Journal of Obstetrics and Gynaecology Canada 32:45-48.

Thomas, M.K., Vriezen, R., Farber, J.M., Currie, A., Schlech, W., \& Fazil, A. (2015). Economic cost of a Listeria monocytogenes outbreak in Canada, 2008. Foodborne Pathogenic Diseases 12:966-971.

Vaillant, V., Maillot, E., Charley, C., \& Stainer, F. (1998). Epidémie de listériose, France Avril-Août 1995. Pages 1-58. Réseau National de Santé Publique, Saint-Maurice, France.

van den Berg, G., Meijer, W.C., Düsterhöft, E.M., \& Smit, G. (2004). Gouda and related cheeses. Pages 103-140 in Cheese: chemistry, physics and microbiology (3rd ed.). Vol. 2. Gouda and related cheeses, ed. P.F. Fox, P.L.H. McSweeney, T.M. Cogan, \& T.P. Guinee, ed. Elsevier Ltd., London, UK.

van Lieverloo, J.H.M., de Roode, M., Fox, M.B., Zwietering, M.H., \& Wells-Bennik, M.H.J. (2013). Multiple regression model for thermal inactivation of Listeria monocytogenes in liquid food products. Food Control 29:394-400.

van Schothorst, M. (2004). A simple guide to understanding and applying the Hazard Analysis Critical Control Point concept (3rd ed.) Concise Monograph Series, ILSI Europe, Brussels, ISBN 1S7881179-1.

Verheul, A., Rombouts, F.M., \& Abee, T. (1998). Utilization of oligopeptides by Listeria monocytogenes Scott A. Applied and Environmental Microbiology 64:1059-1065.

Vít, M., Olejník, R., Dlhý, J., Karpíšková, R., Částková, J., Príkazský, V., Príkazská, M., Beneš, č., \& Petrášs, P. (2007). Outbreak of listeriosis in the Czech Republic, late 2006 - preliminary report. Eurosurveillance 12:31-32.

Waak, E., Tham, W., \& Danielsson-Tham, M.L. (2002). Prevalence and fingerprinting of Listeria monocytogenes strains isolated from raw whole milk in farm bulk tanks and in dairy plant receiving tanks. Applied and Environmental Microbiology 68:3366-3370.

Whiting, R.C., \& Buchanan, R.L. (1993). A classification of models for predictive microbiology. Food Microbiology 10:175-177.

WHO/FAO (2004). Risk assessment of Listeria monocytogenes in ready-to-eat foods. Technical report. http://apps.who.int/iris/bitstream/handle/ 10665/42875/9241562625.pdf?sequence=1\&isAllowed=y. Date last accessed: 02-09-2018.

Wiedmann, M. (2015). Use of whole-genome sequencing in food safety. http://www.foodsafetymagazine. com/magazine-archive1/junejuly-2015/use-of-whole-genomesequencing-in-food-safety/ Date last accessed: 02-09-2018.

Yde, M., Naranjo, M., Mattheus, W., Stragier, P., Pochet, B., Beulens, K., de Schrijver, K., van den Branden, D., Laisnez, V., Flipse, W., Leclercq, A., Lecuit, M., Dierick, K., \& Bertrand, S. (2012). 
Usefulness of the European epidemic intelligence information system in the management of an outbreak of listeriosis, Belgium (2011). Eurosurveillance 17:1-5.

ZuivelNL (2017). Zuivel in cijfers. http://www.zuivelnl.org/wp-content/uploads/2018/08/ZIC2017NL.pdf. Date last accessed: 02-09-2018.

Zwietering, M.H., Jongenburger, I., Rombouts, F.M., \& van 't Riet, K. (1990). Modeling of the bacterial growth curve. Applied and Environmental Microbiology 56:1875-1881.

Zwietering, M.H., Wijtzes, T., de Wit, J.C., \& van 't Riet, K. (1992). A decision support system for prediction of microbial spoilage in foods. Journal of Food Protection 55:973-979. 


\title{
Chapter 2
}

\section{Fate of Listeria monocytogenes in Gouda microcheese: No growth, and substantial inactivation after extended ripening times}

E. Wemmenhove, I. Stampelou, A.C.M. van Hooijdonk, M.H. Zwietering, M.H.J. Wells-Bennik

\begin{abstract}
This challenge study demonstrates that Listeria monocytogenes does not grow in Gouda cheese: during the first 8 weeks of ripening no growth was observed and between 8 and 52 weeks viable numbers declined significantly in a well-established Gouda microcheese system. Cheese milk was artificially contaminated just prior to addition of the starter culture. Three individual L. monocytogenes strains were used, including strains originating from cheese, a cheese plant environment and a reference strain. During curd formation, viable numbers of $L$. monocytogenes increased by $0.5 \operatorname{log~cfu~g}^{-1}$, resulting from entrapment in the curd. No growth was observed during the first 8 weeks of ripening. A significant decline in the viable numbers of L. monocytogenes was observed in Gouda cheese that was ripened for longer than 8 weeks. Two factors that could possibly control the fate of L. monocytogenes in Gouda cheese were lactic acid and water activity.
\end{abstract}

This chapter was published in the International Dairy Journal (2013) 32:192-198 


\subsection{Introduction}

The food-borne pathogen Listeria monocytogenes is the causative agent of listeriosis, a disease that can manifest as meningitis, encephalitis, sepsis, intrauterine infections and gastroenteritis (Vazquez-Boland et al., 2001). Although listeriosis infections are rare, the case-fatality rate is very high (20-30\%), especially for the elderly, the unborn child, infants, and immune-compromised individuals (Doorduyn et al., 2006). L. monocytogenes may be found in a broad range of foods from animal or plant origin, and the microorganism can grow at $\mathrm{pH}$ values ranging from $\mathrm{pH} 4.4$ to 9.0 , at $\mathrm{NaCl}$ concentrations up to $12 \%$, and temperatures from -0.4 to $44{ }^{\circ} \mathrm{C}$ (Lou \& Yousef, 2000). Foodborne outbreaks of L. monocytogenes have been associated with many different categories of food products, including seafood, vegetables, meat products and dairy products (EFSA, 2011), like soft and acid-curd cheeses made from pasteurized milk (Gaulin, Ramsay, \& Bekal, 2012; Koch et al., 2010).

In December 2007, microbiological criteria for L. monocytogenes in ready-to-eat (RTE) foods were implemented in the European Union through regulation 1441/2007. For RTE foods that do not support growth of L. monocytogenes, a maximum level of $100 \mathrm{cfu} \mathrm{g}^{-1}$ is allowed. Criteria for products that do not support growth of L. monocytogenes as given in the EU regulation 1441/2007 are: $\mathrm{pH} \leq 4.4$; $\mathrm{a}_{\mathrm{w}} \leq 0.92$; or $\mathrm{pH} \leq 5.0$ and $\mathrm{a}_{\mathrm{w}} \leq 0.94$. A product does not support growth of L. monocytogenes when it fulfills at least one of the previous criteria. Other conditions that may not allow for growth of L. monocytogenes in a product can be established using a modeling approach and/or challenge tests. For products that can support growth, EU regulation 1441/2007 requires that L. monocytogenes should be absent in 5 samples of $25 \mathrm{~g}$ after production and that the products should not exceed 100 $\mathrm{cfu} \mathrm{g}^{-1}$ at the moment of consumption. Codex Alimentarius (CAC, 2007) similarly specifies absence of the pathogen in 5 samples of $25 \mathrm{~g}$.

When L. monocytogenes was identified as a food-borne pathogen in the 1980s, Northolt et al. (1988) demonstrated the absence of growth of L. monocytogenes in $4.5 \mathrm{~kg}$ Gouda cheeses during a 6 week ripening period. Over the last 3 decades, no listeriosis incidents have been reported related to the consumption of semi-hard Gouda cheeses made from pasteurized milk, this supports the hypothesis that this organism does not grow in Gouda cheese. Nevertheless, as Gouda cheese is a RTE product, due diligence is required with regard to potential contamination of cheeses with L. monocytogenes during manufacturing and potential growth of the organism during ripening.

Gouda cheese is a semi-hard cheese that is made from pasteurized milk in which curd formation is induced by rennet and a mesophilic starter culture. The $\mathrm{pH}$ of young Gouda cheese is 5.3 (van den Berg, Meijer, Düsterhöft \& Smit, 2004), and the $a_{w}$ is 0.95 (Guinee \& 
Fox, 2004). Merely based on this $\mathrm{pH}$ in combination with the $\mathrm{a}_{\mathrm{w}}, \mathrm{L}$. monocytogenes may be expected to grow during extended ripening periods, as has been found in soft cheese models with a moisture content higher than $50 \%$ and a pH higher than 5.9 (Baranyi et al., 2012). These models, however, did not take into account other growth-inhibiting factors, such as the effect of undissociated organic acids. Consequently, there is a need to extend predictive models for L. monocytogenes in semi-hard cheeses by obtaining additional quantitative data on the fate of this organism in Gouda cheese to determine the most important factors for growth/no growth of this pathogen in cheese.

The work presented here constitutes a challenge study of L. monocytogenes in a wellestablished Gouda microcheese ${ }^{\circledR}$ model, that has been developed at NIZO food research (Bachmann, Kruijswijk, Molenaar, Kleerebezem, \& van Hylckama Vlieg, 2009). Different L. monocytogenes strains were artificially inoculated into cheese milk, and following starter-induced curd formation, microcheeses were ripened for a period of up to 12 months. The viable counts of L. monocytogenes were determined at the different stages of cheese making and ripening. In addition, to allow for a direct extrapolation to large scale cheeses, intrinsic parameters of cheese $\left(\mathrm{a}_{\mathrm{w}}\right.$, moisture content, $\mathrm{pH}$ and organic acid concentrations) were determined for the microcheeses and in parallel for industrially produced non-inoculated $12 \mathrm{~kg}$ Gouda cheeses.

\subsection{Materials and methods}

\subsubsection{Cheese milk preparation}

Raw bovine bulk tank milk was standardized (3.5\% fat, 3.4\% protein and $4.5 \%$ lactose) and subjected to a single round of bactofugation and a heat treatment of $73{ }^{\circ} \mathrm{C}$ for $14 \mathrm{~s}$ in a continuous-flow pasteurizer with a capacity of $10,000 \mathrm{~L} \mathrm{~h}^{-1}$ (Alfa Laval, Lund, Sweden). The milk was then frozen using liquid nitrogen and stored at $-40^{\circ} \mathrm{C}$ until further used.

\subsubsection{Bacterial strains and cultures used}

Bos starter culture (CSK food enrichment, Ede, The Netherlands) was selected for the acidification of cheese milk to produce Gouda microcheeses. Bos is a mesophilic starter culture containing a mixture of mainly lactococci and Leuconostoc spp. that is commonly used for Gouda cheese production in The Netherlands. For pre-culturing, an aliquot of a frozen concentrated Bos culture was inoculated into sterilized (115 ${ }^{\circ} \mathrm{C}$ for $10 \mathrm{~min}$ ), 
reconstituted skimmed milk powder (NIZO food research, Ede, The Netherlands) and incubated for $20 \mathrm{~h}$ at $20^{\circ} \mathrm{C}$. Subsequently, this precultured Bos starter culture was added to the cheese milk at an inoculum level of $1 \%$. This yielded $3.3 \cdot 10^{6} \mathrm{cfu} \mathrm{mL}^{-1}$ lactococci and $4.6 \cdot 10^{5} \mathrm{cfu} \mathrm{mL}^{-1}$ Leuconostoc species in the cheese milk; the viable numbers of Leuconostoc and lactococci were determined by plating on Lactobacillus agar (De Man, Rogosa and Sharpe agar; MRS agar, Merck, Darmstadt, Germany) and plating on M17 agar (Merck) to which $0.5 \%$ lactose was added after sterilization, respectively. Acidification during curd formation using the Bos starter culture was monitored by $\mathrm{pH}$ measurements of the cheese milk, the first curd, the second curd, and the whey.

Three strains of L. monocytogenes were selected for use in the challenge study: a cheese isolate (strain $2 \mathrm{~F}$ serotype $1 / 2 \mathrm{a}$ ), an environmental isolate from a cheese factory (strain $6 \mathrm{E}$, serotype 1/2a), and a reference strain L. monocytogenes Scott A (milk outbreak isolate, serotype $4 b$ ) (Table 2.1). These strains were included in a previous study in which the phenotypic properties of 138 L. monocytogenes strains were determined (van der Veen, Moezelaar, Abee, \& Wells-Bennik, 2008). Strain 6E and 2F were selected because these strains showed the highest resistance to lactic acid while strain Scott $A$ had the lowest resistance to lactic acid (van der Veen et al. 2008; Wemmenhove, van Valenberg, Zwietering, van Hooijdonk, \& Wells-Bennik, 2016). Growth of strains Scott A, 2F and 6E was assessed in the Gouda microcheese system, using four different $\mathrm{NaCl}$ concentrations $(0.9 \%$, $3.1 \%, 3.8 \%$ and $4.1 \% \mathrm{NaCl}$ on a dry matter basis) for a ripening period of up to one year.

Table 2.1 L. monocytogenes strains used in this study, their serotype, resistance to lactic acid (van der Veen et al. 2008) and origin

\begin{tabular}{llll}
\hline Strain & Serotype & $\begin{array}{l}\text { Minimal concentration (mM) } \\
\text { of undissociated lactic acid } \\
\text { needed to inhibit growth }\end{array}$ & Origin \\
\hline Scott A & $4 \mathrm{~b}$ & 2.5 & Milk outbreak (Massachusetts, US, 1983) \\
\hline $2 \mathrm{~F}$ & $1 / 2 \mathrm{a}$ & 4.0 & Cheese (Dijon, France, 1990) \\
\hline $6 \mathrm{E}$ & $1 / 2 \mathrm{a}$ & 7.5 & $\begin{array}{l}\text { Cheese equipment of an industrial } \\
\text { cheese-making plant (Dijon, France, } \\
1990)\end{array}$ \\
\hline
\end{tabular}

\subsubsection{Production of Gouda-type cheeses with different $\mathrm{NaCl}$ concentrations and artificial Listeria contamination during curd formation}

To produce Gouda microcheeses, the frozen milk was thawed and warmed to $30.5^{\circ} \mathrm{C}$. The following were added per liter of cheese milk: $200 \mu \mathrm{L}$ rennet enzyme (Kalase ${ }^{\circledR}, 150$ IMCU, 
CSK Food Enrichment), $400 \mu \mathrm{L} \mathrm{CaCl} 2$ (35\% w/v, Akzo Nobel, Frankfurt, Germany), $0.5 \mathrm{~g}$ Delvocid (DSM food specialties, Delft, The Netherlands). Individual L. monocytogenes strains were added to separate batches to a final level of approximately $10^{7} \mathrm{cfu} \mathrm{mL} \mathrm{m}^{-1}$; the exact levels were determined by plating on PALCAM-selective agar (VWR, Amsterdam, The Netherlands). A pre-cultured Bos starter culture was then added to the artificially contaminated milk at an inoculum level of $1 \%$.

Subsequently, $1.7 \mathrm{~mL}$ aliquots of the inoculated cheese milk were put in a deep-well microplate (Greiner, Alphen a/d Rijn, The Netherlands) and incubated at $30.5{ }^{\circ} \mathrm{C}$. After approximately 60 min the curd was cut, using a custom-made stirring device, as described before (Bachmann et al., 2009). The next steps consisted of stirring, settling and resting, taking an overall time of approximately $25 \mathrm{~min}$. Then deep-well microplates were centrifuged ( $1000 \mathrm{x} \mathrm{g}$ for $5 \mathrm{~min}$ ) to slightly compact the curds and facilitate whey removal. Following centrifugation, $620 \mu \mathrm{L}$ of whey was removed and $550 \mu \mathrm{L}$ of sterile washing water of $55^{\circ} \mathrm{C}$ was added to mimic the curd washing step in the large-scale process and simultaneously increase the temperature of the microcheeses to $35.5^{\circ} \mathrm{C}$. The microplates were incubated at $35.5^{\circ} \mathrm{C}$ for $40 \mathrm{~min}$ with stirring and an additional $20 \mathrm{~min}$ without stirring. Subsequently, the plates were subjected to centrifugation (4000 x $\mathrm{g}$ for $60 \mathrm{~min}$ ), after which the second whey was removed using pipettes, and by turning the plates upside down on a sterile tissue paper for $10 \mathrm{~min}$. More detailed information on the sample size, $\mathrm{pH}$, time and temperature of each of the phases is presented in Table 2.2. The $\mathrm{pH}$ and moisture content were measured $4 \mathrm{~h}$ after the addition of the starter to check the acidification capacity of the Bos starter culture and to assess curd formation. After $24 \mathrm{~h}$ the $\mathrm{pH}$ was determined again.

To determine the effect of $\mathrm{NaCl}$ in cheese on L. monocytogenes, Gouda cheeses with different concentrations of $\mathrm{NaCl}$ were produced and stored under controlled conditions throughout the ripening. To adjust the $\mathrm{NaCl}$ concentrations in the microcheeses, $17 \mu \mathrm{L}$ aliquots of sterile $\mathrm{NaCl}$ solution (different concentrations in the range of 80,200, 280 and $350 \mathrm{~g} \mathrm{~L}^{-1}$ ) were added to each microcheese, and microcheese plates were then centrifuged (1000 x g for $5 \mathrm{~min}$ ). This resulted in $\mathrm{NaCl}$ concentrations of $0.9,3.1,3.8$ and $4.1 \%$ on a dry matter basis, as determined using method NEN 3762 (van 't Westende, 1977). After 24 h, the target moisture content of the microcheese was $42-45 \%$, and plates were then sealed in 0.8 atmospheres of $100 \%$ nitrogen, followed by storage at $12{ }^{\circ} \mathrm{C}$ for ripening periods of 2, 4, 6, 8, 16, 28 and 52 weeks. Microcheeses with different $\mathrm{NaCl}$ concentrations were present in different wells of one microcheese plate. For each ripening period a different microplate was opened and analysed. Two independent experiments were performed per condition and per strain, and moisture and $\mathrm{pH}$ analyses were performed in duplicate. 
Table 2.2 Viable counts of L. monocytogenes strains Scott A, 2F and 6E during the successive stages of curd formation ${ }^{a}$

\begin{tabular}{|c|c|c|c|c|c|c|c|c|}
\hline \multirow[t]{2}{*}{ Code } & \multirow[t]{2}{*}{ Sample } & \multirow[t]{2}{*}{$\begin{array}{l}\text { Sample } \\
\text { size }(g)\end{array}$} & \multirow[t]{2}{*}{$\mathrm{pH}$} & \multirow{2}{*}{$\begin{array}{l}\text { Time (min) } \\
\text { after starter } \\
\text { addition }\end{array}$} & \multirow{2}{*}{$\begin{array}{l}\text { Tempe- } \\
\text { rature } \\
\left({ }^{\circ} \mathrm{C}\right)\end{array}$} & \multicolumn{3}{|c|}{$\begin{array}{l}\text { L. monocytogenes viable counts } \\
\left(\mathrm{cfu} \mathrm{g}^{-1}\right)^{\mathrm{a}}\end{array}$} \\
\hline & & & & & & Scott A & $2 \mathrm{~F}$ & $6 \mathrm{E}$ \\
\hline$A$ & Milk & 1.7 & 6.7 & 0 & 30.5 & $\begin{array}{l}6.5 \cdot 10^{7} \\
\pm 1.1 \cdot 10^{6}\end{array}$ & $\begin{array}{l}4.8 \cdot 10^{7} \\
\pm 5.5 \cdot 10^{5}\end{array}$ & $\begin{array}{l}2.3 \cdot 10^{7} \\
\pm 4.0 \cdot 10^{5}\end{array}$ \\
\hline B & Renneted milk & 1.7 & 6.6 & 20 & 30.5 & $\begin{array}{l}2.9 \cdot 10^{7} \\
\pm 1.0 \cdot 10^{6}\end{array}$ & $\begin{array}{l}1.2 \cdot 10^{7} \\
\pm 4.9 \cdot 10^{5}\end{array}$ & $\begin{array}{l}3.6 \cdot 10^{6} \\
\pm 7.2 \cdot 10^{4}\end{array}$ \\
\hline$C_{1}$ & First curd & 1.08 & 6.4 & 60 & 30.5 & $\begin{array}{l}8.7 \cdot 10^{7} \\
\pm 1.0 \cdot 10^{4} \\
\end{array}$ & $\begin{array}{l}4.7 \cdot 10^{7} \\
\pm 2.0 \cdot 10^{5}\end{array}$ & $\begin{array}{l}3.9 \cdot 10^{7} \\
\pm 2.3 \cdot 10^{5}\end{array}$ \\
\hline $\mathrm{C}_{2}$ & First whey & 0.62 & 6.6 & 60 & 30.5 & $\begin{array}{l}2.6 \cdot 10^{6} \\
\pm 4.6 \cdot 10^{4} \\
\end{array}$ & $\begin{array}{l}4.7 \cdot 10^{5} \\
\pm 8.3 \cdot 10^{3}\end{array}$ & $\begin{array}{l}4.3 \cdot 10^{5} \\
\pm 2.5 \cdot 10^{3}\end{array}$ \\
\hline$D$ & $\begin{array}{l}\text { First curd with } \\
0.55 \mathrm{ml} \mathrm{H}_{2} \mathrm{O}\end{array}$ & 1.63 & 6.4 & 60 & 35.5 & $\begin{array}{l}5.8 \cdot 10^{7} \\
\pm 1.0 \cdot 10^{4}\end{array}$ & $\begin{array}{l}3.1 \cdot 10^{7} \\
\pm 2.0 \cdot 10^{5}\end{array}$ & $\begin{array}{l}2.6 \cdot 10^{7} \\
\pm 2.3 \cdot 10^{5}\end{array}$ \\
\hline$E$ & $\begin{array}{l}\text { First curd } \\
\text { before whey } \\
\text { separation }\end{array}$ & 1.63 & 6.2 & 130 & 35.5 & $\begin{array}{l}5.7 \cdot 10^{7} \\
\pm 3.5 \cdot 10^{5}\end{array}$ & $\begin{array}{l}3.2 \cdot 10^{7} \\
\pm 2.5 \cdot 10^{4}\end{array}$ & $\begin{array}{l}4.7 \cdot 10^{7} \\
\pm 3.9 \cdot 10^{5}\end{array}$ \\
\hline $\mathrm{F}_{1}$ & Second curd & 0.17 & 5.7 & 200 & 35.5 & $\begin{array}{l}1.3 \cdot 10^{8} \\
\pm 3.4 \cdot 10^{7}\end{array}$ & $\begin{array}{l}1.4 \cdot 10^{8} \\
\pm 3.2 \cdot 10^{7}\end{array}$ & $\begin{array}{l}1.5 \cdot 10^{8} \\
\pm 1.1 \cdot 10^{7}\end{array}$ \\
\hline $\mathrm{F}_{2}$ & Second whey & 1.46 & 6.4 & 200 & 35.5 & $\begin{array}{l}1.3 \cdot 10^{4} \\
\pm 1.5 \cdot 10^{3}\end{array}$ & $\begin{array}{l}1.6 \cdot 10^{5} \\
\pm 1.5 \cdot 10^{3}\end{array}$ & $\begin{array}{l}2.3 \cdot 10^{4} \\
\pm 3.2 \cdot 10^{3}\end{array}$ \\
\hline
\end{tabular}

a The sample size, $\mathrm{pH}$, time (after starter addition) and temperature of each stage of curd formation are specified. Results are expressed as average \pm stdev of triplicate determinations. Codes A-F: see Fig. 2.1A.

\subsubsection{Microbial analyses}

The viable numbers of $L$. monocytogenes Scott $A, 2 F$, and $6 E$ were determined in triplicate in milk, in first and second whey (60 min and 200 min after addition of starter to the milk, respectively), and in the first (60 and $130 \mathrm{~min}$ after addition of starter) and second curd. For the analysis of curd, whey and cheese, samples from five wells of the 96 wells plate were collected and pooled. Before making ten-fold serial dilutions, the cheese and curd samples were homogenized using a stomacher and dissolved by adding $9 \mathrm{~mL}$ of $2 \%$ trisodium citrate to $1 \mathrm{~g}$ cheese or curd. Ten-fold serial dilutions were made in peptone physiological $\mathrm{NaCl}$ and samples were plated on PALCAM-selective agar (VWR). The viable numbers of $L$. monocytogenes during ripening were determined in duplicate in the microcheeses after 2, 4, 6, 8, 16, 28 and 52 weeks. The numbers enumerated throughout the 12 month ripening period at different time points were compared with initial levels of L. monocytogenes in microcheeses directly after curd formation to correct for small differences in inoculation levels of different strains for the different experiments. 
The logarithmic increase of L. monocytogenes throughout ripening was calculated as follows:

$$
\text { Log increase }=\log C_{t}-\log C_{0}
$$

where $C_{t}=$ viable numbers of $L$. monocytogenes $\left(\mathrm{cfu} \mathrm{g}^{-1}\right)$ determined in Gouda microcheeses after $\mathrm{t}$ weeks of ripening and $C_{0}=C_{\text {second curd }}=$ initial viable numbers $\left(\mathrm{cfu} \mathrm{g}^{-1}\right)$ determined in Gouda microcheeses directly after curd formation.

\subsubsection{Chemical parameters during ripening of Gouda microcheeses}

Organic acids, $\mathrm{pH}$, moisture content, and water activity were determined in the Gouda microcheeses after $2,4,6,8,16,28$ and 52 weeks of ripening. The acidification by the starter bacteria in the Gouda microcheeses was determined by measuring the $\mathrm{pH}$ immediately after curd formation. The $\mathrm{pH}$ was measured with a $3 \mathrm{~mm}$-electrode (BioTrode, Metrohm, Herisau, Switzerland) directly in the microcheeses. Organic acid concentrations (lactic, acetic and propionic acid) present in the microcheeses were determined after $2,4,6,8,16$, 28 and 52 weeks of ripening using analytical reverse phase high pressure liquid chromatography (RP-HPLC) as described by Visser, Slangen and Rollema (1986). The moisture content was determined according to NEN 3755 (van 't Westende, 1998). Water activity was measured using the dewpoint method (Decagon Aqualab, Pullman, WA, USA) at 2, 4, 8, 28 and 52 weeks. Factory-scale (12 kg) Gouda cheeses aged 2 weeks, 2 months and 6 months were collected from 5 different Gouda cheese factories and for these cheeses the $\mathrm{pH}$, organic acid concentrations and moisture content were determined.

\subsection{Results}

Gouda microcheeses were artificially contaminated by introducing three different strains of L. monocytogenes in the cheese milk before starter addition, to establish the fate of the pathogen throughout curd formation and during ripening of the cheeses for a period of up to 1 year. This situation mimics the hypothetical presence of L. monocytogenes in cheese milk after pasteurization, in a worst case scenario as a result of post-processing contamination or due to incidents relating to failure in the pasteurization process. 


\subsubsection{Curd formation of Gouda microcheeses: concentration and limited growth of added L. monocytogenes}

To establish the fate of L. monocytogenes during curd formation after artificial contamination of the cheese milk, the viable counts of L. monocytogenes were determined in the cheese milk, renneted milk, in the first curd, first whey, in the first curd with added washing water, in the first curd just before separation of the second whey, and in the second curd and whey. These data are presented in Fig. 2.1 The pH decreased from 6.7 in the cheese milk to 6.4 in the renneted milk just before separation of the first curd and first whey (Table 2.2). The concentration of L. monocytogenes strains Scott A, $2 \mathrm{~F}$ and $6 \mathrm{E}$ decreased by 0.6 log cfu g ${ }^{-1}$ during this part of the process (Table 2.2, Fig. 2.1). Upon separation of the first curd and first whey, 97-99\% of the L. monocytogenes cells were recovered from the curd of the Gouda microcheese. At the same time, the weight was reduced from $1.7 \mathrm{~g}$ to $1.08 \mathrm{~g}$ due to whey removal, and concentrations of L. monocytogenes Scott A, $2 \mathrm{~F}$ and $6 \mathrm{E}$ showed an increase of $0.7 \mathrm{log} \mathrm{cfu}^{-1}$, respectively. At the time of second curd formation, a decrease in viable numbers was observed (Table 2.2, Fig. 2.1A) for all three L. monocytogenes strains. At this time, the temperature was $35.5^{\circ} \mathrm{C}$, and the $\mathrm{pH}$ was 6.2 before separation of the second whey and was 5.7 after separation. The overall increase in viable numbers of $L$. monocytogenes Scott $A, 2 F$ and $6 \mathrm{E}$, was $0.3,0.5$ and $0.8 \mathrm{log} \mathrm{cfu} \mathrm{g}^{-1}$. There was a 10 -fold decrease in volume from cheese milk to second curd, and $99.9 \%$ of the L. monocytogenes cells were trapped in the cheese matrix (Table 2.2, Fig. 2.1A). This implies that the increase of L. monocytogenes during the initial stages of fermentation and curd formation is primarily due to concentration and not to growth. In cheese milk without starter culture that was kept at $30{ }^{\circ} \mathrm{C}$ for $200 \mathrm{~min}$, the observed increase of the different L. monocytogenes strains due to growth was significantly higher, i.e. $1.6 \mathrm{log}_{\mathrm{cfu} \mathrm{g}}{ }^{-1}, 1.0 \mathrm{cfu} \mathrm{g}^{-1}$ and $0.67 \mathrm{cfu} \mathrm{g}^{-1}$ for Scott A, 2F and 6E, respectively (Fig. 2.1B). 
A)

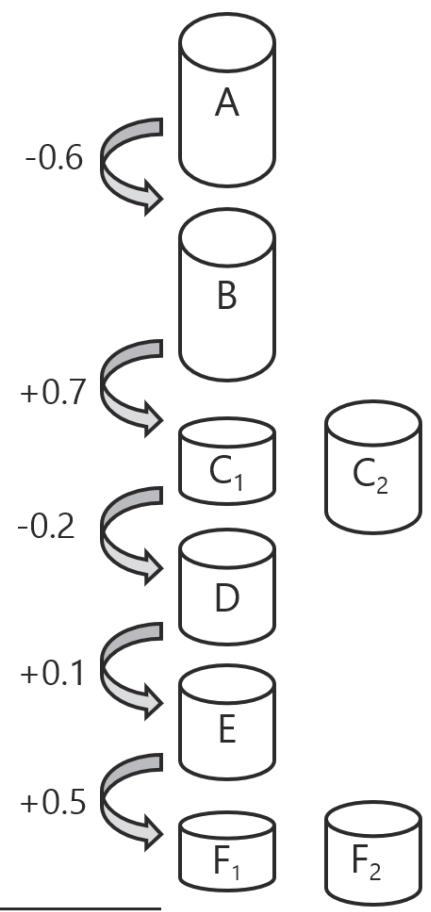

Overall: +0.5 log increase
B)

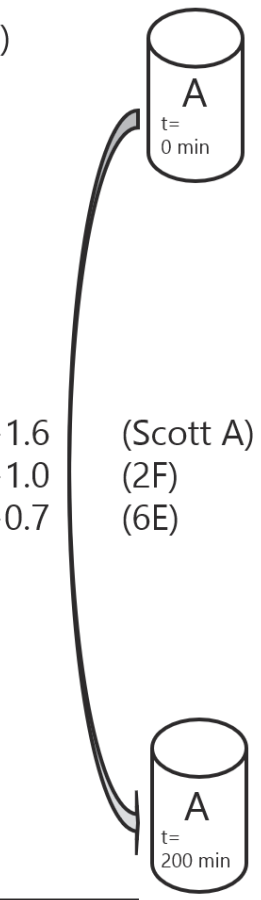

Overall: +1.1 log increase

Fig. 2.1 The curd formation process. Changes in viable counts (cfu g ${ }^{-1}$ ) of L. monocytogenes strains Scott $A$, $2 \mathrm{~F}$ and $6 \mathrm{E}$ during curd formation of Gouda microcheeses (one experiment, in triplicate per strain per time point) are presented. Cheese milk was artificially contaminated with either L. monocytogenes strain Scott A, $2 \mathrm{~F}$ or $6 \mathrm{E}$, and the concentrations were subsequently determined in the cheese milk (sample A), renneted milk (sample B), first curd (sample $C_{1}$ ), first whey (sample $C_{2}$ ), first curd with added washing water (sample D), first curd before whey separation (sample $E$ ), second curd (sample $F_{1}$ ) and second whey (sample $F_{2}$ ). Changes in viable counts ( $\mathrm{cfu} \mathrm{g}^{-1}$ ) during curd formation (Fig. 2.1A) were compared with changes in viable counts of L. monocytogenes in milk kept at $30^{\circ} \mathrm{C}$ for $200 \mathrm{~min}$ (Fig. 2.1B).

\subsubsection{No growth of L. monocytogenes during the first 8 weeks of ripening of Gouda microcheeses}

The viable counts of L. monocytogenes during the ripening of the Gouda microcheeses with different $\mathrm{NaCl}$ concentrations are presented in Fig. 2.2. Using the definition of growth and inactivation of Koutsoumanis and Sofos (2005) and Skandamis et al. (2007), an increase of more than 0.5 log cfu g ${ }^{-1}$ was considered as growth, and a decrease in numbers of more than $1.0 \operatorname{log~cfu~g}^{-1}$ is defined as inactivation. For all three L. monocytogenes strains (Scott $\mathrm{A}, 2 \mathrm{~F}$ and $6 \mathrm{E}$ ) an increase in viable numbers of more than $0.5 \mathrm{log}$ was not observed under any of the conditions tested (different strains and $\mathrm{NaCl}$ concentrations throughout ripening). Inactivation (i.e. decrease of $\geq 1.0 \mathrm{log} \mathrm{cfu} \mathrm{g}^{-1}$ ) was not observed in the first 8 weeks. Young Gouda cheese is typically consumed within 4-6 weeks after production. 
A)

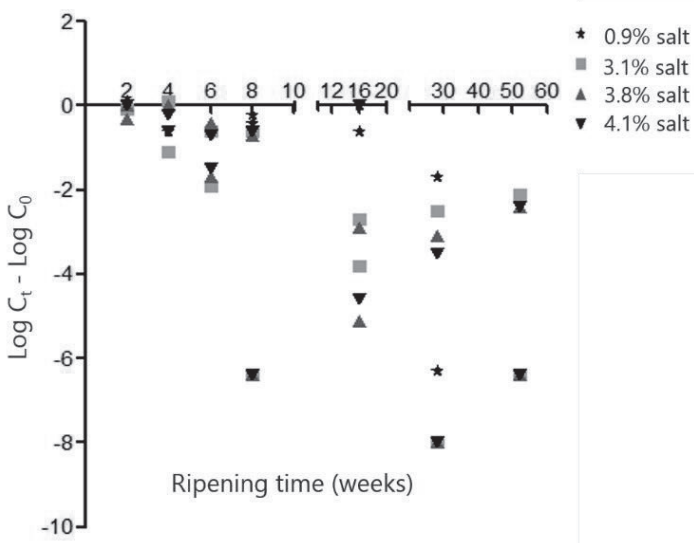

B)

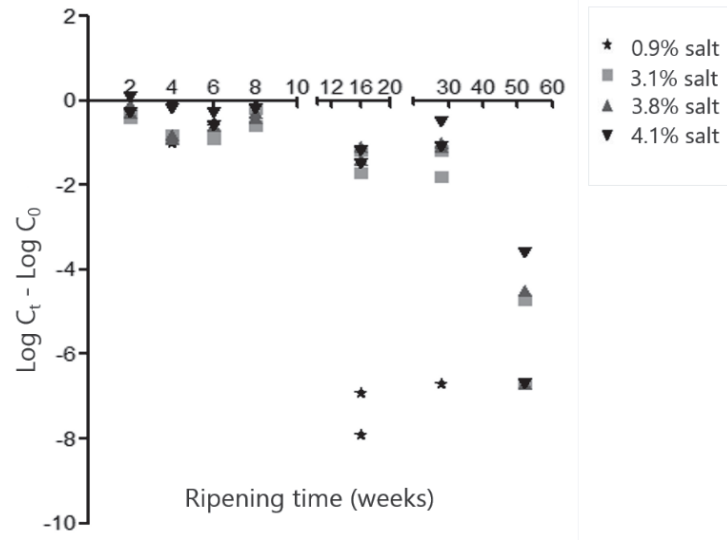

C)

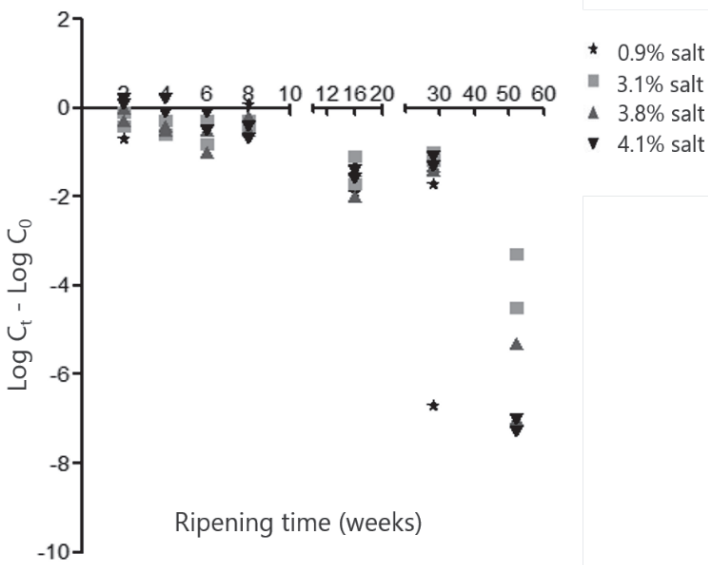

Fig. 2.2 Inactivation of L. monocytogenes strain Scott A (Fig. 2.2A), strain 2F (Fig. 2.2B) and strain 6E (Fig. 2.2C) during early (2-8 weeks) and prolonged (16-52 weeks) ripening of Gouda microcheeses. Initial concentrations $\left(C_{0}\right.$ in log cfu g $\left.{ }^{-1}\right)$ in the cheese curd $\left(t=0\right.$ weeks) were subtracted from viable numbers $\left(C_{t}\right.$ in log cfu g $\left.\mathrm{g}^{-1}\right)$ at a given time point. Values are displayed as individual determinations $(n=2$ per strain and per time point and per salt concentration). Salt concentrations were: $\star, 0.9 \% ;, 3.1 \% ; \boldsymbol{\Lambda}, 3.8 \%, \boldsymbol{\nabla}, 4.1 \%$. Negative log values represent lower viable counts at the given time point than initial levels.

\subsubsection{Reduction of L. monocytogenes during extended ripening of Gouda microcheeses.}

The viable numbers of L. monocytogenes significantly decreased in Gouda microcheeses during ripening for an extended period of time (16, 28 and 52 weeks). The viable numbers of strains $2 \mathrm{~F}$ and $6 \mathrm{E}$ in microcheeses were at least 1.0 log units lower after ripening for 16 weeks (except for one experiment with strain $2 \mathrm{~F}$ in microcheeses ripened for 28 weeks). In comparison with the counts in the second curd; viable counts of strain Scott $A$ were reduced by more than 1.0 log after 28 weeks and longer (Fig. 2.2). 
The reduction in viable numbers of L. monocytogenes strain Scott $A$ in microcheeses in which the $\mathrm{NaCl}$ content was $0.9 \%$ on dry matter basis was lower than in microcheeses with $3.1,3.6$ and $4.1 \%$ on dry matter basis. The inactivation of strains $2 \mathrm{~F}$ and $6 \mathrm{E}$ was more profound in microcheeses with $0.9 \% \mathrm{NaCl}$ on dry matter basis than in cheeses with 3.1, 3.6 and $4.1 \% \mathrm{NaCl}$ on dry matter basis. Overall, the survival and inactivation of L. monocytogenes strains was not affected by the $\mathrm{NaCl}$ concentrations set in different microcheeses. At extended ripening times, variability in the decrease of viable counts between independent duplicates was observed; this varied from $0 \operatorname{log~cfu~g}^{-1}$ to $4 \log \mathrm{cfu}$ $\mathrm{g}^{-1}$.

\subsubsection{Chemical parameters during ripening of Gouda microcheeses.}

The $\mathrm{pH}$ attained in the curd of the microcheeses ( $24 \mathrm{~h}$ after inoculation of the starter culture) was 5.3. During ripening, the $\mathrm{pH}$ of the microcheeses increased from $\mathrm{pH} 5.3$ after 1 day, to $\mathrm{pH} 5.5$ after 7 months and pH 6.1 after 1 year (Fig. 2.3A). The organic acids that were detected in the microcheeses were lactic acid and acetic acid, that were present at concentrations of $13.9 \mathrm{~g} \mathrm{~kg}^{-1}$ and $1.1 \mathrm{~g} \mathrm{~kg}^{-1}$, respectively. The concentrations did not significantly change over time (Fig. 2.4A). As a reference, the $\mathrm{pH}$ and organic acid concentrations in the $12 \mathrm{~kg}$ commercial Gouda cheeses were also determined; the $\mathrm{pH}$ was between 5.3 and 5.5 in Gouda cheeses after 2 weeks of ripening and was not significantly higher after 6 months (Fig. 2.3B). The organic acids that were detected were also lactic acid and acetic acid at concentrations of $13.7 \mathrm{~g} \mathrm{~kg}^{-1}$ and $0.9 \mathrm{~g} \mathrm{~kg}^{-1}$, respectively. No significant changes in the organic acid concentrations were observed over time (Fig. 2.4B). Citric acid and propionic acid were not detected in Gouda microcheeses or commercial $12 \mathrm{~kg}$ cheeses after ripening times of 2 weeks or longer. 
A)

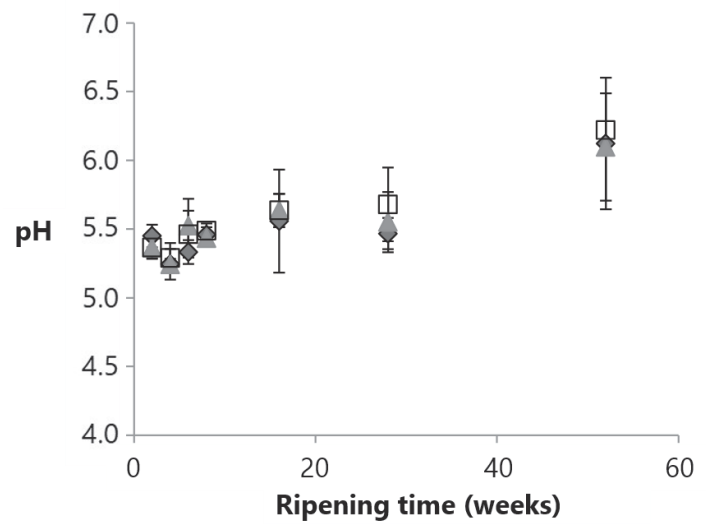

B)

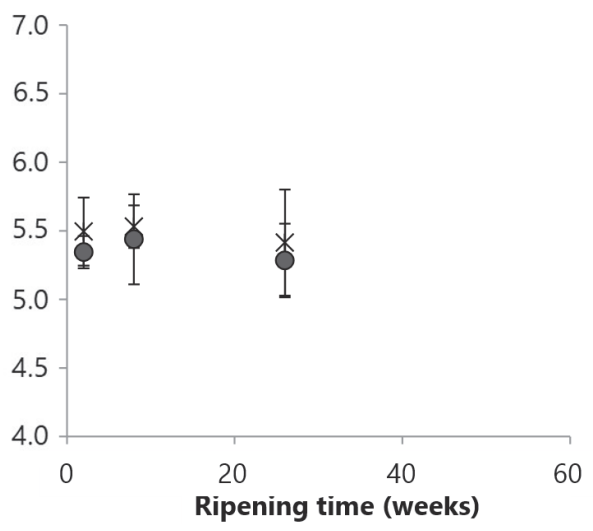

Fig. $2.3 \mathrm{pH}$ (average \pm stdev with $\mathrm{n}=2$ per strain and per time point and per salt concentration) of Gouda microcheeses, with microcheeses challenged with L. monocytogenes strain Scott A depicted as (depicted as $\triangle$ ) and $6 \mathrm{E}$ (depicted as $\square$ ) (Fig. 2.3A), versus $12 \mathrm{~kg}$ factory scale cheeses (average \pm stdev with $\mathrm{n}=$ 10 per time point) with $(\mathrm{X})$ depicting the crust and $(\bullet)$ depicting the core of factory-scale Gouda cheese during ripening (Fig. 2.3B).

A)

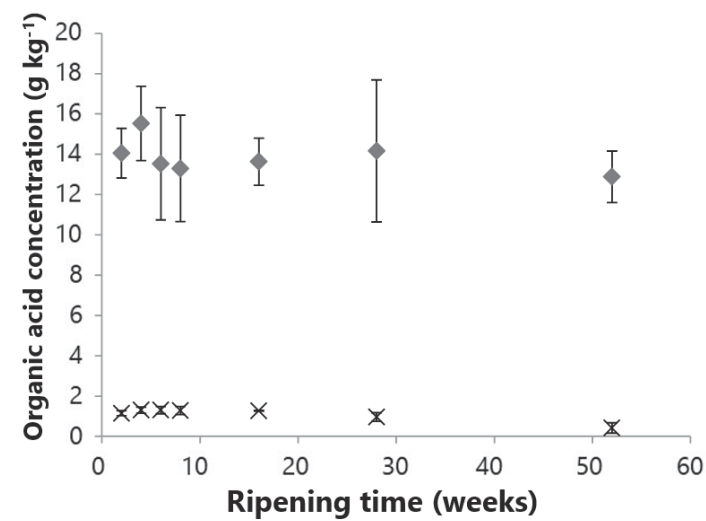

B)

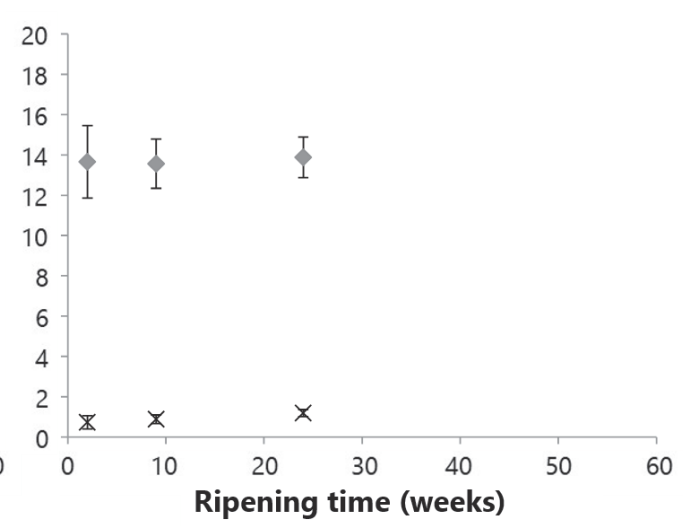

Fig. 2.4 Total concentrations (average \pm stdev based on independent measurements, $n=5$ ) of lactic $(\checkmark)$ and acetic (X) acid ( $\mathrm{g} \mathrm{kg}^{-1}$ ) of Gouda microcheeses (Fig. 2.4A) and of $12 \mathrm{~kg}$ Gouda cheeses (Fig. 2.4B), analysed during ripening.

The microcheeses had a moisture content of $45 \%$ directly after curd formation, $42 \%$ after 8 weeks of ripening (young Gouda cheese) and 39\% after 1 year of ripening (Fig. 2.5). The reduction of the moisture content in time corresponds with a decline in water activity $\left(\mathrm{a}_{\mathrm{w}}\right.$ $=0.98$ after 8 weeks; 0.92 after 7 months, and 0.84 after 1 year). These water activities are comparable with those of large Gouda cheeses, in which the $\mathrm{a}_{\mathrm{w}}$ is 0.92 in the crust and 0.94 in the core after 7 months (data not shown). The $\mathrm{NaCl}$ concentration (concentrations varied 
between 0.9 and $4.1 \%$ dry matter) and the $\mathrm{pH}$ did not have an effect on the moisture content within the range tested (results not shown).

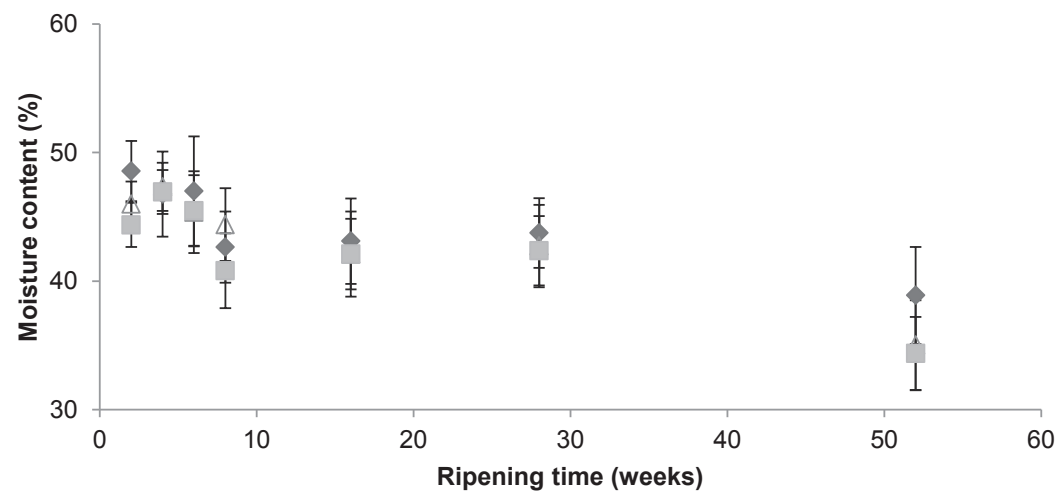

Fig. 2.5 Moisture content of Gouda microcheeses (average \pm stdev based on independent measurements, $n=9$ per time point) during ripening of the microcheeses that were inoculated with L. monocytogenes strains Scott $\mathrm{A}(\diamond), 2 \mathrm{~F}(\Delta)$ and $6 \mathrm{E}(\varpi)$.

\subsection{Discussion}

In this challenge study, no growth of L. monocytogenes was observed in Gouda microcheeses throughout the Gouda cheese making process and a 52 week ripening period; in fact, the numbers declined during ripening. The cheese milk was artificially contaminated with 3 different L. monocytogenes strains. Because this took place at the very start of the cheese making process, it mimicked post pasteurization contamination of the milk or failure of the pasteurization process of contaminated raw milk.

The viable numbers of this pathogen were determined in the curd and the whey, as well as in the cheese during a ripening period of 52 weeks. During the first stages of cheese production, L. monocytogenes was concentrated in the curd upon whey separation: for the three different strains, 97-99\% of L. monocytogenes cells were retrieved from the curd. Such enclosures in the curd are in line with findings of Yousef \& Marth (1988), showing that $97.6 \%$ of L. monocytogenes cells were trapped in the curd during manufacture of Colby cheese. For other bacteria, notably the lactic acid bacteria in starter cultures, it is also known that only a small fraction of the bacteria ends up in the whey (Kalab, 1979). Growth of L. monocytogenes during formation of the first curd is another factor contributing to the increase in viable counts in the first hour after starter inoculation and artificial contamination of the cheese milk.

Acidification at that stage $(\mathrm{pH} \mathrm{6.4)}$ is still limited in the first curd and the lactic acid concentrations are not high enough to fully inhibit growth of L. monocytogenes, based on 
previously established lactic acid concentrations that are minimally needed to fully inhibit growth of L. monocytogenes (Coroller et al., 2005; Houtsma, de Wit, \& Rombouts, 1996; Wemmenhove, van Valenberg, Zwietering, van Hooijdonk, \& Wells-Bennik, 2016). The increase in viable counts of L. monocytogenes strains Scott $A, 2 F$ and $6 \mathrm{E}$ during curd formation was +0.3 to $+0.8 \mathrm{log} \mathrm{cfu} \mathrm{g}^{-1}$ cheese. Considering that a 10 -fold concentration of L. monocytogenes resulted from enclosure in the curd, the actual concentration of L. monocytogenes in the cheese milk until the separation of whey and curd decreased by -0.2 to $-0.7 \log$ cfu g $^{-1}$ cheese. The increase in pasteurized cheese milk that was left at 30 ${ }^{\circ} \mathrm{C}$ was +0.7 to $+1.6 \mathrm{log} \mathrm{cfu} \mathrm{g}^{-1}$ milk, to final concentration of $8.5 \mathrm{log} \mathrm{cfu} \mathrm{g}^{-1}$. In a recent study, Schvartzman et al. (2011) studied the fate of L. monocytogenes during curd formation in a model system in which pasteurized milk was acidified with F-DVS CHN-19 starter culture that contained Lactococcus subsp. cremoris, lactis and diacetylactis, and Leuconostoc mesenteroides. These authors reported a 2.0 log increase of L. monocytogenes, starting with cheese milk and ending up with cheese curd after incubation at $30{ }^{\circ} \mathrm{C}$ for $5 \mathrm{~h}$. The inoculation level of the starter culture was $0.02 \%$, resulting in $0.17 \mathrm{~g}$ lactic acid per $\mathrm{kg}$ cheese, which is lower than the $13.9 \mathrm{~g}$ lactic acid per $\mathrm{kg}$ Gouda cheese obtained in our study using an inoculation level of $1 \%$. The acidification level of the cheeses in the study by Schvartzman et al. (2011) was relatively low, i.e. a pH decrease from 6.7 to 6.3 after $4.4 \mathrm{~h}$ while in this study, a pH decrease from 6.7 to 5.7 was observed in Gouda cheeses. Clearly, it is important to take the effect of the starter culture and the degree of acidification into account when assessing the growth potential of L. monocytogenes.

No growth of L. monocytogenes was observed during the first 8 weeks of ripening of Gouda. These findings correspond with a previous Gouda challenge study that was performed by Northolt et al. in 1988, showing no growth of L. monocytogenes in $4.5 \mathrm{~kg}$ cheeses during the first six weeks of ripening. Lactic acid is the most prominent organic acid in Gouda cheese (Fig. 2.4). The potential of this acid in its undissociated form to inhibit the growth of $L$. monocytogenes has been described in various papers (Ahamad \& Marth, 1989; Coroller et al., 2005; Vasseur, Baverel, Hébraud, \& Labadie, 1999; Young \& Foegeding, 1993). Van der Veen et al. (2008) also demonstrated that $2 \%$ sodium lactate at $\mathrm{pH} \leq 5.2$ led to full inhibition of growth of 138 different L. monocytogenes strains. Once formed, the concentration of lactic acid did not change during ripening of Gouda (Fig. 2.4A). Another factor that may contribute to growth inhibition of L. monocytogenes in Gouda cheese is nutrient limitation or absence of fermentable sugars (Degeest, Vaningelgem, \& de Vuyst, 2001; Loubiere, Cocaign-Bousquet, Matos, Goma, \& Lindley, 1997). Viable counts of all L. monocytogenes strains clearly decreased in all Gouda microcheeses after ripening periods of 7 months and longer, with a drop in viable numbers of at least 1 log unit and up to 7 log units. Gradual inactivation after prolonged ripening has also been observed in previous experiments with L. monocytogenes in Swiss, Cheddar, Colby and Feta cheese 
(Buazzi, Johnson, \& Marth, 1992; Genigeorgis, Carniciu, Dutulescu, \& Farver, 1991; Ryser \& Marth, 1987; Shrestha, Grieder, McMahon, \& Nummer, 2011).

After a ripening time of $\geq 8$ weeks, the $\mathrm{pH}$ of the microcheeses increased from 5.3 to 5.5 and even to $\mathrm{pH} 6.1$ after 1 year of ripening. Such a $\mathrm{pH}$ increase in the microcheeses can be explained by proteolysis and by yeast and mould growth, although the latter was not observed in the analyzed cheeses. Between 8 and 52 weeks of ripening, the moisture content of the microcheeses declined, resulting in a lowered water activity. This coincided with inactivation of L. monocytogenes in cheese.

The $\mathrm{NaCl}$ contents (tested range $0.9-4.1 \%$ dry matter) corresponded very well with the $\mathrm{NaCl}$ concentrations of large-scale Gouda cheeses of 2.9-3.6\% dry matter (van den Berg et al., 2004). In this range, $\mathrm{NaCl}$ did not affect the fate of $L$. monocytogenes during ripening. The concentrations of $\mathrm{NaCl}$ to which L. monocytogenes strains were exposed in cheese were substantially lower than the $\mathrm{NaCl}$ concentrations that constitute the growth limits of strains Scott A, 2F and 6E in culture medium; these were $11.7 \% \mathrm{w} / \mathrm{v} \mathrm{NaCl}$ (van der Veen et al., 2008). Furthermore, the $\mathrm{NaCl}$ content does not influence the water activity to a large extent within the range of $0.9-4.1 \% \mathrm{NaCl}$ in dry matter (results not shown). Based on these results, the probability of growth of L. monocytogenes is not expected to be higher in Gouda microcheeses than in large-scale cheeses in the range of $0.9-4.1 \%$ salt dry matter. This outcome is confirmed in a recent study on L. monocytogenes in low-salt Cheddar cheese (Shrestha et al. 2011).

The Gouda microcheese model has previously been validated as a model for the Gouda cheese process to systematically screen cheese starter cultures for their flavour profiles over time (Bachmann et al., 2009). This study substantiated the use of the Gouda microcheese as a model system for larger scale $12 \mathrm{~kg}$ Gouda cheeses, as the main intrinsic parameters, namely, $\mathrm{pH}$, organic acid concentrations, $\mathrm{NaCl}$ concentrations, $\mathrm{a}_{\mathrm{w}}$ and moisture content were very comparable during ripening. The microcheese system is also a suitable model system for Gouda cheese challenge tests with pathogens or spoilage organisms in the presence of a starter culture, as temperature, $\mathrm{pH}$, organic acid and water activity profiles in microcheeses were similar to those of factory-scale cheeses. Generated data from the microcheese system can be used for validation of quantitative microbiological risk models on semi-hard cheese made from starter-induced curd formation.

This study has shown that 3 individual L. monocytogenes strains with origins from cheese, dairy plant environment and a reference strain do not grow in Gouda cheese and that their numbers decline during extended ripening periods. The main factors that contributed to the inhibition of L. monocytogenes are likely to be lactic acid and the decreasing water activity during ripening. 


\subsection{Conclusions}

L. monocytogenes does not grow in Gouda cheese during the first 8 weeks of ripening. Viable numbers of L. monocytogenes in Gouda cheese decrease in the ripening period between 8 and 52 weeks. A $0.5 \mathrm{log} \mathrm{cfu} \mathrm{g}^{-1}$ increase of L. monocytogenes during curd formation results from entrapment in the curd and is not due to growth.

\section{Acknowledgements}

The authors would like to thank Roelie Holleman en Jan de Wit from NIZO food research, Ede, The Netherlands, for their technical assistance. The study was supported by the Dutch Dairy Organisation (NZO) and the Dutch Dairy Board (PZ). 


\section{References}

Ahamad, N., \& Marth, E.H. (1989). Behavior of Listeria monocytogenes at 7, 13, 21, and 35C in tryptose broth acidified with acetic, citric, or lactic acid. Journal of Food Protection 52:688-695.

Bachmann, H., Kruijswijk, Z., Molenaar, D., Kleerebezem, M., \& van Hylckama Vlieg, J.E.T. (2009). A highthroughput cheese manufacturing model for effective cheese starter culture screening. Journal of Dairy Science 92:5868-5882.

Baranyi, J., Tamplin, M.L., Juneja, V.K., Itturriaga, M.H., Amezquita, A., Koseki, S., Nychas, G.J., \& Koutsoumanis K. (2012). Combase growth predictor. Retrieved 23-07-2012, from http://www.combase.cc/index.php/en/predictive-models/134-combase-predictor.

Buazzi, M.M., Johnson, M.E., \& Marth, E.H. (1992). Survival of Listeria monocytogenes during the manufacture and ripening of Swiss cheese. Journal of Dairy Science 75:380-386.

CAC (2007). Guidelines on the application of general principles of food hygiene to the control of Listeria monocytogenes in foods (CAC-GL 61-2007). pp. 1-28.

Coroller, L., Guerrot, V., Huchet, V., Le Marc, Y., Mafart, P., Sohier, D., \& Thuault, D. (2005). Modelling the influence of single acid and mixture on bacterial growth. International Journal of Food Microbiology 100:167-178.

Degeest, B., Vaningelgem, F., \& de Vuyst, L. (2001). Microbial physiology, fermentation kinetics, and process engineering of heteropolysaccharide production by lactic acid bacteria. International Dairy Journal 11:747-757.

Doorduyn, Y., de Jager, C., van der Zwaluw, W., Wannet, W., van der Ende, A., Spanjaard, L., \& van Duynhoven, Y. (2006). Invasive Listeria monocytogenes infections in the Netherlands, 1995-2003. European Journal of Clinical Microbiology \& Infectious Diseases 25:433-442.

EFSA (2011). The European Union summary report on trends and sources of zoonoses, zoonotic agents and food-borne outbreaks in 2009. EFSA Journal 9:2090.

Gaulin, C., Ramsay, D., \& Bekal, S. (2012). Widespread listeriosis outbreak attributable to pasteurized cheese, which led to extensive cross-contamination affecting cheese retailers, Quebec, Canada, 2008. Journal of Food Protection 75:71-78.

Genigeorgis, C., Carniciu, M., Dutulescu, D., \& Farver, T.B. (1991). Growth and survival of Listeria monocytogenes in market cheeses stored at $4 C$ to 30C. Journal of Food Protection 54:662-668.

Guinee, T.P., \& Fox, P.F. (2004). Salt in cheese: physical, chemical and biological aspects. Pages 207-259 in Cheese: chemistry, physics and microbiology (3rd ed.). Vol. 1. P.F. Fox, P.L.H. McSweeney, T.M. Cogan, \& T.P. Guinee, ed. Elsevier Ltd., London.

Houtsma, P.C., de Wit, J.C., \& Rombouts, F.M. (1996). Minimum inhibitory concentration (MIC) of sodium lactate and sodium chloride for spoilage organisms and pathogens at different $\mathrm{pH}$ values and temperatures. Journal of Food Protection 59:1300-1304.

Kalab, M. (1979). Microstructure of dairy foods. 1. Milk products based on protein. Journal of Dairy Science 62:1352-1364.

Koch, J., Dworak, R., Prager, R., Becker, B., Brockmann, S., Wicke, A., Wichmann-Schauer, H., Hof, H., Werber, D., \& Stark, K. (2010). Large listeriosis outbreak linked to cheese made from pasteurized milk, Germany, 2006-2007. Foodborne Pathogenic Diseases 7:1581-1584. 
Koutsoumanis, K.P., \& Sofos, J.N. (2005). Effect of inoculum size on the combined temperature, pH and aw limits for growth of Listeria monocytogenes. International Journal of Food Microbiology 104:83-91.

Lou, Y., \& Yousef, A.E. (2000). Characteristics of Listeria monocytogenes important to food processors. In Listeria, Listeriosis and Food Safety. New York: Marcel Dekker.

Loubiere, P., Cocaign-Bousquet, M., Matos, J., Goma, G., \& Lindley, N.D. (1997). Influence of endproducts inhibition and nutrient limitations on the growth of Lactococcus lactis subsp. lactis. Journal of Applied Microbiology 82:95-100.

Northolt, M.D., Beckers, H.J., Vecht, U., Toepoel, L., Soentoro, P.S.S., \& Wisselink, H.J. (1988). Listeria monocytogenes. heat resistance and behaviour during storage of milk and whey and making of Dutch types of cheese. Netherlands Milk Dairy Journal 42:207-219.

Ryser, E.T., \& Marth, E.H. (1987). Behavior of Listeria monocytogenes during the manufacture and ripening of Cheddar cheese. Journal of Food Protection 50:7-13.

Schvartzman, M.S., Maffre, A., Tenenhaus-Aziza, F., Sanaa, M., Butler, F., \& Jordan, K. (2011). Modelling the fate of Listeria monocytogenes during manufacture and ripening of smeared cheese made with pasteurised or raw milk. International Journal of Food Microbiology, 145:S31-S38.

Shrestha, S., Grieder, J.A., McMahon, D.J., \& Nummer, B.A. (2011). Survival of Listeria monocytogenes introduced as a post-aging contaminant during storage of low-salt Cheddar cheese at 4, 10, and $21^{\circ} \mathrm{C}$. Journal of Dairy Science 94:4329-4335.

Skandamis, P.N., Stopforth, J.D., Kendall, P.A., Belk, K.E., Scanga, J.A., Smith, G.C., \& Sofos, J.N. (2007). Modeling the effect of inoculum size and acid adaptation on growth/no growth interface of Escherichia coli O157:H7. International Journal of Food Microbiology 120:237-249.

van den Berg, G., Meijer, W.C. Düsterhöft, E.M., \& Smit, G. (2004). Gouda and related cheeses. Pages 103-140 in Cheese: chemistry, physics and microbiology (3rd ed.). Vol. 2. P.F. Fox, P.L.H. McSweeney, T.M. Cogan, \& T.P. Guinee, ed. Elsevier Ltd., London.

van 't Westende, Y.A.M. (1977). Cheese - Physical and chemical test methods - Determination of the chloride content (routine method). NEN 3762:1977.

van 't Westende, Y.A.M. (1998). Cheese - Physical and chemical test methods - Determination of the moisture content. NEN-3755:1998.

van der Veen, S., Moezelaar, R., Abee, T., \& Wells-Bennik, M.H.J. (2008). The growth limits of a large number of Listeria monocytogenes strains at combinations of stresses show serotype- and nichespecific traits. Journal of Applied Microbiology 105:1246-1258.

Vasseur, C., Baverel, L., Hébraud, M., \& Labadie, J. (1999). Effect of osmotic, alkaline, acid or thermal stresses on the growth and inhibition of Listeria monocytogenes. Journal of Applied Microbiology 86:469-476.

Vazquez-Boland, J.A., Kuhn, M., Berche, P., Chakraborty, T., Dominguez-Bernal, G., Goebel, W., Gonzalez-Zorn, B., Wehland, J., \& Kreft, J. (2001). Listeria pathogenesis and molecular virulence determinants. Clinical Microbiological Reviews 14:584-640.

Visser, S., Slangen, K.J., \& Rollema, H.S. (1986). High-performance liquid-chromatography of bovine caseins with the application of various stationary phases. Milchwissenschaft-Milk Science International 41:559-562. 
Wemmenhove, E., van Valenberg H.J.F., Zwietering M.H., van Hooijdonk A.C.M., \& Wells-Bennik M.H.J. (2016). Minimal inhibitory concentrations of undissociated lactic, acetic, citric and propionic acid for Listeria monocytogenes under conditions relevant to Dutch-type cheeses. Food Microbiology 58:63-67.

Young, K.M., \& Foegeding, P.M. (1993). Acetic, lactic and citric acids and pH inhibition of Listeria monocytogenes Scott A and the effect on intracellular pH. Journal of Applied Bacteriology 74:515520.

Yousef, A.E., \& Marth, E.H. (1988). Behavior of Listeria monocytogenes during the manufacture and storage of Colby cheese. Journal of Food Protection 51:12-15. 


\title{
Chapter 3
}

\section{The fate of Listeria monocytogenes in brine and on Gouda cheese following artificial contamination during brining}

E. Wemmenhove, R.R. Beumer, A.C.M. van Hooijdonk, M.H. Zwietering, M.H.J. Wells-Bennik

\begin{abstract}
The fate of 3 different Listeria monocytogenes strains (Scott $A, 2 F$ and 6E) was studied independently in brine and on factory-scale Gouda cheeses that had been submerged in brine that was artificially contaminated with these individual strains. Viable numbers of L. monocytogenes in the brine decreased during brining $(0,1,2.9$ and $8.9 \mathrm{~d})$. L. monocytogenes was enumerated on the surface of Gouda cheese directly after brining and over 26 weeks of ripening at $12.5^{\circ} \mathrm{C}$. Transfer of L. monocytogenes from brine to cheese during brining was limited. L. monocytogenes was detected in the outer layer of Gouda cheese but not in the center directly after brining or during ripening. Throughout the ripening period, the viable numbers of L. monocytogenes declined significantly. This study adds to the understanding of the fate of L. monocytogenes in brine and on Gouda cheese, and demonstrates that growth of L. monocytogenes on Gouda cheese is not supported following contamination during brining.
\end{abstract}

This chapter was published in the International Dairy Journal (2014) 39:253-258 


\subsection{Introduction}

Listeria monocytogenes is a food-borne pathogen that is the causative agent of listeriosis. Infection with L. monocytogenes can result in meningitis, encephalitis, sepsis and gastroenteritis, with high fatality rates (20-25\%), especially in unborn children, infants, the elderly and immune-compromised people (Vázquez-Boland et al., 2001). The bacterium has the ability to grow at refrigeration temperatures and form biofilms, and has a high tolerance to salt and acid (Gandhi \& Chikindas, 2007). Food-borne infections of L. monocytogenes have been associated with ready-to-eat foods like seafood, vegetables and meat products, as well as dairy products (EFSA/ECDC, 2011; FDA, 2003). Strict guidelines for L. monocytogenes have been set for ready-to-eat foods (EFSA/ECDC, 2011; FDA, 2003), a category of foods that includes cheese.

Gouda cheese is a dairy product with an average $\mathrm{pH}$ of 5.3 , an average water activity of 0.95 and a shelf-life longer than 5 days (Guinee \& Fox, 2004; Fox, McSweeney, Cogan, \& Guinee, 2004b; WHO, 2004). For products with an average pH higher than 5.0 in combination with an average water activity above 0.94 and a shelf-life more than 5 days, the $\mathrm{EU}$ law requires the absence of $L$. monocytogenes after production in 5 samples of 25 $\mathrm{g}$, and concentrations may not exceed $100 \mathrm{cfu} \mathrm{g}^{-1}$ in 5 samples during shelf-life (European Commission, 2007). This specification applies unless producers can demonstrate that growth of $L$. monocytogenes is not supported in the food; in that case, concentrations may not exceed 100 cfu g $^{-1}$ in 5 samples during shelf-life.

Using the growth and inactivation definition of Koutsoumanis and Sofos (2005) and Skandamis et al. (2007), an increase of more than $0.5 \mathrm{log} \mathrm{cfu} \mathrm{g}^{-1}$ is considered to indicate growth, and a decrease in numbers of more than $1.0 \operatorname{log~cfu~}^{-1}$ as inactivation.

In published challenge studies, the fate of L. monocytogenes in cheese has been assessed in semi-hard cheese made from pasteurised milk after artificial contamination of the milk with L. monocytogenes (Northolt et al., 1988; Wemmenhove, Stampelou, van Hooijdonk, Zwietering, \& Wells-Bennik, 2013). Growth of L. monocytogenes in semi-hard cheeses made of pasteurised milk such as Gouda has not been observed so far, nor have these cheeses been associated with listeriosis. As L. monocytogenes is highly resistant to acid and salt, contamination of cheese with this pathogen could potentially also occur during brining. The fate of Listeria on cheese when contamination occurs via this route has so far not been described in literature.

The aim of the current study was to assess the fate of L. monocytogenes on cheese following artificial contamination of the cheese via brine. Firstly, the fate of three different L. monocytogenes strains in brine was established using brine conditions typical for the 
Dutch-type cheese industry. Subsequently, Gouda cheeses were submerged in brine that was artificially contaminated with L. monocytogenes and the level of transfer of L. monocytogenes to the cheese was assessed. The fate of the pathogen on the cheese was also determined throughout a ripening period of 6 months, at different depths in the cheese from the surface to the center.

\subsection{Materials and methods}

\subsubsection{Bacterial strains}

L. monocytogenes strain Scott A (serotype 4b, milk outbreak isolate), strain $2 \mathrm{~F}(1 / 2 \mathrm{a}$, cheese isolate; see also Table S1 and S3 in van der Veen, Moezelaar, Abee, \& Wells-Bennik, $2008)$ and strain $6 E(1 / 2 a$, isolate from wall in cheese factory, see also Table S1 and S3 in the supplemental material of van der Veen et al., 2008) were selected from the NIZO culture collection. L. monocytogenes strains were individually inoculated into Brain Heart Infusion Broth (BHIB) (Merck, Darmstadt, Germany) of $\mathrm{pH} 7.0$ and incubated at $30{ }^{\circ} \mathrm{C}$ for $18 \mathrm{~h}$. Bacterial cells from the individual cultures were subsequently concentrated by centrifugation at $4800 \times \mathrm{g}$ for $15 \mathrm{~min}$.

\subsubsection{Exposure to brine and enumeration of L. monocytogenes from the brine}

For adaptation to brine conditions, the cells of L. monocytogenes cultures that were individually incubated overnight were sedimented by centrifugation at $4800 \mathrm{xg}$ for $15 \mathrm{~min}$ and the cell pellets were resuspended in a mixture of 1 part BHIB and 1 part industrial brine (consisting of $18 \% \mathrm{NaCl}, 0.04 \% \mathrm{w} / \mathrm{v}$ lactic acid, with $\mathrm{pH}$ adjusted to 4.4 with $\mathrm{HCl}$ ) from a Dutch Gouda cheese production plant and left for 3 days at $12{ }^{\circ} \mathrm{C}$. Subsequently, the cells were sedimented again by centrifugation and the pellets were dispersed in brine. The industrial brine that was obtained from the factory, and transported to NIZO for inoculation with L. monocytogenes, was monitored regularly in the factory as part of routine analyses (e.g., 75 samples in 2011, with experiments being performed in May 2011). In all 75 samples (including 4 samples in May 2011), L. monocytogenes was shown to be absent. In the routine analysis, the brine was analysed as follows: $10 \mathrm{~mL}$ brine was enriched in $100 \mathrm{~mL}$ of Half Fraser broth (incubation at $30{ }^{\circ} \mathrm{C}$ for $24 \mathrm{~h}$ ) followed by secondary enrichment in Fraser broth (incubation at $37^{\circ} \mathrm{C}$ for $48 \mathrm{~h}$ ) according to ISO 11290, and then a loopful $(1 \mu \mathrm{L})$ was spread plated on Rapid'Lmono agar plates (BioRad, Marne la Coquette, 
France) and on Oxoid Chromogenic Listeria Agar agar plates (Oxoid, Landsmeer, The Netherlands). Confirmation of suspected colonies, normally showing as typical blue colonies on Rapid L'mono (Biorad) and blue colonies surrounded by semi-transparent white halos on OCLA (Oxoid), was routinely performed using the Bax ${ }^{\circledR}$ Lmono system PCR Assay (Dupont, Dordrecht, The Netherlands) to detect L. monocytogenes. This brine was separated into three brine baths of $200 \mathrm{~L}$ and these baths were inoculated with cells of either strain Scott A, 2F or 6E that were diluted and resuspended in the brine (and adapted to brine, see above), to a final concentration of approximately $7 \cdot 10^{5} \mathrm{cfu} \mathrm{mL}^{-1}$ (5.9 log cfu $\mathrm{mL}^{-1}$ ). Each brine solution was stirred continuously (80 rpm) at $12^{\circ} \mathrm{C}$ to mimic the brining procedure at industrial level. Viable numbers of L. monocytogenes were determined in brine over 8.9 days by taking triplicate samples of $1 \mathrm{~mL}$ from each brine solution at $\mathrm{t}=0$ and after 1.0, 2.9 and $8.9 \mathrm{~d}$, and determining viable numbers by plating appropriate dilutions in triplicate on PALCAM-Listeria selective agar (VWR, Amsterdam, The Netherlands), followed by enumeration after incubation at $30^{\circ} \mathrm{C}$ for $48 \mathrm{~h}$.

\subsubsection{Exposure of Gouda cheeses to L. monocytogenes from the brine}

Eighteen wheel-type Gouda cheeses of $4.5 \mathrm{~kg}$ from a commercial production lot were supplied by an industrial producer of Gouda cheese from pasteurised milk. For cheeses in the batch, absence of $L$. monocytogenes in 5 samples of $25 \mathrm{~g}$ of cheese was demonstrated by the producer, according to ISO 11290, and the cheese production lot was released for human consumption. The cheeses were obtained immediately after pressing and separated into three groups of six cheeses. Each group was put into a different brine solution that had been artificially contaminated with one of the three strains of L. monocytogenes, $3 \mathrm{~h}$ after pressing of the cheeses. In each group, two cheeses were brined for $0.33 \mathrm{~d}$, two for $2.1 \mathrm{~d}$ and two for $8.9 \mathrm{~d}$ (i.e., duplicate samples) to obtain lowsalt, normal-salt and high-salt cheeses. Immediately after brining and after ageing at $12.5^{\circ} \mathrm{C}$ and sampling, cheeses were coated with commercially available coating solution (CSK food enrichment, Ede, The Netherlands) containing $0.02 \%$ natamycin to prevent mould growth during ripening, according to standard cheese-making protocols.

\subsubsection{Cheese sampling and enumeration of L. monocytogenes from the cheeses}

Immediately after brining $(t=0)$ and after 2, 4, 7, 12, 19 and 26 wk of ripening, cheese wheels were placed on the flat side and cheese samples, consisting of blocks of 
approximately $1 \times 1 \times 1 \mathrm{~cm}$ (length $\mathrm{x}$ width $\mathrm{x}$ height), were taken approximately $5 \mathrm{~cm}$ from the center of the cheese (cheese diameter of $22 \mathrm{~cm}$ ) using a sterile cheese scoop. Subsequently, each cheese sample was analysed at different distances from the crust: 0-1 $\mathrm{cm}$ (duplicate samples), 2-3 cm (duplicate samples) and at 4-5 cm (center). Considering these determinations to be independent measurements, the viable counts were analysed in four replicates for the $0-1 \mathrm{~cm}$ sample (crust) as well as for the $2-3 \mathrm{~cm}$ sample. For enumeration of $L$. monocytogenes, cheese samples of $1 \mathrm{~g}$ were obtained from the different sections, and diluted 10 -fold using $9 \mathrm{~mL}$ of $2 \%$ sodium citrate of $40^{\circ} \mathrm{C}$. Each cheese diluent was divided into two parts of $5 \mathrm{~g}$ and put in large sterile petri dishes (VWR, Amsterdam, The Netherlands) with a diameter of $145 \mathrm{~mm}$. Subsequently, $50 \mathrm{~mL}$ of PALCAM-selective agar was added to each petri dish to obtain two pour plates with PALCAM-selective agar and the cheese suspension. Viable numbers were determined after $48 \mathrm{~h}$ incubation at $30^{\circ} \mathrm{C}$ by pour-plating using PALCAM-selective agar.

\subsubsection{Validation of plating method}

The method of pour-plating, using PALCAM Listeria-selective agar, of brine and cheese samples containing L. monocytogenes was validated by comparing the results of this enumeration method with results of the plating method described in ISO 11290. Appropriate dilutions were pour-plated using PALCAM-selective agar, and spread-plated onto PALCAM agar, Rapid L'mono agar (Biorad, Marne la Coquette, France) and OCLA agar (Oxoid, Landsmeer, The Netherlands). For this evaluation, an overnight culture of L. monocytogenes grown in BHIB was used; furthermore, cells of L. monocytogenes were used that were pre-exposed to a 50/50 volume ratio of brine and BHIB for 3 days at $12{ }^{\circ} \mathrm{C}$. All three individual cultures of the $L$. monocytogenes strains that were incubated overnight in BHIB were diluted approximately one thousand fold in BHIB to $\sim 5.6$ log cfu mL $\mathrm{mb}^{-1}$ prior to plating. The viable counts of the diluted cultures were subsequently determined by pour-plating using PALCAM-selective agar and by spread plating onto PALCAM agar, Rapid L'mono agar or OCLA agar. In addition, the viable counts were determined using these plating methods and media for cultures of all three L. monocytogenes strains that were pre-exposed for 3 days to a mixture of brine and BHIB using a 50/50 volume ratio, having a concentration of $\sim 5.6 \mathrm{log} \mathrm{cfu} \mathrm{mL}^{-1}$ prior to plating. After incubation of the plates at $37^{\circ} \mathrm{C}$ for $48 \mathrm{~h}$, the viable counts were recorded and 5 suspected colonies were obtained from each plate. Each of those colonies was enriched in $100 \mathrm{~mL}$ Half Fraser broth, subsequently enriched in Fraser broth, and then a loopful $(1 \mu \mathrm{L})$ was spread plated on Rapid'Lmono and OCLA agar. Blue colonies on Rapid'Lmono and blue colonies surrounded by semi-transparent white halos on OCLA plates were suspected to be L. monocytogenes, and these were further confirmed as L. monocytogenes according to ISO 11290 using the 
Bax ${ }^{\circledR L}$ Lmono PCR Assay (Dupont, Dordrecht, The Netherlands). The logarithmic average and $95 \%$ standard deviation were taken to minimise the influence of outliers in viable counts, assuming that the measurement error is normally distributed after log transformation.

\subsubsection{Determination of the salt content, moisture content, water activity and $\mathrm{pH}$ of cheese}

The salt content of cheese was determined according to NEN 3762 (NEN, 1977), and the moisture content of cheese was determined using method NEN 3755 (NEN, 1998). The pH was measured by inserting a $3 \mathrm{~mm}$ electrode (BioTrode, Metrohm, Herisau, Switzerland) directly into the cheese. The dew point method (Decagon Aqualab, Pullman, WA, USA) was used to determine the water activity of the cheese.

\subsection{Results and discussion}

Viable counts of L. monocytogenes that were determined using PALCAM pour plates did not significantly differ $(p>0.05)$ from counts on spread plates using either PALCAMselective agar, Rapid L'mono agar or OCLA agar. This was the case for cells of L. monocytogenes that were cultured overnight and then plated. This implies that the recovery of $L$. monocytogenes did not differ for the different plating media. For the cells of L. monocytogenes that were pre-exposed to brine and $\mathrm{BHIB}$ at a 50/50 ratio, no significant differences ( $p>0.05$ ) were observed between the different media for strain $2 F$, but for strains Scott $A$ and $6 E$, the viable counts were slightly higher $(p=0.02)$ in PALCAMpour plates than on spread plates of PALCAM, Rapid L'mono and OCLA (Table 3.1). As the recovery from the different media was very comparable for cells that were pre-exposed to brine and BHIB at a 50/50 ratio, it was concluded that pre-exposure to brine did not affect the sensitivity of L. monocytogenes to different plating media. Furthermore, counts of L. monocytogenes in and on cheese were determined with pour-plating.

Brining for $0.33,2.1$ and $8.9 \mathrm{~d}$ resulted in low-salt, normal-salt and high-salt cheeses, respectively, with salt in dry matter contents (mean $\pm 95 \%$ standard deviation in \%) varying between the surface and the center of the cheese from $1.4 \% \pm 0.05$ to $2.4 \% \pm 0.01$ in cheeses brined for $0.33 \mathrm{~d}$ (with $1.9 \%$ on average), salt in dry matter contents varying from $3.0 \% \pm 0.23$ to $5.0 \% \pm 0.04$ in cheeses brined for $2.1 \mathrm{~d}$ (with $4.0 \%$ on average) and salt in dry matter contents varying from $5.1 \% \pm 0.49$ to $8.6 \% \pm 0.13$ in cheeses brined for $8.9 \mathrm{~d}(6.9 \%$ on average). 
No typical colonies were found in the brine before inoculation with L. monocytogenes. After inoculation, inactivation during brining was observed for the three strains tested. The extent of inactivation of L. monocytogenes in brine significantly differed between the tested strains; strain Scott A (serotype 4b) showed a decrease of 2.8 log cfu g-1, corresponding to a decimal reduction of 3.2 days, while strains $2 \mathrm{~F}$ and $6 \mathrm{E}$ (serotype $1 / 2 \mathrm{a}$ ) each only showed a 0.7 log decrease, corresponding to a decimal reduction of 14.4 and 14.9 days, respectively (Fig. 3.1). The serotype $1 / 2$ a strains had previously been shown to be relatively acid-resistant (van der Veen et al., 2008). L. monocytogenes strains with serotype $1 / 2$ a are more often isolated from cheese (or cheese equipment) than serotype 4b (Farber \& Peterkin, 1991). A previous study reported that serotype 4b isolates generally show a higher resistance to $\mathrm{NaCl}$ at $30{ }^{\circ} \mathrm{C}$, but that serotype $1 / 2$ is more resistant to $\mathrm{NaCl}$ at $7{ }^{\circ} \mathrm{C}$ (van der Veen et al., 2008). Natural selection and/or adaptation to a high-salt and acidic environment could be an explanation for the higher resistance of strains with serotype $1 / 2$ a to high salt and acid conditions. Lack of proliferation but rather inactivation of L. monocytogenes in brine was likely the result of the high salt and acidic conditions. The highest concentrations of $\mathrm{NaCl}$ at which growth of L. monocytogenes have been observed are 10-12\% (Lou \& Yousef, 2000; Swaminathan, Cabanes, Zhang, \& Cossart, 2007). The absence of growth, but survival and inactivation of L. monocytogenes in brine is consistent with previous studies (Durmaz, Aygun, \& Ardic, 2009; Larson, Johnson, \& Nelson, 1999). In a recent study from Schirmer, Heir, Lindstedt, Møretrø \& Langsrud (2014), L. monocytogenes was inactivated in brine of $\mathrm{pH} 4.5-6.0$ that contained $14.1-26.9 \% \mathrm{NaCl}$. This inactivation was faster in brine of low $\mathrm{pH}$ (4.5) and at a low $\mathrm{NaCl}$ concentration (15\%) than at higher $\mathrm{pH}$ values and $\mathrm{NaCl}$ concentrations. This observation suggests that lowering the $\mathrm{NaCl}$ concentration of brine from $18 \%$ to $15 \%$ whilst maintaining a low pH (4.5) would not cause a risk to food safety.

In this study, the sample sizes were $1 \mathrm{~g}$, to allow for sampling of each cheese at seven time points $(0,2,4,7,12,19$ and 26 weeks) in duplicate. Variation in the observed inactivation of L. monocytogenes strains in cheese could be partly due to the sample size. The probability of detection was increased in this work by artificially contaminating the brine with a high concentration of $L$. monocytogenes and by stirring the brine solutions during cheese salting to obtain an equal distribution of Listeria on the cheese surface. In practice, concentrations of L. monocytogenes in brine that would be as high as the concentrations studied in this work would be very unlikely, even when the brine is strongly contaminated. 


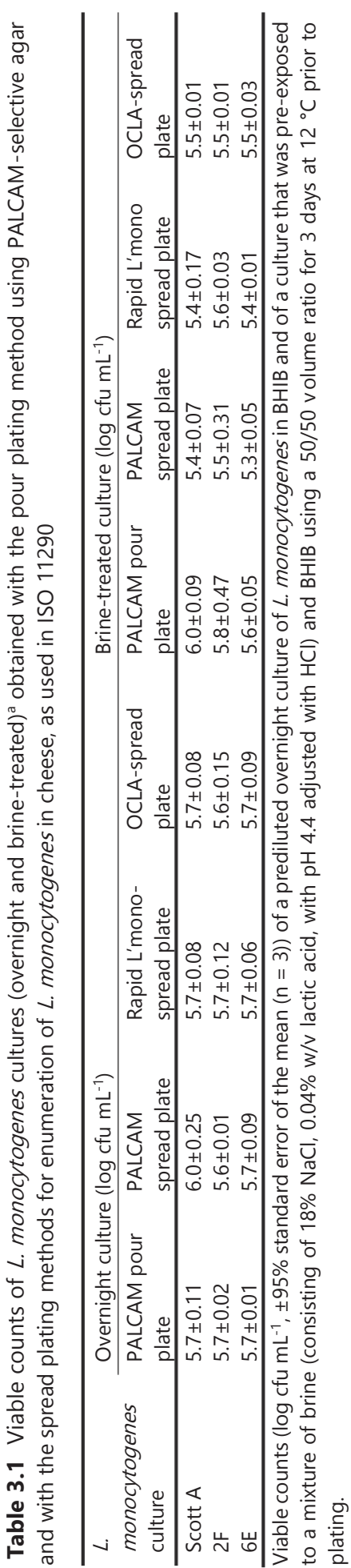




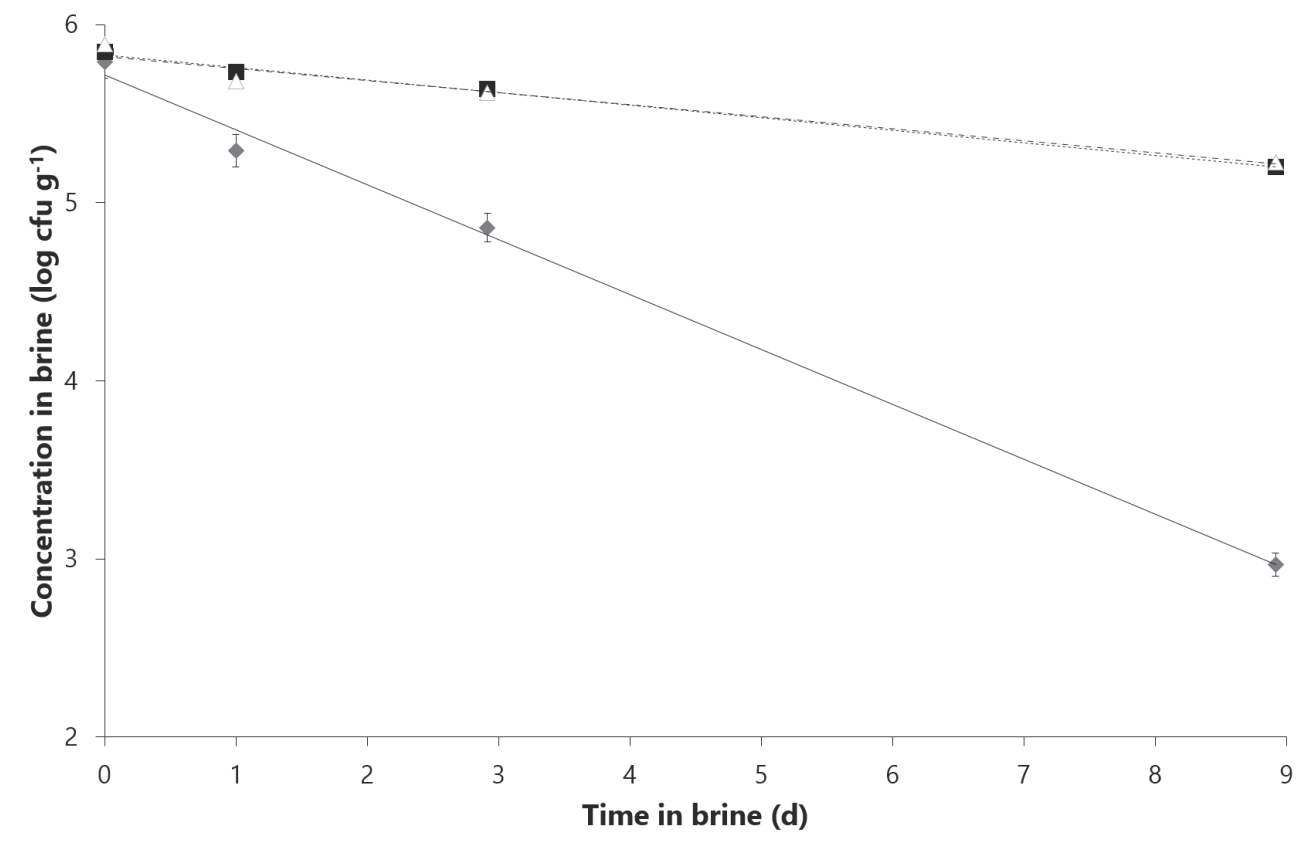

Fig. 3.1 Levels of L. monocytogenes strains Scott $\mathrm{A}(\diamond), 2 \mathrm{~F}(\boldsymbol{\square})$ and $6 \mathrm{E}(\Delta)$ after artificial contamination of brine with individual strains. Viable numbers (logarithmic mean $\pm 95 \%$ standard error of the mean; $n=3$ ) are expressed in log cfu g-1, based on a density of brine of $1.12 \mathrm{~g} \mathrm{~mL}^{-1}$. The calculated decimal reduction times and corresponding $r^{2}$ values are 3.2 days and 0.995 for Scott $A, 14.4$ days and 0.995 for $2 F$, and 14.9 days and 0.954 for $6 \mathrm{E}$, respectively (in certain cases, the standard deviation was so small that the error bar is not visible).

The transfer of L. monocytogenes from brine to cheese was assessed by comparing the concentrations of the bacteria on the crust of Gouda cheese with the initial concentration in the brine. A weight loss of $2 \%$ occurred during brining, as $5 \% \mathrm{w} / \mathrm{v}$ of moisture was expelled from the cheese and $3 \% \mathrm{w} / \mathrm{v}$ salt migrated into the cheese during brining, which is typical for Gouda cheese (Fox, McSweeney, Cogan, \& Guinee, 2004b). For all three L. monocytogenes strains, the viable counts in cfu per $g$ in the outer layer of the cheeses $(0-1 \mathrm{~cm})$ immediately after removal from the brining solutions at $\mathrm{t}=0$ weeks were 100 times lower than the concentrations present in brine immediately after immersion of the cheeses into the brine solutions.

The levels of $L$. monocytogenes strain Scott A (mean $\pm 95 \%$ standard deviation in log cfu $\mathrm{g}^{-1}$ ) were $5.8 \pm 0.09 \mathrm{log} \mathrm{cfu} \mathrm{g}^{-1}$ in the brine and $3.4 \pm 0.5,2.2 \pm 0.2$ or $2.4 \pm 0.5 \mathrm{log} \mathrm{cfu} \mathrm{g}^{-1}$ in the outer layer of cheeses that were brined for $0.33,2.1$ or 8.9 days, respectively; the levels of strain $2 \mathrm{~F}$ were $5.8 \pm 0.07 \mathrm{log} \mathrm{cfu} \mathrm{g}^{-1}$ in the brine and immediately after brining these levels were $3.1 \pm 0.5,2.5 \pm 0.3$ or $2.9 \pm 0.7 \mathrm{log} \mathrm{cfu} \mathrm{g}^{-1}$ in the outer layer of cheeses that were brined for $0.33,2.1$ and 8.9 days, respectively; and the levels of strain $6 \mathrm{E}$ were $5.9 \pm 0.05 \mathrm{log} \mathrm{cfu} \mathrm{g}^{-1}$ in the brine and immediately after brining these levels were $3.0 \pm 0.8,2.7 \pm 0.8$ or $3.8 \pm 0.7$ $\log \mathrm{cfu} \mathrm{g}^{-1}$ in the outer layer of cheeses that were brined for $0.33,2.1$ and 8.9 days, 
respectively (Fig. 3.2-3.4). L. monocytogenes was not found at an average concentration above 1.0 log cfu g ${ }^{-1}$ in the deeper layers throughout the whole study, i.e., from the time immediately after brining up to 26 weeks of ripening. Therefore, the standard deviation was only displayed for the $0-1 \mathrm{~cm}$ cheese samples. Although L. monocytogenes can be motile through its ability to express flagella at temperatures below $37^{\circ} \mathrm{C}$, this capacity is greatly reduced at lower temperatures (Farber \& Peterkin, 1991; Peel, Donachie, \& Shaw, 1988). In this study, no evidence was obtained that L. monocytogenes can spread throughout Gouda cheese during ripening. The $\mathrm{pH}$ did not significantly $(p>0.05)$ differ between cheeses that were brined for $0.33,2.1$ or 8.9 days. The $\mathrm{pH}$ of the cheeses increased from $5.05 \pm 0.10$ directly after brining to $5.40 \pm 0.03$ after 19 weeks, and decreased to $5.25 \pm 0.03$ after 26 weeks (Fig. 3.5). The $\mathrm{pH}$ was lower in the center than in the outer layers until 19 weeks, but after 26 weeks the $\mathrm{pH}$ values were equal in the different parts of the cheese. Although the acid and salt conditions are much more favourable for L. monocytogenes in cheese than in brine, no growth and only inactivation ( $\geq 1.0 \mathrm{log} \mathrm{cfu}$ $\mathrm{g}^{-1}$ decrease in viable counts) was observed for all three strains of $L$. monocytogenes in the crust of all cheeses tested. Compared with the initial count on the crust, a significant decrease $(p<0.05)$ of at least $2.0 \operatorname{log~cfu~g~}^{-1}$ was observed after 19 weeks in all cheeses for all three strains of L. monocytogenes.

Inactivation of L. monocytogenes in Gouda cheese during ripening occurred faster in this brine study than in previous studies in which L. monocytogenes was dispersed throughout the cheese following artificial contamination of cheese milk. In those studies, L. monocytogenes survived throughout the study period of 13 and 6 weeks (Bachmann \& Spahr, 1995; Northolt et al., 1988) and was inactivated after 16-28 weeks (Wemmenhove et al., 2013). The faster inactivation of L. monocytogenes in cheese during ripening in the latter study was likely due to the decreasing water activity in cheese over time and the presence of undissociated lactic acid. The water activity in Gouda cheese decreases during ripening as a result of salt diffusion and evaporation of water. In coated cheeses, the water activity can drop to values near or below the minimal water activity limit of 0.92 that is required for growth of $L$. monocytogenes (ICMSF, 1996), resulting in inactivation. The water activity in the outer $0-1 \mathrm{~cm}$ layer immediately after brining was $0.95,0.93$ and 0.90 for the cheeses that were subjected to the three different brining times, due to salt diffusion from the brine into the cheese and moisture loss from the cheese to the brine, while the water activity in the center of the cheese was 0.99 . The low water activity in the outer layer of the cheese in this study probably contributed to faster inactivation of L. monocytogenes compared with inactivation observed in previous challenge studies of Gouda with L. monocytogenes during curd formation (Wemmenhove et al., 2013). In line with this, the fastest inactivation of $L$. monocytogenes was observed in the cheese with the highest salt content (Fig. 3.2C, 3.3C, 3.4C), as the water activity in this cheese was as low as 0.90 . 


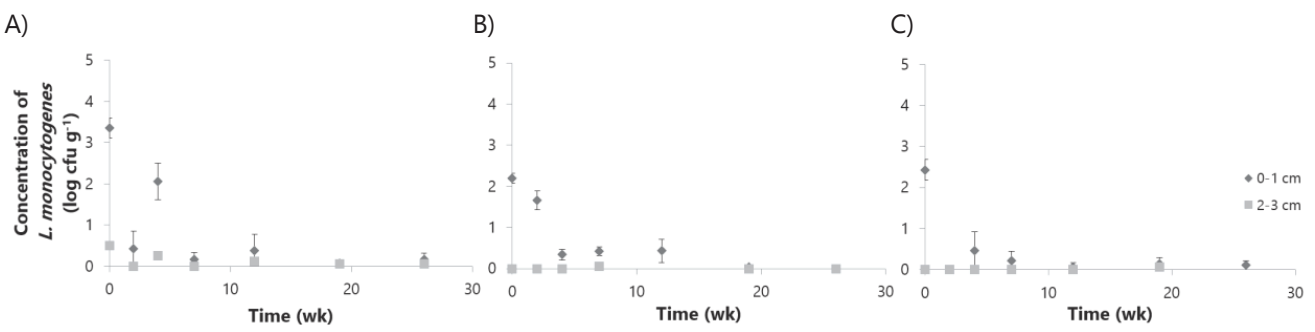

Fig. 3.2 Levels of L. monocytogenes Scott A in Gouda cheese containing (A) $1.9 \% \mathrm{NaCl}$; (B) $4.0 \% \mathrm{NaCl}$; and (C) $6.9 \% \mathrm{NaCl}$ on dry matter basis after ripening for $0,2,4,7,12,19$ and 26 weeks at $12.5^{\circ} \mathrm{C}$. The logarithmic mean $\pm 95 \%$ standard error of the mean $(n=4)$ are expressed in log cfu g ${ }^{-1}$. Diamonds indicate $0-1 \mathrm{~cm}$ (crust sample) and squares $2-3 \mathrm{~cm}$ (layer between 2 and $3 \mathrm{~cm}$ from the crust). In samples from the center of the cheese (4-5 cm samples), L. monocytogenes was not detected.

A)

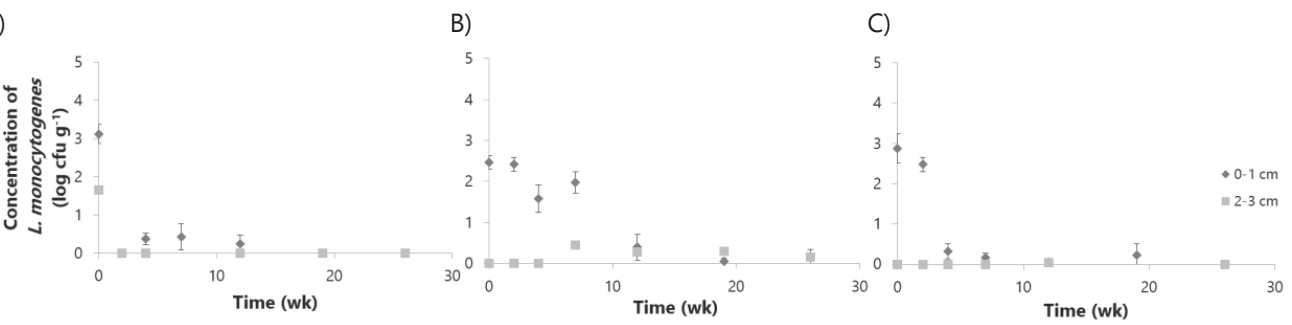

Fig. 3.3 Levels of L. monocytogenes $2 \mathrm{~F}$ in Gouda cheese containing (A) $1.9 \% \mathrm{NaCl}$; (B) $4.0 \% \mathrm{NaCl}$; and (C) $6.9 \% \mathrm{NaCl}$ on dry matter basis after ripening for $0,2,4,7,12,19$ and 26 weeks at $12.5^{\circ} \mathrm{C}$. The logarithmic mean $\pm 95 \%$ standard error of the mean $(n=4)$ are expressed in log cfu g ${ }^{-1}$. Diamonds indicate $0-1 \mathrm{~cm}(\mathrm{crust}$ sample) and squares $2-3 \mathrm{~cm}$ (layer between 2 and $3 \mathrm{~cm}$ from the crust). In samples from the center of the cheese (4-5 cm samples), L. monocytogenes was not detected.

A)

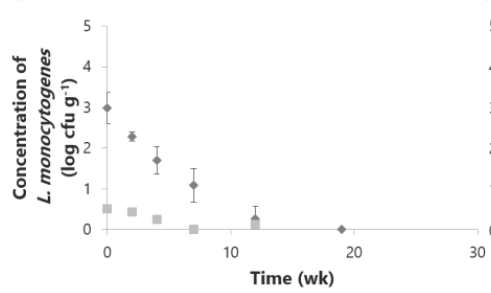

B)

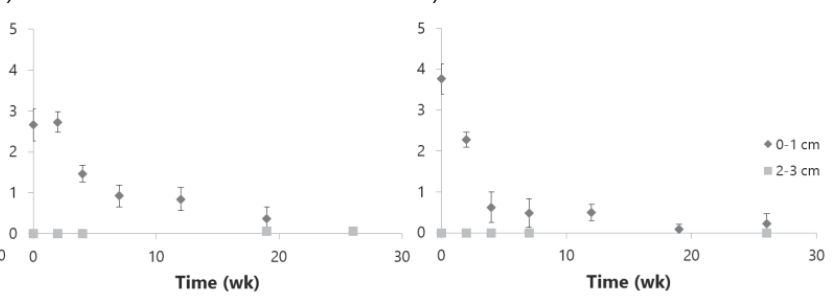

Fig. 3.4 Levels of L. monocytogenes $6 \mathrm{E}$ in Gouda cheese containing (A) $1.9 \% \mathrm{NaCl}$; (B) $4.0 \% \mathrm{NaCl}$; and (C) $6.9 \% \mathrm{NaCl}$ on dry matter basis after ripening for $0,2,4,7,12,19$ and 26 weeks at $12.5{ }^{\circ} \mathrm{C}$. The logarithmic mean $\pm 95 \%$ standard error of the mean $(n=4)$ are expressed in log cfu g-1. Diamonds indicate $0-1 \mathrm{~cm}(\mathrm{crust}$ sample) and squares $2-3 \mathrm{~cm}$ (layer between 2 and $3 \mathrm{~cm}$ from the crust). In samples from the center of the cheese (4-5 cm samples), L. monocytogenes was not detected. 


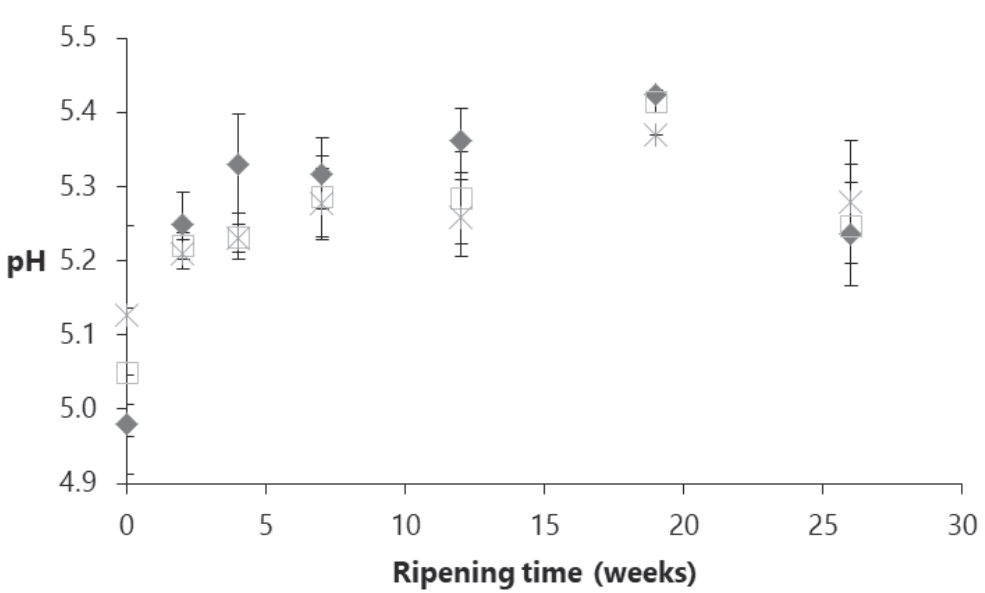

Fig. 3.5 The $\mathrm{pH}$ of Gouda cheese during ripening for $0,2,4,7,12,19$ and 26 weeks at $12.5^{\circ} \mathrm{C}$. The $\mathrm{pH}$ values represent mean $\pm 95 \%$ standard deviation (duplicate measurement) of cheese samples containing $1.9 \%, 4.0 \%$ and $6.9 \% \mathrm{NaCl}$ on average on a dry matter basis, giving $\mathrm{n}=6$ per time point and location in the cheese, as no significant differences in $\mathrm{pH}$ were observed in cheeses of different salt concentrations. Diamonds indicate the $\mathrm{pH}$ in the $0-1 \mathrm{~cm}$ (crust) sample, squares in the $2-3 \mathrm{~cm}$ sample (layer between 2 and $3 \mathrm{~cm}$ from the crust) and crosses indicate the $\mathrm{pH}$ in the $4-5 \mathrm{~cm}$ samples (centre).

\subsection{Conclusion}

Based on the findings in this research, namely that (i) a 0.1-2.8 log decrease of L. monocytogenes occurred during brining; (ii) concentrations on the cheese surface were 100 times lower than in brine; and (iii) a significant decrease in L. monocytogenes occurred in cheese after ripening times of 2-12 weeks, it was concluded that the probability that a brine contamination will result in detectable levels (per $25 \mathrm{~g}$ ) of L. monocytogenes in Gouda cheese during shelf-life is negligible. Moreover, L. monocytogenes that contaminated the surface of the Gouda cheese during brining declined in numbers during ripening.

\section{Acknowledgements}

The authors would like to thank Mr. A. Wagendorp from NIZO food research, Ede, The Netherlands, for his technical assistance. The study was supported by the Dutch Dairy Organization and the Dutch Dairy Board. 


\section{References}

Bachmann, H.P., \& Spahr, U. (1995). The fate of potentially pathogenic bacteria in Swiss hard and semihard cheeses made from raw milk. Journal of Dairy Science 78:476-483.

Durmaz, H., Aygun, O., \& Ardic, M. (2009). The effect of cheese brine concentrations on survival of Listeria monocytogenes. Journal of Food, Agriculture \& Environment 7:11-13.

EFSA/ECDC (2011). The European Union summary report on trends and sources of zoonoses, zoonotic agents and food-borne outbreaks in 2009. EFSA Journal 9:2090.

European Commission (2007). Commission regulation (EC) No 1441/2007 of 5 December 2007. Official Journal of the European Union 322:12-29.

Farber, J.M., \& Peterkin, P.I. (1991). Listeria monocytogenes, a food-borne pathogen. Microbiological Reviews 55:476-511.

FDA (2003). Quantitative assessment of relative risk to public health from foodborne Listeria monocytogenes among selected categories of ready-to-eat foods. FDA report.

http://www.fda.gov/

downloads/food/scienceresearch/researchareas/riskassessmentsafetyassessment/ucm197330.pdf. Last accessed: 05-12-2013.

Fox, P.F., McSweeney, P.L.H., Cogan, T.M., \& Guinee, T.P. (2004b). Cheese: chemistry, physics and microbiology (3rd ed.) Vol. 2, pp. 24 (Chapter 2) and pp. 114 (Chapter 5). London, UK: Elsevier Academic Press.

Gandhi, M., \& Chikindas, M.L. (2007). Listeria: A foodborne pathogen that knows how to survive. International Journal of Food Microbiology 113:1-15.

Guinee, T.P., \& Fox, P.F. (2004). Salt in cheese: physical, chemical and biological aspects. Pages 207-259 in Cheese: chemistry, physics and microbiology (3rd ed.), Vol. 1. P.F. Fox, P.L.H. McSweeney, T.M. Cogan, \& T.P. Guinee, ed. Elsevier Ltd., London.

ICMSF (1996). Microorganisms in foods, Microbiological specifications of food pathogens. pp. 141182. Vol. 5, Blackie, London.

Koutsoumanis, K.P., \& Sofos, J.N. (2005). Effect of inoculum size on the combined temperature, pH and aw limits for growth of Listeria monocytogenes. International Journal of Food Microbiology 104:83-91.

Larson, A.E., Johnson, E.A., \& Nelson, J.H. (1999). Survival of Listeria monocytogenes in commercial cheese brines. Journal of Dairy Science 82:1860-1868.

Lou, Y., \& Yousef, A.E. (2000). Characteristics of Listeria monocytogenes important to food processors. In E.T. Ryser \& E.H. Marth (Eds.) Listeria, Listeriosis and Food Safety. New York' NY, USA: Marcel Dekker.

NEN (1977). Cheese - Physical and chemical test methods - Determination of the chloride content (routine method). NEN-3762:1977.

NEN (1998). Cheese - Physical and chemical test methods - Determination of the moisture content. NEN-3755:1998. 
Northolt, M.D., Beckers, H.J., Vecht, U., Toepoel, L., Soentoro, P.S.S., \& Wisselink, H.J. (1988). Listeria monocytogenes. heat resistance and behaviour during storage of milk and whey and making of Dutch types of cheese. Netherlands Milk Dairy Journal 42:207-219.

Peel, M., Donachie, W., \& Shaw, A. (1988). Temperature-dependent expression of flagella of Listeria monocytogenes studied by electron microscopy, SDS-page and Western blotting. Journal of General Microbiology 134:2171-2178.

Schirmer, B.C.T., Heir, E., Lindstedt, B.A., Møretrø, T., \& Langsrud, S. (2014). Use of used vs. fresh cheese brines and the effect of $\mathrm{pH}$ and salt concentration on the survival of Listeria monocytogenes. Journal of Dairy Research 81:113-119.

Skandamis, P.N., Stopforth, J.D., Kendall, P.A., Belk, K.E., Scanga, J.A., Smith, G.C., \& Sofos, J.N. (2007). Modeling the effect of inoculum size and acid adaptation on growth/no growth interface of Escherichia coli O157:H7. International Journal of Food Microbiology 120:237-249.

Swaminathan, B., Cabanes, D., Zhang, W., \& Cossart, P. (2007). Chapter 21: Listeria monocytogenes. In M.P. Doyle, L.R. Beuchat, T.J. Montville (Eds.), Food Microbiology: Fundamentals and Frontiers, 457-491. ASM Press, Washington D.C., USA.

van der Veen, S., Moezelaar, R., Abee, T., \& Wells-Bennik, M.H.J. (2008). The growth limits of a large number of Listeria monocytogenes strains at combinations of stresses show serotype- and nichespecific traits. Journal of Applied Microbiology 105:1246-1258.

Vázquez-Boland, J.A., Kuhn, M., Berche, P., Chakraborty, T., Dominguez-Bernal, G., Goebel, W., Gonzalez-Zorn, B., Wehland, J., \& Kreft, J. (2001). Listeria pathogenesis and molecular virulence determinants. Clinical Microbiological Reviews 14:584-640.

Wemmenhove, E., Stampelou, I., van Hooijdonk, A.C.M., Zwietering, M.H., \& Wells-Bennik, M.H.J. (2013). Listeria monocytogenes in semi-hard Gouda cheese artificially contaminated during curd formation: no growth, but substantial inactivation after extended ripening times. International Dairy Journal 32:192-198.

WHO (2004). Risk assessment of Listeria monocytogenes in ready-to-eat foods: Interpretative summary. Microbiology Risk Assessment series 4, Geneva, Switzerland. http://www.who.int/foodsafety/ publications/micro/en/mra4.pdf. Last accessed: 05-03-2013. 


\title{
Chapter 4
}

\section{How $\mathrm{NaCl}$ and water content determine water activity during ripening of Gouda cheese, and the predicted effect on inhibition of Listeria monocytogenes}

E. Wemmenhove, M.H.J. Wells-Bennik, A. Stara, A.C.M. van Hooijdonk, M.H. Zwietering

\begin{abstract}
This study describes the diffusion of $\mathrm{NaCl}$ and water in Gouda cheese during brining and ripening. Furthermore, we established water activity as a function of the $\mathrm{NaCl}$-in-moisture content in Gouda cheese during ripening. We determined $\mathrm{NaCl}$ content, water content, and water activity in blocktype Gouda cheeses that were brined for $3.8 \mathrm{~d}$ and foil-ripened for a period of $26 \mathrm{wk}$, and in wheeltype Gouda cheeses that were brined for $0.33,2.1$, or $8.9 \mathrm{~d}$ and subsequently nature-ripened for a period of $26 \mathrm{wk}$. The calculated diffusion coefficients of $\mathrm{NaCl}$ during brining were $3.6 \cdot 10^{-10} \mathrm{~m}^{2} \mathrm{~s}^{-1}$ in the block-type Gouda cheeses and $3.5 \cdot 10^{-10} \mathrm{~m}^{2} \mathrm{~s}^{-1}$ in the wheel-type Gouda cheeses. Immediately after brining, gradients of $\mathrm{NaCl}$ and water were observed throughout both types of cheese. During ripening, these gradients disappeared, except for the water gradient in nature-ripened cheeses. An empirical model was derived for Gouda cheese, in which the water activity is expressed as a function of the $\mathrm{NaCl}$-in-moisture content, as established for different brining times, locations and ripening times. Moreover, the effect of a reduced water activity on inhibition of growth of L. monocytogenes in Gouda cheese was calculated. In addition to the presence of lactate and a $\mathrm{pH}$ of 5.2-5.3, the reduced water activity as seen in Gouda cheese can substantially contribute to inhibition of microbial growth, and even to inactivation when cheeses are brined and ripened for extended times and subjected to nature-ripening.
\end{abstract}

This chapter was published in the Journal of Dairy Science (2016) 99:5192-5201 


\subsection{Introduction}

Gouda cheese is a ready-to-eat (RTE) product that is made from pasteurized cow milk. Many factors contribute to the microbial safety and quality of Gouda cheese. This includes pasteurization of raw milk $\left(72^{\circ} \mathrm{C}\right.$ for $\left.15 \mathrm{~s}\right)$, hygienic processing, the use of acidifying starter cultures during curd formation, and salting or brining after pressing of the curd. The intrinsic properties of cheese, such as the presence of organic acids and a low $\mathrm{pH}$, but also reduced water activity due to the presence of $\mathrm{NaCl}$, are important factors to control the outgrowth of undesirable microorganisms (Koutsoumanis \& Sofos, 2005). Gouda cheese has a typical pH value of 5.2 to 5.3 , due to the activity of the starter lactic acid bacteria (including Lactococcus lactis and Leuconostocs mesenteroides) that convert lactose to lactic acid. Salt is introduced by immersing Gouda cheeses in brine (that typically has a pH of 4.4 and contains $18-19 \% \mathrm{wt} / \mathrm{vol}$ sodium chloride) for 2 to $4 \mathrm{~d}$ at 12 to $13^{\circ} \mathrm{C}$. The brining time is chosen based on the desired final sodium chloride $(\mathrm{NaCl})$ content and on the geometry and mass of the cheese. The average water activity of Gouda is 0.95 , but this value depends on the exact position within the cheese (e.g, close to the rind or the core), and it changes during brining and ripening due to salt and water migration (Guinee \& Fox, 2004). Ripening conditions of Gouda cheese can vary. Nature-ripened Gouda cheeses (usually wheel-type cheeses) are turned and coated regularly during ripening and are stored on wooden shelves at 12 to $13^{\circ} \mathrm{C}$ for a period of $4 \mathrm{wk}$ up to more than $1 \mathrm{yr}$. Foilripened Gouda cheeses (block-type cheeses) are wrapped in plastic and ripened for 4 to 8 wk at $\sim 5^{\circ} \mathrm{C}$, and these cheeses are not coated and turned.

An important microbiological hazard for dairy foods such as cheese is the bacterium Listeria monocytogenes (Greig \& Ravel, 2009), which is the causative agent of listeriosis (Vazquez-Boland et al., 2001), a disease that can have a case-fatality rate as high as 20 to $30 \%$ (Swaminathan \& Gerner-Smidt, 2007). The organism can grow at low temperatures and is highly tolerant to salt and acid (Lou \& Yousef, 2000). Microbiological criteria have been set in EU regulation EC 2073/2005 (European Commission, 2005) for L. monocytogenes in RTE foods such as Gouda cheese. Based on these criteria, Gouda belongs to the category of RTE foods not intended for infants and medical purposes that can potentially support growth of $L$. monocytogenes, as the shelf life is $>5 \mathrm{~d}$, the average $\mathrm{pH}>5.0$ and the average water activity $>0.94$.

Since the recognition of L. monocytogenes as the causative agent in the 1980s (Schlech et al., 1983), listeriosis has mainly been associated with consumption of Mexican-style cheeses (Silk et al., 2012), with soft cheeses made from pasteurized milk (Koch et al., 2010; Gaulin, Ramsay, \& Bekal, 2012; Gould, Mungai, \& Behravesh, 2014) and Mimolette cheese (Yde et al., 2012), but not with consumption of Dutch-type cheeses such as Gouda and Maasdam or with Emmental. The latter cheeses do not support growth of 
L. monocytogenes in challenge studies with the pathogen (Northolt et al., 1988; Buazzi, Johnson, \& Marth, 1992; Bachmann \& Spahr, 1995; Wemmenhove et al., 2013, 2014). Undissociated lactic acid present in Gouda cheese plays an important role in inhibition of growth of this pathogen: we recently demonstrated that the highest concentration required to inhibit all growth of 6 different L. monocytogenes strains is $9.0 \mathrm{mM}$, and that this is around the same level as the average concentration of undissociated lactic acid that is typically present in Gouda cheese, that is $9.2 \mathrm{mM}$ at $\mathrm{pH} 5.3$ based on $13.9 \mathrm{~g}$ of lactic acid $\mathrm{kg}^{-1}$ cheese (Wemmenhove et al., 2016).

In addition to the effect of undissociated lactic acid, the major salt in Gouda cheese, $\mathrm{NaCl}$, may further contribute to inhibition of growth of L. monocytogenes due to its effect on water activity of the cheese. At low water activities, less water is freely available for bacteria, which can lead to inhibition of growth. Water activity $\left(a_{w}\right)$ is a physicochemical parameter equivalent to the vapor pressure of water in a system $(p)$ divided by the vapor pressure of pure water $\left(p_{0}\right)$ :

$$
a_{w}=\frac{p}{p_{0}}
$$

The effect of water activity on inhibition of growth of food-borne pathogens has been modeled together with other factors in secondary models based on the Gamma concept (Zwietering, Wijtzes, Rombouts, \& van 't Riet, 1993) that is widely used. According to this model, the inhibiting effect of water activity is expressed in the gamma factor for growth $\left(\gamma_{a_{w}}\right)$, which can be calculated as follows if $a_{w}>a_{w_{\text {min }}}$ :

$$
\gamma_{a_{w}}=\frac{a_{w}-a_{w_{\min }}}{1-a_{w_{\min }}}
$$

in which $a_{w}$ is the water activity that is actually present in the cheese, and in which $a_{w_{\text {min }}}$ is the minimal water activity at which growth of a bacterium can occur; $a_{w_{\min }}$ is 0.92 for L. monocytogenes according to ICMSF (1996). If the water activity is $>0.92$, it can still contribute to inhibition of growth of L. monocytogenes and growth can be fully inhibited when other factors are also present (e.g. pH, organic acids), according to the Gamma concept (Zwietering et al., 1993).

As indicated above, $\mathrm{NaCl}$ is added to Gouda cheese during brining and is the major salt that affects the water activity of this product. It migrates into the cheese during brining and ripening, and water migrates from the cheese to the brine. Resnik \& Chirife (1988) predicted the theoretical water activity based on measurements in saturated $\mathrm{NaCl}$ solutions at a temperature ranging from 15 to $50{ }^{\circ} \mathrm{C}$ : 


$$
a_{w}=e^{\left(\frac{\varphi \cdot v_{i} \cdot m_{i}}{-55.51}\right)}
$$

in which $\varphi$ is the ionic strength and $v_{i}$ is the number of particles into which each solute of molality $m_{i}$ dissociates.

Several empirical models are available for other types of cheese in which the water activity depends on the solutes (e.g. $\mathrm{NaCl}$ ) and water content of the cheese. In those models the $\mathrm{NaCl}$ content is expressed in $\mathrm{NaCl}$-in-moisture (\%, wt/wt). An empirical model has been established for fresh cheeses with a water-in-cheese content $\geq 40 \%$ by Marcos, Alcalá, León, Fernández-Salguero, \& Esteban (1981) and Marcos Millán, Esteban, Alcalá, \& Fernández-Salguero (1983):

$$
a_{w}=1.00-0.00565 \cdot[\mathrm{NaCl}]_{\mathrm{H}_{2} \mathrm{O}}
$$

in which $[\mathrm{NaCl}]_{\mathrm{H} 2 \mathrm{O}}$ as $\mathrm{NaCl}$-in-moisture $(\%, \mathrm{wt} / \mathrm{wt})$.

In addition, Saurel, Pajonk, \& Andrieu (2004) proposed a model for Emmental cheese based on measurements of water activity and $\mathrm{NaCl}$-in-moisture content during brining $\left(\mathrm{a}_{\mathrm{w}}\right.$ varying from 0.80 to 0.99 and $\left[\mathrm{NaCl}_{\mathrm{H}_{2} \mathrm{O}}\right.$ varying from an $\mathrm{NaCl}$-in-moisture of 0 to $30 \%$, wt/wt):

$$
a_{w}=0.997-0.00604 \cdot[\mathrm{NaCl}]_{\mathrm{H}_{2} \mathrm{O}}
$$

So far, the effect of the $\mathrm{NaCl}$ content and the water content on the water activity has not been investigated for Dutch-type cheeses. In the current study, we assessed the water activity of Gouda cheese based on migration of $\mathrm{NaCl}$ and water that occurs in the cheese during brining and ripening. An empirical model is presented and compared with the previous empirical models developed for other types of cheeses. In addition, we predict the impact of water activity on inhibition of growth of L. monocytogenes. The results presented in this study are based on cheeses that were brined for $3.8 \mathrm{~d}$ and then foilripened, and on cheeses that were brined for different times and subsequently natureripened. The goals of this study were (1) to establish the diffusion of $\mathrm{NaCl}$ and water in Gouda cheese during brining and ripening, (2) to establish the water activity as a function of the $\mathrm{NaCl}$ content and the water content, and (3) to predict the effect of water activity on growth inhibition of microbial pathogens such as L. monocytogenes in Gouda cheese. 


\subsection{Materials and methods}

\subsubsection{Manufacturing of Gouda cheese, brining and ripening procedure}

Two block-type Gouda cheeses (weight $15.7 \mathrm{~kg}, 0.30$ x 0.50 x $0.11 \mathrm{~m}, 48 \%$ fat in DM) from one production lot, and 6 wheel-type Gouda cheeses (weight $4.5 \mathrm{~kg}$, height $0.097 \mathrm{~m}$, diameter $0.245 \mathrm{~m}, 48 \%$ fat in DM) from one production lot were supplied by an industrial producer of pasteurized-milk Gouda cheeses in The Netherlands. Pressed fresh cheeses were transported in molds (protected with aseptic plastic bags) from the production location to NIZO food research and within $3 \mathrm{~h}$ after pressing (as is common practice in Dutch-type Gouda cheese production), all cheeses were immersed in brine (consisting of $18.4 \%$ wt/vol $\mathrm{NaCl}$, with $\mathrm{pH}$ adjusted to 4.4 with $\mathrm{HCl}$ ) that was slowly but continuously agitated. The block-type cheeses were brined for $3.8 \mathrm{~d}$. Brining was performed at $12{ }^{\circ} \mathrm{C}$. Of the 6 wheel-type cheeses, 2 cheeses (i.e. duplicate samples) were brined for $0.33 \mathrm{~d}, 2$ cheeses for $2.1 \mathrm{~d}$, and 2 cheeses for $8.9 \mathrm{~d}$, resulting in cheeses defined as low-salt, normalsalt and high-salt cheeses, respectively. The 2 cheeses brined for $2.1 \mathrm{~d}$ and the 2 blocktype cheeses that were brined for $3.8 \mathrm{~d}$ had the same $\mathrm{NaCl}$-in-cheese content after 4 wk of ripening (both normal-salt cheeses).

After brining, the cheeses were removed in pairs and of each cheese, samples were taken independently before ripening started (for details see Cheese sampling section). Subsequently, the block-type cheeses were vacuumed using thermoforming PA/PE foil with a thickness of $100 \mu \mathrm{m}$ (Hevel, Zaandam, The Netherlands) and ripened at NIZO food research at $5{ }^{\circ} \mathrm{C}$ and $62.5 \%$ humidity, as normally applied in Dutch cheese-making factories for this type of cheese. The wheel-type cheeses were coated with commercially available coating solution (CSK food enrichment, Ede, The Netherlands) containing $0.02 \%$ natamycin as commonly applied for nature-ripened Gouda cheese to prevent growth of mold during ripening. The wheel-type cheeses were ripened at $12.5{ }^{\circ} \mathrm{C}$ and $85 \%$ relative humidity at NIZO Food Research.

\subsubsection{Cheese sampling}

Two different cheeses were analyzed per brining condition and each of these cheeses was sampled immediately after coating of the cheeses $(t=0)$ and after 2, 4, 7, 12, 19 and 26 wk of ripening. Cheese samples (slices of 25-30 g) were taken at approximately 0.005, 0.025 and $0.045 \mathrm{~m}$ from the rind of the cheese. From each slice of sampled cheese, the 
coating was removed and the slice was dissected to obtain 2 samples $0-0.01 \mathrm{~m}$ from the rind (cheese rind or the $0.005-\mathrm{m}$ sample), 2 samples $0.02-0.03 \mathrm{~m}$ from the rind $(0.025-\mathrm{m}$ sample) and 1 sample 0.04-0.05 $\mathrm{m}$ from the rind (cheese core or the 0.045-m sample), yielding 5 samples per cheese. Each cheese sample was grated and mixed to obtain a homogeneous sample. After grating, the samples were immediately stored in $180-\mathrm{mL}$ plastic sample containers with screw caps (VWR, Amsterdam, The Netherlands) at room temperature and analyzed within $2 \mathrm{~h}$ after storage to prevent water evaporation during sample preparation.

\subsubsection{Cheese analysis}

Each cheese sample of 25-30 g was grated, and the $\mathrm{NaCl}$-in-cheese content, water-incheese content and the water activity were analyzed. The $\mathrm{NaCl}$-in-cheese content was determined on the basis of the chloride content by a potentiometric titration of the chloride ions with silver nitrate according to NEN 3762 (NEN, 1977). The NaCl-in-moisture (\%, wt/wt) was calculated from the $\mathrm{NaCl}$-in-cheese content by multiplying the $\mathrm{NaCl}$-in-

cheese content $(\%, w t / w t)$ by $\frac{100 \%}{\text { water-in-cheese content, } \%(w t / w t)}$. The water-in-cheese content (\%, wt/wt) was analyzed by determining the mass of the grated cheese sample before and after heating at $160{ }^{\circ} \mathrm{C}$ in an oven (Kern MLS, Balingen, Germany) for 30 min according to NEN 3755 (NEN, 1998). The water activity was determined with an Aqualab Series 3 water activity measuring device (Decagon, Washington, USA). All analyses were performed in duplicate, and the average value of each determination was reported.

\subsubsection{Diffusion coefficient of $\mathrm{NaCl}$ during brining in Gouda cheese}

The diffusion of $\mathrm{NaCl}$-in-moisture (\%, wt/wt) was studied during brining of block-type and wheel-type Gouda cheeses. The displacement of $\mathrm{NaCl}$ in the vertical direction was assumed to be unaffected by the lateral displacements for both the block-type cheeses and the wheel-type cheeses, as the width was much greater than the height for both cheeses. Assuming no influence of lateral displacement, the diffusion coefficient, $D^{*}$, was established according to the error function (erf) for surface convection based on the diffusion law of Fick, as described by Geurts (1972): 


$$
\frac{C^{\prime}-c}{C^{\prime}-C_{0}}=\operatorname{erf}\left(\frac{x}{2 \sqrt{\left(D^{*} t\right)}}\right)
$$

in which $C^{\prime}=$ concentration of $\mathrm{NaCl}$ at the rind in $\mathrm{NaCl}$-in-moisture (\%,wt/wt), $c=$ concentration of $\mathrm{NaCl}$-inmoisture (\%,wt/wt) in the cheese sample, $C_{0}=$ concentration of $\mathrm{NaCl}$-in-moisture $(\%, \mathrm{wt} / \mathrm{wt})$ in the cheese before brining, $x=$ distance $(\mathrm{m})$ from the rind in the direction to which $\mathrm{NaCl}$ has diffused, $t=$ brining time $(\mathrm{s})$ and $D^{*}=$ diffusion coefficient of $\mathrm{NaCl}$-in-moisture (in $\mathrm{m}^{2} \mathrm{~s}^{-1}$ ).

The diffusion coefficient $D^{*}$ of $\mathrm{NaCl}$ during brining of Gouda cheese was calculated for each sample according to Equation [4.6]. In the initial unbrined cheeses, chloride ions were already present at a level of $0.39 \mathrm{~g}$ per $100 \mathrm{~g}$ cheese moisture $\left(C_{0}=0.39 \%\right.$, wt $\left./ \mathrm{wt}\right)$ due to addition of calcium chloride $\left(\mathrm{CaCl}_{2}\right)$ to the cheese milk. The bulk concentration of $\mathrm{NaCl}$ in brine $\left(C^{\prime}\right)$ and the average diffusion coefficient $\left(D^{\prime}\right)$ were estimated using the Solver function in Excel (based on the minimal residual sum of squares between the measured and fitted values for $c$ determined per cheese sample) from Microsoft Office (Microsoft Corp., Redmond, WA).

\subsubsection{Deriving an empirical model for the water activity of Gouda cheese}

An empirical model for the water activity as a function of the $\mathrm{NaCl}$-in-moisture content of Gouda cheese was derived using linear regression (based on the highest $\mathrm{R}^{2}$ value and an intercept of 0.995 , representing the water activity of Gouda before brining). This model was based on analysis of 70 samples from the block-type cheeses ( 7 ripening times $x 2$ cheeses $x 5$ samples per cheese) and 210 samples from the wheel-type cheeses (7 ripening times $\times 2$ cheeses $\times 3$ brining times $\times 5$ samples per cheese). The $\mathrm{NaCl}$ content was expressed as $\mathrm{NaCl}$-in-moisture $(\%, w t / w t)$ to incorporate the changes in the water-incheese content of the cheese throughout ripening.

\subsubsection{Calculating the effect of water activity on growth inhibition of L. monocytogenes}

The effect of water activity on inhibition of growth of L. monocytogenes was calculated using the previously established gamma factor for water activity $\gamma_{a_{w}}$ as described in Equation [4.2]; $\gamma_{a_{w}}$ was calculated at each location at which the $\mathrm{NaCl}$ content and water content were established in the cheese $(0.005,0.025$ or $0.045 \mathrm{~m}$ from the rind) and plotted against time for all types of cheeses (block-type cheeses that were brined for $3.8 \mathrm{~d}$ and 
wheel-type cheeses that were brined for $0.33,2.1$, or $8.9 \mathrm{~d}$ ). The lower the value of $\gamma_{a_{w^{\prime}}}$ the greater the effect of water activity on growth inhibition of $L$. monocytogenes in that cheese at that time. When, at a given time, the $\gamma_{a_{w}}$ was equal to or lower than zero, water activity was predicted to fully inhibit growth of $L$. monocytogenes.

\subsection{Results and discussion}

\subsubsection{Diffusion coefficient of $\mathrm{NaCl}$ in Gouda}

In this study, the diffusion of $\mathrm{NaCl}$ was determined in Dutch-type Gouda cheeses which were subjected to different brining times (Fig. 4.1). The $D^{\star}$ value of $\mathrm{NaCl}$ was determined during brining of Gouda cheeses produced in a Dutch cheese-making factory (The Netherlands) with, on average, a pH of 5.1 and water content of $47 \%$ before brining. The average $D^{*}$ value determined in this study was $3.6 \cdot 10^{-10} \mathrm{~m}^{2} \mathrm{~s}^{-1}$ in the $15.7 \mathrm{~kg}$ block-type Gouda cheeses (Fig. 4.1A) and $3.5 \cdot 10^{-10} \mathrm{~m}^{2} \mathrm{~s}^{-1}$ in the $4.5 \mathrm{~kg}$ wheel-type Gouda cheeses (Fig. 4.1B). The diffusion coefficients for $\mathrm{NaCl}$ as determined in the block-type and the wheeltype Gouda cheeses are in the range of those reported for Emmental, Cheddar, Feta and Camembert cheeses; namely, 1.0 to $5.3 \cdot 10^{-10} \mathrm{~m}^{2} \mathrm{~s}^{-1}$ (Floury, Jeanson, Ally, \& Lortal, 2010). The diffusion coefficient of $\mathrm{NaCl}$ in Gouda cheese was higher than that reported by Geurts (1972), who calculated a $D^{\star}$ value of 1.9 to $2.2 \cdot 10^{-10} \mathrm{~m}^{2} \mathrm{~s}^{-1}$ in Gouda cheese. The higher coefficient found in Gouda in this study than in Geurts (1972) might be explained by differences in processing conditions. Geurts (1972) did not add $\mathrm{CaCl}_{2}$ to the cheeses, but left the freshly pressed cheeses for $2.5 \mathrm{~d}$ before brining, to allow for further acidification and rind formation. The matrix and rind of the Gouda cheese of Geurts (1972) may have been more rigid and less permeable, which could explain the lower diffusion of $\mathrm{NaCl}$ in those cheeses. The higher $D^{*}$ value found in the current study compared with Geurts (1972) may also be explained by the higher water-in-cheese content of cheeses before brining in this study than in Geurts (1972). When the water-in-cheese content is increased, the protein-in-cheese fraction will be decreased, leading to a lower rigidity of the cheese and a higher diffusion of $\mathrm{NaCl}$. In the study of Geurts (1972), the water-in-cheese content before brining was not reported, but the water-in-cheese content after $8.1 \mathrm{~d}$ of brining varied from $31 \%$ in the rind to $43 \%$ in the core. The water-in-cheese contents observed in this study were higher (38\% in the rind and $46 \%$ in the core after $8.9 \mathrm{~d}$ of brining). The initial water-in-cheese content of the cheeses of Geurts (1972) therefore appears to be $\sim 4 \%$ lower, likely explaining the reported lower $D^{*}$ values. 
A)

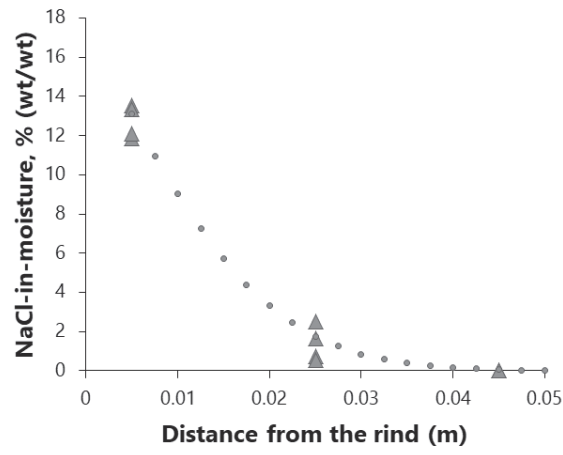

B)

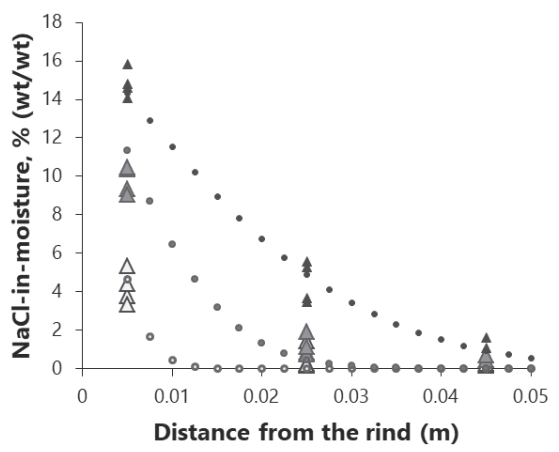

Fig. 4.1 NaCl-in-moisture (\%, wt/wt) of Gouda cheeses immediately after brining. Samples were taken at distances of $0.005,0.025$ and $0.045 \mathrm{~m}$ from the rind of (A) 2 block-type cheeses of $15.7 \mathrm{~kg}$ that were brined for $3.8 \mathrm{~d}$ at $12{ }^{\circ} \mathrm{C}$, and at $0.005,0.025$ and $0.045 \mathrm{~m}$ from the rind of (B) 6 wheel-type cheeses of $4.5 \mathrm{~kg}$ that were brined for $0.33 \mathrm{~d}$ ( 2 cheeses, white triangles), for $2.1 \mathrm{~d}$ ( 2 cheeses, grey triangles), and for $8.9 \mathrm{~d}$ ( 2 cheeses, black triangles) at $12{ }^{\circ} \mathrm{C}$. Contents of $\mathrm{NaCl}$ for each distance are presented individually. The fitted $\mathrm{NaCl}$ contents (plotted as dotted lines) are based on concentration of $\mathrm{NaCl}$-in-moisture (\%, wt/wt) in the cheese before brining $\left(C_{0}\right)=0.39 \%(\mathrm{wt} / \mathrm{wt})$, diffusion coefficient $\left(D^{\prime}\right)=3.6 \cdot 10^{-10} \mathrm{~m}^{2} \mathrm{~s}^{-1}$, and concentration of $\mathrm{NaCl}$ at the rind $\left(C^{\prime}\right)=17.7 \%\left(\mathrm{wt} / \mathrm{wt}\right.$ ) for the block-type cheeses and $D^{*}=3.5 \cdot 10^{-10} \mathrm{~m}^{2} \mathrm{~s}^{-1}$ and $C^{\prime}=17.2 \%(\mathrm{wt} / \mathrm{wt}$ ) for the wheel-type cheeses, as calculated using Equation [4.6], with the $\mathrm{NaCl}$ concentrations in the cheeses as predicted before and after brining, brining times and distances from the rind as input parameters.

\subsubsection{Profiles of $\mathrm{NaCl}$ and water during ripening}

The gradient in the $\mathrm{NaCl}$-in-moisture (\%, wt/wt) disappeared in all cheeses during ripening (Fig. 4.2A and 4.2B). Immediately after brining, the $\mathrm{NaCl}$-in-moisture content was $~ 9$ times higher in the rind than in the core for the wheel-type cheeses that were brined for 0.33 , 2.1 or $8.9 \mathrm{~d}$. Not surprisingly, the highest concentration of $\mathrm{NaCl}$-in-moisture content was measured in the rind of the cheeses with the longest brining time (8.9 d; Fig. 4.2B). Immediately after brining, the $\mathrm{NaCl}$-in-moisture content was $5.1 \%$ (wt/wt), on average, in the block-type Gouda cheeses that were brined for $3.8 \mathrm{~d}$ (Fig. 4.2A). In wheel-type natureripened Gouda cheeses that were brined for 0.33, 2.1 and $8.9 \mathrm{~d}$, the average $\mathrm{NaCl}$-inmoisture contents were 2.0, 4.2 and $7.2 \%$ (wt/wt), respectively. The average $\mathrm{NaCl}$-inmoisture content of the wheel-type nature-ripened cheeses increased to 4.8, 9.6 and 19.0 $\%$ (wt/wt) after ripening for $26 \mathrm{wk}$ (Fig. 4.2B). NaCl migrated from the outer to the inner layers of the cheese during ripening. According to Guinee \& Fox (2004), it can take 9 wk for the $\mathrm{NaCl}$ gradient to disappear within large Gouda cheese blocks. In the 15.7-kg blocktype cheeses that were wrapped in foil, the $\mathrm{NaCl}$ gradient disappeared between 4 and 7 wk of ripening, resulting in an average $\mathrm{NaCl}$-in-moisture content throughout the cheese of $5.3 \%$ (wt/wt; Fig. 4.2A). After a similar time the $\mathrm{NaCl}$-in-moisture gradient also disappeared in the wheel-type cheeses (Fig. 4.2B). 
The average water-in-cheese content in the block-type cheeses that underwent foilripening was constant (Fig. 4.3A) but decreased in the wheel-type cheeses that were nature-ripened (Fig. 4.3B). The gradient in water-in-cheese content between rind and core had already disappeared in the block-type cheeses after 2 wk of ripening (Fig. 4.3A), but persisted in the nature-ripened cheeses (due to evaporation, Fig. 4.3B). The average waterin-cheese content was lower in the cheese that was brined for $8.9 \mathrm{~d}$ than in the cheese that was brined for $0.33 \mathrm{~d}$, with a difference of 3.5\% directly after brining and $2.2 \%$ after 26 wk of ripening. Overall, an increase in the content of $\mathrm{NaCl}$-in-moisture was observed in the wheel-type cheeses during ripening (Fig. 4.2B) due to an inwards migration of $\mathrm{NaCl}$ and an outwards migration of water.

A)

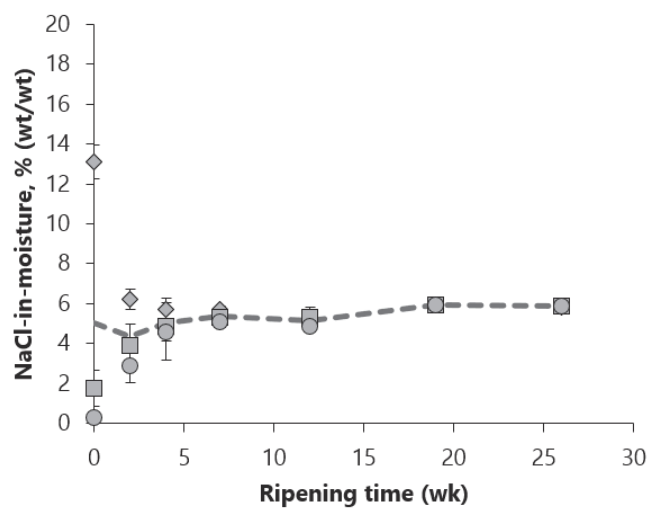

B)

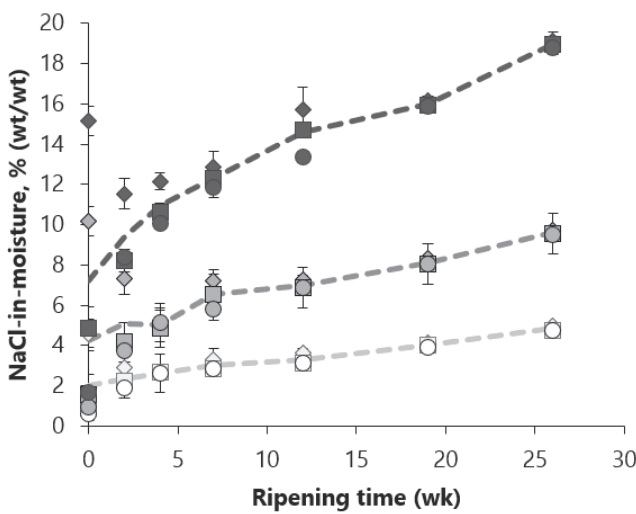

Fig. 4.2 Sodium chloride $(\mathrm{NaCl})$-in-moisture (\%, wt/wt) of Gouda cheese at different time points during ripening, showing the $\mathrm{NaCl}$ content (mean $\pm \mathrm{SD}$ ) in samples taken at different distances from the rind at each time point: $0.005 \mathrm{~m}$ from the rind (diamonds, $\mathrm{n}=4$ ), $0.025 \mathrm{~m}$ from the rind (squares, $\mathrm{n}=4$ ), and $0.045 \mathrm{~m}$ from the rind (circles, $n=2)$. In addition, the average $\mathrm{NaCl}$-in-moisture $(\%, w t / w t)$ is plotted (dashed lines) for each brining time in (A) block-type foil-ripened cheese of $15.7 \mathrm{~kg}$ brined for $3.8 \mathrm{~d}$; and (B) wheel-type natureripened cheese of $4.5 \mathrm{~kg}$ brined for $0.33 \mathrm{~d}$ (open white symbols), $2.1 \mathrm{~d}$ (grey symbols), or $8.9 \mathrm{~d}$ (black symbols). 
A)

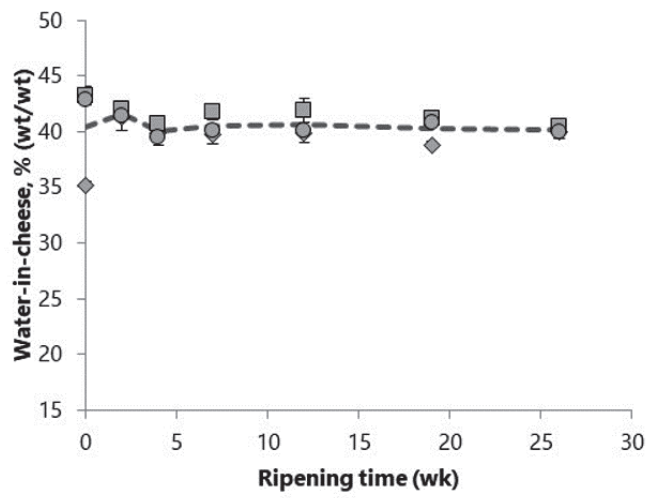

B)

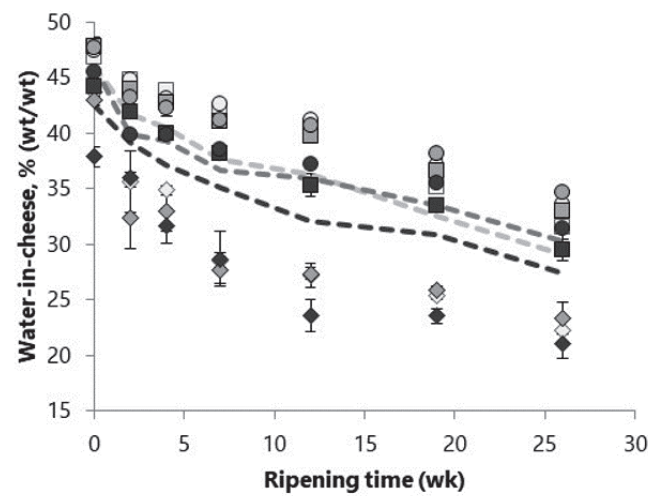

Fig. 4.3 Water-in-cheese (\%, wt/wt) of Gouda cheese at different time points during ripening, showing the water-in-cheese content (mean $\pm S D$ ) in samples taken at different distances from the rind at each time point: $0.005 \mathrm{~m}$ from the rind (diamonds; $\mathrm{n}=4$ ), $0.025 \mathrm{~m}$ from the rind (squares; $\mathrm{n}=4$ ), and $0.045 \mathrm{~m}$ from the rind (circles; $n=2)$. In addition, the mean water-in-cheese content $(\%, w t / w t)$ is plotted (dashed lines) for each brining time in (A) block-type foil-ripened cheese of $15.7 \mathrm{~kg}$ brined for $3.8 \mathrm{~d}$; and (B) wheel-type natureripened cheese of $4.5 \mathrm{~kg}$ brined for $0.33 \mathrm{~d}$ (open white symbols), $2.1 \mathrm{~d}$ (grey symbols), or $8.9 \mathrm{~d}$ (black symbols).

\subsubsection{Water activity during ripening}

Fig. 4.4 displays the water activity during ripening of Gouda cheese. In the block-type cheeses that were brined for $3.8 \mathrm{~d}$ and subsequently foil-ripened, the water activity in the rind immediately after brining was as low as 0.91 , but it rapidly increased to a value of 0.96 during ripening of the cheese (Fig. 4.4A). Subsequently, the water activity in the foilripened cheeses was stable during maturation because the foil prevented evaporation of water. In the nature-ripened cheeses, a decline in the average water activity was observed during ripening, concomitant with a reduction of the water-in-cheese content. Immediately after brining for $0.33,2.1$ and $8.9 \mathrm{~d}$, the water activity in the rind was 0.96 , 0.93 and 0.90 , respectively, in the nature-ripened cheeses. The water activity in the core of these cheeses was 0.99 . The average water activity decreased from 0.98 to 0.93 in the cheeses that were brined for $0.33 \mathrm{~d}$, from 0.97 to 0.91 in the cheeses that were brined for $2.1 \mathrm{~d}$, and from 0.95 to 0.85 in the cheeses that were brined for $8.9 \mathrm{~d}$ between 0 and 26 wk of ripening. The differences in water activity values observed after brining between the cheeses that were brined for 0.33, 2.1 and $8.9 \mathrm{~d}$ persisted during maturation (Fig. 4.4B). 
A)

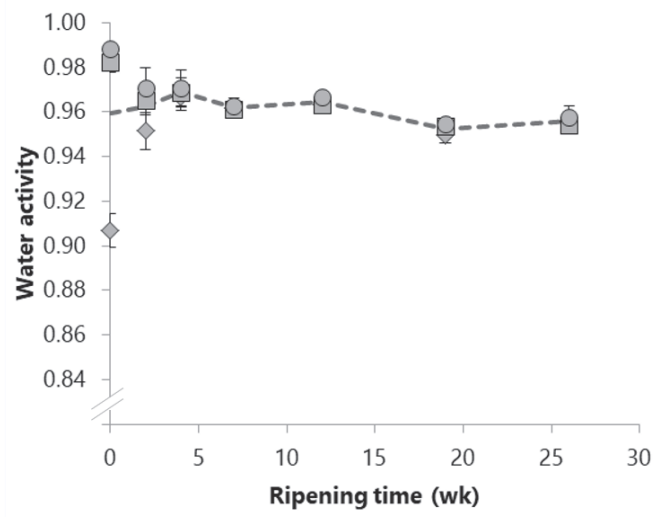

B)

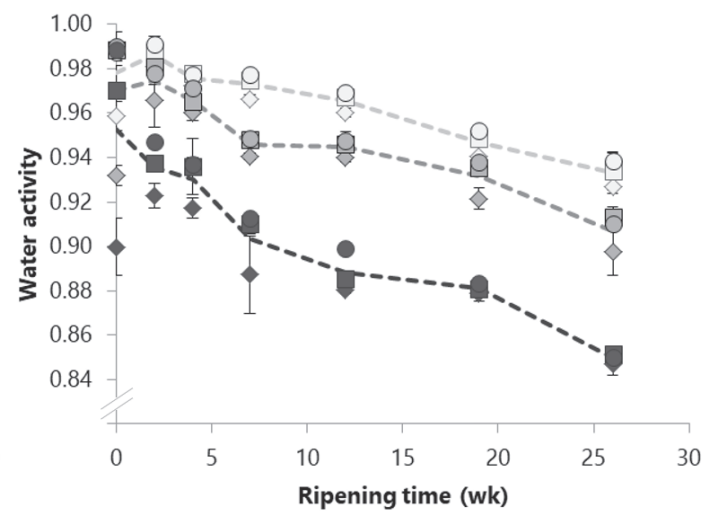

Fig. 4.4 Water activity ( $a_{w}$ ) of Gouda cheese at different time points during ripening, showing the water activity (mean \pm SD) in samples taken at different distances from the rind at each time point: $0.005 \mathrm{~m}$ from the rind (diamonds; $n=4$ ), $0.025 \mathrm{~m}$ from the rind (squares; $n=4$ ), and $0.045 \mathrm{~m}$ from the rind (circles; $\mathrm{n}=2$ ). In addition, the average water activity is plotted (dashed lines) for each brining time in (A) block-type foilripened cheese of $15.7 \mathrm{~kg}$ brined for $3.8 \mathrm{~d}$; and (B) wheel-type nature-ripened cheese of $4.5 \mathrm{~kg}$ brined for $0.33 \mathrm{~d}$ (open white symbols), $2.1 \mathrm{~d}$ (grey symbols), or $8.9 \mathrm{~d}$ (black symbols).

\subsubsection{Empirical model for the water activity of Gouda cheese}

An empirical model $\left(R^{2}=0.89\right.$, regression coefficient $\left.-0.00721 \pm-0.0003\right)$ for the water activity of Gouda cheese as a function of the $\mathrm{NaCl}$-in-moisture content was derived (based on the data presented in Fig. 4.5):

$$
a_{w}=0.995-0.00721 \cdot \mathrm{NaCl}_{\mathrm{H}_{2} \mathrm{O}}
$$

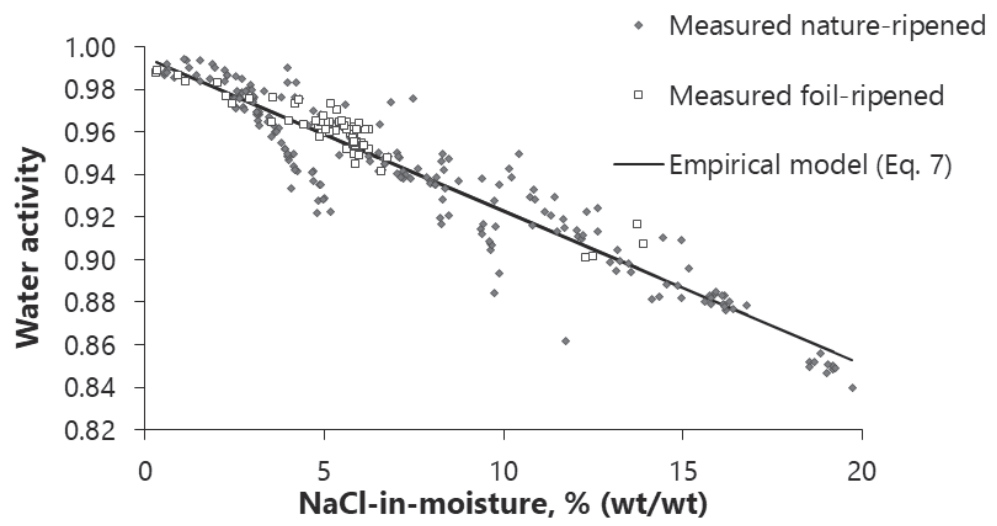

Fig. 4.5 Empirical model $\left(R^{2}=0.89\right)$ for the water activity $\left(a_{w}\right)$ of Gouda cheese as a function of the NaCl-inmoisture content $\left(\mathrm{NaCl}_{\mathrm{H}_{2} \mathrm{O}}\right)$ in \%, wt/wt: $a_{w}=0.995-0.00721 \cdot \mathrm{NaCl}_{\mathrm{H}_{2} \mathrm{O}}$ (with $-0.00721 \pm-0.0003$ ). 
Freshly pressed but unsalted cheese already contains some solutes, rendering a water activity of 0.995 (water activity of pure water is 1.000). Therefore, the latter value was used as intercept in the empirical model. The model presented here is independent of time and is valid during brining and ripening. It incorporates both the $\mathrm{NaCl}$ content and the water content, which are the main factors that change during brining and ripening of Gouda cheese. The model presented here is similar to the empirical model for water activity of Emmental cheese during brining, as derived by Saurel et al. (2004) in Equation [4.5]. That model likely resembles the empirical model for Gouda, because part of the $\mathrm{a}_{\mathrm{w}} / \mathrm{NaCl}_{\mathrm{H}_{2} \mathrm{O}}$ intervals of Gouda were similar to that of Emmental cheese (the $\mathrm{a}_{\mathrm{w}}$ and $\mathrm{NaCl}_{\mathrm{H} 2 \mathrm{O}}$ of aged Gouda cheese seem similar to those of fresh Emmental). The $\mathrm{R}^{2}(0.89)$ and the regression coefficient (-0.00721) in this empirical model are lower than those in the model of Saurel et al. (2004; $R^{2}$ of 0.98 and a regression coefficient of -0.00604 ), but that model was based only on samples taken during brining, whereas it does not include samples during ripening. The regression coefficient of -0.00721 that we established (see Equation [4.7]) was smaller than that determined by Marcos et al. $(1981,1983)$. This implies that the effect of the $\mathrm{NaCl}_{\mathrm{H}_{2} \mathrm{O}}$ factor on the water activity is greater than expected based on the data of the latter reports. Moreover, our empirical model has a broader scope as it also includes cheeses with a water-in-cheese content $<40 \%$ and a water activity $<0.96$.

\subsubsection{Implications of reduced brining time and foil-ripening for L. monocytogenes}

Immediately after brining, the water activities were 0.93 and 0.90 in the outer layer of the cheeses that were brined for 2.1 and $8.9 \mathrm{~d}$, respectively. These values are close to or lower than the $a_{w}$ growth limit for L. monocytogenes. Such low water activities in the outer layer of the cheese can likely hinder outgrowth of L. monocytogenes in Gouda cheese following a contamination after curd formation (e.g. by the brine bath or conveyors). Such conditions may even lead to inactivation of the pathogen, as was observed by Wemmenhove et al. (2014).

Food producers that use foil-ripening or that shorten their brining times (e.g., to produce low-salt cheeses) must be aware that a lower salt content and a higher water content can have a negative impact on inhibition of bacterial growth. A lower salt content or a higher water content results in a reduced water activity hurdle for microbial pathogens. According to the Gamma model described in Equation [4.2], a shortened brining time will lead to a higher $a_{w}$ and a smaller effect on inhibition of growth. The water activity was 0.96 in the outer layer of the cheese immediately after brining when cheeses were brined for only $0.33 \mathrm{~d}$. In addition to water activity, other microbial hurdles (e.g., $\mathrm{pH}$ and the presence of 
organic acid) are present in cheese that can contribute to full inhibition of growth of L. monocytogenes or other pathogens, even at higher water activity values, such as occurring in foil-ripened cheeses and in cheeses with shortened brining times. Fig. 4.6 displays the effect of water activity $\left(\gamma_{a_{w}}\right)$ on growth inhibition of L. monocytogenes during ripening, as predicted from the Gamma model. The effect of water activity on growth inhibition of L. monocytogenes in foil-ripened cheese seems stable during ripening (Fig. $4.6 \mathrm{~A}$ ), as the average water activity during ripening is stable within this type of cheese (Fig. 4.4A). Full growth inhibition of L. monocytogenes as a result of low water activity can be expected after 26 wk of ripening in Gouda cheese that was brined for $2.1 \mathrm{~d}$, as in the nature-ripened cheeses, the $a_{w}$ decreases to values below the critical $a_{w}$ limit for growth of L. monocytogenes (Fig. 4.6C).
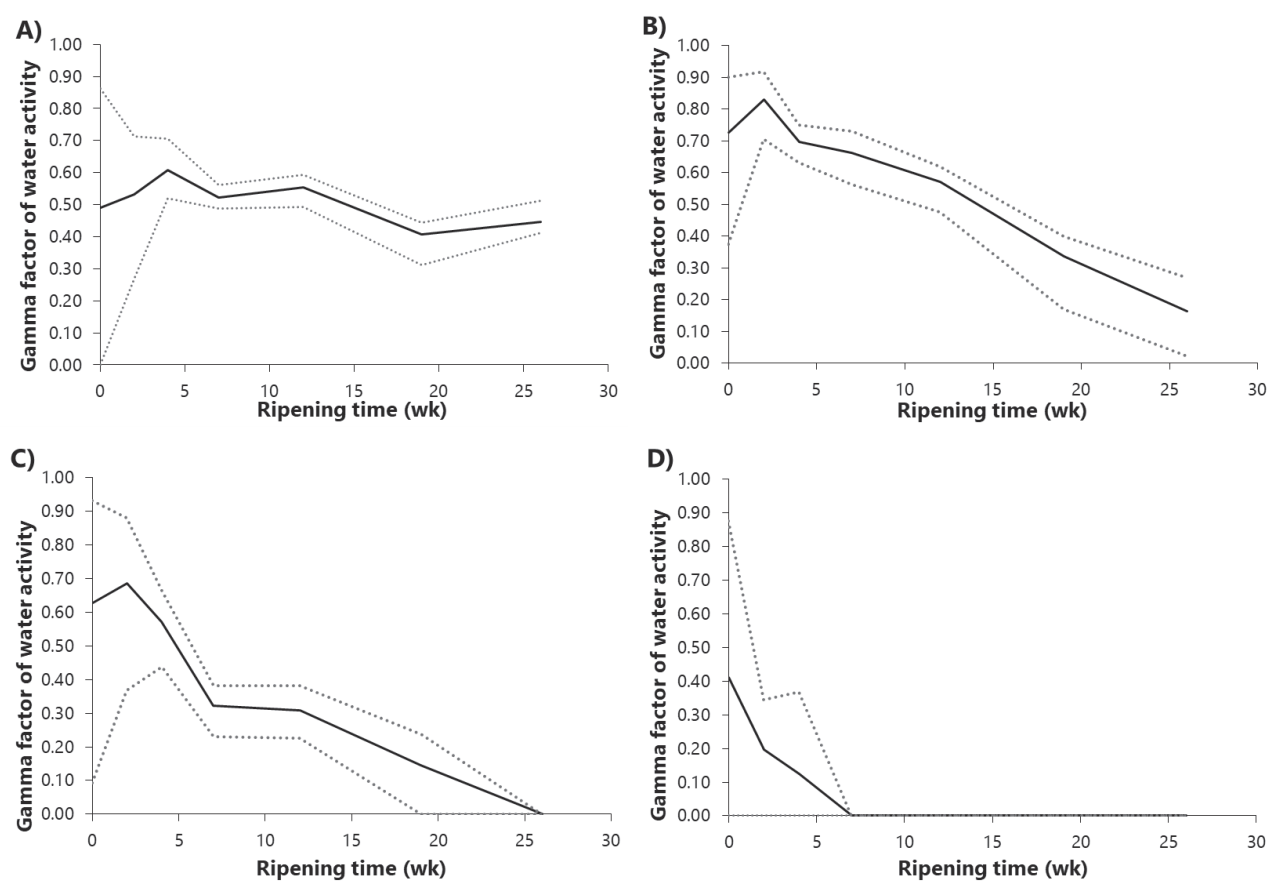

Fig. 4.6 The effect of water activity $\left(\gamma_{a_{w}}\right)$ on growth inhibition of L. monocytogenes during ripening as predicted from the Gamma model, with (A) foil-ripened block-type Gouda cheeses that were brined for $3.8 \mathrm{~d}$ at $12{ }^{\circ} \mathrm{C}$ and with nature-ripened wheel-type Gouda cheeses that were brined for (B) $\left.0.33 \mathrm{~d}, \mathrm{C}\right) 2.1 \mathrm{~d}$ or D) 8.9 $\mathrm{d}$ at $12{ }^{\circ} \mathrm{C}$. Dotted lines present the minimum and maximum gamma factors; straight lines are the average gamma factors of water activity within Gouda cheese at the indicated ripening time.

We recently demonstrated absence of growth of L. monocytogenes in and on Gouda cheese (Wemmenhove et al. 2013, 2014), and furthermore showed that the concentrations of undissociated lactate that are present in Gouda cheese contribute significantly to the inhibition of growth of this pathogen (Wemmenhove et al., 2016). The current study shows 
that low water activity can also contribute significantly to inhibition of growth of this bacterium in cheese. Conditions of low water activity may completely suppress growth of L. monocytogenes. In fact, inactivation of L. monocytogenes in model Gouda cheeses was seen after 28 wk of ripening when $a_{w}$ decreased below 0.92; that is, the minimum $a_{w}$ required for growth of $L$. monocytogenes (Wemmenhove et al., 2013). These findings are in line with the study of Koutsoumanis \& Sofos (2005), who showed that growth of L. monocytogenes was inhibited at an $\mathrm{a}_{\mathrm{w}}$ lower than 0.93 in combination with a $\mathrm{pH}$ lower than 5.0 in tryptic soy broth.

Overall, our $\mathrm{a}_{\mathrm{w}}$ study has delivered an empirical model for water activity as a function of the $\mathrm{NaCl}$ and water content and underlines the importance of the $\mathrm{a}_{\mathrm{w}}$ as a factor that can lead to inhibition of growth of L. monocytogenes in Gouda cheese.

\section{Acknowledgements}

This study was supported by the Dutch Dairy Organization (The Hague, The Netherlands) and the Dutch Dairy Board (The Hague, The Netherlands). 


\section{References}

Bachmann, H.P., \& Spahr, U. (1995). The fate of potentially pathogenic bacteria in Swiss hard and semihard cheeses made from raw milk. Journal of Dairy Science 78:476-483.

Buazzi, M.M., Johnson, M.E., \& Marth, E.H. (1992). Survival of Listeria monocytogenes during the manufacture and ripening of Swiss cheese. Journal of Dairy Science 75:380-386.

European Commission (2005). Commission regulation (EC) No 2073/2005 of 15 November 2005 on microbiological criteria for foodstuffs. Official Journal of the European Union, 48:1-26.

Floury, J., Jeanson, S., Aly, S., \& Lortal, S. (2010). Determination of the diffusion coefficients of small solutes in cheese: a review. Dairy Science \& Technology 90:477-508.

Gaulin, C., Ramsay, D., \& Bekal, S. (2012). Widespread listeriosis outbreak attributable to pasteurized cheese, which led to extensive cross-contamination affecting cheese retailers, Quebec, Canada, 2008. Journal of Food Protection 75:71-78.

Geurts, T.J. (1972). Diffusie van zout en water bij het zouten van kaas. Wageningen University. PhD thesis, http://edepot.wur.nl/194048.

Gould, L.H., Mungai, E., \& Behravesh, B.C. (2014). Outbreaks attributed to cheese: differences between outbreaks caused by unpasteurized and pasteurized dairy products, United States, 1998-2011. Foodborne Pathogenic Diseases 11:545-551.

Greig, J.D., \& Ravel, A. (2009). Analysis of foodborne outbreak data reported internationally for source attribution. International Journal of Food Microbiology 130:77-87.

Guinee, T.P., \& Fox, P.F. (2004). Salt in cheese: physical, chemical and biological aspects. Pages 207259 in Cheese: Chemistry, Physics and Microbiology (3rd ed.), Vol. 1. Elsevier Academic Press, San Diego, CA.

ICMSF (1996). Microorganisms in foods, Microbiological specifications of food pathogens. Vol. 5 , Blackie, London, UK.

Koch, J., Dworak, R., Prager, R., Becker, B., Brockmann, S., Wicke, A., Wichmann-Schauer, H., Hof, H., Werber, D., \& Stark, K. (2010). Large listeriosis outbreak linked to cheese made from pasteurized milk, Germany, 2006-2007. Foodborne Pathogenic Diseases 7:1581-1584.

Koutsoumanis, K.P., \& Sofos, J.N. (2005). Effect of inoculum size on the combined temperature, pH and aw limits for growth of Listeria monocytogenes. International Journal of Food Microbiology 104:83-91.

Lou, Y., \& Yousef, A.E. (2000). Characteristics of Listeria monocytogenes important to food processors. Pages 131-224 in Listeria, Listeriosis and Food Safety. E.T. Ryser, \& E.H. Marth, ed. Marcel Dekker, New York, NY.

Marcos, A., Alcalá, M., León, F., Fernández-Salguero, J., \& Esteban, M.A. (1981). Water activity and chemical composition of cheese. Journal of Dairy Science 64:622-626.

Marcos, A., Millán, R., Esteban, M.A., Alcalá, M., \& Fernandez-Salguero, J. (1983). Chemical composition and water activity of Spanish cheeses. Journal of Dairy Science 66:2488-2493.

NEN (1977). Cheese - Physical and chemical test methods - Determination of the chloride content (routine method). NEN-3762:1977. 
NEN (1998). Cheese - Physical and chemical test methods - Determination of the moisture content. NEN-3755:1998.

Northolt, M.D., Beckers, H.J., Vecht, U., Toepoel, L., Soentoro, P.S.S., \& Wisselink, H.J. (1988). Listeria monocytogenes. heat resistance and behaviour during storage of milk and whey and making of Dutch types of cheese. Netherlands Milk Dairy Journal 42:207-219.

Resnik, S.L., \& Chirife, J. (1988). Proposed theoretical water activity values at various temperatures for selected solutions to be used as reference sources in the range of microbial growth. Journal of Food Protection 51:419-423.

Saurel, R., Pajonk, A., \& Andrieu, J. (2004). Modelling of French Emmental cheese water activity during salting and ripening periods. Journal of Food Engineering 63:163-170.

Schlech, W.F., Lavigne, P.M., Bortolussi, R.A., Allen, A.C., Haldane, E.V., Wort, A.J., Hightower, A.W., Johnson, S.E., King, S.H., Nichols, E.S., \& Broome, C.V. (1983). Epidemic listeriosis-evidence for transmission by food. New England Journal of Medicine 308:203-206.

Silk, B.J., Date K.A., Jackson, K.A., Pouillot, R., Holt, K.G., Graves, L.M., Ong, K.L., Hurd, S., Meyer, R., Marcus, R., Shiferaw, B., Norton, D.M., Medus, C., Zansky, S.M., Cronquist, A.B., Henao, O.L., Jones, T.F., Vugia, D.J., Farley, M.M., \& Mahon, B.E. (2012). Invasive listeriosis in the foodborne diseases active surveillance network (FoodNet), 2004-2009: further targeted prevention needed for higher-risk groups. Clinical Infectious Diseases 54:S396-404.

Swaminathan, B., \& Gerner-Smidt, P. (2007). The epidemiology of human listeriosis. Microbes and Infection 9:1236-1243.

Vazquez-Boland, J.A., Kuhn, M., Berche, P., Chakraborty, T., Dominguez-Bernal, G., Goebel, W., Gonzalez-Zorn, B., Wehland, J., \& Kreft J. (2001). Listeria pathogenesis and molecular virulence determinants. Clinical Microbiological Reviews 14:584-640.

Wemmenhove, E., Beumer, R.R., van Hooijdonk, A.C.M., Zwietering, M.H., \& Wells-Bennik, M.H.J. (2014). The fate of Listeria monocytogenes in brine and on Gouda cheese following artificial contamination during brining. International Dairy Journal 39:253-258.

Wemmenhove, E., Stampelou, I., van Hooijdonk, A.C.M., Zwietering, M.H., \& Wells-Bennik, M.H.J. (2013). Fate of Listeria monocytogenes in Gouda cheese: no growth, and substantial inactivation after extended ripening times. International Dairy Journal 32:192-198.

Wemmenhove, E., van Valenberg, H.J.F., Zwietering, M.H., van Hooijdonk, A.C.M., \& Wells-Bennik, M.H.J. (2016). Minimal inhibitory concentrations of undissociated lactic, acetic, citric and propionic acid for Listeria monocytogenes under conditions relevant to Dutch-type cheeses. Food Microbiology 58:63-67.

Yde, M., Naranjo, M., Mattheus, W., Stragier, P., Pochet, B., Beulens, K., de Schrijver, K., van den Branden, D., Laisnez, V., Flipse, W., Leclercq, A., Lecuit M., Dierick, K., \& Bertrand, S. (2012). Usefulness of the European epidemic intelligence information system in the management of an outbreak of listeriosis, Belgium, 2011. Eurosurveillance 17:38:1.

Zwietering, M.H., Wijtzes, T., Rombouts, F.M., \& van 't Riet, K. (1993). A decision support system for prediction of microbial spoilage in foods. Journal of Industrial Microbiology 12:324-329. 


\title{
Chapter 5
}

\section{Minimal inhibitory concentrations of undissociated lactic, acetic, citric and propionic acid for Listeria monocytogenes under conditions relevant to cheese}

E. Wemmenhove, H.J.F. van Valenberg, M.H. Zwietering, A.C.M. van Hooijdonk, M.H.J. WellsBennik

\begin{abstract}
Minimal inhibitory concentrations (MICs) of undissociated lactic acid were determined for six different Listeria monocytogenes strains at $30^{\circ} \mathrm{C}$ and in a pH range of $4.2-5.8$. Small increments in $\mathrm{pH}$ and acid concentrations were used to accurately establish the growth/no growth limits of L. monocytogenes for these acids. The MICs of undissociated lactic acid in the $\mathrm{pH}$ range of 5.2-5.8 were generally higher than at $\mathrm{pH} 4.6$ for the different $L$. monocytogenes strains. The average MIC of undissociated lactic acid was 5.0 (SD 1.5) $\mathrm{mM}$ in the $\mathrm{pH}$ range 5.2-5.6, which is relevant to Gouda cheese. Significant differences in MICs of undissociated lactic acid were found between strains of L. monocytogenes at a given $\mathrm{pH}$, with a maximum observed level of $9.0 \mathrm{mM}$. Variations in MICs were mostly due to strain variation. In the $\mathrm{pH}$ range $5.2-5.6$, the MICs of undissociated lactic acid were not significantly different at $12{ }^{\circ} \mathrm{C}$ and $30{ }^{\circ} \mathrm{C}$. The average MICs of undissociated acetic acid, citric acid, and propionic acid were 19.0 (SD 6.5) mM, 3.8 (SD 0.9) mM, and 11.0 (SD 6.3) mM, respectively, for the six L. monocytogenes strains tested in the $\mathrm{pH}$ range 5.2-5.6. Variations in MICs of these organic acids for L. monocytogenes were also mostly due to strain variation. The generated data contribute to improved predictions of growth/no growth of L. monocytogenes in cheese and other foods containing these organic acids.
\end{abstract}

This chapter was published in the Food Microbiology (2016) 58:63-67 


\subsection{Introduction}

Listeria monocytogenes is a Gram-positive foodborne pathogen (Vazquez-Boland et al., 2001). Growth of this bacterium can be inhibited effectively with short-chain organic acids in their undissociated form; these can pass through the bacterial cell membrane. The acid subsequently dissociates in the cytoplasm, resulting in an increased hydrogen ion concentration in the cell. To restore the intracellular $\mathrm{pH}$, the hydrogen ions are pumped out, but this disturbance of the proton motive force is an energetically unfavorable process for bacteria (Mitchell, 1961).

The concentration of undissociated acid in watery solutions is determined by the total concentration of the acid, the $\mathrm{pH}$, and the dissociation constant $\mathrm{pK}_{\mathrm{a}}$. Minimal inhibitory concentrations (MICs) of the undissociated forms of lactic acid, acetic acid, citric acid and propionic acid for L. monocytogenes have been reported in various studies (Ahamad \& Marth, 1989; Aryani, den Besten, Hazeleger, \& Zwietering, 2015; Chen \& Shelef, 1992; Conner, Scott, \& Bernard, 1990; Coroller et al., 2005; Houtsma, de Wit, \& Rombouts, 1993; van der Veen, Moezelaar, Abee, \& Wells-Bennik, 2008; Vasseur, Baverel, Hébraud, \& Labadie, 1999; Young \& Foegeding, 1993). However, the data on MICs of undissociated acids for L. monocytogenes available in literature are limited, varying from 2 to 46 data points per acid. In a number of studies available in literature, relatively large intervals between undissociated acid concentrations were used, resulting in quite rough estimations of the actual lowest concentrations that inhibit growth (Ahamad \& Marth, 1989; Conner et al., 1990; Coroller et al., 2005; van der Veen et al., 2008). Furthermore, a large variability in MIC values between different strains of $L$. monocytogenes has been observed in previous studies (Coroller et al., 2005; van der Veen et al., 2008).

To allow for prediction of growth/no growth of L. monocytogenes in foods that contain short-chain organic acids, more comprehensive datasets with MICs of these acids (using small increments in total acid concentrations and $\mathrm{pH}$ values) are needed for a variety of L. monocytogenes strains. For instance, in the case of Dutch-type cheeses like Gouda, Edam and Maasdam, made from pasteurized milk with rennet-induced curd formation, it is known that a low $\mathrm{pH}$ and the presence of short-chain organic acids are important factors contributing to inhibition of growth of L. monocytogenes (Millet, Saubusse, Didienne, Tessier, \& Montel, 2006).

The aim of this study was to establish accurate minimum inhibitory concentrations of undissociated lactic acid, acetic acid, citric acid and propionic acid for six different strains of $L$. monocytogenes. The inhibitory effects of the undissociated acids were established in a range of $\mathrm{pH}$ values from 4.2 to 5.8 , thus including conditions that are relevant to Dutchtype cheeses. In addition, the effects of different salts that are present in cheese were 
tested in the presence of lactate. MICs of the different acids for L. monocytogenes were determined at $30{ }^{\circ} \mathrm{C}$, reflecting normal processing temperatures for cheese-making, and in addition, MICs of lactate were established at $12{ }^{\circ} \mathrm{C}$, reflecting cheese ripening temperatures.

\subsection{Materials and methods}

\subsubsection{Listeria monocytogenes strain selection and cultivation}

Six strains of L. monocytogenes were selected from the NIZO culture collection (containing 138 L. monocytogenes strains) based on the origin of the strains, the serotype and the resistance to lactic acid, which were previously established (van der Veen et al., 2008). The following strains were selected, based on reported MICs of undissociated lactic acid in van der Veen et al. (2008): L. monocytogenes strain 1F (1/2a, cheese isolate, reported MIC 7.5 $\mathrm{mM}), 2 \mathrm{~F}(1 / 2 \mathrm{a}$, cheese isolate, reported MIC $4.0 \mathrm{mM}), 6 \mathrm{E}(1 / 2 \mathrm{a}$, isolate from wall in cheese factory, reported MIC $7.5 \mathrm{mM}$ ), EGDe (1/2a, rabbit isolate, reported MIC $2.5 \mathrm{mM}), \mathrm{L} 4$ (1/2b, milk isolate, reported MIC $7.5 \mathrm{mM}$ ) and Scott A (4b, outbreak isolate linked with milk, reported MIC $2.5 \mathrm{mM}$ ); see also Tables S1 and S3 in van der Veen et al. (2008). The strains were cultured individually in Brain Heart Infusion (BHI, Merck, Darmstadt, Germany) for $\sim 19 \mathrm{~h}$ and the initial OD of the individual strains was normalized by varying the culturing time at $30{ }^{\circ} \mathrm{C}$ before exposure to acid.

\subsubsection{Generation of datasets to determine MICs of organic acids for L. monocytogenes}

Four datasets were generated to determine the MICs of organic acids in $\mathrm{BHI}$ (Supplementary Table S1).

Dataset 1 was generated to establish the MICs of undissociated lactic acid for six different L. monocytogenes strains ( $1 \mathrm{~F}, 2 \mathrm{~F}, 6 \mathrm{E}, \mathrm{EGDe}, \mathrm{L} 4$, Scott A), using final total concentrations of 0.009, 0.013, 0.020, 0.030, 0.040, 0.046, 0.059, 0.071, 0.088, 0.11, 0.13, 0.18, 0.21, 0.32, 0.50, or $0.79 \mathrm{M}$, at nine different $\mathrm{pH}$ values (ranging from 4.2 to 5.8 with intervals of 0.2 ), and one temperature in two independent experiments with three replicates per experiment. Incubation was performed at $30{ }^{\circ} \mathrm{C}$ up to one month, reflecting normal processing temperatures during cheese-making. 
As Dutch-type cheese contains sodium chloride and calcium chloride, dataset 2 was generated to determine the effect of addition of salt on the MIC of lactate for L. monocytogenes. The MIC of lactate was determined for the same concentration interval of lactate and for the same six L. monocytogenes strains as in dataset 1 , but using $\mathrm{pH}$ values ranging from 5.2 to 5.6 with intervals of 0.2 , and in the absence or in the presence of salts ( $0.20 \mathrm{M}$ sodium chloride, $0.36 \mathrm{M}$ calcium chloride and $0.20 \mathrm{M}$ sodium chloride + $0.36 \mathrm{M}$ calcium chloride in dataset 2).

Dataset 3 was generated to establish the MICs of undissociated acetic acid, citric acid and propionic acid for $L$. monocytogenes. The same six L. monocytogenes strains were used as in dataset 1 , using $\mathrm{pH}$ values ranging from 5.2 to 5.6 with intervals of 0.2 , and the following final total acid concentrations: acetic acid, 0.006, 0.014, 0.029, 0.032, 0.043, 0.057, 0.071, $0.081,0.086,0.16,0.24,0.32,0.40$, or $0.49 \mathrm{M}$; citric acid, $0.014,0.14,0.35,0.71,2.13 \mathrm{M}$; propionic acid $0.0077,0.015,0.031,0.062,0.093,0.12,0.15,0.19 \mathrm{M}$.

Dataset 4 was generated to investigate whether lowering the temperature to that of cheese ripening would influence the MIC of organic acids. In dataset 4, the MICs of lactate were determined as in dataset 1 , but generated in one single experiment with three replicates and incubated at $12{ }^{\circ} \mathrm{C}$ (cheese ripening temperature) up to three months. The MICs of lactate of dataset 4 were generated simultaneously with the first duplicate determination of the MICs of lactate of dataset 1 , incubated at $30{ }^{\circ} \mathrm{C}$ up to one month. The simultaneous assessment at $12{ }^{\circ} \mathrm{C}$ and $30^{\circ} \mathrm{C}$ allowed for a comparison of the MICs at those temperatures.

\subsubsection{Determination of the MICs of undissociated organic acids for L. monocytogenes}

Culture medium with different $\mathrm{pH}$ values and concentration ranges of organic acids were prepared as follows. Equimolar stock solutions of an organic acid and of its potassium salt (both dissolved in water) were made at 2.1 times the final target concentrations (as listed above in paragraph 5.2.2) and mixed to obtain the desired pH (i.e. 4.2 to 5.8 with intervals of 0.2 for datasets 1 and 4, and 5.2 to 5.6 with intervals of 0.2 for dataset 2 and 3). The 2.1fold concentrated organic acid solutions (with different organic acid concentrations and $\mathrm{pH}$ values) were filter-sterilized using Nalgene $0.2 \mu \mathrm{m}$ filters (Sigma Aldrich, Seele, Germany) and $95 \mu \mathrm{L}$ aliquots were added to wells of 96 -well plates containing $95 \mu \mathrm{L}$ of two-fold concentrated filter sterilized $\mathrm{BH}$ that was adjusted with hydrochloric acid (Sigma Aldrich) to the same $\mathrm{pH}$ as the organic acid solution that was added. The final $\mathrm{pH}$ was recorded prior to incubation. Finally, $10 \mu \mathrm{L}$ of a bacterial inoculum in $\mathrm{BHI}$ was added. The bacterial inoculum was obtained by culturing six strains of L. monocytogenes individually 
overnight at $30{ }^{\circ} \mathrm{C}$ to an $\mathrm{OD}_{630}$ of approximately $1.0\left(\sim 3.6 \cdot 10^{9} \mathrm{cfu} \mathrm{mL}-1\right)$. Cells from $100 \mu \mathrm{L}$ of the culture were concentrated by centrifugation (15 min, 5000x g), and the cell pellet was resuspended in $10 \mathrm{~mL} \mathrm{BHI}$ of which the $\mathrm{pH}$ was adjusted to match the $\mathrm{pH}$ used in the experiments to determine the MICs. The volume of $10 \mu \mathrm{L}$ of the bacterial inoculum was suspended in the 96 -well plates (in wells with corresponding $\mathrm{pH}$ values) to obtain final concentrations of individual L. monocytogenes strains of $\sim 1.8 \cdot 10^{6} \mathrm{cfu} \mathrm{mL}^{-1}$ as determined by plate counts on BHI agar (Sigma Aldrich, Seele, Germany) in $200 \mu \mathrm{L}$ final volumes. Incubation was performed at $30{ }^{\circ} \mathrm{C}$ and growth of L. monocytogenes was monitored in triplicate in two independent experiments by measurements of the optical density at 630 nm (OD 630$)$ using an EL808 IU-PC spectrophotometer (Bio-Tek, Winooski, Vermont, USA) throughout a 1-month incubation period. Growth was defined as an increase in $\mathrm{OD}_{630}$ greater than 0.05 compared with the negative control. To confirm the growth/no growth limits that were determined based on optical density readings, counts in the wells with an $\mathrm{OD}_{630}$ increase less than 0.05 were determined by plating on $\mathrm{BHI}$ agar and compared with the initial inoculum level.

MICs of undissociated organic acid for L. monocytogenes were calculated based on equation [5.1], which was derived from the Henderson-Hasselbalch equation.

$$
[\text { Undissociated acid }]=\frac{[\text { Total acid }]}{1+10^{p H-p K_{a}}}
$$

The molarities of the total acid solutions were pre-set, and the $\mathrm{pH}$ values used in these calculations were determined prior to incubation. The equilibrium constants $\mathrm{K}$ for ionization of the undissociated form of the different acids were established previously (Dawson, Elliott, Elliott, \& Jones, 1986), i.e. pK $_{\mathrm{a}} 3.86$ for lactic acid, 4.76 for acetic acid, 3.13 for citric acid and 4.86 for propionic acid.

\subsubsection{Literature search}

Previously reported MICs of undissociated lactic acid, acetic acid, citric acid and propionic acid were obtained from literature (first 200 hits in Scopus, sorted on relevance). The following keywords were used in the search: (L. monocytogenes AND MIC AND [undissociated acid OR organic acid OR lactic acid OR acetic acid OR citric acid OR propionic acid OR lactate OR acetate OR citrate OR propionate]). Furthermore, a literature search was performed using Web of Science and Google Scholar. 


\subsubsection{Statistical analysis}

A general linear model ANOVA (between subjects design, pairwise comparison, Product Tukey test at 95\%) was constructed in Minitab (Minitab Inc., Pine Hall, Pennsylvania, USA) to determine if the MIC was determined by the fixed factors of study or by random variation. Datasets 1, 2 and 3 consisted of data from two independent experiments. For those datasets, 'experiment' and 'replicates' were defined as random factors. Fixed factors were ' $\mathrm{pH}^{\prime}$ and 'strain' in dataset 1, 'pH', 'strain' and 'type of salt' in dataset 2, and 'pH', 'strain' and 'type of organic acid' in dataset 3. In dataset 4, the MICs of undissociated lactic acid were determined at $\mathrm{pH}$ values ranging from 4.2 to 5.8 at $12{ }^{\circ} \mathrm{C}$ and compared with the MICs at $30^{\circ} \mathrm{C}$ of the first duplicate determination of dataset 1. 'Replicates' were treated as random factor and ' $\mathrm{pH}^{\prime}$, 'strain' and 'temperature' were treated as fixed factors in the ANOVA analysis of dataset 4 . Residual plots and boxplots were constructed to check for normality and outliers. Post-hoc ANOVA tests (Product Tukey test at 95\%) were performed using Fizz software (Biosystèmes, Couternon, France) to determine the factors significantly affecting the MIC.

\subsection{Results and discussion}

In this study, the MIC values of undissociated lactic acid, acetic acid, citric acid and propionic acid were established for the six L. monocytogenes strains at $\mathrm{pH} 4.2-5.8$. No growth was observed at $\mathrm{pH}$ values 4.2 or 4.4 for any of the strains, independent of the absence or presence of organic acids (Fig. 5.1). This is in line with the lowest pH growth limit reported by ICMSF (1996), which is $\mathrm{pH} 4.4$ for L. monocytogenes.

The MICs of undissociated lactic acid for L. monocytogenes showed a $\mathrm{pH}$ dependency, with significantly lower values at $\mathrm{pH} 4.6$ than at $\mathrm{pH}$ 5.2, 5.6 and 5.8 for strains 1F, EGDe, L4 and Scott $A$ and significantly higher values at $\mathrm{pH} 5.8$ than at $\mathrm{pH} 4.6-5.6$ for strains $2 \mathrm{~F}$ and 6E (Fig. 5.1 and Supplementary Table S2). Between strains, significant differences in MICs of undissociated organic acid at a given $\mathrm{pH}$ were seen in all four datasets generated (Supplementary Table S1). More specifically, the MICs of undissociated lactic acid showed significant differences between strains of L. monocytogenes at pH 4.8, 5.0, 5.2, 5.4 and 5.6, but not at pH 4.6 and pH 5.8 (Supplementary Table S3).

Relatively high standard deviations were observed for MICs at low pH values (Fig. 5.1, Supplementary Tables S2 and S3). This likely results from a heterogeneous response to severe acid stress of cells within a population, with only certain cells able to overcome this stress and grow (this phenomenon was recently reviewed by Abee, Koomen, Metselaar, 
Zwietering, \& den Besten, 2016). In addition, some high standard deviations were found for MICs at pH 5.6 in the presence of high concentrations of undissociated acids; here, the variation is likely due to increasing intervals between the concentrations at the top end of the range.

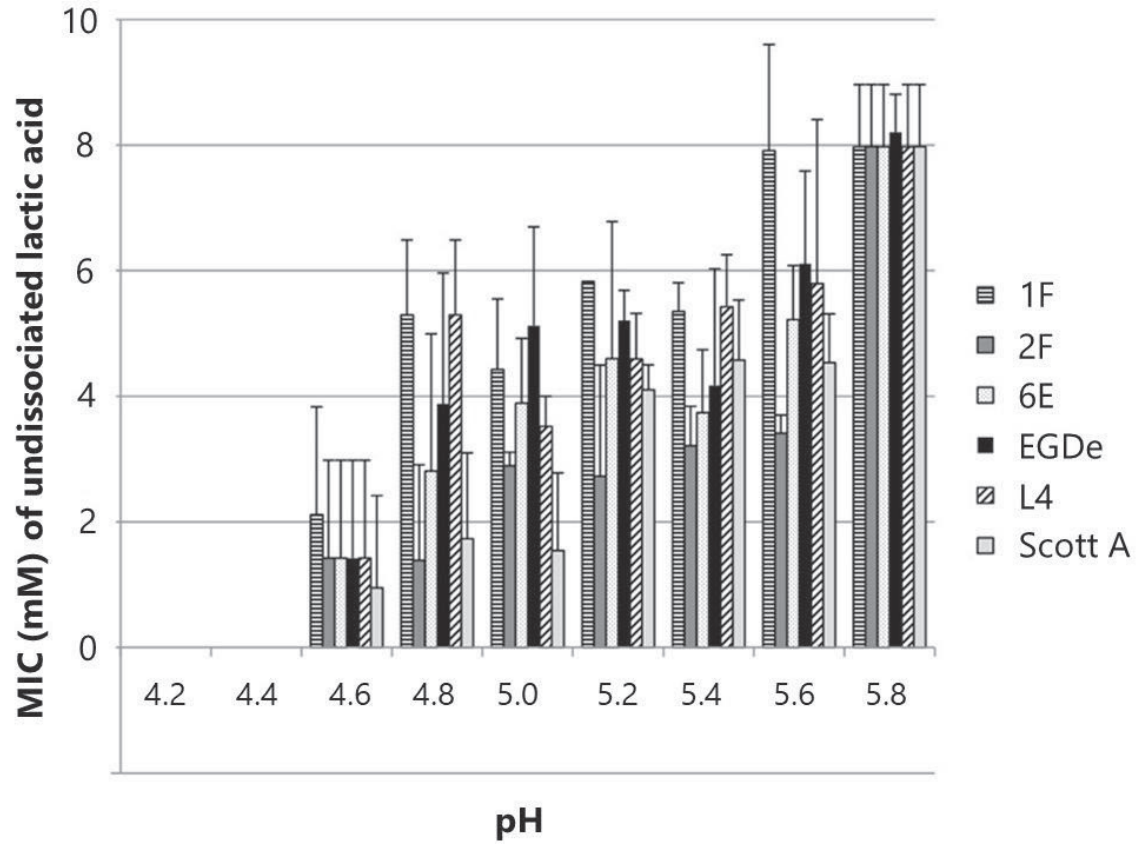

Fig. 5.1 Average MIC of undissociated lactic acid (mM) for L. monocytogenes strains 1F, 2F, 6E, EGDe, L4 and Scott $\mathrm{A}$ at $\mathrm{pH}$ values ranging from 4.2 to 5.8 , determined in $\mathrm{BHI}$ at $30^{\circ} \mathrm{C}$. Growth of L. monocytogenes was only observed at $\mathrm{pH}$ values higher than 4.4 . At $\mathrm{pH} 4.2$ and 4.4 growth was not observed in the absence or presence of lactic acid. Upper error bars are used to show the standard deviation of six measurements ( $n=6$ for each strain and for each $\mathrm{pH}$ ).

At $\mathrm{pH}$ values relevant to Gouda cheese, namely $\mathrm{pH}$ 5.2, 5.4 and 5.6, no significant differences were observed between the MICs of undissociated lactic acid per individual strain at these three $\mathrm{pH}$ values, except in the case of strain $1 \mathrm{~F}$ (Supplementary Table S2). For the individual strains, the MIC data generated at $\mathrm{pH}$ 5.2, 5.4 and 5.6 were subsequently combined in further analyses.

Differences between strains were observed: MIC values of undissociated lactic acid were significantly higher for L. monocytogenes strain $1 \mathrm{~F}$ (average MIC of $6.1 \mathrm{mM}$ ) than for strains 2F, 6E and Scott A (average MICs of 3.0, 5.1 and $4.3 \mathrm{mM}$, respectively), but not significantly higher or lower than the MICs for strains EGDe and L4 (average MICs of 5.5 and $5.6 \mathrm{mM}$ ) (Supplementary Table S4). These findings indicate that strain variation contributes significantly to the observed variation in the concentrations of lactic acid that are required to inhibit growth. The average MIC of undissociated lactic acid determined at 
$\mathrm{pH}$ 5.2-5.6 for all six strains combined was $5.0 \mathrm{mM}$ with a standard deviation of $1.5 \mathrm{mM}$, as seen in dataset 1 and 2 (Supplementary Table S4). The highest value observed in this $\mathrm{pH}$ range was $9.0 \mathrm{mM}$ (Fig. 5.1).

The cumulative frequency plot of the MICs of undissociated lactic acid at pH 5.2-5.6 obtained in this study and MICs reported in literature are presented in Fig. 5.2A. The previously reported MICs are in the same range as the ones determined in this study. The small increments in consecutive concentrations of undissociated lactic acid used in this study resulted in more accurate estimations of the actual MICs for L. monocytogenes (Fig. $5.2 A)$.

At a temperature commonly used during cheese ripening, namely $12{ }^{\circ} \mathrm{C}$, the MICs of undissociated lactic acid for L. monocytogenes after one month of incubation were not significantly different $(p>0.05$ ) from those determined after incubation for one month at $30{ }^{\circ} \mathrm{C}$ in the $\mathrm{pH}$ range 5.2-5.6. When taking all data over the full $\mathrm{pH}$ range tested into account, i.e. at $\mathrm{pH} 4.6-5.8$, the average MICs were slightly lower at $12{ }^{\circ} \mathrm{C}(3.2 \mathrm{mM}$ on average) than at $30^{\circ} \mathrm{C}$ ( $3.5 \mathrm{mM}$ on average) (see Supplementary Table S1, $\mathrm{p}=0.02$ ). Similar effects were seen by Houtsma (1996) who reported lower MICs of undissociated lactic acid for $L$. innocua at $4{ }^{\circ} \mathrm{C}$ after three weeks than at 10,20 , or $30^{\circ} \mathrm{C}$.

MICs of undissociated lactic acid for strains EGDe and Scott A were significantly lower in the presence of sodium chloride together with calcium chloride at concentrations relevant to cheese $(0.20 \mathrm{M}$ and $0.36 \mathrm{M}$, respectively) than in the absence of these added salts or in the presence of these salts added individually. For the other four strains, no significant differences were observed (results not shown). Hence, the effect of sodium chloride and calcium chloride on the MIC of undissociated lactic acid for L. monocytogenes in cheese appears overall limited, but may be strain dependent.

For undissociated acetic acid, the average MIC for all six L. monocytogenes strains tested in $\mathrm{pH}$ range $5.2-5.6$ was $19.0 \mathrm{mM}$ with a standard deviation of $6.5 \mathrm{mM}$. The highest MIC observed was $30.2 \mathrm{mM}$ (Fig. 5.2B). The average MIC at pH 5.6 was $20.7 \mathrm{mM}$, which was significantly higher than the average MICs of undissociated acetic acid at pH 5.2 and 5.4 (18.0 and $17.7 \mathrm{mM}$ ). The consecutive MIC intervals of acetic acid were larger at $\mathrm{pH} 5.6$ than at $\mathrm{pH} 5.2$ and 5.4 (data not shown), which might result in greater deviations between the determined and the true MICs at $\mathrm{pH} 5.6$ than at $\mathrm{pH} 5.2$ and 5.4. The MIC for L. monocytogenes strain Scott A $(11.6 \mathrm{mM})$ was significantly lower than the MICs for strains 1F, 2F, 6E, EGDe and L4 (18.3 - 21.8 mM; see Supplementary Table S4). The MICs of undissociated acetic acid are in line with the MICs in previous studies for L. monocytogenes (Fig. 5.2B), which varied from 6.2 to $43.9 \mathrm{mM}$, with an average of 19.7 mM (Ahamad \& Marth, 1989; Conner et al., 1990; Coroller et al., 2005; Vasseur et al., 1999; Young and Foegeding, 1993). 


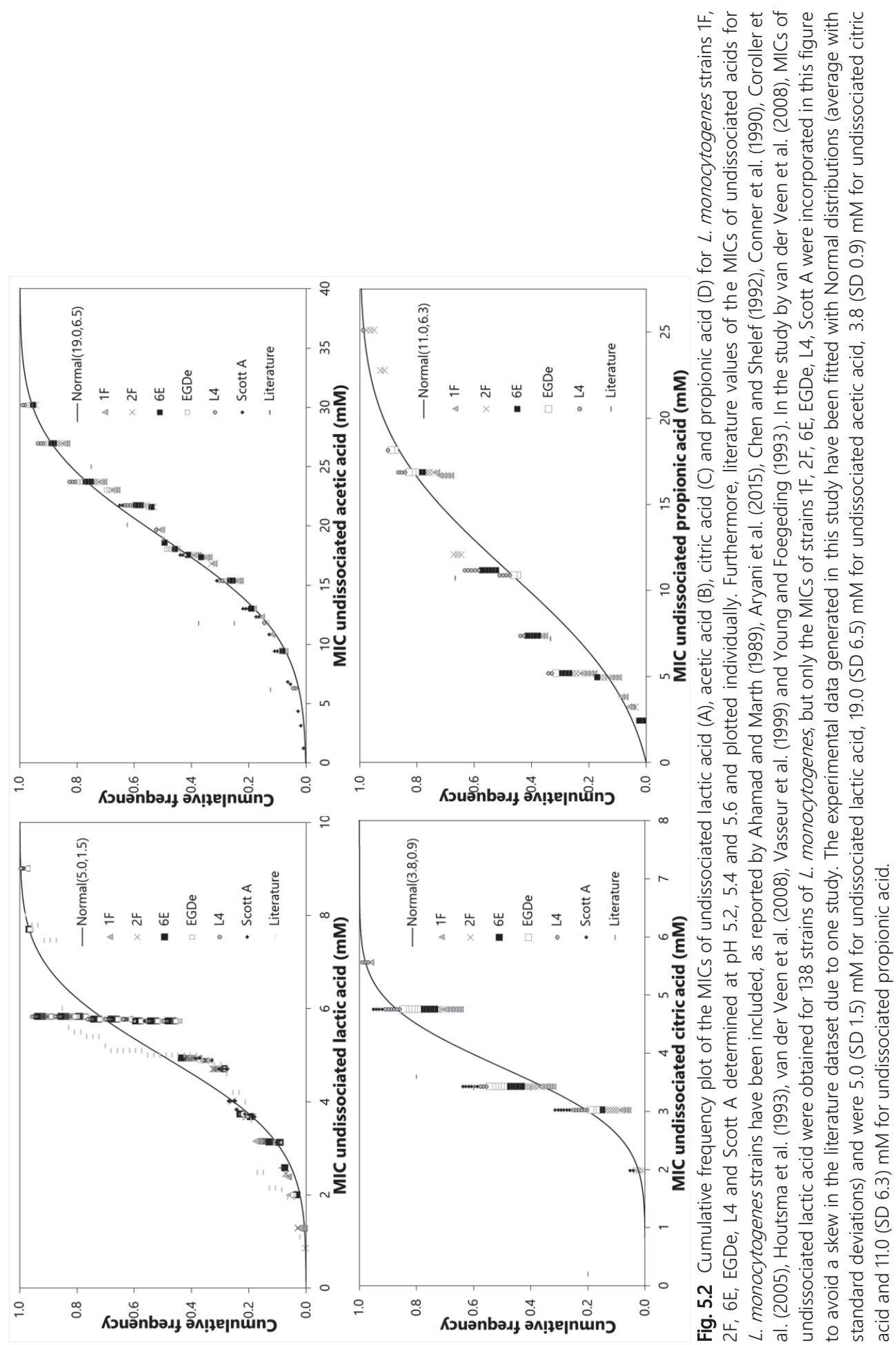


For undissociated citric acid, the average MIC value for all six strains of $L$. monocytogenes tested in $\mathrm{pH}$ range 5.2-5.6 was $3.8 \mathrm{mM}$ with a standard deviation of $0.9 \mathrm{mM}$ (Supplementary Table S4) and a highest MIC of $5.6 \mathrm{mM}$ (Fig. 5.2C). The MIC for strain 2F (3.3 $\mathrm{mM}$ on average) was significantly lower than that of strains $1 \mathrm{~F}$ and $\mathrm{L} 4$ ( 4.0 and $4.1 \mathrm{mM}$ on average). For strains $6 \mathrm{E}, \mathrm{EGDe}$ and Scott $\mathrm{A}$, the MIC values of undissociated citric acid (3.4 to $3.9 \mathrm{mM}$ ) did not differ significantly from the MICs for 1F, 2F and L4 (Supplementary Table S4). The MICs determined for undissociated citric acid in this study are similar to or higher than the previously reported MICs of 3.4 mM (Ahamad \& Marth, 1989), 0.2, and 3.6 $\mathrm{mM}$ (Coroller et al., 2005). The MIC reported by Ahamad and Marth (1989) was determined at $\mathrm{pH} 4.5$, which is near the $\mathrm{pH}$ limit for growth of L. monocytogenes. This could explain the lower MIC observed in that study compared with those found in this study. Coroller et al. (2005) determined the MICs of undissociated citric acid at a concentration range of 0 $300 \mathrm{mM}$ total citric acid and at $\mathrm{pH} 5.0$ to 7.0. Only the lowest and highest MICs of undissociated citric acid were reported, but not the consecutive concentrations of undissociated citric acid tested. This complicates a direct comparison between MIC values of undissociated citric acid obtained by Coroller et al. (2005) and the ones established in this study.

For undissociated propionic acid, the average MIC for the L. monocytogenes strains tested in $\mathrm{pH}$ range $5.2-5.6$ was $11.0 \mathrm{mM}$ with a standard deviation of $6.3 \mathrm{mM}$ (Supplementary Table S4). The highest value observed was $25.1 \mathrm{mM}$ (Fig. 5.2D). The MICs for strains $1 \mathrm{~F}$ and $6 \mathrm{E}$ ( 8.2 and $8.3 \mathrm{mM}$ on average) were consistent with the MICs previously determined by Coroller et al. (2005) of 7.2 and 10.7 mM (Fig. 5.2D), but were significantly different from the MICs for strains 2F and EGDe (average MICs of 13.4 and $15.3 \mathrm{mM}$, respectively). The MIC of undissociated propionic acid for strain L4 (average MIC of $12.2 \mathrm{mM}$ ) was not significantly different from the other strains (Supplementary Table S4).

Growth of L. monocytogenes has not been observed in challenge studies using Gouda and Swiss-type cheese; in fact, inactivation was observed after extended ripening times (Bachmann \& Spahr, 1995; Buazzi, Johnson, \& Marth, 1992; Northolt, Vecht, Toepoel, Soentoro, \& Wisselink, 1988; Wemmenhove, Stampelou, van Hooijdonk, Zwietering, \& Wells-Bennik, 2013; Wemmenhove, Beumer, van Hooijdonk, Zwietering, \& Wells-Bennik, 2014). In Dutch-type cheeses, several short-chain organic acids can be found, such as lactic acid, acetic acid, citric acid and propionic acid. Cow's milk naturally contains 0.05-0.8 mM acetate, $9 \mathrm{mM}$ citrate and $<0.4 \mathrm{mM}$ lactate (total acid) and has a $\mathrm{pH}$ of around 6.5 to 6.7 (Walstra \& Jenness, 1984). It also contains lactose, which starter lactic acid bacteria used in cheese manufacturing can convert to lactic acid (Fox, McSweeney, Cogan, \& Guinee, 2004a). In Gouda cheese ripened for 4 weeks or longer, concentrations of total lactic acid and acetic acid were 13.9 and $1.1 \mathrm{~g} \mathrm{~kg}^{-1}$, respectively, whereas citric acid and propionic acid were absent (Wemmenhove et al., 2013). The estimated concentration of 
undissociated lactic acid in the water phase of Gouda cheese is $9.2 \mathrm{mM}$ (Supplementary Table S5), thus higher than the average and highest MICs needed for full inhibition of growth of L. monocytogenes (i.e. $5.0 \mathrm{mM}$ and $9.0 \mathrm{mM}$, respectively). The estimated concentration of undissociated acetic acid in Gouda is $9.0 \mathrm{mM}$ (Supplementary Table S5), which is lower than the average MIC (19.0 mM) needed for full inhibition of growth of L. monocytogenes. Therefore, lactic acid appears to be a critical factor for inhibition of growth of this pathogen in Gouda cheese.

In semi-hard cheeses with propionic acid fermentation, such as Maasdam and Swiss-type cheese, propionic acid bacteria convert the lactic acid produced by lactic acid bacteria to other organic acids during ripening, resulting in an increase of the pH from 5.3 to 5.8 (Fox, McSweeney, Cogan, \& Guinee, 2004b). Total concentrations of $3.5 \mathrm{~g}$ lactic acid per kg cheese, $2.0 \mathrm{~g}$ acetic acid per $\mathrm{kg}$ cheese and $5.0 \mathrm{~g}$ propionic acetic acid per $\mathrm{kg}$ cheese have been reported in a 35-day old Swiss-type cheese (Fox et al., 2004a). This results in estimated concentrations of $0.95 \mathrm{mM}$ undissociated lactic acid, $8.1 \mathrm{mM}$ undissociated acetic acid, and $17.3 \mathrm{mM}$ undissociated propionic acid in the water phase of the cheese, respectively (Supplementary Table S5). Given the MICs of these acids (average $5.0 \mathrm{mM}$, $19.0 \mathrm{mM}$ and $11.0 \mathrm{mM}$ undissociated acid, respectively), propionic acid is thought to play an important role in inhibition of growth of L. monocytogenes during ripening of such cheeses.

\subsection{Conclusions}

MICs of undissociated lactic acid for six strains of $L$. monocytogenes were generally lower at $\mathrm{pH}$ values approaching the $\mathrm{pH}$ limit for growth of this bacterium (i.e. $\mathrm{pH}$ 4.4) than at $\mathrm{pH}$ values above 5.2. MICs of undissociated lactic acid, acetic acid, citric acid and propionic acid for L. monocytogenes at $\mathrm{pH}$ values relevant to cheese (in the range 5.2 to 5.6 ) showed variations for each of the acids, which could mostly be attributed to strain variation. Undissociated lactic acid is expected to have a substantial inhibitory effect on growth of L. monocytogenes in Gouda cheese, whereas propionic acid is expected to play an important role in semi-hard cheeses that undergo propionic acid fermentation. The generated data on MICs of undissociated organic acids in Dutch-type cheeses for different strains of $L$. monocytogenes can be used to improve risk assessments. 


\section{Acknowledgements}

The authors would like to thank Ms. M.E. Hagen for her help with the statistical analysis. This work was supported by the Dutch Dairy Board and the Dutch Dairy Organisation (NZO) (The Hague, The Netherlands). 


\section{References}

Abee, T., Koomen, J., Metselaar, K.I., Zwietering, M.H., \& den Besten, H.M. (2016). Impact of pathogen population heterogeneity and stress-resistant variants on food safety. Annual Review of Food Science and Technology 7:439-456.

Ahamad, N., \& Marth, E.H. (1989). Behavior of Listeria monocytogenes at 7, 13, 21, and $35{ }^{\circ} \mathrm{C}$ in tryptose broth acidified with acetic, citric, or lactic acid. Journal of Food Protection 52:688-695.

Aryani, D.C., den Besten, H.M.W., Hazeleger, W.C., \& Zwietering, M.H. (2015). Quantifying strain variability in modeling growth of Listeria monocytogenes. International Journal of Food Microbiology 208:19-29.

Bachmann, H.P., \& Spahr, U. (1995). The fate of potentially pathogenic bacteria in Swiss hard and semihard cheeses made from raw milk. Journal of Dairy Science 78:476-483.

Buazzi, M.M., Johnson, M.E., \& Marth, E.H. (1992). Survival of Listeria monocytogenes during the manufacture and ripening of Swiss cheese. Journal of Dairy Science 75:380-386.

Chen, N., \& Shelef, L.A. (1992). Relationship between water activity, salts of lactic acid, and growth of Listeria monocytogenes in a meat model system. Journal of Food Protection 55:574-578.

Conner, D.E., Scott, V.N., \& Bernard, D.T. (1990). Growth, inhibition, and survival of Listeria monocytogenes as affected by acidic conditions. Journal of Food Protection 53:652-655.

Coroller, L., Guerrot, V., Huchet, V., Le Marc, Y., Mafart, P., Sohier, D., \& Thuault, D. (2005). Modelling the influence of single acid and mixture on bacterial growth. International Journal of Food Microbiology 100:167-178.

Dawson, R.M.C., Elliott, D.C., Elliott, W.H., \& Jones, K.M. (1986). Data for biochemical research (3rd ed.). Oxford: Clarendon Press, UK. pp. 1-580.

Fox, P.F., McSweeney, P.L.H., Cogan, T.M., \& Guinee, T.P. (2004a). Cheese: chemistry, physics and microbiology (3rd ed.). Vol. 1. London, UK: Elsevier Academic Press. pp. 1-617.

Fox, P.F., McSweeney, P.L.H., Cogan, T.M., \& Guinee, T.P. (2004b). Cheese: chemistry, physics and microbiology (3rd ed.). Vol. 2. London, UK: Elsevier Academic Press. pp. 1-434.

Houtsma, P.C., de Wit, J.C., \& Rombouts, F.M. (1993). Minimum inhibitory concentration (MIC) of sodium lactate for pathogens and spoilage organisms occuring in meat products. International Journal of Food Microbiology 20:247-257.

Houtsma, P.C. (1996). The antimicrobial activity of sodium lactate. Wageningen UR/University of Groningen, Wageningen, The Netherlands, PhD thesis. pp. 1-125.

ICMSF (1996). Micro-organisms in foods. Vol. 5. Characteristics of microbial pathogens (1st ed.). pp. 1513. London: Blackie Academic \& Professional, UK.

Millet, L., Saubusse, M., Didienne, R., Tessier, L., \& Montel, M.C. (2006). Control of Listeria monocytogenes in raw-milk cheeses. International Journal of Food Microbiology 108:105-114.

Mitchell, P. (1961). Coupling of phosphorylation to electron and hydrogen transfer by a chemi-osmotic type of mechanism. Nature 191:144-148. 
Northolt, M.D., Vecht, U., Toepoel, L., Soentoro, P.S.S., \& Wisselink, H.J. (1988). Listeria monocytogenes. heat resistance and behaviour during storage of milk and whey and making of Dutch types of cheese. Netherlands Milk Dairy Journal 42:207-219.

van der Veen, S., Moezelaar, R., Abee, T., \& Wells-Bennik, M.H.J. (2008). The growth limits of a large number of Listeria monocytogenes strains at combinations of stresses show serotype- and nichespecific traits. Journal of Applied Microbiology 105:1246-1258.

Vasseur, C., Baverel, L., Hébraud, M., \& Labadie, J. (1999). Effect of osmotic, alkaline, acid or thermal stresses on the growth and inhibition of Listeria monocytogenes. Journal of Applied Microbiology 86:469-476.

Vazquez-Boland, J.A., Kuhn, M., Berche, P., Chakraborty, T., Domínguez-Bernal, G., Goebel, W., González-Zorn, B., Wehland, J., \& Kreft, J. (2001). Listeria pathogenesis and molecular virulence determinants. Clinical Microbiological Reviews 14:584-640.

Walstra, P., \& Jenness, R. (1984). Dairy chemistry and physics, New York: John Wiley, USA. pp. 1-467.

Wemmenhove, E., Stampelou, I., van Hooijdonk, A.C.M., Zwietering, M.H., \& Wells-Bennik, M.H.J. (2013). Fate of Listeria monocytogenes in Gouda microcheese: No growth, and substantial inactivation after extended ripening times. International Dairy Journal 32:192-198.

Wemmenhove, E., Beumer, R.R., van Hooijdonk, A.C.M., Zwietering, M.H., \& Wells-Bennik, M.H.J. (2014). The fate of Listeria monocytogenes in brine and on Gouda cheese following artificial contamination during brining. International Dairy Journal 39:253-258.

Young, K.M., \& Foegeding, P.M. (1993). Acetic, lactic and citric acids and pH inhibition of Listeria monocytogenes Scott A and the effect on intracellular pH. Journal of Applied Bacteriology 74:515-520. 


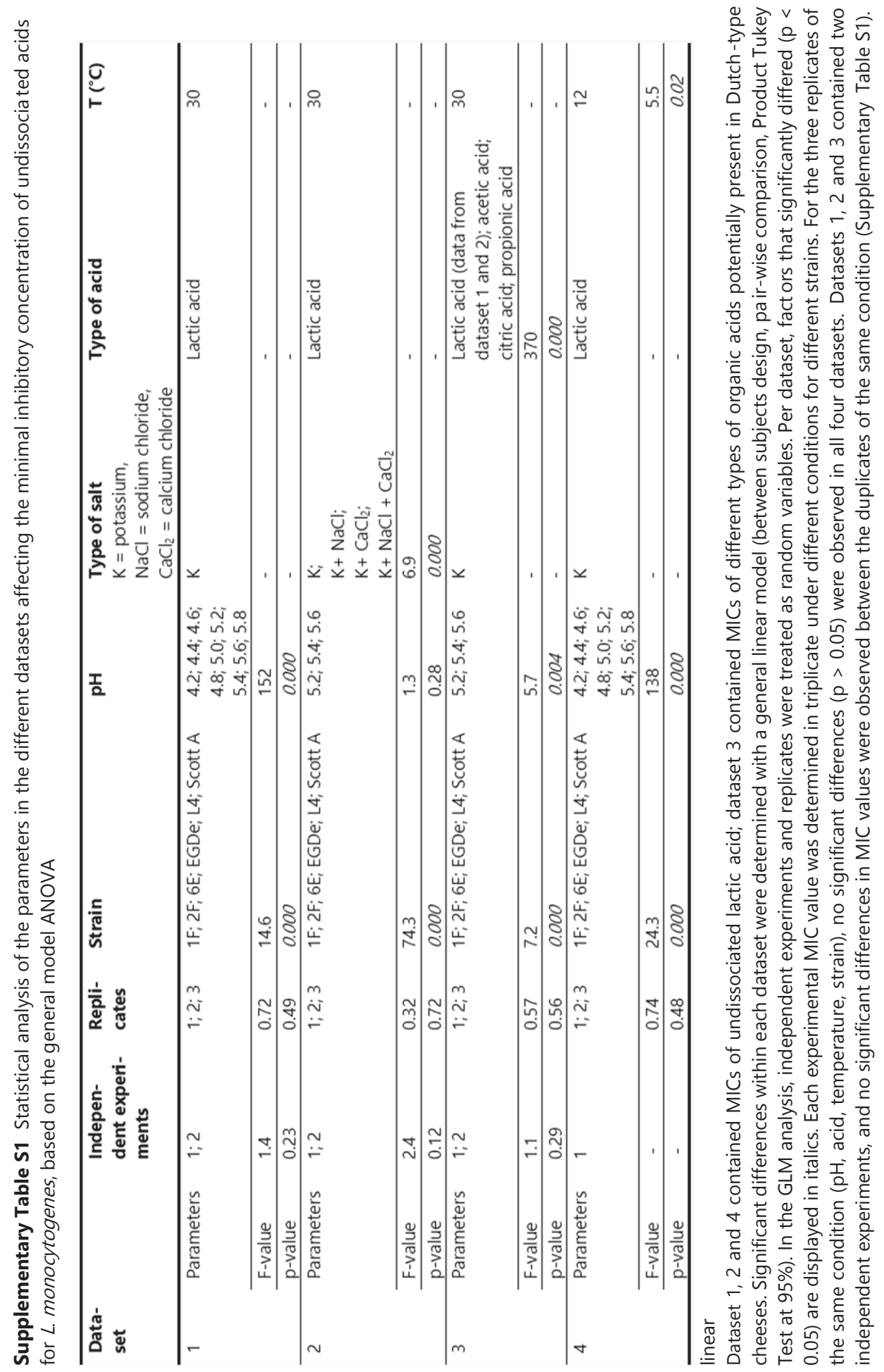




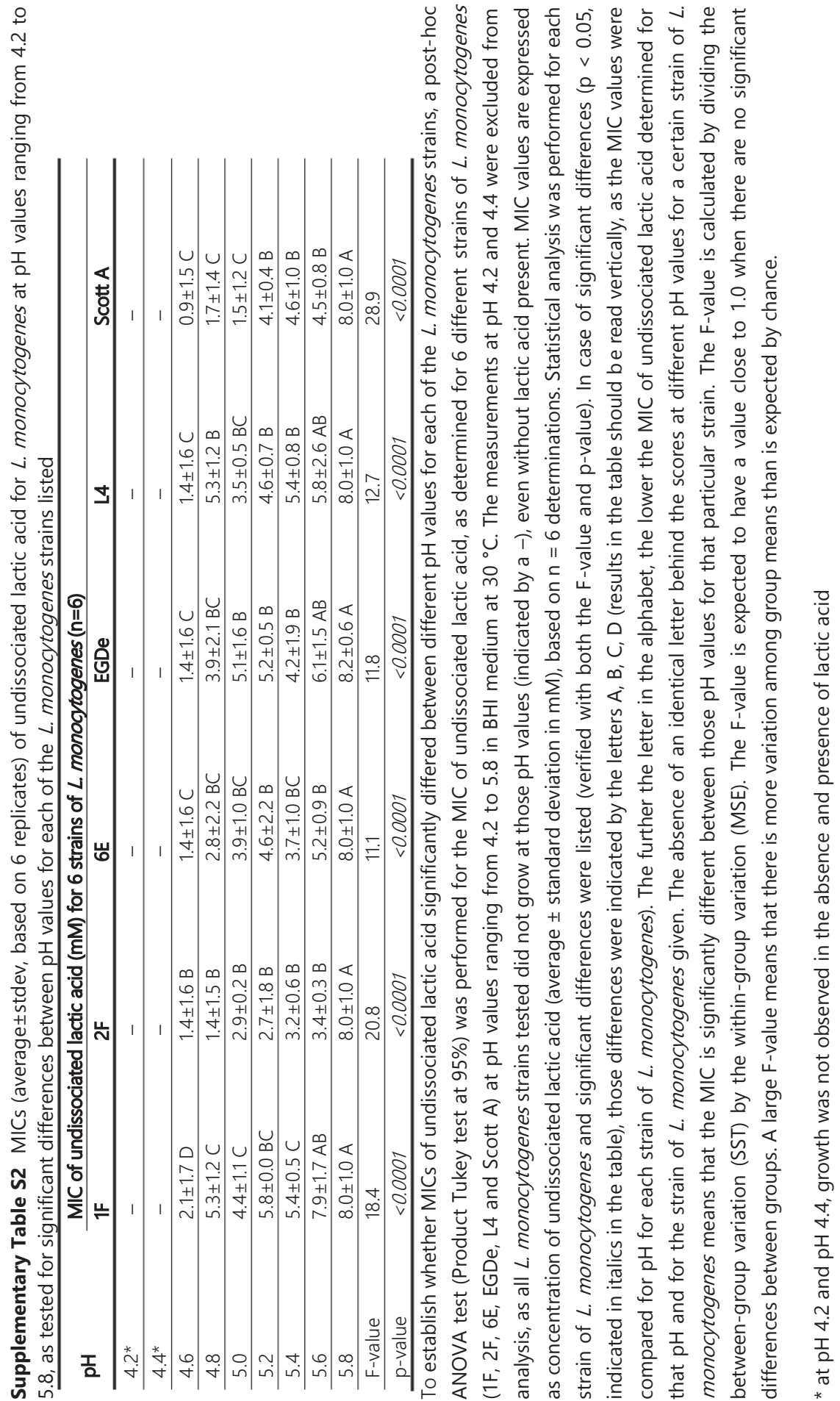




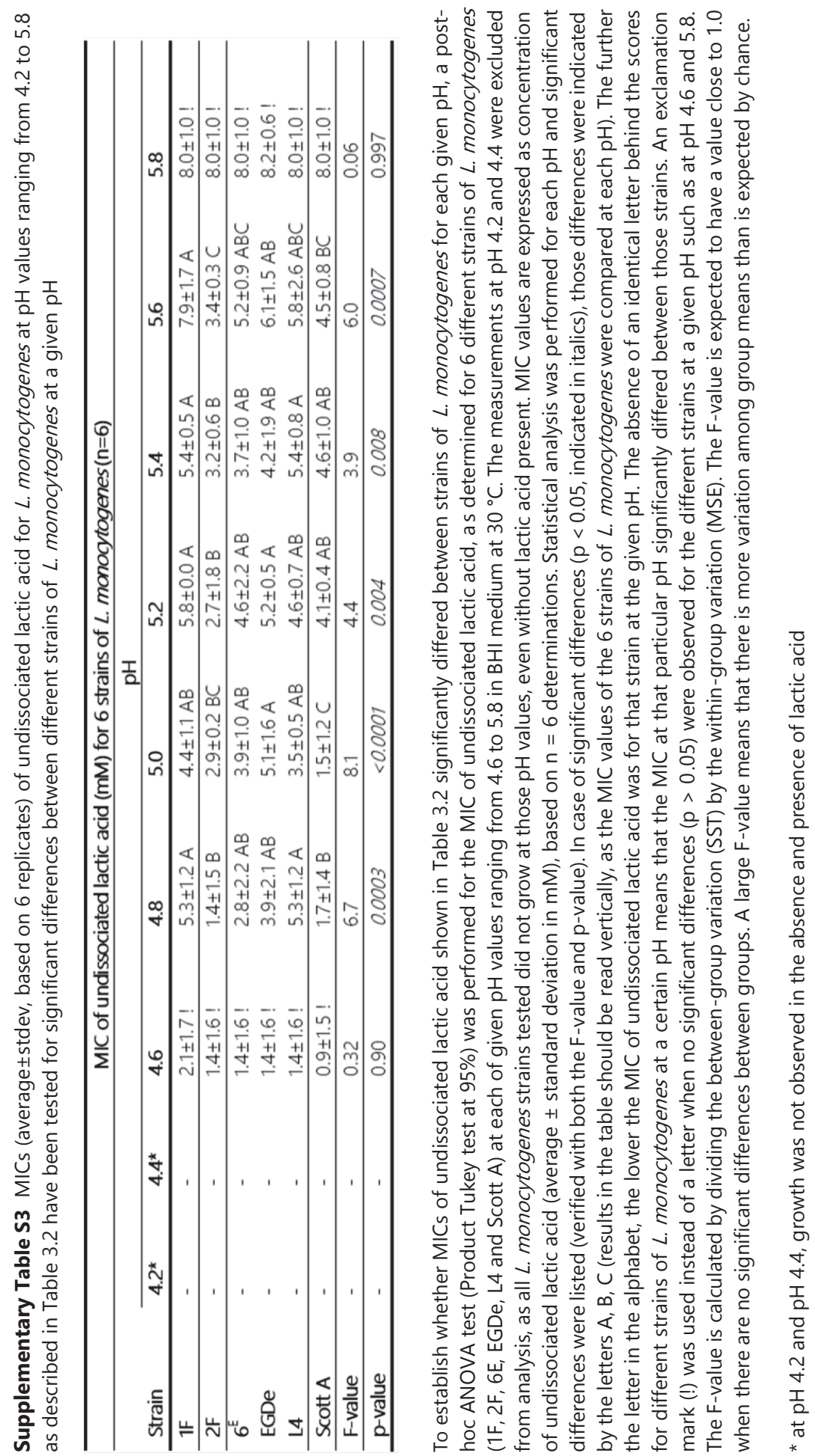




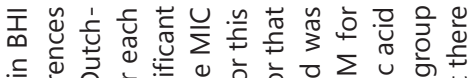

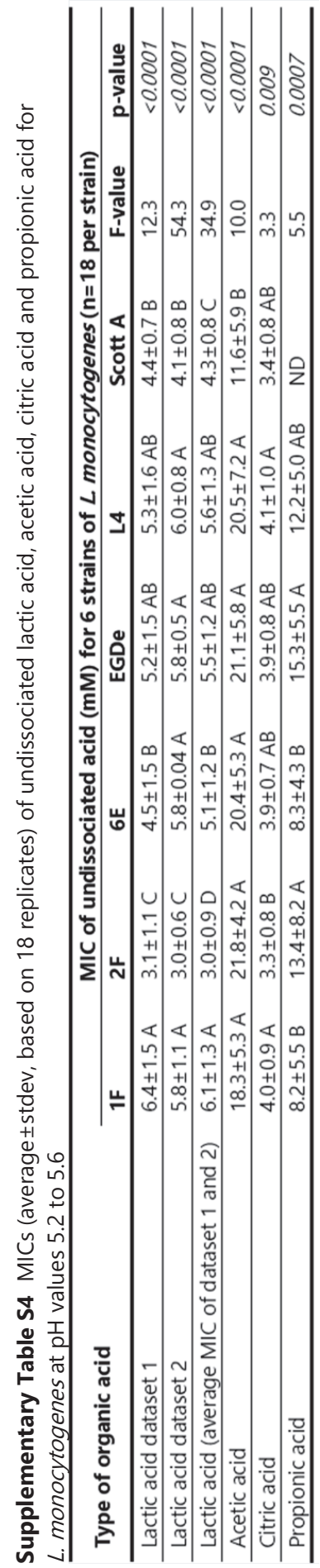

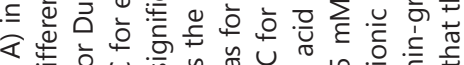

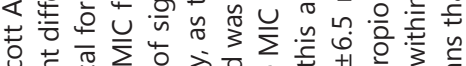

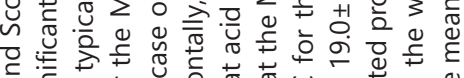

ป

बे

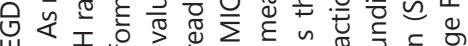

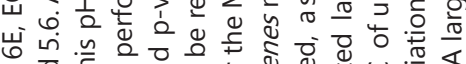

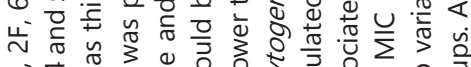

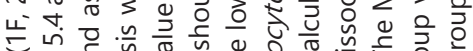

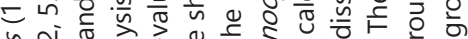

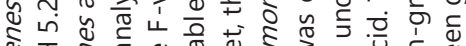

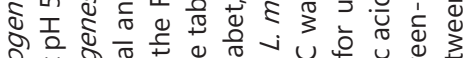

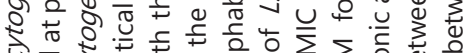

ऽ。

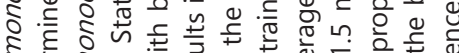

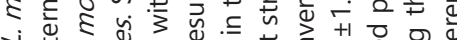

ن

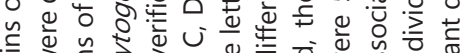

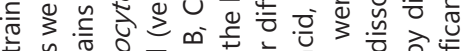

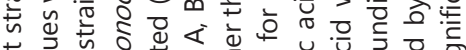

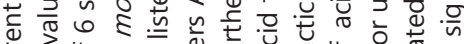

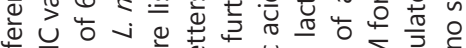

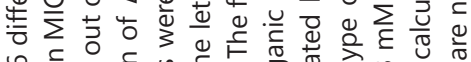

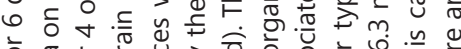

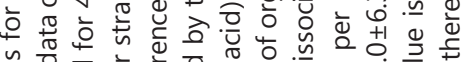

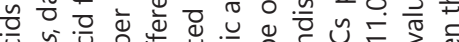

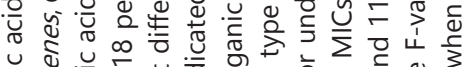

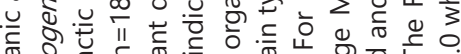

ปั

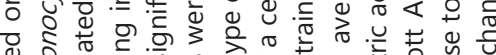

d

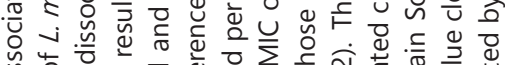

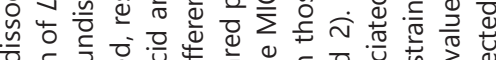

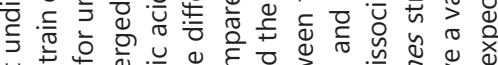

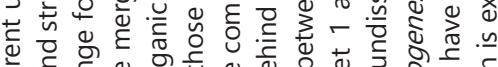

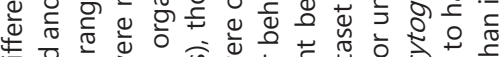

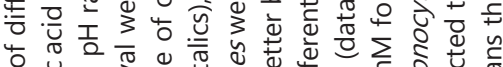

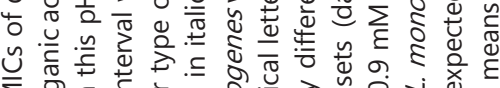

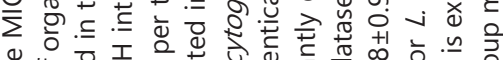

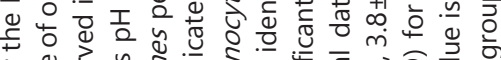

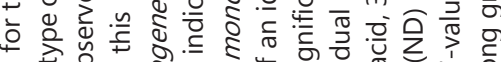

$y=0$

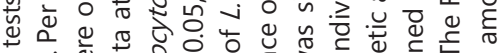

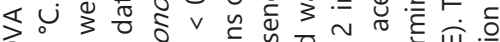

o일

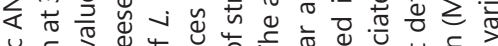

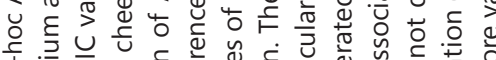

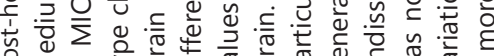

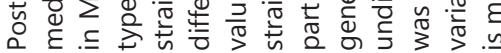




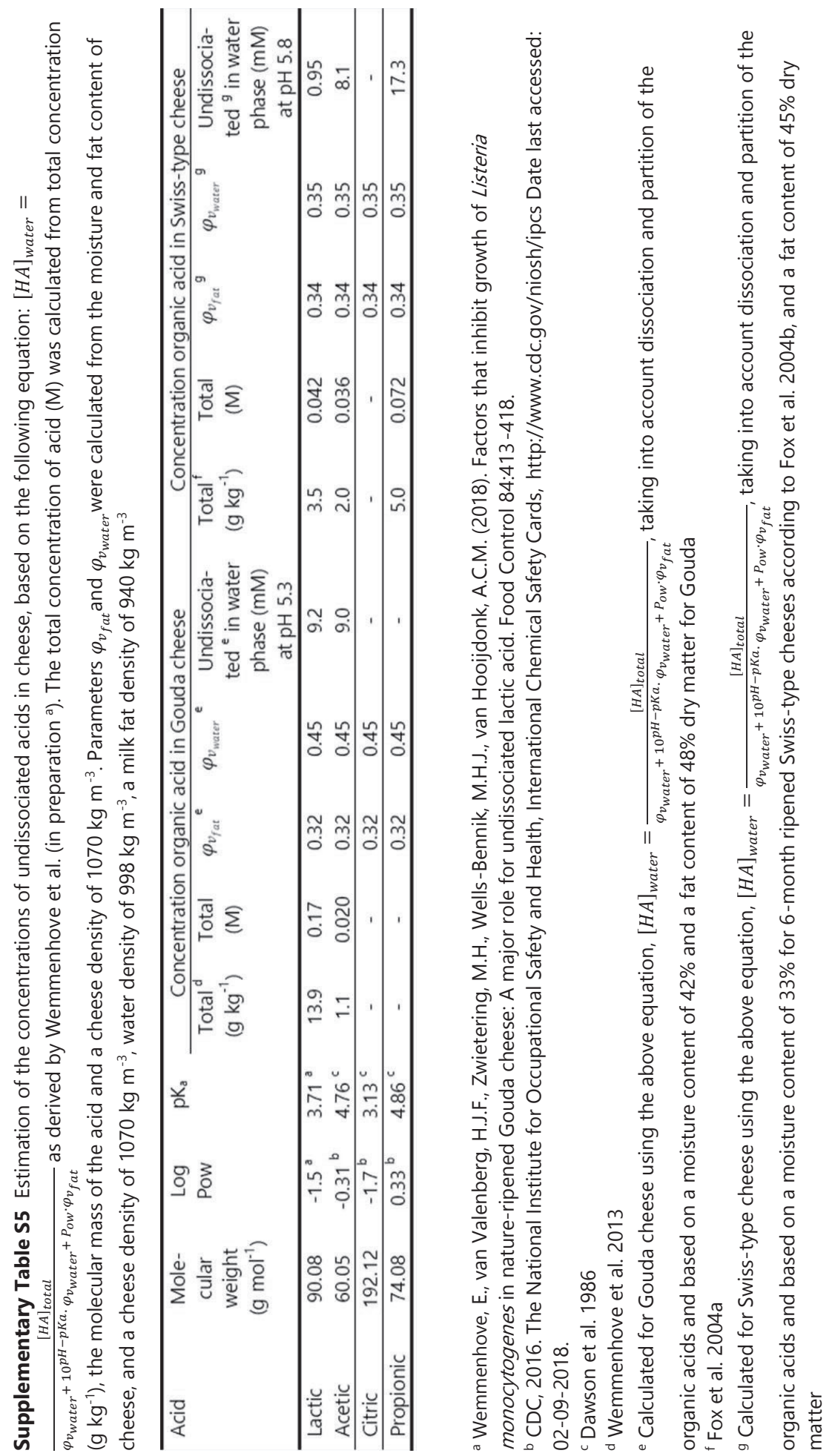




\title{
Chapter 6
}

\section{Factors that inhibit growth of Listeria monocytogenes in nature- ripened Gouda cheese: A major role for undissociated lactic acid}

\author{
E. Wemmenhove, H.J.F. van Valenberg, A.C.M. van Hooijdonk, M.H.J. Wells-Bennik, \\ M.H. Zwietering
}

\begin{abstract}
In this study, factors relevant to nature-ripened Gouda cheese were evaluated for their potential to inhibit growth of Listeria monocytogenes. Factors included water activity, $\mathrm{pH}$, undissociated acetic and lactic acid, diacetyl, free fatty acids, lactoferrin, nitrate, nitrite and nisin. In addition, the effect of temperature was evaluated. For each factor, the actual concentrations and values relevant to Gouda cheese were obtained and the inhibitory effect of these individual factors on growth of $L$. monocytogenes was assessed. This evaluation revealed that undissociated lactic acid is the most important factor for growth inhibition of L. monocytogenes in Gouda cheese and that, additionally, low water activity as present in the cheese rind and after prolonged ripening times can also cause full growth inhibition. Gouda cheeses have a typical total lactic acid content of $1.47 \% \mathrm{w} / \mathrm{w}$. In a 2 week old Gouda cheese, with a pH value of 5.25 and a moisture content of $42 \% \mathrm{w} / \mathrm{w}$, the concentration of undissociated lactic acid in the water phase is $10.9 \mathrm{mM}$. Growth of L. monocytogenes is not supported when the undissociated lactic acid concentration is $>6.35 \mathrm{mM}$. Concentrations of undissociated lactic acid in the water phase of Gouda cheese will be higher than this value when the total lactic acid content is $>0.86 \% \mathrm{w} / \mathrm{w}$ at a $\mathrm{pH}<5.25$ (relevant to young Gouda cheese), or $>1.26 \% \mathrm{w} / \mathrm{w}$ at a $\mathrm{pH}<5.50$ for mature Gouda cheese (moisture content of $35 \% \mathrm{w} / \mathrm{w}$ ). This study underlines the importance of undissociated lactic acid as growth inhibitor for L. monocytogenes in Gouda cheese.
\end{abstract}

This chapter was published in Food Control (2018) 84:413-418 


\subsection{Introduction}

Listeria monocytogenes is a foodborne pathogen and the causative agent of listeriosis (Lou \& Yousef, 2000). L. monocytogenes is able to form biofilms (Pan, Breidt, \& Kathariou, 2006), can grow at low temperatures and can adapt to highly acidic or saline conditions (Cole, Jones, \& Holyoak, 1990). This pathogen is a concern to the food industry, in particular in ready-to-eat (RTE) products.

Nature-ripened Dutch-type Gouda cheese is cheese that is coated after production and then dried during ripening. This study focused on the vast majority of Dutch-type Gouda cheeses which are produced using mesophilic starter cultures that primarily consist of strains of Lactococcus lactis subsp. cremoris and Lactococcus lactis subsp. lactis, but may also contain Leuconostoc species and Lactococcus lactis subsp. lactis var. diacetylactis (Stadhouders, 1974). Nature-ripened Dutch-type Gouda cheese as produced on an industrial scale by the Dutch dairy industry is made from pasteurized cow's milk and is a RTE food. To avoid contamination of cheese with L. monocytogenes, raw milk is subjected to minimal pasteurization conditions of $15 \mathrm{~s} 72{ }^{\circ} \mathrm{C}$ as one of the options according to regulation (EC) No 1662/2006 (European Commission, 2006) amending regulation (EC) No $853 / 2004$ laying down specific hygiene rules for food of animal origin (European Commission, 2004). The estimated concentration of L. monocytogenes in raw milk is low: Meyer-Broseta, Diot, Bastian, Rivière, \& Cerf (2003) reported maximum concentrations of $0.1 \mathrm{cfu} \mathrm{mL} \mathrm{L}^{-1}$ in $7.7 \%$ of the raw milk samples $\left(<0.04 \mathrm{cfu} \mathrm{mL}^{-1}\right.$ for the remaining $92.3 \%$ of

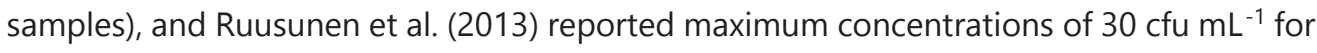

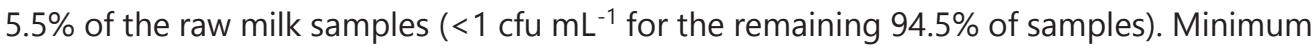
pasteurization of $15 \mathrm{~s}$ at $72{ }^{\circ} \mathrm{C}$ leads to a reduction of L. monocytogenes with $10.4 \mathrm{log}$ units based on the average $D_{72^{\circ} \mathrm{C}}$ (and a minimum inactivation of 2.7 logs based on the 95\% prediction interval of $D_{72^{\circ} \mathrm{C}}$ [den Besten \& Zwietering, 2012; ILSI, 2012]). Contamination of cheese during further processing and storage is furthermore limited by applying good manufacturing processing conditions, and sampling schemes are in place to verify absence of $L$. monocytogenes in processing areas, on equipment and on finished products.

Microbiological food safety criteria have been set in European Union regulation EC 2073/2005, which includes criteria for L. monocytogenes in RTE foods for three different RTE food categories (European Commission, 2005). For food category 1.1, "Ready-to-eat foods intended for infants and ready-to-eat foods for special medical purposes" this is absence in $25 \mathrm{~g}(\mathrm{n}=10)$ for products placed on the market during shelf life. For food category 1.2, "Ready-to-eat foods able to support the growth of L. monocytogenes, other than those intended for infants and for special medical purposes" the maximum limit is $100 \mathrm{cfu} \mathrm{g}^{-1}(n=5)$ for products placed on the market during their shelf-life. This criterion 
shall apply if the manufacturer is able to demonstrate, to the satisfaction of the competent authority, that the product will not exceed the limit $100 \mathrm{cfu} \mathrm{g}^{-1}$ throughout the shelf-life. The operator may fix intermediate limits during the process that must be low enough to guarantee that the limit of $100 \mathrm{cfu} \mathrm{g}^{-1}$ is not exceeded at the end of shelf-life. For food category 1.2, an alternative criterion may apply, namely, absence in $25 \mathrm{~g}(\mathrm{n}=5)$ before the food has left the immediate control of the food business operator, who has produced it; this criterion shall apply to products before they have left the immediate control of the producing food business operator, when he is not able to demonstrate, to the satisfaction of the competent authority, that the product will not exceed the limit $100 \mathrm{cfu} \mathrm{g}^{-1}$ throughout the shelf-life. Lastly, for food category 1.3, "Ready-to-eat foods unable to support the growth of L. monocytogenes, other than those intended for infants and for special medical purposes" the maximum limit is $100 \mathrm{cfu} \mathrm{g}^{-1}(n=5)$ for products placed on the market during their shelf-life.

When a RTE product intended for consumption by the general population has a $\mathrm{pH} \leq 4.4$ or $\mathrm{a}_{\mathrm{w}} \leq 0.92$, a $\mathrm{pH} \leq 5.0$ and $\mathrm{a}_{\mathrm{w}} \leq 0.94$, or a shelf life $<5$ days, the product falls in category 1.3. If this is not the case, evidence for no growth potential can be obtained by predictive mathematical modelling, durability tests and/or challenge tests (European Commission, 2005).

In the case of Dutch-type Gouda cheese, the $\mathrm{pH}$ is $>5.0$ and $\mathrm{a}_{\mathrm{w}}>0.94$. Nevertheless, various challenge studies have shown that $L$. monocytogenes does not grow within or on this cheese (Northolt, Vecht, Toepoel, Soentoro, \& Wisselink, 1988; Wemmenhove, Beumer, van Hooijdonk, Zwietering, \& Wells-Bennik, 2014; Wemmenhove, Stampelou, van Hooijdonk, Zwietering, \& Wells-Bennik, 2013). In this study, the impact of growthinhibiting factors that are present in Gouda cheese or relevant to storage of Gouda cheese was evaluated for growth inhibition of L. monocytogenes, and the predictions were compared with the fate of this bacterium in Gouda as determined in previous challenge studies. Factors with potential to inhibit growth in this evaluation included temperature $(\mathrm{T}), \mathrm{pH}$, water activity $\left(\mathrm{a}_{\mathrm{w}}\right)$, undissociated acetic acid, undissociated lactic acid, diacetyl, free fatty acids, lactoferrin, nitrate, nitrite and nisin. Data were obtained from literature, or experimentally obtained in absence of data in the literature. This evaluation leads to a better understanding of the most important factors in Gouda cheese that result in growth inhibition of L. monocytogenes. 


\subsection{Materials and methods}

\subsubsection{Comparison of growth-inhibiting potentials}

Components that are present in Gouda cheese were evaluated individually for their potential to inhibit growth of L. monocytogenes and ranked in order of importance for growth inhibition. The evaluation was based on the concentration present in cheese, the concentration needed for inhibition of growth of L. monocytogenes in culture medium and/or cheese, and the Gamma factor formula describing the relationship between the concentration in cheese and the concentration needed for inhibition of the pathogen.

\subsubsection{Data search}

For each component that had the potential to inhibit growth, the scientific literature was evaluated for data on concentrations in Gouda cheese, critical growth limits and Gamma factor formulas. Data on concentrations in Gouda cheese were obtained using a cheese handbook (Fox, McSweeney, Cogan, \& Guinee, 2004) and various literature databases (Web of Science, Scopus, PubMed) by using the search terms [cheese] AND [temperature OR water activity OR pH OR diacetyl OR lactoferrin OR nitrate OR nitrite OR nisin OR acetic acid OR lactic acid]. Data on concentrations that are minimally needed to inhibit growth of $L$. monocytogenes were obtained from publications and by using the same search terms as for data on concentrations in Gouda cheese, but by replacing the term [cheese] with [Listeria monocytogenes]. In addition, data on concentrations needed for growth inhibition were obtained from Combase (www.combase.cc) using terms ([Listeria monocytogenes]; [cheese]; minimum pH OR minimum water activity OR minimum temperature]). The obtained results were sorted on relevance, and data were extracted from the first 500 hits. Critical growth limits for $\mathrm{T}, \mathrm{a}_{\mathrm{w}}$ and $\mathrm{pH}$ in culture medium were obtained from ICMSF (1996). Additional experimental data were generated (see sections 6.2.3 and 6.2.4) when no literature data were available.

Additional data on the $\mathrm{pH}$ of Gouda after two weeks of ripening and on the total lactic acid content of Gouda ripened during 3-26 weeks were supplied by four Dutch cheeseproducing companies (BelLeerdammer, DOC kaas, FrieslandCampina and Rouveen Kaasspecialiteiten), resulting in $\mathrm{n}=24502$ data points for $\mathrm{pH}$ and $\mathrm{n}=89$ data points for the total lactic acid content. The data on $\mathrm{pH}$ as supplied by different companies were clustered, following a Posthoc test (Duncan, alpha $=0.05$, harmonized mean sample size) with SPSS Statistics (IBM, NY, US) showing alpha $>0.05$. All available data on the total 
lactic acid content obtained from cheeses of different ages were clustered, as it has previously been observed that the total lactic acid content did not change in Gouda cheese ripened for two weeks until six months (Wemmenhove et al., 2013).

Gamma factor formulas were available in literature for $\mathrm{T}, \mathrm{a}_{\mathrm{w}}, \mathrm{pH}$, undissociated lactic acid and acetic acid (Supplemental Material S1), but not for diacetyl, free fatty acids, lactoferrin, nitrate, nitrite, and nisin. For these potential factors, we assumed a linear relation between the concentration of the factor in the cheese and the degree of inhibition of growth of L. monocytogenes. The Gamma factors were calculated by dividing the concentration of the inhibiting factor in cheese by the maximum concentration needed to inhibit growth of L. monocytogenes and subtracting this fraction from 1 (as in Equation [6.5] from Supplemental Material S1).

\subsubsection{Experimental determination of concentrations of free fatty acids in Gouda cheese}

Data on the concentrations of free fatty acids present in Gouda cheese were not available in the literature. The concentrations of free fatty acids were analyzed in 2-week, 2-month and 6-month ripened Gouda cheeses ( $\mathrm{n}=12$ data points) produced by four different Dutch producers. Analysis of free fatty acids was performed in duplicate according to the method described by de Jong \& Badings (1990).

\subsubsection{Experimental assessment of concentrations of factors present in cheese with inhibitory potential}

No literature data were available on growth inhibition of L. monocytogenes by nitrate and nitrite, and insufficient data were available for growth inhibition by free fatty acids, therefore additional data were generated for these factors. The experimental design to determine the effects of additional nitrate and nitrite in Brain Heart Infusion (BHI) is described in Supplemental Material S2. Experiments to determine concentrations of free fatty acids with potential to inhibit growth of L. monocytogenes were performed with capric acid and lauric acid, as these free fatty acids reportedly have a higher inhibitory potential than other free fatty acids in culture medium (Chen, Nummer, \& Walsh, 2014; Petrone et al., 1998; Sprong, Hulstein, \& van der Meer, 2001; Wang \& Johnson, 1992;). Additional experiments were performed to investigate whether growth inhibition by free fatty acids was impaired in cheese compared with their presence in culture medium due to the presence of calcium, which may form complexes with the fatty acids (Galbraith, 
Miller, Paton, \& Thompson, 1971), and casein, which may complex the fatty acids and therewith limit the available concentrations to inhibit L. monocytogenes (Wang \& Johnson, 1992). The experiments in this study were performed in $\mathrm{BHI}$ with and without calcium chloride $\left(\mathrm{CaCl}_{2}\right)$ and Tween 80 , and in model Gouda cheeses (experimental design also described in Supplemental Material S2).

\subsubsection{Calculation of growth inhibition by lactic and acetic acid}

The Gamma factors of lactic and acetic acid were calculated according to Equations [6.5] and [6.6] in Supplemental Material S1, with the highest and lowest $[\mathrm{HLac}]_{M I C}$ and $[\text { HAcet }]_{M I C}$ in culture medium as input values, in comparison to the average $[\text { HLAc }]_{\text {water }}$ and $[\text { HAcet }]_{\text {water }}$ as calculated in Supplemental Material S3. Additional experiments (Supplemental Material S4) were performed for lactic acid to obtain the dissociation constant $\left(\mathrm{pK}_{\mathrm{a}}\right)$ in cheese, which contains high concentrations of $\mathrm{Ca}^{2+}$ and $\mathrm{Na}^{+}$ that compete with $\mathrm{H}^{+}$for complexation with $\mathrm{Lac}^{-}$, and to obtain the lactic acid logarithmic partition coefficient $\left(\log P_{f w}\right)$ in cheese using milk fat, as cheese contains milk fat instead of octanol, which is normally the apolar phase when determining the logarithmic partition coefficient $\left(\log P_{\text {ow }}\right)$.

$[\text { HAcet }]_{\text {water }}$ was also calculated according to Equation [6.12], but with $\mathrm{pK}_{\mathrm{a}}=4.76$ (Dawson, 1986) and $\log P_{\text {ow }}=-0.31(C D C, 2016)$.

The contribution of undissociated lactic acid to the overall inhibition of growth of L. monocytogenes in Gouda cheese was assessed by computational predictions, taking into account the variation in undissociated lactic acid concentrations in Gouda cheese and the concentrations of undissociated lactic acid needed to inhibit L. monocytogenes. Hereby, it was assessed in how many cases out of 1,000,000 produced cheeses undissociated lactic acid alone ensures full inhibition of growth of L. monocytogenes, starting with a hypothetical assumption that all cheeses were contaminated with L. monocytogenes. A Monte Carlo simulation with 1,000,000 iterations was run using @Risk 7 (Palisade Corporation, Ithaca, USA) and in each iteration the calculated concentration of undissociated lactic acid present in the water phase of Gouda ( $[\mathrm{HLac}]_{\text {water }}$ ) was compared with the minimal inhibitory concentration (MIC) of undissociated lactic acid for L. monocytogenes ([HLac $\left.]_{M I C}\right)$. A Kolmogorov-Smirnov test was used to find the best fits describing the variation in $[\mathrm{HLac}]_{\text {water }}$ and $[\mathrm{HLac}]_{\text {MIC }}$. The $[\mathrm{HLac}]_{\text {water }}$ was calculated according to Equation [6.12], by using the variation in total concentrations of lactic acid from data provided by Gouda cheese manufacturing companies (total lactic acid content of $1.44 \% \mathrm{w} / \mathrm{w}$ cheese as displayed in Supplementary 
Table S1) and own measurements in Gouda cheeses (total lactic acid content of $1.50 \% \mathrm{w} / \mathrm{w}$ cheese as displayed in Supplementary Table S2). Its variation was described with a Normal distribution: Normal $(8.32,0.69) \mathrm{mM}$ for data provided by companies as presented in Supplementary Table S1 and Normal $(11.48,3.91) \mathrm{mM}$ for the dataset as presented in Supplementary Table S2. [HLac $]_{M I C}$ was described by a Normal distribution with an average value of $5.11 \mathrm{mM}$ and a standard deviation of $0.31 \mathrm{mM}$ according to Aryani, den Besten, Hazeleger, \& Zwietering (2015). In case that in an iteration [HLac $]_{\text {water }}$ was higher than $[\mathrm{HLaC}]_{M I C}$, undissociated lactic acid was indicated as able to inhibit growth of L. monocytogenes, so no growth of the pathogen was predicted.

\subsection{Results and discussion}

\subsubsection{The effect of $\mathrm{T}, \mathrm{a}_{\mathrm{w}}$ and $\mathrm{pH}$}

An overview of growth inhibition by the individual factors present in Gouda cheese is given in Fig. 6.1. The factors are ranked in order of magnitude of growth inhibition. The most generic growth-inhibiting factors, namely, $\mathrm{T}, \mathrm{a}_{\mathrm{w}}$ and $\mathrm{pH}$ had a relevant effect on growth of L. monocytogenes. These three factors are often included in growth models (Augustin, Zuliani, Cornu, \& Guiller, 2005; Mataragas, Stergiou, \& Nychas, 2008; Schvartzman et al., 2011).

During curd formation $\mathrm{T}$ is favorable for growth of L. monocytogenes, but it is relatively low during ripening of Gouda (e.g. $12-13^{\circ} \mathrm{C}$ ), resulting in a large growth-inhibiting effect on L. monocytogenes. Nevertheless, $T$ is not expected to fully inhibit growth of L. monocytogenes, as growth can occur at lower temperatures (ICMSF, 1996). In addition, ripening times can be very long. The $a_{w}$ of Gouda cheese depends highly on the brining and ripening time and the location within a cheese (Wemmenhove, Wells-Bennik, Stara, van Hooijdonk, \& Zwietering, 2016b). As a result, the Gamma factor for $a_{w}$ may vary from values close to 0 (especially on the cheese rind after brining which makes $a_{w}$ a very relevant growth inhibiting factor if a cheese would be contaminated on the surface, and inside a cheese after prolonged ripening times) to values close to 1 (for example initially in the centre of a cheese). The $\mathrm{pH}$ is also an important factor for growth inhibition of L. monocytogenes. The minimum pH limit for growth is 4.4 in culture medium (ICMSF, 1996) and 4.32 in acidified milk (El-Shenawy \& Marth, 1990). The pH of a 2-week old Gouda cheese is 5.25 (SD 0.06) (Supplementary Table S3). In this range, the $\mathrm{pH}$ contributes to growth inhibition of L. monocytogenes (Gamma factor 0.55 in culture medium and 0.57 in cheese). In addition, pH affects the degree of dissociation of organic acids. Gouda cheese 
contains lactic acid and acetic acid, and lower $\mathrm{pH}$ values result in increased concentrations of their undissociated forms, which have growth-inhibiting effects.

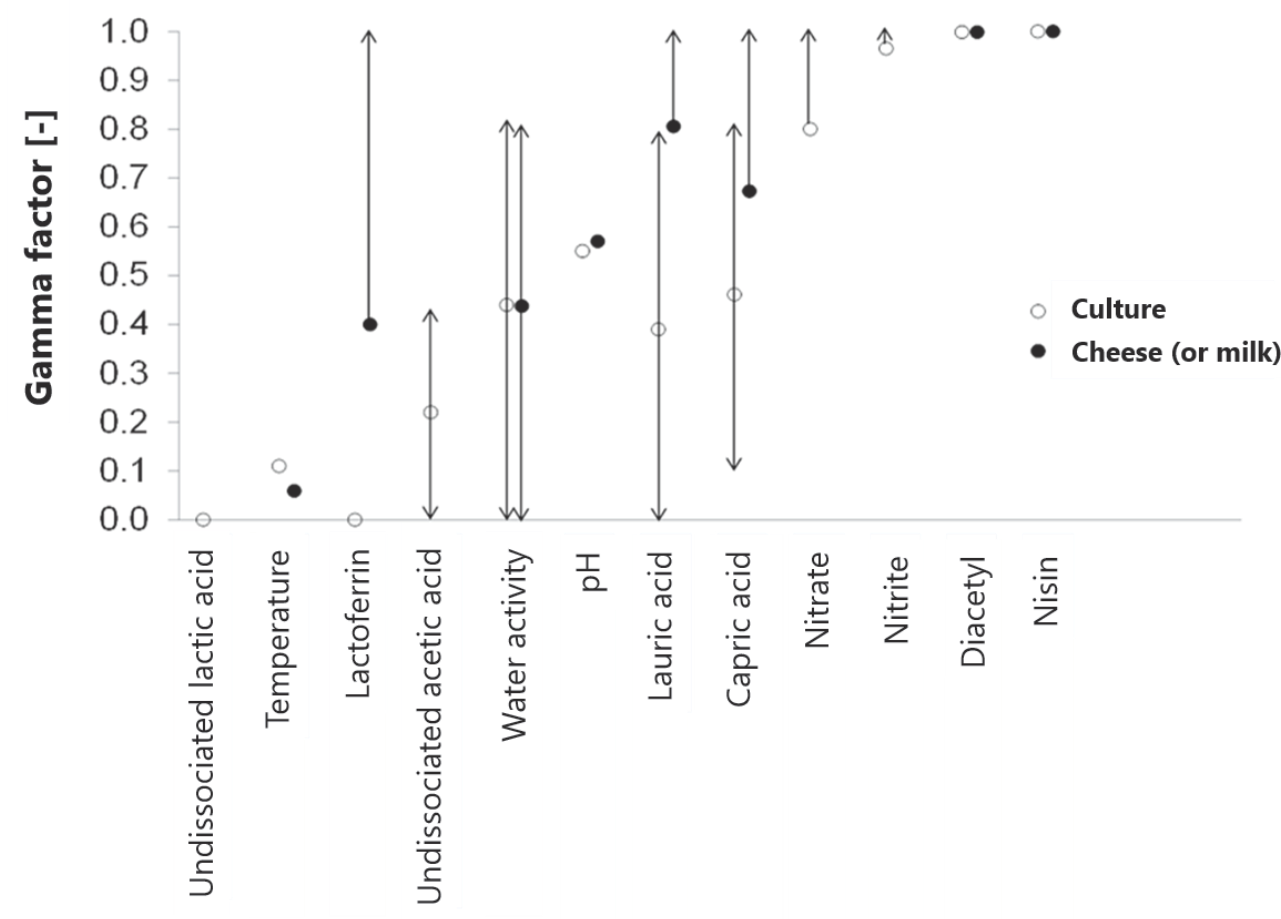

Fig. 6.1 The growth-inhibiting potential (Gamma factor) of undissociated lactic acid, T, lactoferrin, undissociated acetic acid, $\mathrm{a}_{\mathrm{w}}, \mathrm{pH}$, lauric acid, capric acid, nitrate, nitrite, diacetyl and nisin for L. monocytogenes. Average Gamma factors were calculated for each inhibitor based on the concentration as prevailing in cheese, which was compared with the concentration needed to inhibit growth in culture medium ( $)$ according to the calculations presented in Supplementary Table S3. The concentration as prevailing in cheese was also compared with the concentration needed to inhibit growth in cheese or milk (•), if data were available. The Gamma factor is indicated with an arrow with two ends if the Gamma factor spans a range, in case in the literature minimum and maximum values were available for the concentration in cheese and/or for the concentration needed to inhibit growth of L. monocytogenes. An arrow with only an upper end is used for an inhibitor in case growth of L. monocytogenes was not inhibited at the highest concentration tested, implicating that for that inhibitor, the actual Gamma factor is higher than the Gamma factor indicated with $\circ$ or $\bullet$.

\subsubsection{The effect of lactic and acetic acid}

In addition to $\mathrm{pH}, \mathrm{T}$, and $\mathrm{a}_{\mathrm{w}}$ undissociated lactic acid was evaluated to be the main growthinhibiting factor for L. monocytogenes in Gouda cheese. This factor can explain why the three tested L. monocytogenes strains Scott A, 2F and 6E did not grow in a challenge study with Gouda model cheeses. After two weeks of ripening, these cheeses contained $1.40 \%$ 
lactic acid w/w cheese and had a pH of 5.3 and a moisture content of $48 \%$, equaling $[\mathrm{HLac}]_{\text {water }}$ of $8.1 \mathrm{mM}$; after 26 weeks of ripening, when the $\mathrm{a}_{\mathrm{w}}$ has approached the critical level for growth of L. monocytogenes due to water loss, these cheeses contained $1.40 \%$ lactic acid $\mathrm{w} / \mathrm{w}$ cheese and had a $\mathrm{pH}$ of 5.50 and moisture content of $43 \%$, resulting in $[\mathrm{HLac}]_{\text {water }}$ of $5.8 \mathrm{mM}$. The MIC values of undissociated lactic acid of these strains at $\mathrm{pH}$ 5.4 were 4.3 (SD 0.96) mM for Scott A, 4.1 (SD 1.1) mM for $2 F$ and 4.8 (SD 1.3) mM for $6 \mathrm{E}$ (Wemmenhove, van Valenberg, Zwietering, \& Wells-Bennik, 2016a) with a maximum determined MIC of $5.8 \mathrm{mM}$ for these strains at pH 5.4 in BHI. Wemmenhove et al. (2016a) determined $[\mathrm{HLaC}]_{\text {MIC }}$ for six strains of L. monocytogenes as 4.98 (SD 1.48) mM with a maximum $[\mathrm{HLaC}]_{M I C}$ of $9.00 \mathrm{mM}$ based on 216 measurements ( $3 \mathrm{pH}$ values, measurement in 6-fold, individual replicate measurements). Out of the 216 measurements, the $[\mathrm{HLaC}]_{\text {MIC }}$ of $9.00 \mathrm{mM}$ published by Wemmenhove et al. (2016a) was found in eight instances: four times for strain 1F, once for strain EGDe and three times for strain L4, but only at pH 5.6. At $\mathrm{pH}$ 5.6, the interval between the determined concentrations of undissociated lactic acid was relatively large (from $5.8 \mathrm{mM}$ to $9.0 \mathrm{mM}$ ), resulting in a quite rough estimation of the $[\mathrm{HLaC}]_{M I C}$ (the true $[\mathrm{HLaC}]_{M I C}$ is thus between 5.8 and $9.0 \mathrm{mM}$ in this setting).

The $[\mathrm{HLaC}]_{\text {MIC }}$ data from Aryani et al. (2015) were used to evaluate the growth-inhibiting potential of undissociated lactic acid. The small intervals between the determined concentrations of undissociated lactic acid in their study rendered an accurate determination of the true MIC of strains, and a large number of strains of L. monocytogenes was studied, permitting an accurate estimation of strain variation. In total, Aryani et al. (2015) established $[\mathrm{HLaC}]_{M I C}$ for 20 strains of L. monocytogenes with an average $[\mathrm{HLaC}]_{M I C}$ of 5.11 (SD 0.31) mM and a maximum $[\mathrm{HLaC}]_{M I C}$ of $6.35 \mathrm{mM}$ at pH 5.50. EGDe was one of the strains studied by Aryani et al. (2015) and the maximum determined $[\mathrm{HLaC}]_{\text {MIC }}$ was $5.2 \mathrm{mM}$. In an additional challenge study with Gouda model cheeses as described by Wemmenhove et al. (2013), no growth of EGDe was observed during ripening of Gouda (unpublished work).

The concentration of undissociated lactic acid present in Gouda cheese was calculated based on the $\mathrm{pH}$, total lactic acid content and moisture content (Fig. 6.2): these parameters affect the concentration of undissociated lactic acid, and thereby its potential to inhibit growth of L. monocytogenes. This study focused on nature-ripened Gouda cheese. In such cheeses, an increase in $\mathrm{pH}$ and decrease in moisture content is observed during ripening (Wemmenhove et al., 2013; 2016b). The concentration and growth-inhibiting effect of undissociated lactic acid may be slightly different in other types of Gouda cheeses. For instance, in a foil-ripened cheese the moisture content will not decrease during ripening, and certain variants of Gouda cheese are produced using adjunct cultures in addition to the mesophilic starter culture. Such adjunct cultures may have proteolytic, lipolytic or lactate-converting activity, and under such circumstances the $\mathrm{pH}$ after ripening may be 
slightly higher than in a Gouda that is produced without adjunct cultures. If the concentration of undissociated lactic acid is insufficient to ensure complete growth inhibition, other growth-inhibiting factors become more important.

The distributions of $[\mathrm{HLac}]_{\text {water }}$ (based on input parameters of Supplementary Table S1 and S2) and $\left[\mathrm{HLaC}_{M I C}\right.$ (obtained from Aryani et al., 2015) are based on a Monte Carlo simulation with 1,000,000 iterations and presented in Fig. 6.3 In the unlikely case that Gouda cheeses were contaminated with L. monocytogenes, we predict that undissociated lactic acid will inhibit growth of L. monocytogenes in $100 \%$ of cases, based on a $[\text { HLac }]_{\text {water }}$ of 8.32 (SD 0.69) $\mathrm{mM}$ from process data of 89 Gouda cheeses obtained from Dutch manufacturers of these cheeses (Fig. 6.3A and dataset of Supplementary Table S1). For another set of Gouda cheeses, [HLac $]_{\text {water }}$ was calculated as 11.48 (SD 3.91) mM (Fig. 6.3B and Supplementary Table S2). For this dataset, we predict that undissociated lactic acid will inhibit growth of L. monocytogenes in $98.3 \%$ of cases. In one out of 20 cheeses, $[\mathrm{HLac}]_{\text {water }}$ was $5.25 \mathrm{mM}$, which is below the maximum $[\mathrm{HLac}]_{\text {MIC }}$ of $6.35 \mathrm{mM}$. At such a condition, there will be a need for growth-inhibiting factors other than undissociated lactic acid to inhibit growth of L. monocytogenes in case of a contamination. The data of Supplementary Table S2 only consisted of 20 measurements and in one out of these 20 cases $[\mathrm{HLac}]_{\text {water }}$ was $<6.35 \mathrm{mM}$. The standard deviation was much larger for this dataset than for the dataset of process data provided by companies, for which the lowest $[\text { HLac }]_{\text {water }}$ was $7.07 \mathrm{mM}$. The food industry can ensure growth inhibition of L. monocytogenes in Gouda by controlling the amount of lactic acid and $\mathrm{pH}$ and its variation.

A)

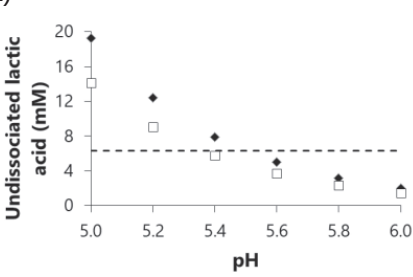

B)

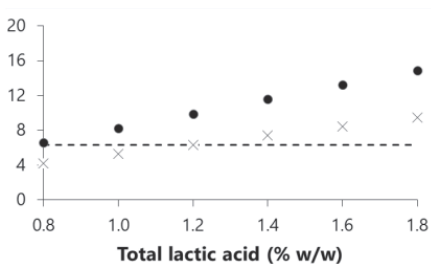

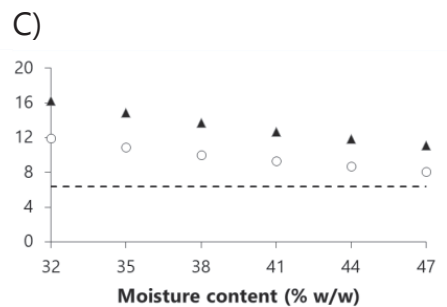

Fig. 6.2 Concentration ( $\mathrm{mM})$ of undissociated lactic acid in the water phase of cheese $\left([\mathrm{HLac}]_{\text {water }}\right)$, as dependent on A) pH (based on a total lactic acid content of 1.1 ( $\square$ ) and $1.5 \% \mathrm{w} / \mathrm{w}$ cheese $(\checkmark)$ and a moisture content of $42 \% \mathrm{w} / \mathrm{w}$ cheese), B) total content of lactic acid (\% w/w cheese) (based on a pH of $5.2(\bullet)$ and 5.4 $(\mathrm{x})$ and a moisture content of $42 \% \mathrm{w} / \mathrm{w}$ cheese) and C) moisture content (taking a total lactic acid content of 1.1 ( $\circ$ ) and $1.5 \% \mathrm{w} / \mathrm{w}$ cheese $(\mathbf{\Lambda})$ and an average $\mathrm{pH}$ of 5.2). The concentration of undissociated lactic acid was calculated as described in Supplementary Material S3, taking into account the effects of dissociation and ion associations and partition in milk fat/water. Calculations were based on a fat content of $48 \% \mathrm{w} / \mathrm{w}$ dry matter, a cheese density of $1070 \mathrm{~kg} \mathrm{~m}^{-3}, \mathrm{pK}_{\mathrm{a}}$ of 3.71 and $\log P_{f w}$ of -1.5 . The dotted line indicates the highest minimum concentration of $6.35 \mathrm{mM}$ of undissociated lactic acid needed to inhibit growth of L. monocytogenes in BHI, based on previous results from Aryani et al. (2015). 
A)

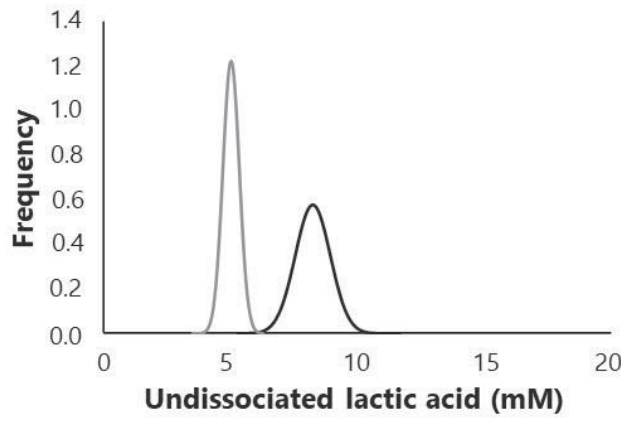

B)

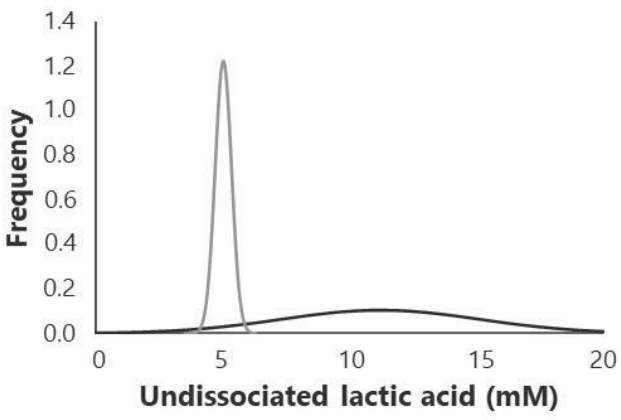

Fig. 6.3 Frequency distribution of the minimal inhibitory concentration of undissociated lactic acid $[\mathrm{HLac}]_{\text {MIC }}$ for L. monocytogenes (indicated with a solid grey line) and of the concentration of undissociated lactic acid in the water phase of cheese $[\mathrm{HLac}]_{\text {water }}$ (indicated with a solid black line). [HLac $]_{M I C}$, as obtained from Aryani et al. (2015) for 20 L. monocytogenes strains, was 5.11 (SD 0.31) mM). [HLac $]_{\text {water }}$ is displayed in A) as 8.32 (SD 0.69) mM based on process data of Dutch Gouda cheese-producing companies $(n=89)$ and in $B$ ) as 11.48 (SD 3.91) mM based on own measurements $(n=20)$.

When taking $[\mathrm{HLaC}]_{\text {water }}$ above $6.35 \mathrm{mM}$ as a basis for no growth of L. monocytogenes in Gouda cheese (based on the maximum $[\mathrm{HLaC}]_{M I C}$ of Aryani et al., 2015), then full growth inhibition of $L$. monocytogenes is expected at a minimum total lactic acid content of $0.86 \%$ $\mathrm{w} / \mathrm{w}$ for a young cheese with $48 \% \mathrm{w} / \mathrm{w}$ fat in dry matter $(\mathrm{pH} 5.25$ and moisture content $42 \% \mathrm{w} / \mathrm{w}$ ) and a minimum total lactic acid content of $1.26 \% \mathrm{w} / \mathrm{w}$ for mature cheese with $48 \% \mathrm{w} / \mathrm{w}$ fat in dry matter (pH 5.50 and moisture content 35\%).

Acetic acid is present in Gouda cheese at concentrations of $0.11 \% \mathrm{w} / \mathrm{w}$ cheese, which is around 10 times lower than those of lactic acid (Wemmenhove et al., 2013). Overall, growth inhibition of L. monocytogenes by undissociated acetic acid in Gouda with $48 \% \mathrm{w} / \mathrm{w}$ fat in dry matter seems limited, as the calculated concentration of undissociated acetic acid is $9.82 \mathrm{mM}$ at $\mathrm{pH} 5.25$ (based on $\mathrm{pK}_{\mathrm{a}}=4.76$ and $\log P_{\text {ow }}=-0.31$ and $42 \% \mathrm{w} / \mathrm{w}$ moisture). The $[\text { HAcet }]_{\text {MIC }}$ of undissociated acetic acid for L. monocytogenes is 19.0 (SD 6.5) $\mathrm{mM}$ with a maximum value of $30.2 \mathrm{mM}$ (Wemmenhove et al., 2016a).

\subsubsection{The effect of other factors}

Other factors with a potential to inhibit growth of L. monocytogenes (e.g. diacetyl, free fatty acids, lactoferrin, nitrate, nitrite and nisin) may contribute to growth inhibition in Gouda cheese, but these are less important than $\mathrm{T}, \mathrm{a}_{\mathrm{w}}, \mathrm{pH}$ and lactic acid (Fig. 6.1 and Supplementary Table S3). The free fatty acids capric and lauric acid inhibited growth of 
L. monocytogenes in culture medium, but their inhibition efficacy decreased in the presence of emulsifier (as shown for Tween 80 ) and $\mathrm{CaCl}_{2}$ (Supplementary Table S3), suggesting a poor growth inhibition by capric and lauric acid in a cheese matrix. Nevertheless, free fatty acids may have the potential to inhibit growth of L. monocytogenes in other types of cheese (e.g. Emmental, Roquefort), given the fact that free fatty acid concentrations can be 4-150 times higher in those cheese types than in Dutch-type cheeses (Woo, Kollodge, \& Lindsay, 1984). Lactoferrin is naturally present in milk and can be present in the cheese as it can withstand pasteurization (Dupont et al., 2006). However, lactoferrin does not contribute to growth inhibition of L. monocytogenes to a large extent, considering Gamma factors higher than 0.4 in milk (Fig. 6.1). Conesa et al. (2010) suggested that growth inhibition by lactoferrin can be counteracted by proteins and divalent cations such as $\mathrm{Ca}^{2+}$ in rich growth media. The growth-inhibiting effect of lactoferrin can be further reduced during ripening because the protein may be degraded as a result of proteolysis. Gamma factors for nitrate and nitrite were at least 0.8 and 0.97 in $\mathrm{BHI}$ (Fig. 6.1), suggesting a non-relevant or very limited growth inhibition for L. monocytogenes. The growth-inhibiting effect of diacetyl is even smaller, which is reflected by a Gamma factor of 1.0. A typical Gouda cheese does not contain nisin, reflected by Gamma factor 1.0, but nisin-producing starter bacteria are sometimes applied. In such cases, nisin can inhibit growth of L. monocytogenes in cheese (Maisnier-Patin, Deschamps, Tatini, \& Richard, 1992; Samelis et al., 2017), but due to proteolysis during ripening, its effect can be reduced over time (Davies, Bevis, \& Delves-Broughton, 1997).

\subsection{Conclusion}

This study provides quantitative insight in the factors that potentially inhibit growth of L. monocytogenes in Gouda cheese. Undissociated lactic acid was evaluated as the most important factor for growth inhibition of L. monocytogenes. Gouda cheeses have a typical total lactic acid content of $1.47 \% \mathrm{w} / \mathrm{w}$ (and $10.9 \mathrm{mM}$ undissociated lactic acid in 2-week old Gouda with pH 5.25). No growth of L. monocytogenes is predicted in Gouda cheese with $48 \% \mathrm{w} / \mathrm{w}$ fat in dry matter and with a total lactic acid content $\geq 0.86 \% \mathrm{w} / \mathrm{w}$ for young cheese $(\mathrm{pH}<5.25)$ and with a total lactic acid content $\geq 1.26 \% \mathrm{w} / \mathrm{w}$ for mature cheese $(\mathrm{pH}$ $<5.50)$. For L. monocytogenes in cheeses, it is very relevant that undissociated lactic acid is included as a factor, in addition to $\mathrm{T}, \mathrm{a}_{\mathrm{w}}$ and $\mathrm{pH}$, in both predictive models and in setting criteria for growth/no growth. 


\section{Acknowledgements}

We would like to thank Dr. Martijn Fox for his assistance in modelling of the concentrations of undissociated lactic acid in cheese. This study was supported by the Dutch Dairy Association (The Hague, The Netherlands) and the Dutch Dairy Board (The Hague, The Netherlands). The authors thank the Dutch dairy cooperatives BelLeerdammer, DOC kaas, FrieslandCampina and Rouveen Kaasspecialiteiten for their kind supply of data on Gouda cheese. 


\section{References}

Aryani, D.C., den Besten, H.M.W., Hazeleger, W.C., \& Zwietering, M.H. (2015). Quantifying strain variability in modeling growth of Listeria monocytogenes. International Journal of Food Microbiology 208:19-29.

Augustin, J.C., Zuliani, V., Cornu, M., \& Guillier, L. (2005). Growth rate and growth probability of Listeria monocytogenes in dairy, meat and seafood products in suboptimal conditions. Journal of Applied Microbiology 99:1019-1042.

CDC (2016). International chemical safety cards. https://www.cdc.gov/niosh/ipcsneng/neng0363.html. (Accessed 16 August 2017).

Chen, Y., Nummer, B., \& Walsh, M.K. (2014). Antilisterial activity of lactose monolaurate in milk, drinkable yogurt and cottage cheese. Letters in Applied Microbiology 58:156-162.

Cole, M.B., Jones, M.V., \& Holyoak, C. (1990). The effect of $\mathrm{pH}$, salt concentration and temperature on the survival and growth of Listeria monocytogenes. Journal of Applied Microbiology 69:63-72.

Conesa, C., Rota, C., Castillo, E., Pérez, M.D., Calvo, M., \& Sánchez, L. (2010). Effect of heat treatment on the antibacterial activity of bovine lactoferrin against three foodborne pathogens. International Journal of Food Technology 63:209-215.

Davies, E.A., Bevis, H.E., \& Delves-Broughton, J. (1997). Effect of heat treatment on the antibacterial activity of bovine lactoferrin against three foodborne pathogens. Letters in Applied Microbiology 24:343-346.

Dawson, R.M.C. (1986). Data for biochemical research. Oxford: Clarendon Press.

De Jong, C., \& Badings, H.T. (1990). Determination of free fatty acids in milk and cheese - Procedures for extraction, clean up, and capillary gas chromatographic analysis. Journal of High Resolution Chromatography 13:94-98.

den Besten, H.M.W., \& Zwietering, M.H. (2012). Meta-analysis for quantitative microbiological risk assessments and benchmarking data. Trends in Food Science \& Technology 25:34-39.

Dupont, D., Arnould, C., Rolet-Repecaud, O., Duboz, G., Faurie, F., Martin, B., \& Beuvier, E. (2006). Determination of bovine lactoferrin concentrations in cheese with specific monoclonal antibodies. International Dairy Journal 16:1081-1087.

El-Shenawy, M.A., \& Marth, E.H. (1990). Behavior of Listeria monocytogenes in the presence of gluconic acid and during preparation of Cottage cheese curd using gluconic acid. Journal of Dairy Science 73:1429-1438.

European Commission (2004). Commission regulation (EC) No 853/2004 of 29 April 2004 laying down specific hygiene rules for on the hygiene of foodstuffs. Official Journal of the European Union L139/55.

European Commission (2005). Commission regulation (EC) No 2073/2005 of 15 November 2005 on microbiological criteria for foodstuffs. Official Journal of the European Union L338/1.

European Commission (2006). Commission regulation (EC) No 1662/2006 of 6 November 2006 amending Regulation (EC) No 853/2004 of the European Parliament and of the Council laying down specific hygiene rules for food of animal origin. Official Journal of the European Union L320/1. 
Fox, P.F., McSweeney, P.L.H., Cogan, T.M., \& Guinee, T.P. (2004). Cheese: Chemistry, Physics and Microbiology (3rd ed.). Vol. 1, pp. 1-617 \& Vol. 2, pp. 1-434. London: Elsevier Academic Press.

Galbraith, H., Miller, T.B., Paton, A.M., \& Thompson, J.K. (1971). Antibacterial activity of long chain fatty acids and the reversal with calcium, magnesium, ergocalciferol and cholesterol. Journal of Applied Bacteriology 34:803-813.

ICMSF (1996). Microorganisms in foods. Microbiological specifications of food pathogens. Vol. 5. London: Blackie, UK.

ILSI (2012). Risk assessment approaches to setting thermal processes in food manufacture. ILSI Europe Report Series.

Lou, Y., \& Yousef, A.E. (2000). Characteristics of Listeria monocytogenes important to food processors. In E.T. Ryser, \& E.H. Marth (Eds.), Listeria, Listeriosis and Food Safety. New York: Marcel Dekker.

Maisnier-Patin, S., Deschamps, N., Tatini, S.R., \& Richard, J. (1992). Inhibition of Listeria monocytogenes in Camembert cheese made with a nisin-producing starter. Lait 72:249-263.

Mataragas, M., Stergiou, V., \& Nychas, G.J. (2008). Modeling survival of Listeria monocytogenes in the traditional Greek soft cheese Katiki. Journal of Food Protection 71:1835-1845.

Meyer-Broseta, S., Diot, A., Bastian, S., Rivière, J., \& Cerf, O. (2003). Estimation of low bacterial concentration: Listeria monocytogenes in raw milk. International Journal of Food Microbiology 80:1-15.

Northolt, M.D., Beckers, H.J., Vecht, U., Toepoel, L., Soentoro, P.S.S., \& Wisselink, H.J. (1988). Listeria monocytogenes. heat resistance and behaviour during storage of milk and whey and making of Dutch types of cheese. Netherlands Milk Dairy Journal 42:207-219.

Pan, Y., Breidt, F., Jr., \& Kathariou, S. (2006). Resistance of Listeria monocytogenes biofilms to sanitizing agents in a simulated food processing environment. Applied and Environmental Microbiology 72:7711-7717.

Petrone, G., Conte, M.P., Longhi, C., Di Santo, S., Superti, F. Ammendolia, M.G., Valenti, P., \& Seganti, L. (1998). Natural milk fatty acids affect survival and invasiveness of Listeria monocytogenes. Letters in Applied Microbiology 27:362-368.

Ruusunen, M., Salonen, M., Pulkkinen, H., Huuskonen, M., Hellström, S., Revez, J., Hänninen, M.L., Fredriksson-Ahomaa, M., \& Lindström, M. (2013). Pathogenic bacteria in Finnish bulk tank milk. Foodborne Pathogens and Disease 10:99-106.

Samelis, J., Giannou, E., Pappa, E. C., Bogović-Matijašić, Lianou, A., Parapouli, M., \& Drainas, C. (2017). Behavior of artificial listerial contamination in model Greek Graviera cheeses manufactured with the indigenous nisin A-producing strain Lactococcus lactis subsp. cremoris M104 as costarter culture. Journal of Food Safety 37, e12326.

Schvartzman, M.S., Maffre, A., Tenenhaus-Aziza, F., Sanaa, M., Butler, F., \& Jordan, K. (2011). Modelling the fate of Listeria monocytogenes during manufacture and ripening of smeared cheese made with pasteurised or raw milk. International Journal of Food Microbiology 145:S31-S38.

Sprong, R.C., Hulstein, M.F.E., \& van der Meer, R. (2001). Bactericidal activities of milk lipids. Antimicrobial Agents and Chemotherapy 45:1298-1301.

Stadhouders, J. (1974). Dairy starter cultures. Milchwissenschaft 29:329-337. 
Wang, L.L., \& Johnson, E.A. (1992). Inhibition of Listeria monocytogenes by fatty acids and monoglycerides. Applied and Environmental Microbiology 58:624-629.

Wemmenhove, E., Beumer, R.R., van Hooijdonk, A.C.M., Zwietering, M.H., \& Wells-Bennik, M.H.J. (2014). The fate of Listeria monocytogenes in brine and on Gouda cheese following artificial contamination during brining. International Dairy Journal 39:253-258.

Wemmenhove, E., Stampelou, I., van Hooijdonk, A.C.M., Zwietering, M.H., \& Wells-Bennik, M.H.J. (2013). Fate of Listeria monocytogenes in Gouda microcheese: No growth, and substantial inactivation after extended ripening times. International Dairy Journal 32:192-198.

Wemmenhove, E., van Valenberg, H.J., Zwietering, M.H., van Hooijdonk, A.C.M., \& Wells-Bennik, M.H.J. (2016a). Minimal inhibitory concentrations of undissociated lactic, acetic, citric and propionic acid for Listeria monocytogenes under conditions relevant to cheese. Food Microbiology 58:63-67.

Wemmenhove, E., Wells-Bennik, M.H., Stara, A., van Hooijdonk, A.C.M., \& Zwietering, M.H. (2016b). How $\mathrm{NaCl}$ and water content determine water activity during ripening of Gouda cheese, and the predicted effect on inhibition of Listeria monocytogenes. Journal of Dairy Science 99:5192-5201.

Woo, A.H., Kollodge, S., \& Lindsay, R.C. (1984). Quantification of major free fatty acids in several cheese varieties. Journal of Dairy Science 67:874-878. 
Supplementary Table S1 $[\mathrm{HLac}]_{\text {water }}$ and its Gamma factors for L. monocytogenes, as calculated from data of 89 Gouda cheeses

\begin{tabular}{|c|c|c|c|c|c|c|}
\hline $\begin{array}{l}\text { Cheese } \\
\text { no. }\end{array}$ & $\begin{array}{l}\text { Total } \\
\text { lactic acid } \\
\text { content } \\
(\% \mathrm{w} / \mathrm{w})\end{array}$ & $\begin{array}{l}\text { Ripe- } \\
\text { ning } \\
\text { time } \\
\text { (weeks) }\end{array}$ & $\begin{array}{l}\text { Moisture } \\
\text { content, \% } \\
\text { (w/w) } \\
\text { (assumed) }\end{array}$ & $\begin{array}{l}\mathrm{pH} \\
\text { (assu- } \\
\text { med) }\end{array}$ & $\begin{array}{l}{[\text { HLac }]_{\text {water }}} \\
(\mathrm{mM})\end{array}$ & $\begin{array}{l}\text { Gamma factor of } \\
\text { undissociated lactic acid for } \\
\text { L. monocytogenes with } \\
\text { maximum }[\text { HLAC }]_{M I C}=6.35 \\
\text { mM }\end{array}$ \\
\hline 1 & 1.30 & 4 & 40.0 & 5.30 & 9.02 & 0 \\
\hline 2 & 1.50 & 13 & 35.0 & 5.50 & 7.57 & 0 \\
\hline 3 & 1.40 & 13 & 35.0 & 5.50 & 7.07 & 0 \\
\hline 4 & 1.50 & 26 & 31.5 & 5.50 & 8.41 & 0 \\
\hline 5 & 1.30 & 26 & 31.5 & 5.50 & 7.29 & 0 \\
\hline 6 & 1.56 & 15 & 35.0 & 5.50 & 7.85 & 0 \\
\hline 7 & 1.52 & 13 & 35.0 & 5.50 & 7.65 & 0 \\
\hline 8 & 1.57 & 13 & 35.0 & 5.50 & 7.90 & 0 \\
\hline 9 & 1.40 & 8 & 36.0 & 5.45 & 7.67 & 0 \\
\hline 10 & 1.41 & 8 & 36.0 & 5.45 & 7.73 & 0 \\
\hline 11 & 1.39 & 7 & 36.0 & 5.40 & 8.57 & 0 \\
\hline 12 & 1.40 & 6 & 37.0 & 5.40 & 8.39 & 0 \\
\hline 13 & 1.36 & 5 & 39.0 & 5.35 & 8.62 & 0 \\
\hline 14 & 1.33 & 5 & 39.0 & 5.35 & 8.47 & 0 \\
\hline 15 & 1.40 & 4 & 40.0 & 5.30 & 9.70 & 0 \\
\hline 16 & 1.34 & 4 & 40.0 & 5.30 & 9.31 & 0 \\
\hline 17 & 1.35 & 3 & 41.0 & 5.25 & 10.19 & 0 \\
\hline 18 & 1.65 & 14 & 35.0 & 5.50 & 8.31 & 0 \\
\hline 19 & 1.49 & 6 & 37.0 & 5.40 & 8.90 & 0 \\
\hline 20 & 1.41 & 6 & 37.0 & 5.40 & 8.45 & 0 \\
\hline 21 & 1.40 & 6 & 37.0 & 5.40 & 8.38 & 0 \\
\hline 22 & 1.54 & 13 & 35.0 & 5.50 & 7.79 & 0 \\
\hline 23 & 1.43 & 5 & 39.0 & 5.35 & 9.07 & 0 \\
\hline 24 & 1.42 & 5 & 39.0 & 5.35 & 9.02 & 0 \\
\hline 25 & 1.52 & 10 & 35.5 & 5.50 & 7.56 & 0 \\
\hline 26 & 1.70 & 16 & 35.0 & 5.50 & 8.59 & 0 \\
\hline 27 & 1.45 & 9 & 36.0 & 5.50 & 7.11 & 0 \\
\hline 28 & 1.40 & 4 & 40.0 & 5.30 & 9.68 & 0 \\
\hline 29 & 1.56 & 12 & 35.5 & 5.50 & 7.79 & 0 \\
\hline 30 & 1.46 & 11 & 35.5 & 5.50 & 7.24 & 0 \\
\hline 31 & 1.37 & 6 & 37.0 & 5.40 & 8.22 & 0 \\
\hline 32 & 1.62 & 15 & 35.0 & 5.50 & 8.20 & 0 \\
\hline 33 & 1.41 & 7 & 36.0 & 5.40 & 8.70 & 0 \\
\hline 34 & 1.36 & 6 & 37.0 & 5.40 & 8.14 & 0 \\
\hline 35 & 1.43 & 8 & 36.0 & 5.45 & 7.83 & 0 \\
\hline 36 & 1.55 & 10 & 35.5 & 5.50 & 7.73 & 0 \\
\hline 37 & 1.60 & 13 & 35.0 & 5.50 & 8.06 & 0 \\
\hline 38 & 1.34 & 7 & 36.0 & 5.40 & 8.25 & 0 \\
\hline 39 & 1.43 & 8 & 36.0 & 5.45 & 7.83 & 0 \\
\hline 40 & 1.45 & 9 & 36.0 & 5.50 & 7.14 & 0 \\
\hline 41 & 1.36 & 7 & 36.0 & 5.40 & 8.38 & 0 \\
\hline 42 & 1.57 & 14 & 35.0 & 5.50 & 7.91 & 0 \\
\hline 43 & 1.52 & 15 & 35.0 & 5.50 & 7.65 & 0 \\
\hline 44 & 1.49 & 15 & 35.0 & 5.50 & 7.51 & 0 \\
\hline 45 & 1.43 & 15 & 35.0 & 5.50 & 7.24 & 0 \\
\hline 46 & 1.48 & 11 & 35.5 & 5.50 & 7.36 & 0 \\
\hline 47 & 1.60 & 11 & 35.5 & 5.50 & 7.97 & 0 \\
\hline 48 & 1.54 & 12 & 35.5 & 5.50 & 7.67 & 0 \\
\hline
\end{tabular}




\begin{tabular}{|c|c|c|c|c|c|c|}
\hline 49 & 1.78 & 17 & 34.5 & 5.50 & 9.13 & 0 \\
\hline 50 & 1.51 & 11 & 35.5 & 5.50 & 7.51 & 0 \\
\hline 51 & 1.42 & 6 & 37.0 & 5.40 & 8.47 & 0 \\
\hline 52 & 1.40 & 6 & 37.0 & 5.40 & 8.41 & 0 \\
\hline 53 & 1.42 & 6 & 37.0 & 5.40 & 8.52 & 0 \\
\hline 54 & 1.42 & 6 & 37.0 & 5.40 & 8.53 & 0 \\
\hline 55 & 1.43 & 6 & 37.0 & 5.40 & 8.58 & 0 \\
\hline 56 & 1.40 & 6 & 37.0 & 5.40 & 8.37 & 0 \\
\hline 57 & 1.41 & 6 & 37.0 & 5.40 & 8.41 & 0 \\
\hline 58 & 1.41 & 6 & 37.0 & 5.40 & 8.46 & 0 \\
\hline 59 & 1.34 & 4 & 40.0 & 5.30 & 9.30 & 0 \\
\hline 60 & 1.47 & 6 & 37.0 & 5.40 & 8.80 & 0 \\
\hline 61 & 1.39 & 6 & 37.0 & 5.40 & 8.29 & 0 \\
\hline 62 & 1.43 & 6 & 37.0 & 5.40 & 8.57 & 0 \\
\hline 63 & 1.40 & 6 & 37.0 & 5.40 & 8.37 & 0 \\
\hline 64 & 1.47 & 7 & 36.0 & 5.40 & 9.07 & 0 \\
\hline 65 & 1.25 & 7 & 36.0 & 5.40 & 7.66 & 0 \\
\hline 66 & 1.37 & 4 & 40.0 & 5.30 & 9.47 & 0 \\
\hline 67 & 1.42 & 4 & 40.0 & 5.30 & 9.84 & 0 \\
\hline 68 & 1.36 & 4 & 40.0 & 5.30 & 9.43 & 0 \\
\hline 69 & 1.35 & 4 & 40.0 & 5.30 & 9.39 & 0 \\
\hline 70 & 1.35 & 7 & 36.0 & 5.40 & 8.32 & 0 \\
\hline 71 & 1.40 & 7 & 36.0 & 5.40 & 8.60 & 0 \\
\hline 72 & 1.40 & 7 & 36.0 & 5.40 & 8.60 & 0 \\
\hline 73 & 1.40 & 7 & 36.0 & 5.40 & 8.60 & 0 \\
\hline 74 & 1.45 & 7 & 36.0 & 5.40 & 8.94 & 0 \\
\hline 75 & 1.41 & 7 & 36.0 & 5.40 & 8.65 & 0 \\
\hline 76 & 1.37 & 7 & 36.0 & 5.40 & 8.46 & 0 \\
\hline 77 & 1.46 & 7 & 36.0 & 5.40 & 9.00 & 0 \\
\hline 78 & 1.43 & 7 & 36.0 & 5.40 & 8.77 & 0 \\
\hline 79 & 1.45 & 7 & 36.0 & 5.40 & 8.94 & 0 \\
\hline 80 & 1.47 & 7 & 36.0 & 5.40 & 9.03 & 0 \\
\hline 81 & 1.48 & 9 & 36.0 & 5.50 & 7.28 & 0 \\
\hline 82 & 1.52 & 12 & 35.5 & 5.50 & 7.57 & 0 \\
\hline 83 & 1.43 & 12 & 35.5 & 5.50 & 7.10 & 0 \\
\hline 84 & 1.43 & 12 & 35.5 & 5.50 & 7.10 & 0 \\
\hline 85 & 1.37 & 7 & 36.0 & 5.40 & 8.42 & 0 \\
\hline 86 & 1.36 & 7 & 36.0 & 5.40 & 8.35 & 0 \\
\hline 87 & 1.40 & 7 & 36.0 & 5.40 & 8.64 & 0 \\
\hline 88 & 1.35 & 7 & 36.0 & 5.40 & 8.30 & 0 \\
\hline 89 & 1.36 & 7 & 36.0 & 5.40 & 8.39 & 0 \\
\hline Average & 1.44 & 8.65 & 36.46 & 5.42 & 8.32 & \\
\hline S.D. & 0.089 & 4.33 & 1.73 & 0.067 & 0.69 & \\
\hline
\end{tabular}

Data were provided by Dutch companies, all from cheeses with $48 \% \mathrm{w} / \mathrm{w}$ fat in dry matter. [HLac $]_{\text {water }}$ was calculated according to Equation [6.12] from Supplementary Material S3, using a cheese density of $1070 \mathrm{~kg}$ $\mathrm{m}^{-3}$, a water density of $998 \mathrm{~kg} \mathrm{~m}^{-3}$, a milk fat density of $940 \mathrm{~kg} \mathrm{~m}^{-3}, \mathrm{pK}_{\mathrm{a}}$ of 3.71, a $\log P_{f w}$ of -1.5 , a molar mass of $90.08 \mathrm{~g} \mathrm{~mol}^{-1}$ for lactic acid. No data on the $\mathrm{pH}$ and moisture content were available for the cheeses, only the total lactic acid content and the age of the cheese analyzed were provided by the companies. The age of the cheese was used for assumptions on the $\mathrm{pH}$ and moisture content. The Gamma factor of undissociated lactic acid for L. monocytogenes was calculated according to Equation [6.5] from Supplemental Material S1, making a worst-case comparison by comparing to the highest MIC determined for L. monocytogenes (with maximum $[\mathrm{HLaC}]_{\text {MIC }}=6.35 \mathrm{mM}$ (the upper $\mathrm{Cl}$ for 1 out of 20 strains of $L$. monocytogenes according to Aryani et al. (2015)). A Gamma factor of 0 indicates full inhibition of growth of L. monocytogenes by undissociated lactic acid, even without the need for other growth inhibitors. 


\section{References Supplementary Table S1}

Aryani, D.C., den Besten, H.M.W., Hazeleger, W.C., \& Zwietering, M.H. (2015). Quantifying strain variability in modeling growth of Listeria monocytogenes. International Journal of Food Microbiology 208:19-29. 
Supplementary Table S2 $[\mathrm{HLac}]_{\text {water }}$ and its Gamma factor for L. monocytogenes, as calculated from 20 Gouda cheeses

\begin{tabular}{llllll}
\hline $\begin{array}{l}\text { Cheese } \\
\text { no. }\end{array}$ & $\begin{array}{l}\text { Total lactic } \\
\text { acid content, } \\
\mathbf{\%}(\mathbf{w} / \mathbf{w})\end{array}$ & $\begin{array}{l}\text { Moisture } \\
\text { content, } \\
\mathbf{\%}(\mathbf{w} / \mathbf{w})\end{array}$ & $\mathbf{p H}$ & $\begin{array}{l}{[\mathbf{H L a c}]_{\text {water }}} \\
\mathbf{( m M )}\end{array}$ & $\begin{array}{l}\text { Gamma factor of undissociated lactic } \\
\text { acid for L. monocytogenes with } \\
{[\mathbf{H L a c}]_{\text {MIC }}=\mathbf{6 . 3 5} \mathbf{~ m M}}\end{array}$ \\
\hline $\mathbf{1}$ & 1.42 & 42 & 5.22 & 11.2 & 0 \\
\hline $\mathbf{2}$ & 1.43 & 42 & 5.22 & 11.3 & 0 \\
\hline $\mathbf{3}$ & 1.14 & 42 & 5.14 & 10.8 & 0 \\
\hline $\mathbf{4}$ & 2.10 & 42 & 5.26 & 15.2 & 0 \\
\hline $\mathbf{5}$ & 1.48 & 37 & 5.22 & 13.3 & 0 \\
\hline $\mathbf{6}$ & 1.43 & 31 & 5.10 & 19.9 & 0 \\
\hline $\mathbf{7}$ & 1.55 & 42 & 5.34 & 9.39 & 0 \\
\hline $\mathbf{8}$ & 1.43 & 37 & 5.51 & 6.66 & 0 \\
\hline $\mathbf{9}$ & 1.25 & 31 & 5.42 & 8.57 & 0 \\
\hline $\mathbf{1 0}$ & 1.32 & 42 & 5.44 & 6.39 & 0 \\
\hline $\mathbf{1 1}$ & 1.20 & 37 & 5.54 & 5.25 & 0.17 \\
\hline $\mathbf{1 2}$ & 1.38 & 31 & 5.56 & 6.84 & 0 \\
\hline $\mathbf{1 3}$ & 1.13 & 42 & 5.24 & 8.57 & 0 \\
\hline $\mathbf{1 4}$ & 1.32 & 37 & 5.18 & 12.9 & 0 \\
\hline $\mathbf{1 5}$ & 1.49 & 31 & 5.21 & 16.3 & 0 \\
\hline $\mathbf{1 6}$ & 1.55 & 40 & 5.30 & 10.9 & 0 \\
\hline $\mathbf{1 7}$ & 1.69 & 37 & 5.26 & 14.0 & 0 \\
\hline $\mathbf{1 8}$ & 1.77 & 34 & 5.41 & 11.3 & 0 \\
\hline $\mathbf{1 9}$ & 1.93 & 30 & 5.42 & 13.6 & 0 \\
\hline $\mathbf{2 0}$ & 1.99 & 28 & 5.36 & 17.3 & 0 \\
\hline Average & 1.50 & 36.75 & 5.32 & 11.48 & \\
\hline S.D. & 0.266 & 4.83 & 0.13 & 3.91 & \\
\hline & & & & \\
\hline
\end{tabular}

Data on 15 Gouda cheeses were obtained from our previous study (Wemmenhove et al., 2013) and determined in five additional Gouda cheeses for this study. All cheeses contained $48 \% \mathrm{w} / \mathrm{w}$ fat in dry matter. $[\mathrm{HLac}]_{\text {water }}$ was calculated according to Equation [6.12] from Supplementary Material S3, using a cheese density of $1070 \mathrm{~kg} \mathrm{~m}^{-3}$, a water density of $998 \mathrm{~kg} \mathrm{~m}^{-3}$, a milk fat density of $940 \mathrm{~kg} \mathrm{~m}^{-3}, \mathrm{pK}_{\mathrm{a}}$ of 3.71 , a $\log P_{f w}$ of -1.5 , a molar mass of $90.08 \mathrm{~g} \mathrm{~mol}^{-1}$ for lactic acid. The Gamma factor of undissociated lactic acid for L. monocytogenes was calculated according to Equation [6.5] from Supplemental Material S1, making a worst-case comparison by comparing to the highest MIC value determined for L. monocytogenes (with maximum $[\mathrm{HLac}]_{\text {MIC }}=6.35 \mathrm{mM}$ (the upper $\mathrm{Cl}$ for 1 out of 20 strains of $L$. monocytogenes according to Aryani et al. (2015)). A Gamma factor of 0 indicates full inhibition of growth of L. monocytogenes by undissociated lactic acid, even without the need for other growth inhibitors.

\section{References Supplementary Table S2}

Aryani, D.C., den Besten, H.M.W., Hazeleger, W.C., \& Zwietering, M.H. (2015). Quantifying strain variability in modeling growth of Listeria monocytogenes. International Journal of Food Microbiology 208:19-29.

Wemmenhove, E., Stampelou, I., van Hooijdonk, A.C.M., Zwietering, M.H., \& Wells-Bennik, M.H.J. (2013). Fate of Listeria monocytogenes in Gouda microcheese: No growth, and substantial inactivation after extended ripening times. International Dairy Journal 32:192-198. 


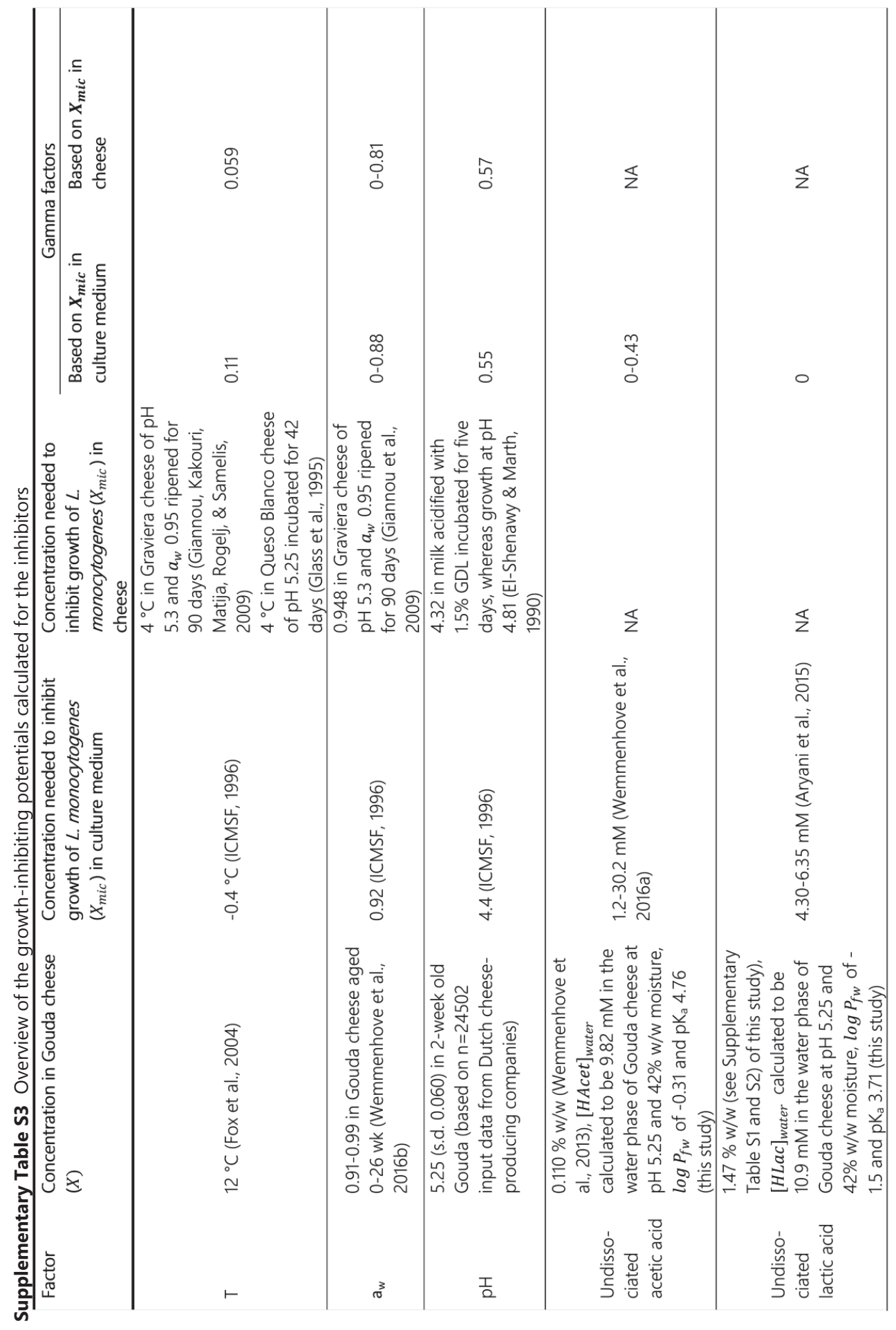




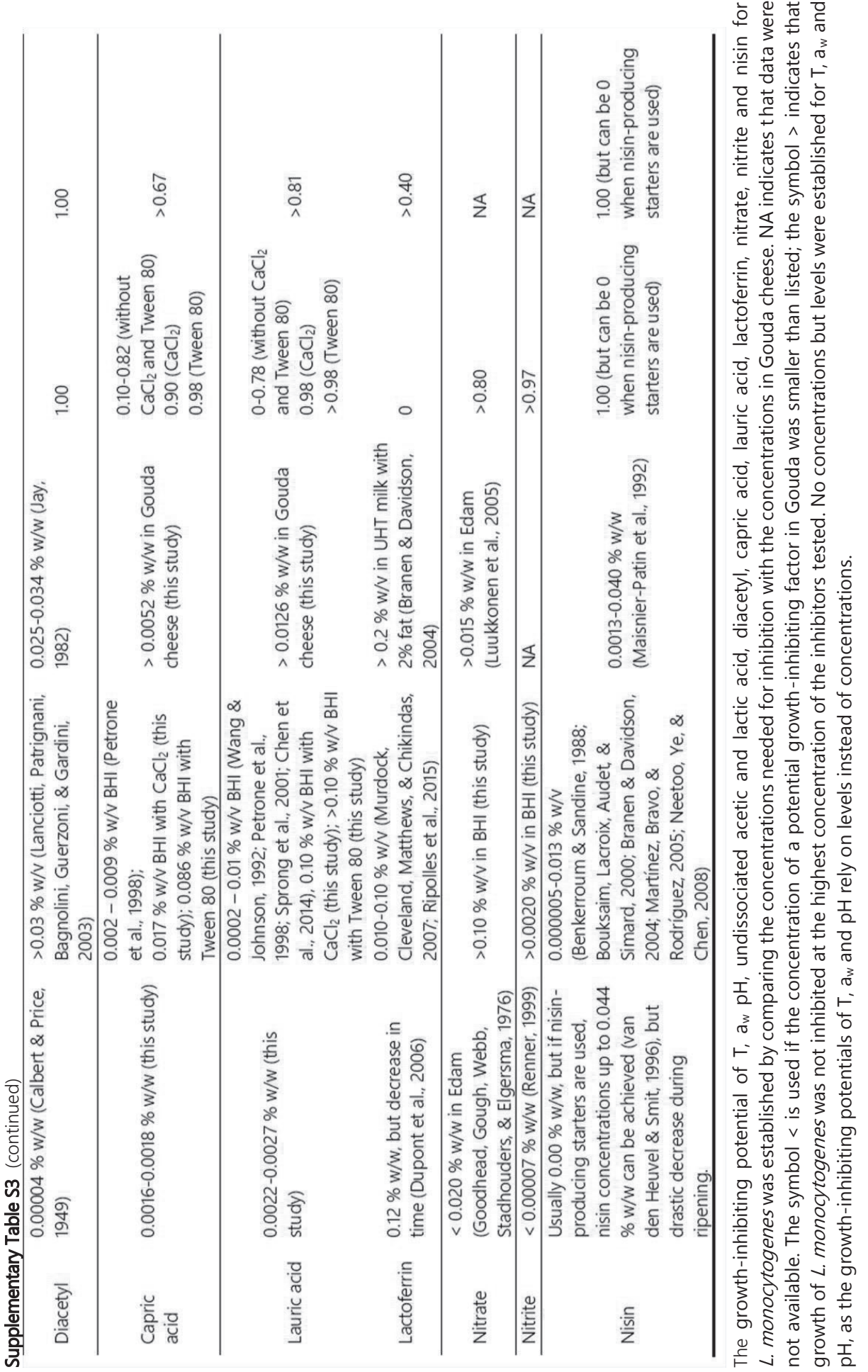




\section{References Supplementary Table S3}

Aryani, D.C., den Besten, H.M.W., Hazeleger, W.C., \& Zwietering, M.H. (2015). Quantifying strain variability in modeling growth of Listeria monocytogenes. International Journal of Food Microbiology 208:19-29.

Benkerroum, N., \& Sandine, W.E. (1988). Inhibitory action of nisin against Listeria monocytogenes. Journal of Dairy Science 71:3237-3245.

Bouksaim, M., Lacroix, C., Audet, P., \& Simard, R.E. (2000). Effects of mixed starter composition on nisin Z production by Lactococcus lactis subsp. lactis biovar. diacetylactis UL 719 during production and ripening of Gouda cheese. International Journal of Food Microbiology 59:141-156.

Branen, J.K., \& Davidson, P.M. (2004). Enhancement of nisin, lysozyme, and monolaurin antimicrobial activities by ethylenediaminetetraacetic acid and lactoferrin. International Journal of Food Microbiology 90:63-74.

Calbert, H.E., \& Price, W.V. (1949). A study of the diacetyl in cheese. I. Diacetyl content and flavor of Cheddar cheese. Journal of Dairy Science 32:515-520.

Chen, Y., Nummer, B., \& Walsh, M.K. (2014). Antilisterial activity of lactose monolaurate in milk, drinkable yogurt and cottage cheese. Letters in Applied Microbiology 58:156-162.

Dupont, D., Arnould, C., Rolet-Repecaud, O., Duboz, G., Faurie, F., Martin, B., \& Beuvier, E. (2006). Determination of bovine lactoferrin concentrations in cheese with specific monoclonal antibodies. International Dairy Journal 16:1081-1087.

El-Shenawy, M.A., \& Marth, E.H. (1990). Behavior of Listeria monocytogenes in the presence of gluconic acid and during preparation of Cottage cheese curd using gluconic acid. Journal of Dairy Science 73:1429-1438.

Fox, P.F., McSweeney, P.L.H., Cogan, T.M., \& Guinee, T.P. (2004). Cheese: Chemistry, Physics and Microbiology (3rd ed.). Vol. 1, pp. 1-617 \& Vol. 2, pp. 1-434. London: Elsevier Academic Press.

Giannou, E., Kakouri, A., Matijasic, B.B., Rogelj, I., \& Samelis, J. (2009). Fate of Listeria monocytogenes on fully ripened Greek Graviera cheese stored at 4,12 , or $25^{\circ} \mathrm{C}$ in air or vacuum packages: in situ PCR detection of a cocktail of bacteriocins potentially contributing to pathogen inhibition. Journal of Food Protection 72:531-538.

Glass, K.A., Prasad, B.B., Schlyter, J.H., Uljas, H.E., Farkye, N.Y., \& Luchansky, J.B. (1995). Effects of acid type and AltaTM2341 on Listeria monocytogenes in a Queso Blanco type of cheese. Journal of Food Protection 58:737-741.

Goodhead, K.T.A., Gough, K.S., Webb, J., Stadhouders, H., \& Elgersma, R.H.C. (1976). The use of nitrate in the manufacture of Gouda cheese. Lack of evidence of nitrosamine formation. Netherlands Milk Dairy Journal 30:207-221.

ICMSF (1996). Microorganisms in foods, Vol. 5, Microbiological specifications of food pathogens. London: Blackie, UK.

Jay, J.M. (1982). Antimicrobial properties of diacetyl. Applied and Environmental Microbiology 44:525532.

Lanciotti, R., Patrignani, F., Bagnolini, F., Guerzoni, M.E., \& Gardini, F. (2003). Evaluation of diacetyl antimicrobial activity against Escherichia coli, Listeria monocytogenes and Staphylococcus aureus. Food Microbiology 20:537-543. 
Luukkonen, J., Kemppinen, A., Kärki, M., Laitinen, H., Mäki, M., Sivelä, S., Taimisto, A.-M., \& Ryhänen, E.L. (2005). The effect of a protective culture and exclusion of nitrate on the survival of enterohemorrhagic E. coli and Listeria in Edam cheese made from Finnish organic milk. International Dairy Journal 15:449-457.

Maisnier-Patin, S., Deschamps, N., Tatini, S.R., \& Richard, J. (1992). Inhibition of Listeria monocytogenes in Camembert cheese made with a nisin-producing starter. Lait 72:249-263.

Martínez, B., Bravo, D., \& Rodríguez, A. (2005). Consequences of the development of nisin-resistant Listeria monocytogenes in fermented dairy products. Journal of Food Protection, 68:2383-2388.

Murdock, C.A., Cleveland, J., Matthews, K.R., \& Chikindas, M.L. (2007). The synergistic effect of nisin and lactoferrin on the inhibition of Listeria monocytogenes and Escherichia coli O157:H7. Letters in Applied Microbiology 44:255-261.

Neetoo, H., Ye, M., \& Chen, H. (2008). Potential antimicrobials to control Listeria monocytogenes in vacuum-packaged cold-smoked salmon pâté and fillets. International Journal of Food Microbiology 123:220-227.

Petrone, G., Conte, M.P., Longhi, C., Di Santo, S., Superti, F. Ammendolia, M.G., Valenti, P., \& Seganti, L. (1998). Natural milk fatty acids affect survival and invasiveness of Listeria monocytogenes. Letters in Applied Microbiology 27:362-368.

Renner, E., 1993. Nutrition aspects of cheese. Pages 557-580 in Cheese: chemistry, physics and microbiology. Vol. 1 (2nd ed.) Fox, P.F. (Eds.) Aspen Publishers, New York, USA.

Ripolles, D., Harouna, S., Parrón, J.A., Calvo, M., Pérez, M., Carramiňana, J.J., \& Sánchez, L. (2015). Antibacterial activity of bovine milk lactoferrin and its hydrolysates prepared with pepsin, chymosin and microbial rennet against foodborne pathogen Listeria monocytogenes. International Dairy Journal 45:15-22.

Sprong, R.C., Hulstein, M.F.E., \& van der Meer, R. (2001). Bactericidal activities of milk lipids. Antimicrobial Agents and Chemotherapy 45:1298-1301.

Stadhouders, J. (1974). Dairy starter cultures. Milchwissenschaft 29:329-337.

van den Heuvel, J.A.M., \& Smit, G. (1996). De bruikbaarheid van nisineproducerend zuursel voor de onderdrukking van de pathogene bacteriën Listeria monocytogenes en Staphylococcus aureus. NOV-2053v. NIZO. Ede, The Netherlands, NIZO food research.

Wang, L.L., \& Johnson, E.A. (1992). Inhibition of Listeria monocytogenes by fatty acids and monoglycerides. Applied and Environmental Microbiology 58:624-629.

Wemmenhove, E., van Valenberg, H.J., Zwietering, M.H., van Hooijdonk, A.C.M., \& Wells-Bennik, M.H.J. (2016a). Minimal inhibitory concentrations of undissociated lactic, acetic, citric and propionic acid for Listeria monocytogenes under conditions relevant to cheese. Food Microbiology 58:63-67.

Wemmenhove, E., Wells-Bennik, M.H., Stara, A., van Hooijdonk, A.C.M., \& Zwietering, M.H. (2016b). How $\mathrm{NaCl}$ and water content determine water activity during ripening of Gouda cheese, and the predicted effect on inhibition of Listeria monocytogenes. Journal of Dairy Science 99:5192-5201. 
Supplemental Material S1 Description of the inhibitory effects of $\mathrm{T}, \mathrm{a}_{\mathrm{w}}, \mathrm{pH}$, lactic and acetic acid, using Gamma factors.

The Gamma factors for $\mathrm{T}, \mathrm{a}_{\mathrm{w}}$ and $\mathrm{pH}$ were described in the literature according to the multiplicative approach established by Zwietering, Wijtzes, de Wit, \& van 't Riet (1992):

$$
\mu_{\max }=\mu_{o p t} \cdot \gamma(T) \cdot \gamma\left(a_{w}\right) \cdot \gamma(p H) \cdot \gamma(i)
$$

with $\gamma(T), \gamma\left(a_{w}\right)$ and $\gamma(p H)$ as the Gamma factors for $\mathrm{T}, \mathrm{a}_{\mathrm{w}}$ and $\mathrm{pH}$, and with $\gamma(i)$ as the Gamma factors for the other growth-inhibiting factors identified.

The conditions for the factors $\mathrm{T}, \mathrm{a}_{\mathrm{w}}$ and $\mathrm{pH}$ in Gouda cheese are suboptimal for growth of L. monocytogenes (e.g. $\mathrm{pH}<7.0, \mathrm{a}_{\mathrm{w}}<1.00$ and $\mathrm{T}<37^{\circ} \mathrm{C}$ ). The potential of these growth inhibitors on L. monocytogenes was calculated from the Gamma factors of $\mathrm{T}, \mathrm{a}_{\mathrm{w}}$ and $\mathrm{pH}$ defined previously by te Giffel and Zwietering (1999):

$$
\gamma(T)=\left(\frac{\left(T-T_{\min }\right)}{\left(T_{o p t}-T_{\min }\right)}\right)^{2}
$$

with $T_{\min }=-1.5^{\circ} \mathrm{C}$ and $T_{o p t}=37^{\circ} \mathrm{C}$.

$$
\gamma\left(a_{w}\right)=\frac{a_{w}-a_{w, \min }}{1-a_{w, \min }}
$$

with $a_{w, \min }=0.920$.

$$
\gamma(p H)=\frac{\left(p H-p H_{\min }\right) \cdot\left(2 \cdot p H_{o p t}-p H_{\min }-p H\right)}{\left(p H_{o p t}-p H_{\min }\right)^{2}}
$$

with $p H_{\text {min }}=4.4$ and $p H_{\text {opt }}=7.0$.

The Gamma factor for undissociated lactic acid was obtained from the literature:

$$
\gamma(x)(\text { undissociated lactic acid })=1-\frac{H L a c_{\text {water }}}{H L a c_{M I C}}
$$

with $H L a c_{\text {water }}$ as the concentration of the undissociated acid present in the water phase of the cheese and $H_{L A C}$ MIC as the undissociated concentration of the acid found to be needed to inhibit growth of L. monocytogenes in culture medium.

Equation [6.5] was slightly altered for undissociated acetic acid based on observations of Le Marc et al. (2002):

$$
\gamma(x)(\text { undissociated acetic acid })=1-\sqrt{\frac{\text { HAcet }_{\text {water }}}{\text { HAcet }_{\text {MIC }}}}
$$




\section{References Supplemental Material S1}

te Giffel M.C., \& Zwietering, M.H. (1999). Validation of predictive models describing the growth of Listeria monocytogenes. International Journal of Food Microbiology 46:135-149.

Zwietering M.H., Wijtzes, T., de Wit, J.C., \& van 't Riet K. (1992). A decision support system for prediction of microbial spoilage in foods. Journal of Food Protection 55:973-979. 
Supplemental Material S2 Experimental design for determination of growth inhibition of L. monocytogenes by nitrate and nitrite in $\mathrm{BHI}$ and by capric acid and lauric acid in $\mathrm{BHI}$ and in model cheeses.

\section{Growth inhibition by nitrate and nitrite in BHI}

Inhibitory effects of nitrate (VWR, Amsterdam, The Netherlands) and nitrite (VWR) were established in Brain Heart Infusion (BHI, Merck, Darmstadt, Germany) set at pH 7.0. Inhibition was investigated for three individual strains of L. monocytogenes. Scott $\mathrm{A}$ (serotype $4 \mathrm{~b}$, human isolate from a listeriosis outbreak with pasteurized milk), $2 \mathrm{~F}$ (serotype $1 / 2 \mathrm{a}$, cheese isolate) and $6 \mathrm{E}$ (serotype $1 / 2 \mathrm{a}$, cheese equipment isolate). Strains were grown overnight in BHI before exposure and added at a final initial concentration of $\sim 2.5 \cdot 10^{6} \mathrm{cfu} \mathrm{mL}^{-1}$. The exposure experiment included a positive and negative control and was performed in 96-well microtiter plates (Greiner Bio-One, Frickenhausen, Germany) in which successive concentrations of nitrate ( 5 times serially diluted, concentrations varying from $0.063 \mathrm{~g} \mathrm{~L}^{-1}$ to $1.0 \mathrm{~g} \mathrm{~L}^{-1}$ ) and nitrite (5 times serially diluted, concentrations varying from $0.0013 \mathrm{~g} \mathrm{~L}^{-1}$ to $0.020 \mathrm{~g} \mathrm{~L}^{-1}$ ) were incubated at $30^{\circ} \mathrm{C}$ for $24 \mathrm{~h}$ The growth/no growth limits were established based on optical density measured at $630 \mathrm{~nm}$ using an EL808 IU-PC spectrophotometer (Bio-Tek, Winooski, Vermont, USA). No growth was defined as the concentration of the component where no increase in optical density greater than 0.05 (compared to the negative control) was observed in three separate wells in two independent experiments. Growth/no growth limits were confirmed by pour-plating on PALCAM-Listeria selective agar (VWR).

\section{Capric acid and lauric acid in BHI}

The experiments in BHI (Merck) were performed with and without $4.4 \mathrm{~g} \mathrm{~L}^{-1} \mathrm{CaCl}_{2}$ (Merck) and $11 \mathrm{~g} \mathrm{~L}^{-1}$ emulsifier Tween 80 (Merck). The individual inhibitory effects of capric and lauric acid on growth of $L$. monocytogenes were evaluated at 0, 0.2, 1.0 and $5.0 \mathrm{mM}$ in 96-well microtiter plates containing filter sterilized BHI of pH 5.2 or 6.6. Stock solutions (200 $\mathrm{mM}$ ) of capric acid (Fluka, Buchs, Switzerland) and lauric acid (Fluka) were prepared by dissolving capric and lauric acid in $0.1 \mathrm{M} \mathrm{KOH}$ (Scharlau Chemie SA, Barcelona, Spain). The stock solutions of capric and lauric acid were dissolved at 45 ${ }^{\circ} \mathrm{C}$ and were then kept for $24 \mathrm{~h}$ at $37^{\circ} \mathrm{C}$. Prior to the exposure, the stock solutions were diluted in sterile physiological peptone solution (Biotrading Benelux, Mijdrecht, The Netherlands) warmed at $37^{\circ} \mathrm{C}$ to keep the free fatty acids dissolved but prevent exposure of $\mathrm{L}$. monocytogenes to a high concentration of $\mathrm{KOH}$ in $\mathrm{BHI}$. Each well was inoculated with an overnight culture of L. monocytogenes Scott A (initially $\sim 10^{7} \mathrm{cfu} \mathrm{mL}^{-1}$ ) and then continuously stirred at $60 \mathrm{rpm}$ for $24 \mathrm{~h}$ at $30^{\circ} \mathrm{C}$. Each experiment included a negative control and all experiments were performed in triplicate.

\section{Capric acid and lauric acid in model Gouda cheeses}

The inhibitory potential of free fatty acids on L. monocytogenes in Gouda cheese was established using the microcheese protocol (Bachmann, Kruijswijk, Molenaar, Kleerebezem, \& van Hylckama Vlieg, 2009; Wemmenhove et al., 2013). Lipase from a non-pathogenic, non-toxigenic strain of $A$. niger (Sigma-Aldrich, St Louis, MO, USA) was added to part of the microcheeses to obtain elevated concentrations of free fatty acids (e.g. 47 (SD 5) mM capric acid and 119 (SD 10) mM lauric acid instead of 17 (SD 2) mM capric acid and 24 (SD 4) mM lauric acid, as determined in two individual experiments according to de Jong \& Badings (1990). The lipase was prediluted in a phosphate buffer of pH 7.0, kept overnight refrigerated and then added at $0.8 \mathrm{~g} \mathrm{~L}^{-1}$ cheese milk just prior to addition of rennet and DL-starter culture. Simultaneously, L. monocytogenes Scott A cultured overnight in BHI (Merck) was added at $\sim 10^{7} \mathrm{cfu} \mathrm{mL}^{-1}$ to simulate a worst-case scenario with a severe recontamination immediately after pasteurization of the cheese milk. Samples were taken from the inoculated cheese milk, the first and second whey and from the curds $0.7,4$ and $24 \mathrm{~h}$ after renneting. L. monocytogenes was enumerated in duplicate by serial dilution in peptone physiological salt solution and pour-plating on PALCAM-Listeria selective agar, including a negative control. 


\section{References Supplemental Material S2}

Bachmann, H., Kruijswijk, Z., Molenaar, D., Kleerebezem, M., \& van Hylckama Vlieg, J.E.T. (2009). A highthroughput cheese manufacturing model for effective cheese starter culture screening. Journal of Dairy Science 92:5868-5882.

De Jong, C. \& Badings, H.T. (1990). Determination of free fatty acids in milk and cheese - Procedures for extraction, clean up, and capillary gas chromatographic analysis. Journal of High Resolution Chromatography 13:94-98.

Wemmenhove, E., Stampelou, I., van Hooijdonk, A.C.M., Zwietering, M.H., \& Wells-Bennik, M.H.J. (2013). Fate of Listeria monocytogenes in Gouda microcheese: No growth, and substantial inactivation after extended ripening times. International Dairy Journal 32:192-198. 
Supplemental Material S3 Calculation of the concentration of undissociated lactic acid in the water phase of Gouda cheese.

Assuming that Gouda cheese is a homogeneous product in which organic acid is evenly distributed, the total amount of organic acid present in cheese in $\% \mathrm{w} / \mathrm{w}$ cheese can be converted to the total organic acid concentration ( $\mathrm{mol} \mathrm{L}^{-1}$ ) in the cheese. Then the concentration of undissociated acid can be calculated using the Henderson-Hasselbalch equation:

$$
p K_{a}=-\log \frac{\left[H^{+}\right]\left[A^{-}\right]}{[H A]}
$$

Following this equation and the previous assumptions, the following relationship applies:

$$
[H A]=\frac{[\text { Total acid }]}{1+10^{p H-p K_{a}}}
$$

However, Gouda cheese is actually an inhomogeneous product, consisting of water, fat, and water bound to proteins and non-protein/non-fat dry matter. The concentration of undissociated acid should actually be calculated in the water phase, as acids inhibit growth of bacteria mainly through their undissociated form and when present in the water phase (Mitchell, 1961) and we believe only organic acid in the water phase will access L. monocytogenes, which is primarily located on interface of the fat /protein structure of cheese (Kalab, 1979).

Taking lactic acid, being the major organic acid in Gouda cheese, as an example for this calculation, cheese was divided into three different phases:

proteins+minerals+added salt;

water, containing HLac, $\mathrm{LaC}^{-}$and $\mathrm{H}^{+}$;

-and fat, containing HLac.

Organic acids may be present in both the water phase (in the undissociated or dissociated form) and the fat phase (in the undissociated form) of cheese. This yields in:

$$
\text { Total lactic acid }=H L a c_{\text {water }}+L_{a c^{-}} \text {water }+H L a c_{\text {fat }}
$$

in which Total lactic acid is the total amount of lactic acid formed in the cheese.

The concentration of undissociated lactic acid that is present in the water phase strongly depends on the volume ( $V$ ) of water, which decreases during brining and ripening of the cheese:

$$
V_{\text {cheese }}=V_{\text {water }}+V_{\text {fat }}+V_{\text {protein }+ \text { minerals }+ \text { salt }}
$$

with $V_{\text {water }}$ representing the volume of water that can contain undissociated lactic acid.

The logarithmic partition coefficient $\left(\log P_{f w}\right.$ ) of lactic acid between milk fat and water ( $\mathrm{fw}$ ) can be established by the following equation:

$$
\log P_{f w}=\log \frac{[\text { HLac }]_{\text {fat }}}{[\text { HLac }]_{\text {water }}}
$$


Equations [6.7], [6.9], [6.10] and [6.11] can be rewritten:

Total lactic acid $=$ HLac $_{\text {water }}+\mathrm{Lac}^{-}{ }_{\text {water }}+\mathrm{HLac}_{\text {fat }}$

$1=\varphi_{v_{-} \text {water }}+\varphi_{V_{-} \text {fat }}+\varphi_{v_{\text {proteins,minerals,salt }}}$

$V_{\text {cheese }} \cdot[\mathrm{HLac}]_{\text {Total }}=[\mathrm{HLaC}]_{\text {water }} \cdot V_{\text {water }}+\left[\mathrm{Lac}^{-}\right] \cdot V_{\text {water }}+[\mathrm{HLac}]_{\text {fat }} * V_{\text {fat }}$

$[\mathrm{HLac}]_{\text {Total }}=[\mathrm{HLaC}]_{\text {water }} \cdot \varphi_{v_{-} \text {water }}+\frac{K_{a} \cdot[\mathrm{HLac}]_{\text {water }}}{\left[\mathrm{H}^{+}\right]} \cdot \varphi_{v_{-} \text {water }}+P_{f w} \cdot[\mathrm{HLac}]_{\text {water }} \cdot \varphi_{V_{-} f a t}$

$[H L a c]_{\text {Total }}=[H L a c]_{\text {water }}\left(\varphi_{v_{-} \text {water }}+\frac{K_{a}}{H^{+}} \cdot \varphi_{v_{-} \text {water }}+P_{f w} \cdot \varphi_{V_{-} f a t}\right)$.

This leads to an overall expression for $[H L a c]_{\text {water }}$ :

$$
[\text { HLAc }]_{\text {water }}=\frac{[\mathrm{HLac}]_{\text {Total }}}{\varphi_{v_{-} \text {water }}+10^{p H-p K a} \cdot \varphi_{v_{-} \text {water }}+P_{f w} \cdot \varphi_{V_{-} \text {fat }}}
$$

in which $[\mathrm{HLac}]_{\text {Total }}=$ total lactic acid present within the cheese, $[\mathrm{HLac}]_{\text {water }}=$ undissociated lactic acid present in the watery fraction of the cheese, $\left[\mathrm{Lac}^{-}\right]_{\text {water }}=$ dissociated lactic acid present in the watery fraction of the cheese, $[\mathrm{HLac}]_{\text {fat }}=$ undissociated lactic acid present in the fat fraction of the cheese. Components surrounded by square brackets are expressed as concentrations $(\mathrm{M})$ and components not surrounded by square brackets are expressed as content (mol). Furthermore, $\varphi_{v_{-} \text {water, }} \varphi_{V_{-} \text {fat }}$ and $\varphi_{v_{\text {proteins,minerals,salt }}}$ indicate the volume fractions of water, fat and proteins/minerals/salt, and $V_{\text {water }}$ and $V_{\text {fat }}$ indicate the volumes of water and fat. $p K_{a}$ is the logarithmic constant of the dissociation constant for lactic acid and $P_{f w}$ describes the partition of undissociated lactic acid between fat and water (Eq. 6.11).

\section{References Supplemental Material S3}

Kalab, M. (1979). Microstructure of dairy foods. 1. Milk products based on protein. Journal of Dairy Science 62:1352-1364.

Mitchell, P. (1961). Coupling of phosphorylation to electron and hydrogen transfer by a chemi-osmotic type of mechanism. Nature 191:144-148. 
Supplemental Material S4 Determination of $\mathrm{pK}_{\mathrm{a}}$ and $\log P_{f w}$ for undissociated lactic acid in Gouda cheese.

$$
\mathbf{p K a}
$$

The $\mathrm{pK}_{\mathrm{a}}$ for lactic acid is 3.86 in water containing only $\mathrm{HLac}, \mathrm{H}^{+}$and $\mathrm{Lac}^{-}$ions (Lide, 2006). The $\mathrm{pK}_{\mathrm{a}}$ of lactic acid in cheese is lower, as $\mathrm{Ca}^{2+}$ and $\mathrm{Na}^{+} \mathrm{Ca}^{2+}$ and $\mathrm{Na}^{+}$are present in cheese at high concentrations (Holland, Unwin, \& Buss, 1989), allowing them to complex with Lac' and therewith limit complexation of Lac' with $\mathrm{H}^{+}$(Martell \& Smith, 1977; Morris, Holt, Brooker, Banks, \& Manson, 1988; Gao, 2010), lowering the actual $\mathrm{pK}_{\mathrm{a}}$ in the water phase of cheese and thus also lowering the actual concentration of HLac present in cheese. Morris et al. (1988) analyzed juice from a 4-week old Cheddar cheese and determined HLac of $10.2 \mathrm{mM}_{\text {, Lac }}^{-}$of $337.7 \mathrm{mM}$ and $\mathrm{H}^{+}$of 5.89.10$3 \mathrm{mM}$, resulting in a calculated $\mathrm{pK}_{\mathrm{a}}$ of lactic acid of 3.71. We assumed the same $\mathrm{pK}_{\mathrm{a}}$ for lactic acid in Gouda as in Cheddar, as Gouda resembles Cheddar in pH, ion composition and ionic strength (Holland et al., 1989).

$$
\log P_{f w}
$$

The logarithmic octanol/water partition coefficient for HLac is -0.6 . We determined the logarithmic partition coefficient of HLactate between milk fat and water $\left(\log P_{f w}\right)$, as cheese contains no octanol but milk fat, which could be more apolar than octanol, and therefore a lower logarithmic partition coefficient of HLac can be expected for milk fat than for octanol. The $\log P_{f w}$ for HLactate was established based on $[\text { HLac }]_{\text {total }}$ and $[\mathrm{HLac}]_{\text {water }}$ by making samples containing known amounts of anhydrous milk fat, L-lactic acid and $\mathrm{HCl}$ and rotating these samples for $24 \mathrm{~h}$ before analysis of the concentration of lactic acid in the water phase $\left([\mathrm{HLac}]_{\text {water }}\right)$ and to the initial concentration of lactic acid that was added to the sample ([HLac $\left.]_{\text {total }}\right)$, as the following accounts in the milk fat sample:

$$
H L a c_{\text {total }}=H L a c_{\text {milk fat }}+H L a c_{\text {water }}
$$

Anhydrous milk fat (AMF) was obtained from pasteurized cream containing 99.99\% milk fat (FrieslandCampina, Noordwijk, The Netherlands). L-lactic acid (Alfa Aesar, Karlsruhe, Germany) was diluted to an initial concentration of $0.01 \mathrm{M}$. AMF and L-lactic acid were carefully weighed before mixing in different ratios (25/75, 50/50 and 75/25). AMF was liquefied at $40^{\circ} \mathrm{C}$ before L-lactic acid was added. A known amount of $1.0 \mathrm{M} \mathrm{HCl}$ (Merck) was then added to the samples to lower the $\mathrm{pH}$ to 2.8 to make sure all lactic acid was undissociated. Subsequently, the samples were rotated around the transverse axis (20 rpm) on a PTR-60 mechanical shaker (Grant Instruments Ltd., Shepreth, United Kingdom). Rotation for $24 \mathrm{~h}$ was followed by equilibration of the samples for $1 \mathrm{~h}$ at $21^{\circ} \mathrm{C}$ and centrifugation (4000 $\mathrm{g} \times 15 \mathrm{~min}$ ) at $5^{\circ} \mathrm{C}$ to ensure the separation of the water and fat phase and to prevent inclusion of fat in the water phase. After centrifugation, the water phase of each sample was obtained by use of a syringe and the concentration of lactic acid was analyzed at a wavelength of $210 \mathrm{~nm}$ by RP-HPLC using a Diode Array Detector with an eluent of a $20 \mathrm{mM}$ potassium phosphate buffer of $\mathrm{pH} 2.5$ and a flow of $1 \mathrm{~mL} \mathrm{~min}^{-1}$. The $\log P_{f w}$ was determined in duplicate. The determination included negative controls $(1.0 \mathrm{M} \mathrm{HCl}$ and the water phase from demineralised water that was mixed with AMF) and a calibration curve for lactic acid (0, 1, 5, 10 and $50 \mathrm{mM})$. No lactic acid was detected in the negative controls, so the concentration of lactic acid present in milk fat by nature was negligible, and lactic acid was only introduced in the sample by addition of $0.010 \mathrm{M} \mathrm{L-lactic} \mathrm{acid.}$ 
Logarithmic partition coefficient $\left(\log P_{f w}\right)$ of lactic acid between milk fat and water, as determined in three different mass fractions of AMF and water containing $0.01 \mathrm{M}$ lactic acid (75\% AMF and 25\% water, 50\% AMF and 50\% water, $25 \%$ AMF and $75 \%$ water) and rotating these samples for $24 \mathrm{~h}$ at $21{ }^{\circ} \mathrm{C}$. The concentration of lactic acid was analyzed in the water phase $\left([\mathrm{HLac}]_{\text {water }}\right.$ ) and compared to the concentration of lactic acid that was initially added to the sample ([HLac $\left.]_{\text {total }}\right)$. The $\log P_{f w}$ of lactic acid was determined in duplicate.

\begin{tabular}{lccc}
\hline & $\log \boldsymbol{P}_{f w}$ (duplo 1) & $\log \boldsymbol{P}_{f w}$ (duplo 2) & $\log \boldsymbol{P}_{f w}$ (average) \\
\hline 75\% AMF/25\% water: & -1.4 & -1.3 & -1.4 \\
\hline $50 \%$ AMF/50\% water: & -1.6 & -1.4 & -1.5 \\
\hline $25 \%$ AMF/75\% water: & -1.9 & -1.5 & -1.7 \\
\hline $\begin{array}{l}\text { Average of all } \log P_{f w} \\
\text { values determined: }\end{array}$ & & & -1.5 \\
\hline
\end{tabular}

\section{References Supplemental Material S4}

Gao, R. (2010). Ion speciation in milk-like systems. (PhD thesis), 250 p., Wageningen University, The Netherlands.

Holland, B., Unwin, I.D., \& Buss, D.H. (1989). Milk products and eggs. Fourth supplement to McCance and Widdowson's The Composition of Foods. Cambridge: Royal Society of Chemistry.

Lide, D.R. (2006). CDC Handbook on Chemistry and Physics (87th edition). Boca Raton, Florida: CRC.

Lou, Y., \& Yousef, A.E. (2000). Characteristics of Listeria monocytogenes important to food processors. In Ryser, E.T., \& Marth, E.H. Listeria, Listeriosis and Food Safety. New York: Marcel Dekker.

Martell, A.E., \& Smith, R.M. (1977). Critical stability constants. N.Y.P. Press. Vol. 3, 495 p.

Morris, H.A., Holt, C., Brooker, B.E., Banks, J.M., \& Manson, W. (1988). Inorganic constituents of cheese: analysis of juice from a one-month old Cheddar cheese and the use of light and electron microscopy to characterize the crystalline phases. Journal of Dairy Research 55:255-268. 
Chapter 7

General discussion 


\subsection{Introduction}

Ensuring the safety of foods that are placed on the market is paramount to the food industry. This relates to many different hazards, for instance, chemical contaminants, microbial contaminants, foreign bodies and allergens. Amongst the microbial contaminants, many different pathogenic foodborne bacteria can pose a threat to the health of consumers when present in foods. One of these is the pathogen Listeria monocytogenes, which can cause listeriosis. This pathogen is of particular concern to ready-to-eat foods, i.e. products that do not undergo a heat treatment prior to consumption. Food product categories that have been associated with listeriosis outbreaks include meat, seafood and dairy products. In cases of listeriosis that have been associated with dairy products, especially consumption of raw milk and soft cheeses that were contaminated with L. monocytogenes have been linked with the disease. Listeriosis has only sporadically been linked with consumption of semi-hard and hard cheeses, and in cases in which such cheeses were involved, those cheeses were possibly made from raw milk. L. monocytogenes may be present in raw milk at low concentrations, but pasteurization is an effective and widely used procedure to reduce the concentrations of the pathogen in finished products. L. monocytogenes may be persistent in the processing environment and thus, potential contamination of finished products must be controlled as well.

An important cheese type for the Dutch dairy industry is Gouda cheese. Gouda cheese has been categorized in various ways by scientists and legislators with respect to its risk related to L. monocytogenes. The Codex General Standard for Cheese (Codex, 2013) classifies cheese based on the moisture on a fat free basis (MFFB). Gouda, with an MFFB between 53 and 63\% (van den Berg, Meijer, Düsterhöft, \& Smit, 2004), is considered a firm/semi-hard cheese. The classification of cheese by the Food and Drug Administration (FDA, 2003) of the USA is based on the moisture on whole cheese content (moisture\%). Gouda, having a moisture\% of 39 to $50 \%$, is put in the group of semi-soft cheeses by the FDA, together with blue, brick, Monterey and Münster cheese. For the group of semi-soft cheeses, the relative risk of association with L. monocytogenes causing listeriosis is classified as low (FDA, 2003). In the European food safety criteria for RTE foods EC 2073/2005 (European Commission, 2005), products are categorized based on their ability to support growth of L. monocytogenes. 
Gouda has a $\mathrm{pH}>5.0$ and $\mathrm{a}_{\mathrm{w}}>0.94$. Taking only $\mathrm{pH}$ and $\mathrm{a}_{\mathrm{w}}$ criteria into account, Gouda falls into category 1.2 of products that may be able to support the growth of L. monocytogenes (with a maximum limit of $L$. monocytogenes $100 \mathrm{cfu} \mathrm{g}^{-1}$ with $\mathrm{n}=5$ for products placed on the market during their shelf-life*, or absence in $25 \mathrm{~g}$ with $\mathrm{n}=5$ before the food has left the control of the food business operator, who has produced it**), unless it can be proven that the product does not support growth.

Gouda can be made from pasteurized or raw milk. Gouda cheese, when made from pasteurized milk, has never been linked to listeriosis and the only published challenge study of L. monocytogenes in Gouda (Northolt, Vecht, Toepoel, Soentoro, \& Wisselink, 1988) showed survival but no growth of L. monocytogenes during 6 weeks of ripening.

The aim of the work presented in this thesis was to gain a better understanding of factors that inhibit outgrowth of L. monocytogenes in Gouda cheese and to establish criteria related to Gouda cheese composition and properties that warrant safety with respect to L. monocytogenes.

The thesis encompasses five studies (Chapters 2-6). The fate of L. monocytogenes in and on Gouda was assessed by performing two challenge studies. In the first challenge study, L. monocytogenes was added to cheese milk after pasteurization and the fate of the pathogen in Gouda cheese was assessed using micro Gouda cheeses (Chapter 2). The second challenge study was performed using whole Gouda cheeses that were contaminated with L. monocytogenes on the outside during brining (Chapter $\mathbf{3}$ ). The variation in $\mathrm{a}_{\mathrm{w}}$ during the production and ripening of Gouda cheese was evaluated in Chapter 4, and the variation in growth inhibition of L. monocytogenes by organic acid under conditions relevant to Gouda cheese was assessed in Chapter 5. In Chapter 6, the most important factors that determine growth / no growth of L. monocytogenes in Gouda cheese were evaluated based on the minimal inhibitory concentrations (MIC) of antimicrobial substances relevant to Gouda cheese and the actual concentration present in Gouda. Additionally, a criterion was established for growth inhibition of L. monocytogenes in Gouda cheese due to the undissociated lactic acid concentration.

In the following paragraph [7.2] the factors that contribute to the absence of growth of L. monocytogenes in Gouda cheese are addressed. Some insights in the fate of L. monocytogenes in curd are described in paragraph 7.3. To understand the importance of the identified factors that have potential to inhibit growth of L. monocytogenes in various cheeses other than Gouda, growth / no growth of L. monocytogenes was evaluated in 10

\footnotetext{
*This criterion applies if the manufacturer is able to demonstrate, to the satisfaction of the competent authority, that the product will not exceed the limit $100 \mathrm{cfu} \mathrm{g}^{-1}$ throughout the shelf-life. The operator may fix intermediate limits during the process that must be low enough to guarantee that the limit of $100 \mathrm{cfu} \mathrm{g}^{-1}$ is not exceeded at the end of shelf-life.

**This criterion applies to products before they have left the immediate control of the producing food business operator, when he is not able to demonstrate, to the satisfaction of the competent authority, that the product will not exceed the limit of $100 \mathrm{cfu}^{-1}$ throughout the shelf-life.
} 
different types of cheeses in section 7.4. The focus of the work described in this thesis was on nature-ripened whole Gouda cheeses with $48 \%$ w/w fat in dry matter, made from pasteurized milk. The expected fate of L. monocytogenes in other Gouda cheeses (e.g. low-salt, low-fat, slices) is discussed in section 7.5. In the subsequent section 7.6, the importance of undissociated lactic acid as a safety factor in cheese to control L. monocytogenes and implications for applying legislation are discussed. The overall conclusions and recommendations are described in section 7.7.

\subsection{Gouda cheese does not support growth of L. monocytogenes}

In the studies described in this thesis, it was demonstrated that growth of L. monocytogenes is not supported during ripening of Gouda cheese made from artificially contaminated milk. In the studies described, no growth but only survival and inactivation of L. monocytogenes was observed during 2-52 weeks in Gouda cheese that was contaminated with L. monocytogenes during curd formation (Chapter 2). The results are in line with the study of Northolt et al. (1988), who reported survival but no growth of L. monocytogenes in Gouda cheese throughout ripening for 1-6 weeks. In a follow-up study described in Chapter 3, Gouda cheese was contaminated during brining, and inactivation of L. monocytogenes was observed after 2-12 weeks of ripening. The most important factors that are present in Gouda cheese and have an impact on growth of L. monocytogenes were identified as undissociated lactic acid, temperature, $\mathrm{pH}$ and $\mathrm{a}_{\mathrm{w}}$ (Chapter 6). From these four factors, undissociated lactic acid and $a_{w}$ specifically can lead to full growth inhibition of L. monocytogenes in Gouda. Subsequent limits that do not allow for growth of $L$. monocytogenes were established for lactic acid: no growth is predicted at a total lactic acid content of $0.86 \% \mathrm{w} / \mathrm{w}$ for young Gouda with $\mathrm{pH} 5.25$ and $42 \%$ moisture, and $1.26 \%$ w/w for matured Gouda with pH 5.50 and 35\% moisture. Full inhibition of growth of L. monocytogenes by $\mathrm{a}_{\mathrm{w}}$ in Gouda can be expected if $\mathrm{a}_{\mathrm{w}}<0.92$.

The work presented in this thesis focused on the fate of $L$. monocytogenes in finished product, i.e. ready-to-eat Gouda cheese. This product leaves the production facilities of the manufacturer at the earliest 2 weeks after production and is subsequently ripened for at least 2 more weeks. The European food safety criteria for RTE foods (EC 2073/2005) apply to finished ready-to-eat products.

\subsection{Fate of L. monocytogenes during curd formation of Gouda}

In the microcheese study presented in Chapter 2, an increase of 0.5 log cfu g-1 was observed during curd formation. This increase was not caused by growth of L. monocytogenes, but by 
entrapment of L. monocytogenes cells in the curd during whey removal. During curd formation of Gouda, the lactic acid and salt concentrations are relatively low and the temperature is favorable for growth of L. monocytogenes. An increase in the concentration of L. monocytogenes during curd formation was also reported in other challenge studies (Buazzi, Johnson, \& Marth, 1992a; Dominguez, Garayzabal, Vazquiz, Blanco, \& Suarez, 1987; Northolt et al., 1988). Unfortunately, these authors did not specify whether the observed increases resulted from growth or from entrapment in the curd. An increase of L. monocytogenes in the curd of -0.5 to $0.4 \mathrm{log}_{\mathrm{cfu} \mathrm{g}}{ }^{-1}$ was reported for high-moisture Mozzarella (Buazzi et al., 1992a); for semi-hard cheese an increase of 0.2 to $0.7 \mathrm{log} \mathrm{cfu} \mathrm{g}^{-1}$ was found (Dominguez et al., 1987), and for Gouda cheese, a $1.6 \mathrm{log} \mathrm{cfu} \mathrm{g}^{-1}$ has been reported before (Northolt et al., 1988). The highest increase of L. monocytogenes of $1.6 \mathrm{log}_{\mathrm{cfu} \mathrm{g}}{ }^{-1}$ reported by Northolt et al. (1988) is difficult to interpret, as the measuring point was $6 \mathrm{~h}$ after inoculation of the starter culture and the measurement was only performed in singular. Details on curd processing, e.g. amounts of whey and curd, and acidification rate, were lacking in that study. If the time between inoculation and cheese pressing would be $6 \mathrm{~h}$ and if the $\mathrm{pH}$ would only be 5.5 after this time, the acidification rate may have been lower than the acidification rate that is common in current practice. Nowadays, the time between addition of the starter culture to the cheese milk and transformation into a curd that is ready to be pressed is only $3.3 \mathrm{~h}$. At the low acidification rate that appeared to occur during production of Gouda cheese in the study of Northolt et al.

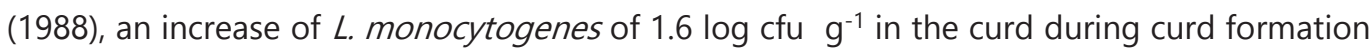
could theoretically be expected (Table 7.1). When considering both growth and entrapment in the curd, an increase of L. monocytogenes of $2.7 \mathrm{log} \mathrm{cfu} \mathrm{g}^{-1}$ is predicted from milk to curd when using $\mu_{\mathrm{opt}}=1.69 \mathrm{~h}^{-1}$ (Table 7.1 and Fig. 7.1a), which is the maximum optimal growth rate of $L$. monocytogenes as extracted from www.combase.cc for milk at temperatures ranging from 30 to $37^{\circ} \mathrm{C}$. An increase of $1.7 \mathrm{log} \mathrm{cfu} \mathrm{g}^{-1}$ is predicted when using $\mu_{\mathrm{opt}}=0.73 \mathrm{~h}^{-1}$, which is the average optimal growth rate as extracted from www.combase.cc. When not considering entrapment of L. monocytogenes in the curd but only growth, increases of 1.7 and $0.74 \mathrm{log}$ cfu are predicted during curd formation when using $\mu_{\mathrm{opt}}=1.69 \mathrm{~h}^{-1}$ and $\mu_{\mathrm{opt}}=0.73 \mathrm{~h}^{-1}$, respectively (Table 7.1 and Fig. 7.1b). The predicted increases did not include lag times or other stress factors that may reduce growth of L. monocytogenes. In practice, a lag time may be present, which Buazzi et al. (1992a) suggested earlier when studying the fate of L. monocytogenes in high-moisture Mozzarella cheese. The $\mu_{\mathrm{opt}}$ values for $L$. monocytogenes extracted from www.combase.cc were based on milk. The actual $\mu_{\text {opt }}$ values may be lower for cheese and curd, as these are semi-solid liquids that could immobilize L. monocytogenes in the matrix. Other reasons for the limited growth 'in situ'as shown in Chapter $\mathbf{2}$ may be growth competition with starter cultures (Beresford, Fitzsimons, Brennan, \& Cogan, 2001) and competitive exclusion due to the presence of lactic acid bacteria (Zhao, Doyle, \& Zhao, 2004). 


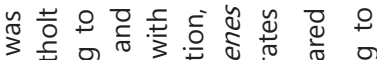

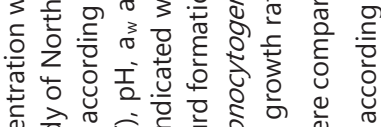

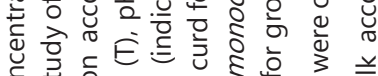

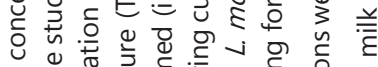
ह

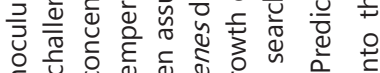

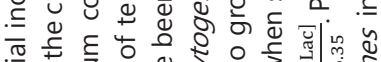

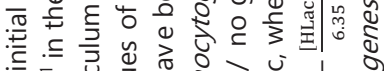
它

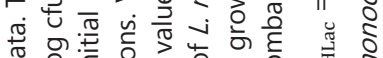

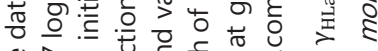

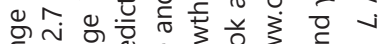

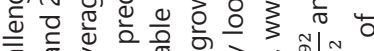

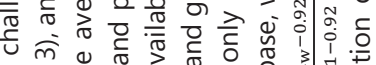

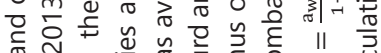

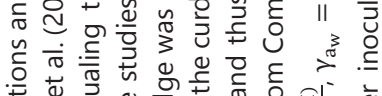

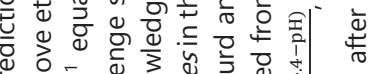

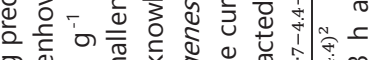
O ब उ

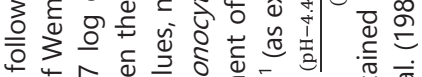

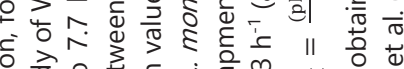

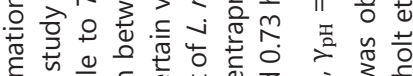

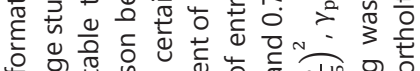

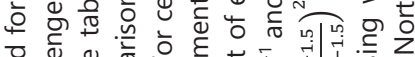

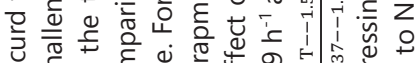

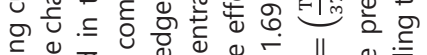

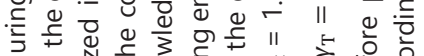

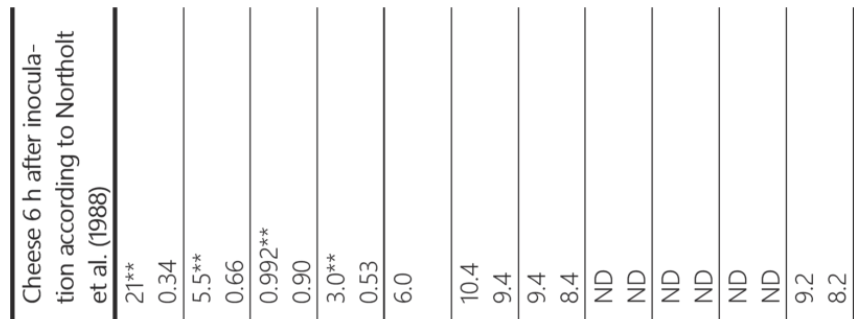

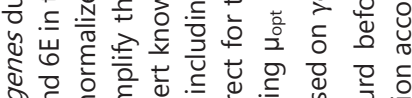

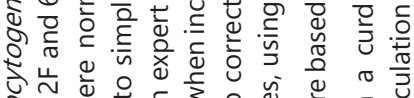

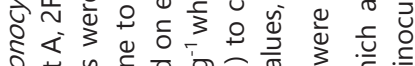

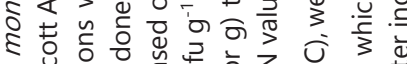

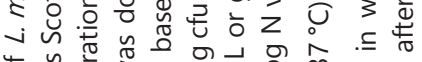

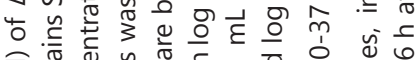

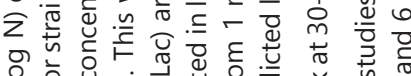
은

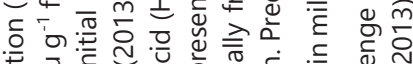

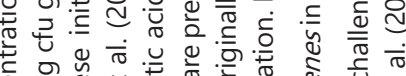

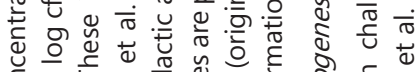

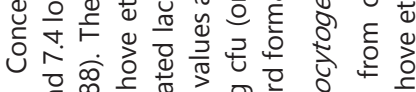

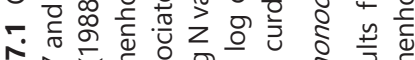

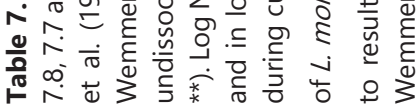

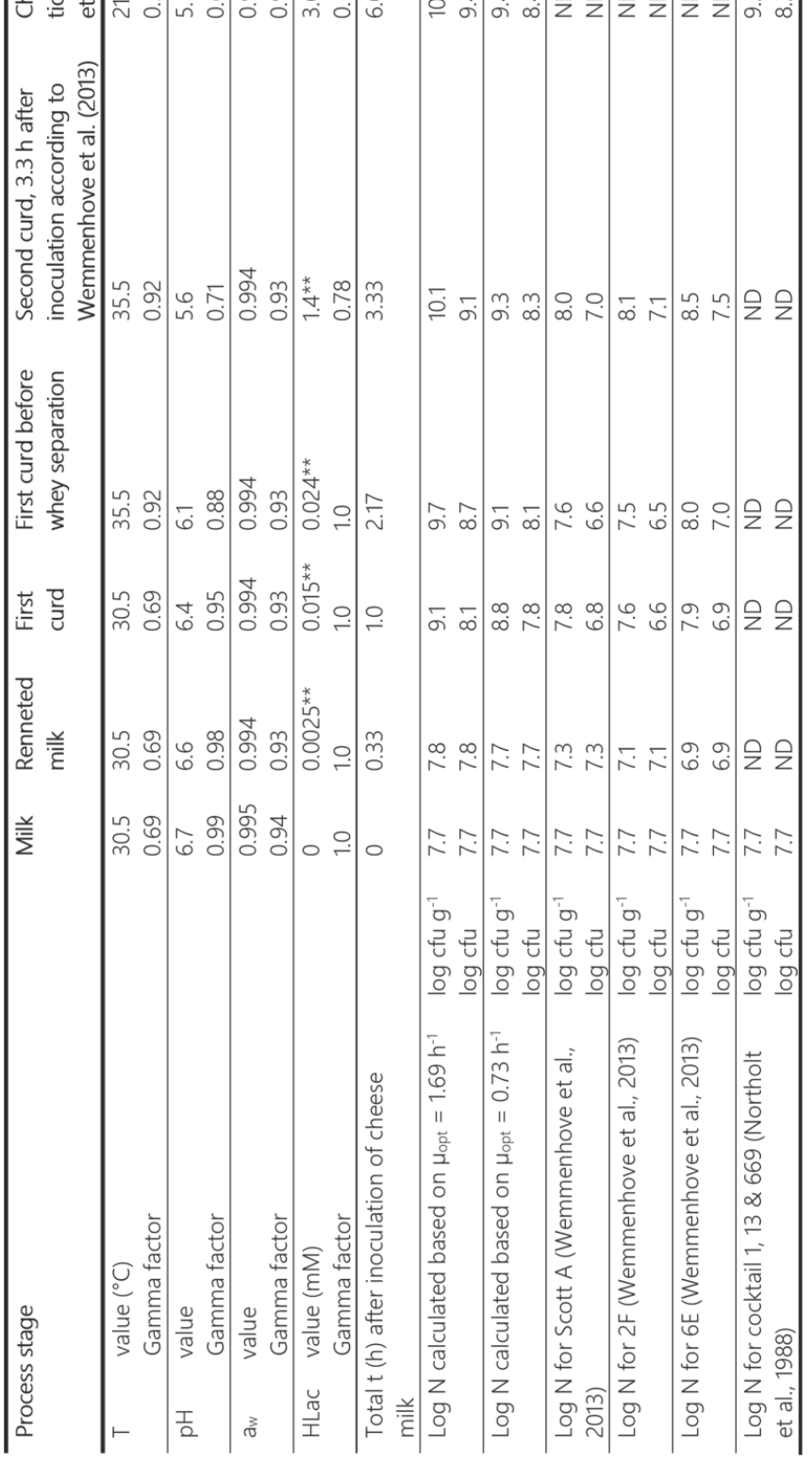




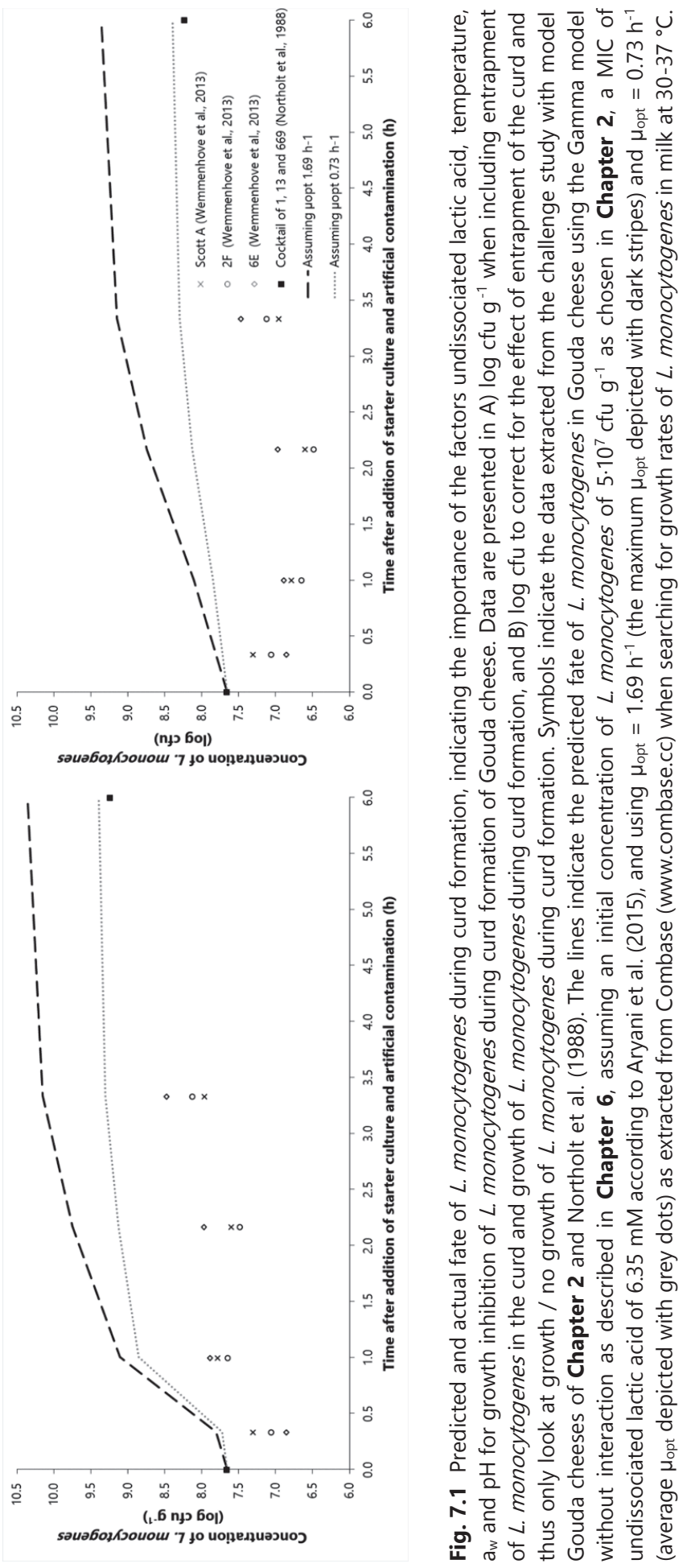




\subsection{The importance of undissociated lactic acid, temperature, $\mathrm{pH}$ and $a_{w}$ in other types of cheeses}

The contribution of undissociated lactic acid, temperature, $\mathrm{pH}$ and $\mathrm{a}_{\mathrm{w}}$ toward the control of L. monocytogenes during ripening of Gouda cheese and nine other cheese types is evaluated below. Per cheese type, available data were extracted from published challenge studies with respect to the fate of L.monocytogenes. In these studies, cheeses were artificially contaminated with L. monocytogenes via the surface/crust, or via the milk/curd. In addition, the growth rates were calculated based on the average values of the aforementioned factors that are relevant to the respective cheeses, whilst using the maximum and average $\mu_{\text {opt }}$ values extracted from www.combase.cc for milk at $30-37{ }^{\circ} \mathrm{C}$, the Gamma factors described in Supplementary Material S1 of Chapter 6, and the concentration of undissociated lactic acid calculated as described in Supplementary Materials S3 and S4 of Chapter 6. The growth rates calculated from the challenge studies and the growth rates of $L$. monocytogenes as predicted based on the characteristics of the different cheeses were compared per cheese type (Fig. 7.2). Similar to Gouda cheese, the same four factors (undissociated lactic acid, temperature, $\mathrm{pH}$ and $a_{w}$ ) appeared to be important for growth inhibition of L. monocytogenes in/on the other types of cheeses. The cheese types selected for the comparison represented all ready-to-eat (RTE) cheese categories identified by the FDA (FDA 2003): fresh soft cheese (Queso Fresco), soft unripened cheeses with $>50 \%$ moisture (Cottage cheese and Ricotta), soft ripened cheeses with $>50 \%$ moisture (Camembert, Feta and high-moisture Mozzarella), semi-soft cheeses with 39-50\% moisture (Blue and Gouda) and hard cheeses with $<39 \%$ moisture (Cheddar and Emmental). For 9 (namely, Ricotta, Queso Fresco, Camembert, high-moisture Mozzarella, Cottage, Blue, Feta, Cheddar and Gouda) out of the above mentioned 10 cheese types, correct predictions of growth / no growth are obtained when including the factors undissociated lactic acid, temperature, $\mathrm{pH}$ and $\mathrm{a}_{\mathrm{w}}$ in the prediction. Growth was correctly predicted for Ricotta, Queso Fresco, Camembert, high-moisture Mozzarella, Cottage and Blue), and no growth was correctly predicted for Feta, Cheddar and Gouda. These results show the importance of undissociated lactic acid, temperature, $\mathrm{pH}$ and $\mathrm{a}_{\mathrm{w}}$ for cheese in general. These four factors do not fully explain why growth of L. monocytogenes is inhibited in practice upon inoculation in cheese or on the surface of Emmental. In the case of Emmental, acetic acid, propionic acid and free fatty acids are possibly important factors for inhibition of growth of L. monocytogenes, in addition to temperature, $\mathrm{pH}$ and $\mathrm{a}_{\mathrm{w}}$. Inhibition of growth of L. monocytogenes by acetic and propionic acid is described in Chapter 5, and by free fatty acids in Chapter $\mathbf{6}$. The actual growth rates of L. monocytogenes in and on high-moisture Mozzarella that have been reported are considerably higher than the predicted growth rates, possibly because the actual growth rates were established at worst-case conditions for $\mathrm{pH}$, whereas the predicted growth rates were based on average conditions for undissociated lactic acid, $\mathrm{pH}$ and $\mathrm{a}_{\mathrm{w}}$. 
The model predictions as presented in this thesis for cheese are based on the Gamma model without interaction between the individual factors (Chapter 6, Supplemental Material S1, S3 and S4), but interactions may exist. Gadotti, Nelson, \& Diez-Gonzalez (2014) reported that a combination of nisin with free fatty acids can fully inhibit growth of L. monocytogenes in Queso Fresco. In another study it was shown that lactoferrin alone did not inhibit growth of L. monocytogenes in UHT milk, but in combination with nisin some growth inhibition was observed (Branen \& Davidson, 2004). Proper understanding of the mechanism of action of each growth-inhibiting factor is necessary to be able to select effective combinations of factors that inhibit growth and to establish an effective control strategy. 


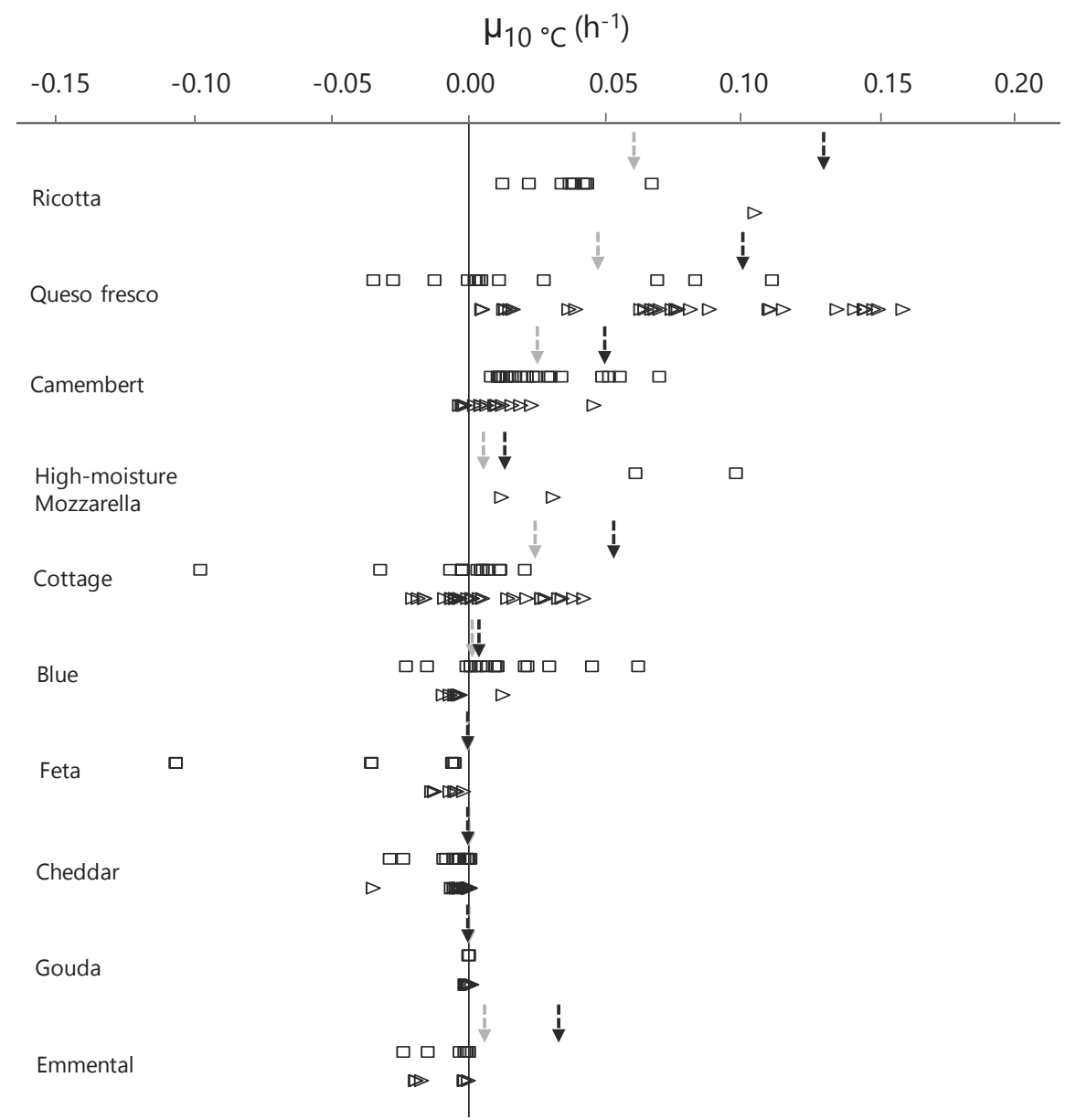

Fig. 7.2 Comparison of the actual and predicted growth rates at $10{ }^{\circ} \mathrm{C}$, to validate the importance of the factors undissociated lactic acid, $\mathrm{a}_{\mathrm{w}}$ and $\mathrm{pH}$ on growth inhibition of L. monocytogenes for 10 different RTE cheese types. The actual growth rates of L. monocytogenes were extracted from 45 challenge studies ( $n=249$ for 10 cheese types, data described in Supplementary Table S2) were compared to predicted growth rates (Table 7.2 and Supplementary Table S1). Per cheese type, the squares display the growth rates for L. monocytogenes after artificial contamination of the surface or crust, and the triangles display the growth after artificial contamination of the cheese curd or milk. For the predicted growth rates, $\mu_{\max }$ values were calculated for each type of cheese using $\frac{\Delta \log N \cdot \ln (10)}{\mathrm{t}}$, with $\Delta \log N$ as the log concentration of L. monocytogenes at the end of sampling minus the log concentration after pressing, and with $\mathrm{t}$ as the time between the end of sampling and after pressing. The predicted growth rates $\left(\mu_{10}{ }^{\circ} \mathrm{C}\right.$ values) were based on $\mu_{\mathrm{opt}}=1.69 \mathrm{~h}^{-1}$ and $\mu_{\mathrm{opt}}=0.73 \mathrm{~h}^{-1}$ as extracted from Combase (www.combase.cc) when searching for growth rates of L. monocytogenes in milk at $30-37^{\circ} \mathrm{C}$. The $\mu_{10} \cdot c$ values calculated with $\mu_{\mathrm{opt}}=1.69 \mathrm{~h}^{-1}$ were indicated with black arrows, and those calculated with $\mu_{\mathrm{opt}}=0.73 \mathrm{~h}^{-1}$ were indicated with grey arrows. The $\mu_{10}{ }^{\circ} \mathrm{C}$ values were based on Gamma factors for undissociated lactic acid, $a_{w_{1}}$ temperature and $\mathrm{pH}$ calculated according to Chapter 6 Supplemental Material S1, S3 and S4), and a MIC of undissociated lactic acid for L. monocytogenes of $6.35 \mathrm{mM}$ according to Aryani et al. (2015). Average conditions were chosen for undissociated lactic acid, $\mathrm{a}_{\mathrm{w}}$ and $\mathrm{pH}$ (according to Table 7.2). The temperature was normalized to $10{ }^{\circ} \mathrm{C}$ by use of the square-root function of McMeekin, Olley, Ross, \& Ratkowsky (1993): $\mu_{\mathrm{T}}=\mu_{\mathrm{ref}} \cdot \frac{\left(\mathrm{T}-\mathrm{T}_{\min }\right)^{2}}{\left(\mathrm{~T}_{\mathrm{ref}}-\mathrm{T}_{\min }\right)^{2}}$ with $\mathrm{T}_{\min }=-1.5^{\circ} \mathrm{C}$ and $\mathrm{T}_{\text {ref }}=10^{\circ} \mathrm{C}$. The application of the square-root function by McMeekin et al. (1993) for temperature is only validated for positive actual growth rates. As for the positive actual growth rates, the negative growth rates were normalized to $10^{\circ} \mathrm{C}$ using the function, but the latter was not scientifically substantiated in this thesis. 


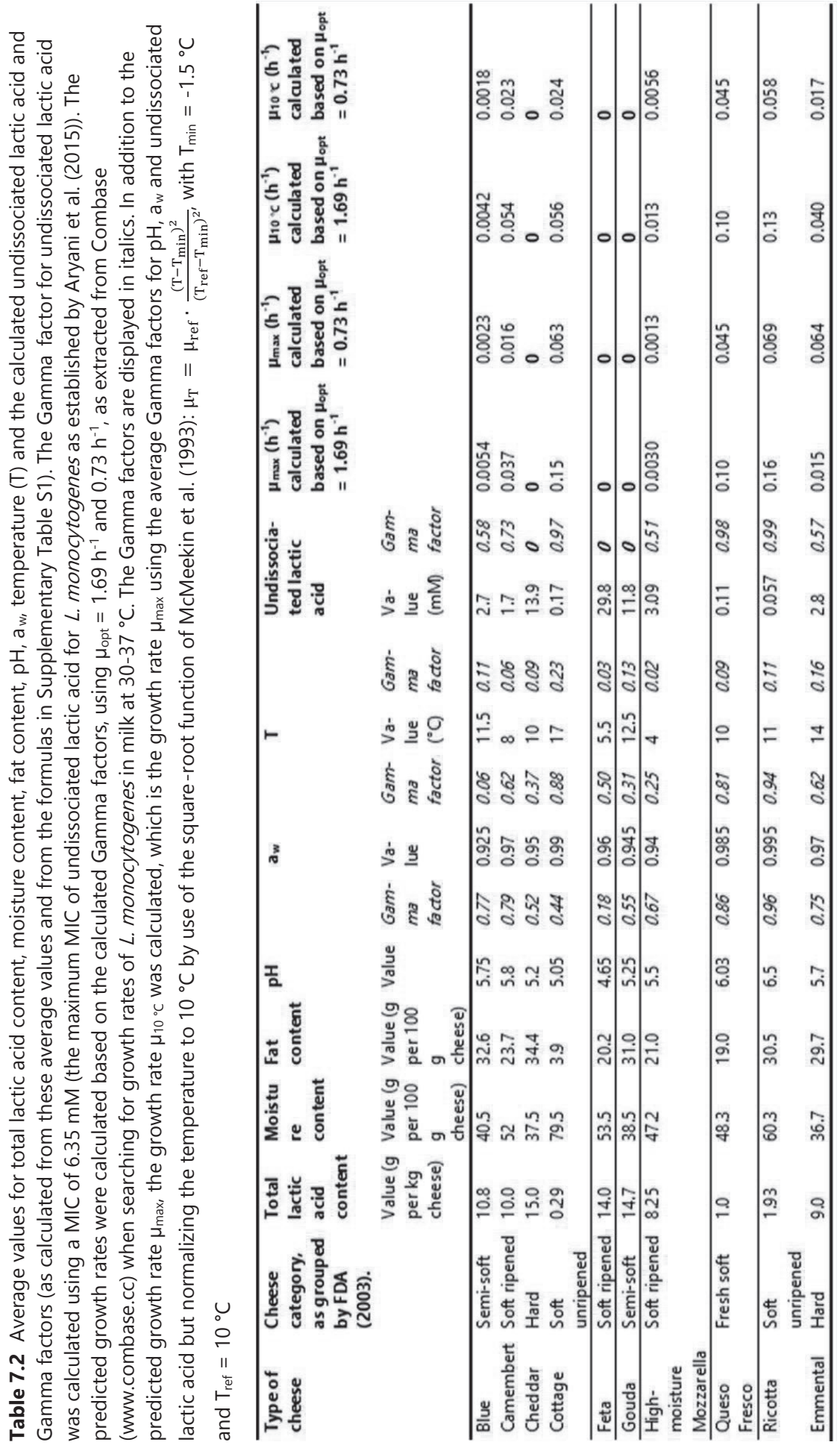




\subsection{Perspectives for low-fat, low-salt and sliced Gouda}

This thesis focused on nature-ripened whole Gouda cheese of $48 \% \mathrm{w} / \mathrm{w}$ fat in dry matter made from pasteurized milk. In addition to this type of Gouda cheese, the Dutch cheese industry produces low-salt cheese, low-fat cheese, foil-ripened cheese and pre-packed Gouda cheese, such as cheese slices or cheese wedges. The expected fate of L. monocytogenes in Gouda produced with such characteristics or stored under such conditions is described below.

The $a_{w}$ can be an important factor contributing to the inhibition of growth of L. monocytogenes in Gouda, and inactivation of L. monocytogenes was seen when the $a_{w}$ drops to values near or below the minimal $a_{w}$ limit of 0.92 (Chapter 4 and 6). Such low $a_{w}$ values can occur after extended ripening times or immediately after brining in the crust. In a low-salt cheese, the Gamma factor of $a_{w}$ for L. monocytogenes is higher than in standard Gouda cheeses, so the growth-inhibiting effect of $\mathrm{a}_{\mathrm{w}}$ on L. monocytogenes in Gouda cheese is smaller. Nevertheless, growth of L. monocytogenes at a low salt content was not observed in the challenge studies described in Chapter 3 (L. monocytogenes on Gouda, artificial contamination of the brine), and Chapter 2 (L. monocytogenes in Gouda model cheeses). Inhibition of growth is primarily controlled by lactic acid. After an extended period of time, inactivation of L. monocytogenes seemed to occur which can likely be attributed to the low $a_{w}$ present. The inactivation of L. monocytogenes seemed slower in low-salt cheeses in which the average $a_{w}$ is higher than in cheeses with normal salt contents. Furthermore, the contribution of salt to inactivation of L. monocytogenes may be smaller within the core of the cheese than the inactivation as observed in the model cheese study of Chapter 2. In industrially produced cheeses, salt diffuses during ripening from the crust to the core (Chapter 4), but in such cheeses that are made from pasteurized milk, the presence of L. monocytogenes inside the cheese is unlikely. In the challenge study with microcheeses described in Chapter 2, L. monocytogenes was added to the cheese milk after pasteurization, and salt was added directly after pressing in the microcheeses; therewith, no salt gradient between crust and core was present at the start of ripening.

In low-fat Gouda cheeses, the risk of outgrowth of L. monocytogenes is not expected to be higher than in standard Gouda cheese, primarily because there is enough undissociated lactic acid to suppress the growth of L. monocytogenes, as explained below. No differences were observed with respect to the fate of L. monocytogenes during curd formation in additional experiments with model Gouda cheeses with $48 \%$ and $30 \% \mathrm{w} / \mathrm{w}$ fat in dry matter (results not shown). Fat (in a cheese with equal dry matter) only minimally affects the concentration of undissociated lactic acid, as can be deduced from Equation [6.12] in Chapter 6. In Gouda cheeses with $30 \% \mathrm{w} / \mathrm{w}$ fat in dry matter, the moisture content is often increased to compensate for texture changes due to the lowered fat content. An increased moisture content leads to an increase in the $a_{w}$ (Chapter 4 ) and a decrease in the concentration of undissociated lactic acid 
(Chapter 6, Fig. 6.3C). In a Gouda cheese with 30\% w/w fat in dry matter, full growth inhibition can be expected when the $\mathrm{pH}<5.25$ and moisture $<50.5 \%$, because the concentration of undissociated lactic acid in the water phase of the cheese would then still be above the critical concentration of $6.35 \mathrm{mM}$ that leads to full inhibition of growth of L. monocytogenes. Leong et al. (2014) studied the fate of L. monocytogenes in normal-fat versus low-fat cheese with high moisture content for Cheddar, Colby Jack and Provolone slices that were artificially contaminated, vacuum packaged and stored at room temperature. No significant differences were observed with respect to the fate of L. monocytogenes after 15-day storage of normalfat and low-fat cheeses (- 0.73 vs $0.41 \operatorname{log~cfu~g~}^{-1}$ for normal-fat vs low-fat Cheddar, -0.32 vs -0.27 log cfu g ${ }^{-1}$ for normal-fat vs low-fat Colby Jack, and -0.92 vs -1.68 log cfu g $^{-1}$ for normalfat vs low-fat Provolone). In Cheddar cheese, reduction of the fat in dry matter content from 48 to $36 \%$ did not alter the fate of L. monocytogenes according to Mehta \& Tatini (1994), even when the moisture content of the low-fat Cheddar was $42.9 \%$ instead of $39.7 \%$ in the normalfat Cheddar. In both studies, the concentration of lactic acid was not determined.

The risk of presence of $L$. monocytogenes may be different in pre-packed sliced Gouda cheese. On slices of Gouda cheese that were artificially contaminated with L. monocytogenes and subsequently vacuum packed, Leong et al. (2014) and Kapetanakou, Gkerekou, Vitzilaiou, \& Skandamis (2017) observed survival but no growth, and subsequent inactivation of L. monocytogenes, thus showing a fate that is similar to the one seen during ripening of whole Gouda cheeses (Northolt et al., 1988; Chapter 2). Further assessment of the data displayed in Fig. 7.2 showed that the fate of $L$. monocytogenes after contamination via the surface was in general similar to the fate after contamination via the cheese curd or milk. Based on these observations, the fate of L. monocytogenes in cheese slices is expected to be similar to the one in or on whole Gouda cheese, if the microbial hurdles present (e.g. concentration of undissociated lactic acid, temperature, $\mathrm{pH}$ and $\mathrm{a}_{\mathrm{w}}$ ) are not altered due to cutting, packaging or other treatments.

\subsection{Implications for legislation and undissociated lactic acid as a classification criterion}

This thesis focused on nature-ripened whole Gouda cheese made from pasteurized milk with $48 \% \mathrm{w} / \mathrm{w}$ fat in dry matter. This cheese should currently be classified as category 1.2 RTE product according to EC 2073/2005 based on $\mathrm{pH}>5.0$ and $\mathrm{a}_{\mathrm{w}}>0.94$, in absence of further evidence that the product does not support the growth of L. monocytogenes. Gouda made from pasteurized milk can be categorized as an RTE product that does not support growth of L. monocytogenes, based on the evidence presented in this thesis, namely, two challenge studies that showed no growth, but only survival and inactivation, and predictive modelling demonstrating the factors that explain growth inhibition of L. monocytogenes in Gouda cheese. 
Overall, Gouda has an average total lactic acid content of 1.47 \% w/w and pH 5.25 (Chapter 6). Undissociated lactic acid can fully inhibit growth when the concentration of undissociated lactic acid in cheese is $\geq 6.35 \mathrm{mM}$ on the basis of the highest MIC observed for L. monocytogenes (Aryani, den Besten, Hazeleger, \& Zwietering, 2015). In an average 2-week old Gouda (moisture content of $42 \%$, a total lactic acid content of $1.47 \% \mathrm{w} / \mathrm{w}$ cheese and a $\mathrm{pH}$ of 5.25), the concentration of undissociated lactic acid was calculated to be $10.9 \mathrm{mM}$. A concentration of undissociated lactic acid of $6.35 \mathrm{mM}$ is reached when the total lactic acid concentration is $>0.86 \% \mathrm{w} / \mathrm{w}$ at a $\mathrm{pH}<5.25$ (relevant to young Gouda cheese with moisture content $42 \% \mathrm{w} / \mathrm{w}$ ), or $>1.26 \% \mathrm{w} / \mathrm{w}$ at a $\mathrm{pH}<5.50$ (relevant to a mature Gouda cheese with moisture content of $35 \% \mathrm{w} / \mathrm{w}$ ) (Chapter 6).

Undissociated lactic acid is thus very important for growth inhibition of L. monocytogenes in Gouda cheese and therefore it seems justified that RTE cheeses are classified based on their undissociated lactic acid concentration, and not only on $\mathrm{pH}$ and $\mathrm{a}_{\mathrm{w}}$. The importance of undissociated lactic acid is underlined by the calculated Gamma factors for 10 cheese types using a MIC of undissociated lactic acid for L. monocytogenes of $6.35 \mathrm{mM}$ and average values for total lactic acid content, moisture content, fat content, $\mathrm{pH}, \mathrm{a}_{\mathrm{w}}$ and temperature (Table 7.2). This calculation showed that in 3 out of 10 cheese types (namely, Feta, Cheddar and Gouda), the Gamma factor for undissociated lactic acid is 0 , implying that undissociated lactic acid alone fully inhibits growth of L. monocytogenes in these three cheeses.

Temperature and $\mathrm{pH}$ can be important growth inhibiting factors for L. monocytogenes, but typical $\mathrm{pH}$ values and ripening temperatures of Gouda cheese will not lead to full inhibition of growth of $L$. monocytogenes (Chapter 6). The $\mathrm{pH}$ has a large effect on growth inhibition of $L$. monocytogenes, as it indirectly affects the concentration of undissociated lactic acid. Spoilage by yeasts and molds can result in an increase of the $\mathrm{pH}$ and subsequently a reduced inhibition of growth as a result of $\mathrm{pH}$ and undissociated lactic acid. A low temperature can delay or completely prevent spoilage by yeasts and molds. However, in the case of RTE cheeses, the $\mathrm{T}_{\min }$ of $-0.4{ }^{\circ} \mathrm{C}$ for $L$. monocytogenes is not reached and therefore it is advised to not include temperature as a criterion for inhibition of growth of L. monocytogenes in RTE cheeses.

In Table 7.3, a suggested categorization according to EU regulation EC 2073/2005 for 10 RTE cheese types is presented. The categorization is based on whether or not the consumption of the cheese was associated with identified cases of listeriosis in the past, and whether or not growth rates extracted from challenge studies and those predicted based on growth-inhibiting factors were positive or not. The data presented lend support to categorization of Gouda, Feta and Cheddar as a category 1.3 food with $\leq 100 \mathrm{cfu} \mathrm{g}^{-1}(\mathrm{n}=5)$ for products placed on the market during their shelf-life. Feta has an average $\mathrm{pH}$ of 4.65 and a total lactic acid content 14 $\mathrm{g}$ per $\mathrm{kg}$ cheese; the undissociated lactic acid concentration is thus calculated to be $29.8 \mathrm{mM}$ (Table 7.2). Cheddar has an average $\mathrm{pH}$ of 5.2 and a total lactic acid content of $15 \mathrm{~g}$ per $\mathrm{kg}$ cheese, resulting in an undissociated lactic acid concentration of $13.9 \mathrm{mM}$ (Table 7.2 ). In all 
challenge studies with Cheddar and Feta, no growth of L. monocytogenes was observed (Fig. 7.2). For high-moisture Mozzarella, growth was both observed and predicted, therefore categorization as a 1.2 food is suggested, especially in high-moisture Mozzarella-type cheeses with $\mathrm{pH}>5.18$ (then $<6.35 \mathrm{mM}$ undissociated lactic acid is calculated). The cheeses Queso Fresco and Camembert can be categorized as category 1.2 foods, requiring absence of L. monocytogenes in $25 \mathrm{~g}(\mathrm{n}=5)$ before the food has left the immediate control of the food business operator, who has produced it. In Queso Fresco and Camembert, average $\mathrm{pH}$ values are 6.0 and 5.8 and average total lactic acid contents are 1 and $10 \mathrm{~g}$ per $\mathrm{kg}$ cheese, respectively, corresponding with undissociated lactic acid concentrations of $0.11 \mathrm{mM}$ and $1.7 \mathrm{mM}$, respectively. As the calculated concentrations of undissociated lactic acid are much lower than the average and maximum MICs of 5.11 and $6.35 \mathrm{mM}$, respectively, for L. monocytogenes (Chapter 5), it is unlikely that undissociated lactic acid is an important growth-inhibiting factor in these cheeses. In practice, Queso Fresco and Camembert cheeses have been linked with listeriosis cases on several occasions, and growth of L. monocytogenes was supported in challenge studies that were performed with these cheeses. When a food is categorized as an RTE food product able to support growth of L. monocytogenes, more stringent sampling guidelines need to be in place. In addition, the food safety risk of cheeses that can support growth of L. monocytogenes can be decreased by applying additional hurdles and different storage regimes (e.g. shorter shelf life, refrigerated storage) (Maisnier-Patin, Deschamps, Tatini, \& Richard, 1992; Davies, Bevis, \& Delves-Broughton, 1997; Soni, Nannapaneni, Schilling \& Jackson, 2010; Soni, Desai, Oladunjoye, Skrobot, \& Nannapaneni, 2012; Spanu et al. 2012). In the case of cottage cheese, sorbic acid may be added which inhibits growth of L. monocytogenes (Østergaard, Eklöw, \& Dalgaard, 2014; Østergaard, Christiansen, \& Dalgaard, 2015).

The $\mu_{\max }$ values were calculated for the different cheeses based on average values of undissociated lactic acid, temperature, $\mathrm{pH}$ and $\mathrm{a}_{\mathrm{w}}$. For most cheeses, only average values were reported in literature. For some cheeses, the variation was assessed for some of the factors (Supplementary Table S1). In studies available in literature, however, it is not clear for each type of cheese whether the variation occurred during processing or whether it occurred between batches. Because of this unclarity, the $\mu_{\max }$ values were only calculated from the average values as stated above. The estimation of the $\mu_{\max }$ values can be improved further by considering the variation and worst-case conditions (e.g. low undissociated lactic acid, and high temperature, $\mathrm{pH}$ and $\mathrm{a}_{\mathrm{w}}$ ) in addition to average conditions for each type of cheese.

\subsection{Conclusion and recommendations}

Gouda cheese does not support growth of L. monocytogenes as demonstrated in all three challenge studies published so far. The most important factors for growth inhibition were 
identified as undissociated lactic acid, temperature, $\mathrm{pH}$ and $\mathrm{a}_{\mathrm{w}}$. From these four factors, undissociated lactic acid and $a_{w}$ can specifically in Gouda lead to full growth inhibition of $L$. monocytogenes. Undissociated lactic acid alone can explain absence of growth of L. monocytogenes in Gouda cheese. Additionally, low $\mathrm{a}_{\mathrm{w}}$ in the cheese rind and after prolonged ripening times can cause full growth inhibition. Even though temperature considerably affects the actual growth rate of L. monocytogenes in Gouda cheese, low temperature alone does not result in full growth inhibition in Gouda cheese, as temperature does not approximate a value at which the growth of L. monocytogenes is completely halted in Gouda. As undissociated lactic acid is evaluated as the primary factor determining growth / no growth factor Gouda and many other RTE cheese types, it is recommended to include undissociated lactic acid in future safety criteria for RTE cheeses, together with $\mathrm{pH}$ and $\mathrm{a}_{\mathrm{w}}$. The cheese-making industry can monitor the total lactic acid content, the moisture content, and the $\mathrm{pH}$ of cheese to calculate the undissociated lactic acid concentration in the water phase of Gouda cheese. If the latter is $\geq 6.35 \mathrm{mM}$, this can be applied as a criterion for non-growth of L. monocytogenes.

This work focused on nature-ripened whole Gouda cheeses. According to studies performed with cheese slices and foil-ripened cheeses, the fate of L. monocytogenes on slices of Gouda and in foil-ripened Gouda cheeses is expected to be similar to that in whole cheeses. In future challenge studies, it is recommended to additionally measure $\mathrm{pH}$, temperature, $\mathrm{a}_{\mathrm{w}}$, and the content of lactic acid so that the impact of the levels of these factors on the fate of L. monocytogenes can be established. It is also recommended to generate more data on $\mathrm{pH}_{\text {, }}$ temperature, lactic acid content, other organic acids and $a_{w}$ during manufacturing, ripening and storage of cheeses other than Gouda. Such data contribute to a better understanding on the variation of these factors during manufacturing and storage and thereby to a better understanding of the effect of manufacturing, ripening and storage steps on growth/no growth of L. monocytogenes in cheese. For Emmental, further study of growth inhibition by organic acids other than lactic acid and/or free fatty acids is recommended.

In this thesis, challenge tests, literature data and predictive models have been used to perform a risk assessment of $L$. monocytogenes in relation to Gouda cheese, ultimately leading to practical advice to the cheese industry and legislators.

Overall, the work presented in this thesis confirmed that Gouda cheese does not support growth of L. monocytogenes. The factors with inhibitory potential toward L. monocytogenes in Gouda cheese were evaluated, and it was shown that undissociated lactic acid is the primary factor that determines growth/no growth of L. monocytogenes in Gouda cheese. Furthermore, it was determined that the levels of undissociated lactic acid that are present in Gouda are sufficiently high to ensure complete inhibition of growth. The knowledge generated in this thesis can be applied by manufacturers of Gouda cheese and authorities. 


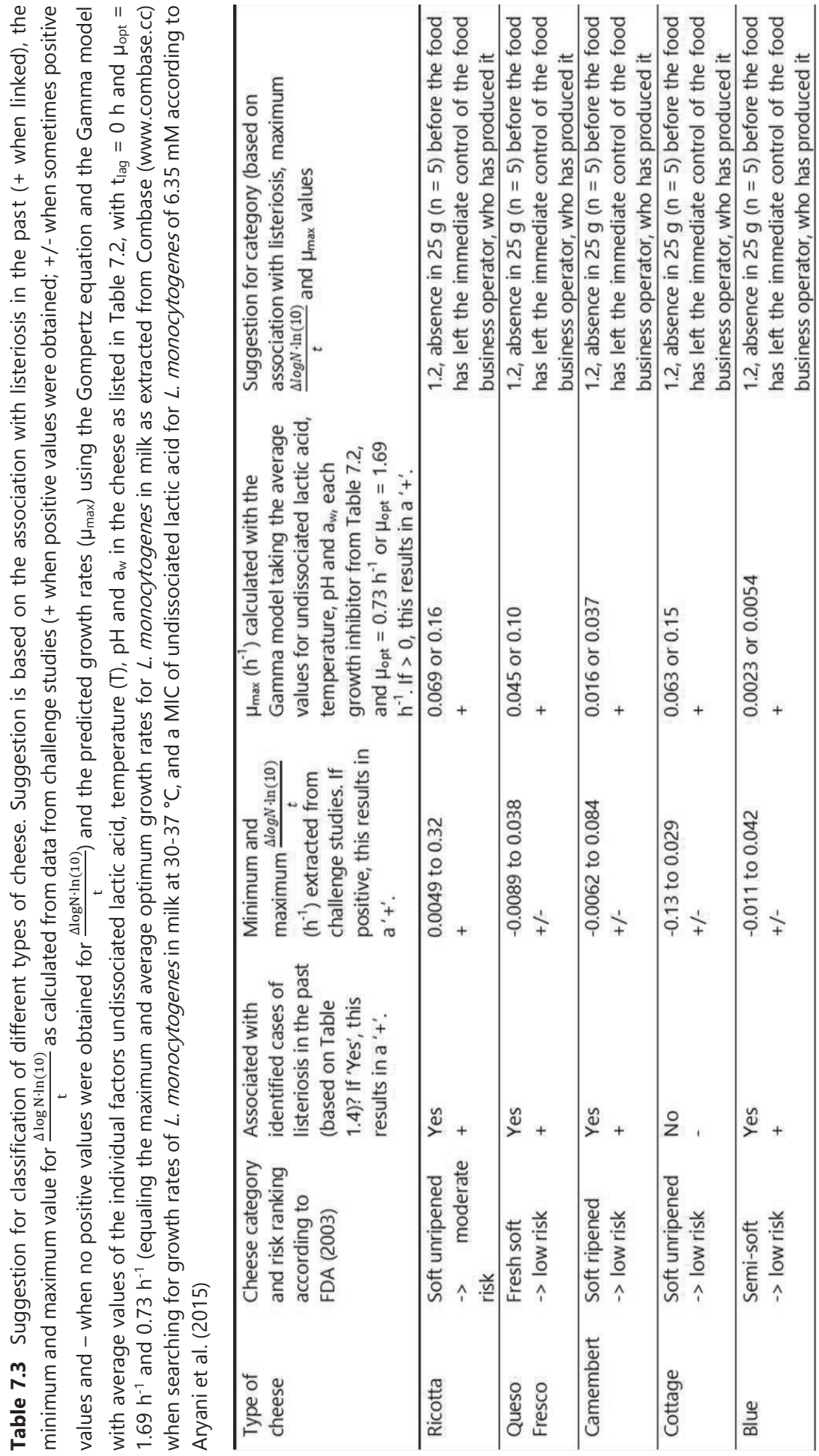




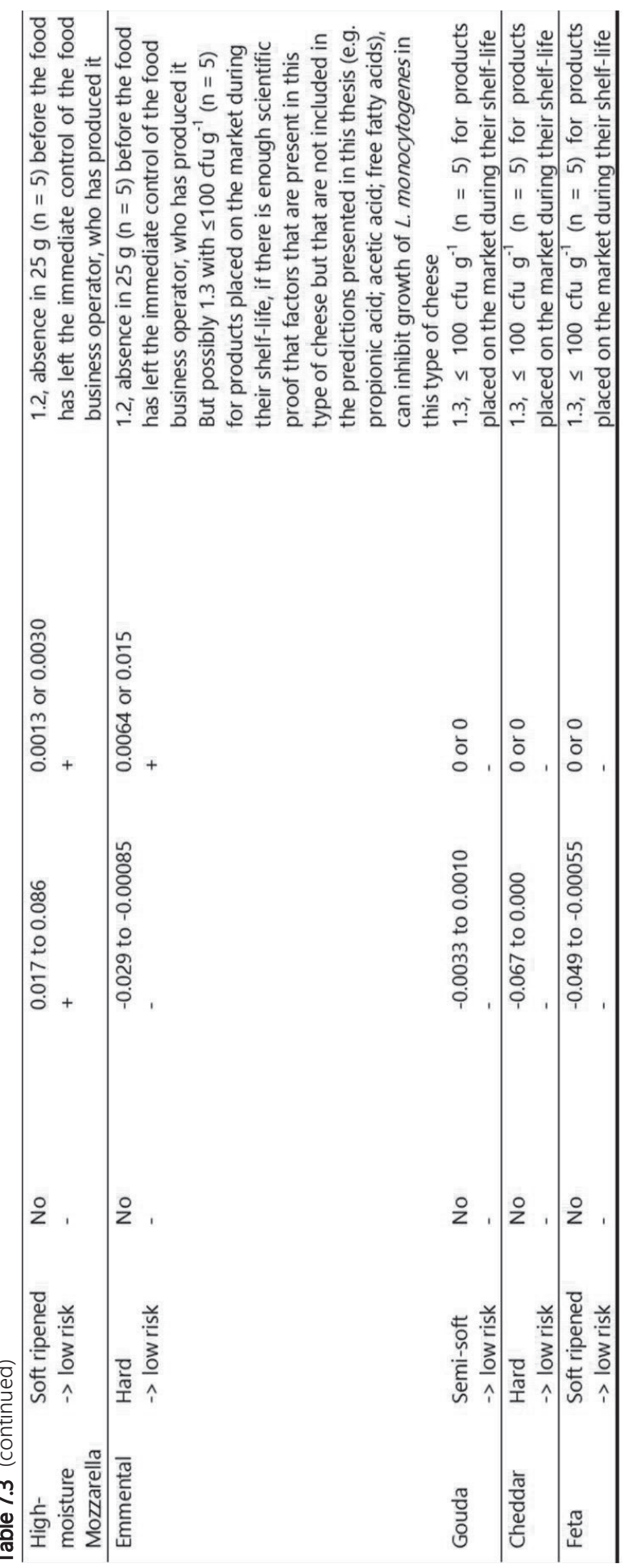




\section{References}

Asensio, C.M., Gallucci, N., de las Mercedes Oliva, M., Demo, M.S., \& Grosso, N.R. (2014). Sensory and biochemical preservation of ricotta cheese using natural products. International Journal of Food Science and Technology 49:2692-2702.

Aryani, D.C., den Besten, H.M.W., Hazeleger, W.C., \& Zwietering, M.H. (2015). Quantifying strain variability in modeling growth of Listeria monocytogenes. International Journal of Food Microbiology 208:19-29.

Bachmann, H.P., \& Spahr, U. (1995). The fate of potentially pathogenic bacteria in Swiss hard and semihard cheeses made from raw milk. Journal of Dairy Science 78:476-483.

Back, J.P., Langford, S.A., \& Kroll, R.G. (1993). Growth of Listeria monocytogenes in Camembert and other soft cheeses at refrigeration temperatures. Journal of Dairy Research 60:421-429.

Belessi, C.I., Papanikolaou, S., Drosinos, E.H., \& Skandamis, P.N. (2008). Survival and acid resistance of Listeria innocua in Feta cheese and yogurt, in the presence or absence of fungi. Journal of Food Protection 71:742-749.

Beresford, T.P., Fitzsimons, N.A., Brennan, N.L., \& Cogan, T.M. (2001). Recent advances in cheese microbiology. International Dairy Journal 11:259-274.

Bernini, V., Bottari, B., Dalzini, E., \& Gatti, M. (2013). The presence, genetic diversity and behaviour of Listeria monocytogenes in blue-veined cheese rinds during the shelf life. Food Control 34:323-330.

Branen, J.K., \& Davidson, P.M. (2004). Enhancement of nisin, lysozyme, and monolaurin antimicrobial activities by ethylenediaminetetraacetic acid and lactoferrin. International Journal of Food Microbiology 90:63-74.

Brocklehurst, T.F., \& Lund, B.M. (1985). Microbiological changes in cottage cheese varieties during storage at $+7^{\circ} \mathrm{C}$. Food Microbiology 2:207-233.

Brown, S.R.B., Kozak, S.M., \& D'Amico, D.J. (2018). Applications of edible coatings formulated with antimicrobials inhibit Listeria monocytogenes growth on Queso Fresco. Frontiers in Sustainable Food Systems 2:1-9.

Buazzi, M.M., Johnson, M.E., \& Marth, E.H. (1992a). Fate of Listeria monocytogenes during the manufacture of Mozzarella cheese. Journal of Food Protection 55:80-83.

Buazzi, M.M., Johnson, M.E., \& Marth, E.H. (1992b). Survival of Listeria monocytogenes during the manufacture and ripening of Swiss cheese. Journal of Dairy Science 75:380-386.

Buyong, N., Kok, J., \& Luchansky, J.B. (1998). Use of a genetically enhanced, pediocin-producing starter culture, Lactococcus lactis subsp. lactis MM217 to control Listeria monocytogenes in Cheddar cheese. Applied and Environmental Microbiology 64:4842-4845.

Chen, H.H., \& Hotchkiss, J.H. (1993). Growth of Listeria monocytogenes and Clostridium sporogenes in cottage cheese in modified atmosphere packaging. Journal of Dairy Science 76:972-977.

Codex, 2013. Codex General Standard for Cheese. Codex Stan 283-1978, rev. 2013. www.fao.org/input/download/standards/175/CXS_283e.pdf. Date last assessed: 24-06-2018.

Dalzini, E., Cosciani-Cunico, E., Monastero, P., Bernini, V., Neviani, E., Bellio, A., Decastelli, L., Losio, M.N., Daminelli, P., \& Varisco, G. (2017). Listeria monocytogenes in Gorgonzola cheese: study of the behaviour throughout the process and growth prediction during shelf life. International Journal of Food Microbiology 262:71-79. 
Davies, E.A., Bevis, H.E., \& Delves-Broughton, J. (1997). The use of the bacteriocin, nisin, as a preservative in ricotta-type cheeses to control the food-borne pathogen Listeria monocytogenes. Letters in Applied Microbiology 24:343-346.

Diezhandino, I., Fernández, D., González, L., McSweeney, P.L., \& Fresno, J.M. (2015). Microbiological, physico-chemical and proteolytic changes in a Spanish blue cheese during ripening (Valdeón cheese). Food Chemistry 168:134-141.

Dominguez, L., Garayzabal, J.F.F., Vazquiz, J.A., Blanco, J.L., \& Suarez, G. (1987). Fate of Listeria monocytogenes during manufacture and ripening of semi-hard cheese. Letters of Applied Microbiology 4:125-127.

El-Ziney, M.G., \& Debevere, J.M. (1998). The effect of reuterin on Listeria monocytogenes and Escherichia coli 0157:H7 in milk and cottage cheese. Journal of Food Protection 61:1275-1280.

Engel, E., Nicklaus, S., Septier, C., Salles, C., \& Le Quéré, J.L. (2001). Evolution of the taste of a bitter Camembert cheese during ripening: characterization of a matrix effect. Journal of Agricultural and Food Chemistry 49:2930-2939.

Esti, M., Messia, M.C., La Notte, E., Lembo, P., Compagnone, D., \& Palleschi, G. (1996). Curd-ripening evaluation by flow injection analysis of L-lactic acid with an electrochemical biocell during Mozzarella cheese manufacture. Journal of Agricultural and Food Chemistry 44:3102-3107.

European Commission (2005). Commission regulation (EC) No. 2073/2005 of 15 November 2005 on microbiological criteria for foodstuffs. Official Journal of the European Union L338:1-26.

FDA (2003). Quantitative assessment of relative risk to public health from foodborne Listeria monocytogenes among selected categories of ready-to-eat foods.

https://www.fda.gov/downloads/Food/

FoodScienceResearch/UCM197330.pdf. Date last accessed: 02-09-2018.

Fox, P.F., Law, J., McSweeney, P.L.H., \& Wallace, J. (1993). Biochemistry of cheese ripening. Pages 389-438 in Cheese: Chemistry, Physics and Microbiology (2nd ed.). Vol. 1. General Aspects. C. Hall. London, UK.

Fox, P.F., McSweeney, P.L.H., Cogan, T.M., \& Guinee, T.P. (2004). Cheese: Chemistry, Physics and Microbiology (3rd ed.). London: Elsevier Academic Press. Vol. 1, pp. 1-617 \& Vol. 2, pp. 1-434.

Gadotti, C., Nelson, L., \& Diez-Gonzalez, F. (2014). Inhibitory effect of combinations of caprylic acid and nisin on Listeria monocytogenes in Queso Fresco. Food Microbiology 39:1-6.

Genigeorgis, C., Carniciu, M., Dutulescu, D., \& Farver, T.B. (1991). Growth and survival of Listeria monocytogenes in market cheeses stored at 4 to $30^{\circ} \mathrm{C}$. Journal of Food Protection 54:662-668.

Giangolini, G., Amatiste, S., Filippetti, F., Boselli, C., Fagiolo, A., \& Rosati, R. (2009). Chemical composition of "Ricotta Romana" cheese. Scienza e Tecnica Lattiero-Casearia 60:131-135.

Guo, L., van Hekken, D.L., Tomasula, P.M., Shieh, J., \& Tunick, M.H. (2011). Effect of salt on the chemical, functional, and rheological properties of Queso Fresco during storage. International Dairy Journal 21:352-357.

Ibarra-Sanchez, L.A., van Tassell, M.L., Miller, M.J. (2018). Antimicrobial behavior of phage endolysin PlyP100 and its synergy with nisin to control Listeria monocytogenes in Queso Fresco. Food Microbiology 72:128-134.

Kapetanakou, A.E., Gkerekou, M.A., Vitzilaiou, E.S., \& Skandamis, P.N. (2017). Assessing the capacity of growth, survival, and acid adaptive response of Listeria monocytogenes during storage of various 
cheeses and subsequent simulated gastric digestion. International Journal of Food Microbiology 246:50-63.

Konteles, S., Sinanoglou, V.J., Batrinou, A., \& Sflomos, K. (2009). Effects of gamma-irradiation on Listeria monocytogenes population, colour, texture and sensory properties of Feta cheese during cold storage. Food Microbiology 26:157-165.

Lahou, E., \& Uyttendaele, M. (2017). Growth potential of Listeria monocytogenes in soft, semi-soft and semi-hard artisanal cheeses after post-processing contamination in deli retail establishments. Food Control 16:13-23.

Larson, A.E., Yu, R.R.Y., Lee, O.A., Price, S., Haas, G.J., \& Johnson, E.A. (1996). Antimicrobial activity of hop extracts against Listeria monocytogenes in media and in food. International Journal of Food Microbiology 33:195-207.

Leggett, L.N., Tomasula, P.M., van Hekken, D.L., Porto-Fett, A.C.S., Shoyer, B., Renye, J.A., Luchansky, J.B., \& Farkye, N. (2012). Effect of storage at 4 and $10 \mathrm{C}$ on the growth of Listeria monocytogenes in and on Queso Fresco. Journal of Food Safety 32:236-245.

Leong, W.M., Geier, R., Engstrom, S., Ingham, S., Ingham, B., \& Smukowski, M. (2014). Growth of Listeria monocytogenes, Salmonella spp., Escherichia coli $0157: \mathrm{H} 7$, and Staphylococcus aureus on cheese during extended storage at $25^{\circ} \mathrm{C}$. Journal of Food Protection 77:1275-1288.

Limjaroen, P., Ryser, E., Lockhart, H., \& Harte, B. (2005). Inactivation of Listeria monocytogenes on beef bologna and Cheddar cheese using polyvinyl-idene chloride films containing sorbic acid. Journal of Food Science 70:M267-M271.

Lin, C.M., Zhang, L., Doyle, M.P., \& Swaminathan, B. (2016). Comparison of media and sampling locations for isolation of Listeria monocytogenes in Queso Fresco cheese. Journal of Food Protection 69:21512156.

Linton, M., Mackle, A.B., Upadhyay, V.K., Kelly, A.L., \& Patterson, M.F. (2008). The fate of Listeria monocytogenes during the manufacture of Camembert-type cheese: a comparison between raw milk and milk treated with high hydrostatic pressure. Innovative Food Science \& Emerging Technologies 9:423-428.

Lourenço, A., Kamnetz, M.B., Gadotti, C., \& Diez-Gonzalez, F. (2017). Antimicrobial treatments to control Listeria monocytogenes in Queso Fresco. Food Microbiology 64:47-55.

Madkor, S., Fox, P.F., Shalabi, S.I., \& Metwalli, N.H. (1987). Studies on the ripening of stilton cheese: Proteolysis. Food Chemistry 25:13-29.

Maisnier-Patin, S., Deschamps, N., Tatini, S.R., \& Richard, J. (1992). Inhibition of Listeria monocytogenes in Camembert cheese made with a nisin-producing starter. Lait 72:249-263.

Manolakia, P., Katsiarib, M.C., \& Alichanidis, E. (2006). Effect of a commercial adjunct culture on organic acid contents of low-fat Feta-type cheese. Food Chemistry 98:658-663.

Martins, J.T., Cerqueira, M.A., Souza, B.W., Carmo Avides, M., \& Vicente, A.A. (2010). Shelf life extension of ricotta cheese using coatings of galactomannans from nonconventional sources incorporating nisin against Listeria monocytogenes. Journal of Agricultural and Food Chemistry 58:1884-1891.

McAuliffe, O., Hill, C., \& Ross, R.P. (1999). Inhibition of Listeria monocytogenes in cottage cheese manufactured with a lacticin 3147-producing starter culture. Journal of Applied Microbiology 86:251256. 
McMeekin, T.A., Olley, J., Ross, T., \& Ratkowsky, D.A. (1993). Predictive microbiology. Theory and application. Taunton, UK: Research Studies Press.

Mehta, A., \& Tatini, S.R. (1994). An evaluation of the microbiological safety of reduced-fat Cheddar-like cheese. Journal of Food Protection 57:776-779.

Menon, V., \& Garg, S.R. (2001). Inhibitory effect of clove oil on Listeria monocytogenes in meat and cheese. Food Microbiology 18:647-650.

Michaelidou, A. (1997). Investigation of protein hydrolysis during Feta cheese ripening. PhD thesis, Aristotle University of Thessaloniki, Greece.

Northolt, M.D., Beckers, H.J., Vecht, U., Toepoel, L., Soentoro, P.S.S., \& Wisselink, H.J. (1988). Listeria monocytogenes. heat resistance and behaviour during storage of milk and whey and making of Dutch types of cheese. Netherland Milk \& Dairy Journal 42:207-219.

Papageorgiou, D.K., \& Marth, E.H. (1989a). Fate of Listeria monocytogenes during the manufacture and ripening of blue cheese. Journal of Food Protection 52:459-465.

Papageorgiou, D.K., \& Marth, E.H. (1989b). Fate of Listeria monocytogenes during the manufacture, ripening and storage of Feta cheese. Journal of Food Protection 52:82-87.

Piccinin, D.M., \& Shelef, L.A. (1995). Survival of Listeria monocytogenes in cottage cheese. Journal of Food Protection 58:128-131.

Rosshaug, P.S., Detmer, A., Ingmer, H., \& Larsen, M.H. (2012). Modeling the growth of Listeria monocytogenes in soft blue-white cheese. Applied and Environmental Microbiology 78:8508-8514.

Ryser, E.T., \& Marth, E.H. (1987). Behavior of Listeria monocytogenes during the manufacture and ripening of Cheddar cheese. Journal of Food Protection 50:7-13.

Ryser, E.T., Marth, E.H., \& Doyle, M.P. (1985). Survival of Listeria monocytogenes during manufacture and storage of cottage cheese. Journal of Food Protection 48:746-750.

Schaffer, S.M., Tatini, S.R., \& Baer, R.J. (1995). Microbiological safety of Blue and Cheddar cheeses containing naturally modified milk fat. Journal of Food Protection 58:132-138.

Shrestha, S., Grieder, J.A., McMahon, D.J., \& Nummer, B.A. (2011). Survival of Listeria monocytogenes introduced as a post-aging contaminant during storage of low-salt Cheddar cheese at 4, 10, and 21 ${ }^{\circ} \mathrm{C}$. Journal of Dairy Science 94:4329-4335.

Soni, K.A., Desai, M., Oladunjoye, A., Skrobot, F., \& Nannapaneni, R. (2012). Reduction of Listeria monocytogenes in Queso Fresco cheese by a combination of listericidal and listeriostatic GRAS antimicrobials. International Journal of Food Microbiology 155:82-88.

Soni, K.A., Nannapaneni, R., Schilling, M.W., \& Jackson, V. (2010). Bactericidal activity of lauric arginate in milk and Queso Fresco cheese against Listeria monocytogenes cold growth. Journal of Dairy Science 93:4518-4525.

Spanu, C., Scarano, C., Spanu, V., Penna, C., Virdis, S., \& de Santis, E.P.L. (2012). Listeria monocytogenes growth potential in Ricotta salata cheese. International Dairy Journal 24:120-122.

Spanu, C., Spanu, V., Pala, C., Virdis, S., Scarano, C., \& de Santis, E.P.L. (2013). Evaluation of a post-lethality treatment against Listeria monocytogenes on Ricotta salata cheese. Food Control 30:200-205.

Stecchini, M.L., Aquili, V., \& Sarais, I. (1995). Behavior of Listeria monocytogenes in Mozzarella cheese in presence of Lactococcus lactis. International Journal of Food Microbiology 25:301-310. 
Sulzer, G., \& Busse, M. (1991). Growth inhibition of Listeria spp. on Camembert cheese by bacteria producing inhibitory substances. International Journal of Food Microbiology 14:287-296.

Torres, N., \& Chandan, R.C. (1981). Latin-American white cheese - a review. Journal of Dairy Science 64:552-557.

Uhlich, G.A., Luchansky, J.B., Tamplin, M.L., Molina-Corral, F.J., Anandan, S., \& Porto-Fett, A.C.S. (2006). Effect of storage temperature on the growth of L. monocytogenes on Queso blanco slices. Journal of Food Safety 26:202-214.

van den Berg, G., Meijer, W.C., Düsterhöft, E.M., Smit, G. (2004). Gouda and related cheeses. Pages 103-140 in Cheese: Chemistry, physics and microbiology (3rd ed.). Vol. 2. London: Elsevier Academic Press.

van Hekken, D.L., \& Farkye, N.Y. (2003). Hispanic cheeses: the quest for Queso. Food Technology 57:32-38.

van Hekken, D.L., Tunick, M.H., Leggett, L.N., \& Tomasula, P.M. (2012). Impact of curd milling on the chemical, functional, and rheological properties of starter-free Queso Fresco. Journal of Dairy Science 95:5527-5535.

Wan, J., Harmark, K., Davidson, B.E., Hillier, A.J., Gordon, J.B., Wilcock, A., Hickey, M.W., \& Coventry, M.J. (1997). Inhibition of Listeria monocytogenes by piscicolin 126 in milk and Camembert cheese manufactured with a thermophilic starter. Journal of Applied Microbiology 82:273-280.

Weimer, B.C. (2007). Improving the flavour of cheese, Woodhead Publishing Limited.

Wemmenhove, E., Stampelou, I., van Hooijdonk, A.C.M., Zwietering, M.H., \& Wells-Bennik M.H.J. (2013). Fate of Listeria monocytogenes in Gouda microcheese: no growth, and substantial inactivation after extended ripening times. International Dairy Journal 32:192-198.

Whitley, E., Muir, D., \& Waites, W.M. (2000). The growth of Listeria monocytogenes in cheese packed under a modified atmosphere. Journal of Applied Microbiology 88:52-57.

Wolf, I.V., Perotti, M.C., \& Zalazar, C.A. (2011). Composition and volatile profiles of commercial Argentinean blue cheeses. Journal of the Science of Food and Agriculture 91:385-393.

Yousef, A.E., \& Marth, E.H. (1990). Fate of Listeria monocytogenes during the manufacture and ripening of Parmesan cheese. Journal of Dairy Science 73:3351-3356.

Zhao, T., Doyle, M.P., \& Zhao, P. (2004). Control of Listeria monocytogenes in a biofilm by competitiveexclusion microorganisms. Applied and Environmental Microbiology 70:3996-4003.

Østergaard, N.B., Eklöw, A., \& Dalgaard, P. (2014). Modelling the effect of lactic acid bacteria from starterand aroma culture on growth of Listeria monocytogenes in cottage cheese. International Journal of Food Microbiology 188:15-25.

Østergaard, N.B., Christiansen, L.E., \& Dalgaard, P. (2015). Stochastic modelling of Listeria monocytogenes single cell growth in cottage cheese with mesophilic lactic acid bacteria from aroma producing cultures. International Journal of Food Microbiology 204:55-65. 


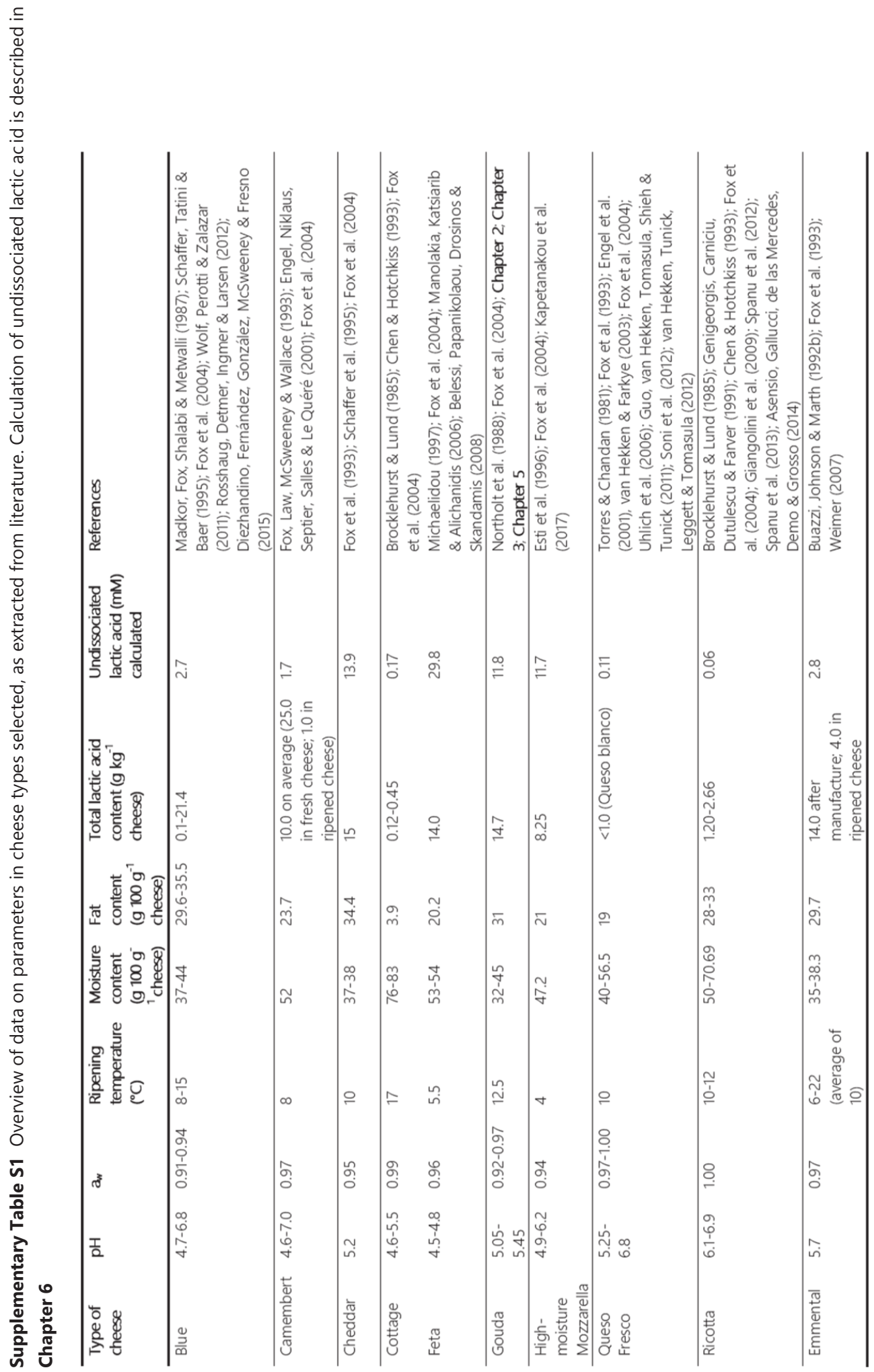


Supplementary Table S2 Overview of growth rates extracted from challenge studies for 10 different cheese types. The growth rates $\mu\left(\mathrm{h}^{-1}\right)$ extracted from challenge studies were calculated according to $\mu=\frac{\Delta \log \cdot \ln (10)}{\mathrm{t}}$, with $t$ as the time after ripening minus the time immediately after pressing the cheese, and $\Delta \log N$ as the $\log$ concentration of L. monocytogenes after ripening the cheese $\left(\mathrm{N}_{\mathrm{t}}\right)$ minus the log concentration of L. monocytogenes immediately after pressing the cheese $\left(\mathrm{N}_{0}\right)$. The growth rates $\mu_{\max }$ were assessed by calculating $\frac{\Delta \log N \cdot \ln (10)}{t}$ from each of the 45 challenge studies. Linear regression was applied to data points taken from the exponential phase. The lag phase and stationary phase were omitted, taking a worst-case approach. To determine $\mu_{\max }$ in the exponential phase, the time interval was studied at which a clear increase of growth could be observed. The search on growth rates from challenge studies resulted in total in 45 studies containing 249 growth rates for 10 types of cheeses. Data from challenge studies were obtained through a literature search (searching Scopus and Web of Science for: monocytogenes AND cheese AND (Blue OR Camembert OR Cheddar OR Cottage OR Emmental OR Feta OR Gouda OR Mozzarella OR Queso Fresco OR Ricotta OR Swiss), sorted on relevance) and Combase (search on www.combase.cc for Listeria monocytogenes AND cheese, data from all scientific article records were incorporated for each of the 10 cheese types). The growth rate $\mu_{10}{ }^{\circ} \mathrm{C}$ is the actual growth rate $\mu_{\max }$ normalized for a temperature of $10^{\circ} \mathrm{C}$ by use of the square-root function of McMeekin et al. (1993): $\mu_{\mathrm{T}}=\mu_{\text {ref }}$. $\frac{\left(\mathrm{T}-\mathrm{T}_{\min }\right)^{2}}{\left(\mathrm{~T}_{\mathrm{ref}}-\mathrm{T}_{\min }\right)^{2}}$, with $\mathrm{T}_{\min }=-1.5^{\circ} \mathrm{C}$ and $\mathrm{T}_{\mathrm{ref}}=10^{\circ} \mathrm{C}$. The application of the square-root function by McMeekin et al. (1993) for temperature is only validated for positive actual growth rates. As for the positive actual growth rates, the negative growth rates were normalized to $10{ }^{\circ} \mathrm{C}$ using the function, but the latter was not scientifically substantiated in this thesis

\begin{tabular}{llllllll}
\hline Cheese type & Reference & $\begin{array}{l}\text { Inoculation } \\
\text { target }\end{array}$ & $\begin{array}{l}\text { Tempe- } \\
\text { rature } \\
\left({ }^{\circ} \mathrm{C}\right)\end{array}$ & $\begin{array}{l}\Delta \log N(\log \\
\left.\mathrm{cfu} \mathrm{g})^{-1}\right)\end{array}$ & $\begin{array}{l}\Delta t \\
(\mathrm{~h})\end{array}$ & $\mu_{\max }\left(\mathrm{h}^{-1}\right)$ & $\mu_{10}{ }^{\circ} \mathrm{C}\left(\mathrm{h}^{-1}\right)$ \\
\hline
\end{tabular}

\begin{tabular}{|c|c|c|c|c|c|c|c|}
\hline Ricotta & $\begin{array}{l}\text { Genigeorgis, Carniciu, } \\
\text { Dutulescu, \& Farver et } \\
\text { al., } 1991\end{array}$ & Surface & 30 & 3.33 & 24 & 0.32 & 0.043 \\
\hline Ricotta & Genigeorgis et al., 1991 & Surface & 8 & 2.11 & 192 & 0.025 & 0.037 \\
\hline Ricotta & Genigeorgis et al., 1991 & Surface & 4 & 1.53 & 720 & 0.0049 & 0.021 \\
\hline Ricotta & Genigeorgis et al., 1991 & Surface & 30 & 2.83 & 24 & 0.27 & 0.036 \\
\hline Ricotta & Genigeorgis et al., 1991 & Surface & 8 & 1.75 & 144 & 0.028 & 0.041 \\
\hline Ricotta & Genigeorgis et al., 1991 & Surface & 4 & 3.58 & 864 & 0.010 & 0.042 \\
\hline Ricotta & Genigeorgis et al., 1991 & Surface & 30 & 3.67 & 96 & 0.088 & 0.012 \\
\hline Ricotta & Genigeorgis et al., 1991 & Surface & 8 & 1.88 & 192 & 0.023 & 0.033 \\
\hline Ricotta & Genigeorgis et al., 1991 & Surface & 4 & 1.97 & 528 & 0.0086 & 0.038 \\
\hline Ricotta & Kapetanakou et al., 2017 & $\begin{array}{l}\text { Cheese } \\
\text { blend }\end{array}$ & 7 & 5.90 & 240 & 0.057 & 0.10 \\
\hline Ricotta & $\begin{array}{l}\text { Martins, Cerqueira, } \\
\text { Souza, Carmo Avides, \& } \\
\text { Vicente, } 2010\end{array}$ & Surface & 4 & 1.10 & 168 & 0.0151 & 0.066 \\
\hline Queso Fresco & $\begin{array}{l}\text { Brown, Kozak, \& } \\
\text { D'Amico, } 2018\end{array}$ & Surface & 7 & 4.1 & 648 & 0.015 & 0.027 \\
\hline Queso Fresco & Gadotti et al., 2014 & Curd & 4 & 5.20 & 480 & 0.025 & 0.11 \\
\hline Queso Fresco & Gadotti et al., 2014 & Curd & 4 & 4.50 & 288 & 0.036 & 0.16 \\
\hline Queso Fresco & Gadotti et al., 2014 & Curd & 4 & 4.10 & 288 & 0.033 & 0.14 \\
\hline Queso Fresco & Gadotti et al., 2014 & Curd & 4 & 4.20 & 288 & 0.034 & 0.15 \\
\hline Queso Fresco & Gadotti et al., 2014 & Curd & 4 & 4.00 & 288 & 0.032 & 0.14 \\
\hline Queso Fresco & Gadotti et al., 2014 & Curd & 4 & 3.20 & 480 & 0.015 & 0.067 \\
\hline Queso Fresco & Genigeorgis et al., 1991 & Surface & 30 & 0.39 & 72 & 0.012 & 0.0017 \\
\hline Queso Fresco & Genigeorgis et al., 1991 & Surface & 8 & -1.30 & 336 & -0.0089 & -0.013 \\
\hline Queso Fresco & Genigeorgis et al., 1991 & Surface & 4 & -2.00 & 720 & -0.0064 & -0.028 \\
\hline Queso Fresco & Genigeorgis et al., 1991 & Surface & 30 & 0.95 & 144 & 0.015 & 0.0020 \\
\hline Queso Fresco & Genigeorgis et al., 1991 & Surface & 8 & -0.05 & 192 & -0.00060 & -0.0009 \\
\hline Queso Fresco & Genigeorgis et al., 1991 & Surface & 4 & -0.84 & 240 & -0.0081 & -0.035 \\
\hline Queso Fresco & Genigeorgis et al., 1991 & Surface & 30 & 0.74 & 72 & 0.024 & 0.0032 \\
\hline Queso Fresco & Genigeorgis et al., 1991 & Surface & 8 & 0.45 & 144 & 0.0072 & 0.011 \\
\hline Queso Fresco & Genigeorgis et al., 1991 & Surface & 4 & 0.28 & 720 & 0.00090 & 0.004 \\
\hline
\end{tabular}




\begin{tabular}{|c|c|c|c|c|c|c|c|}
\hline Queso Fresco & $\begin{array}{l}\text { Ibarra-Sanchez, van } \\
\text { Tassell, \& Miller, } 2018\end{array}$ & Curd & 4 & 1.1 & 168 & 0.015 & 0.066 \\
\hline Queso Fresco & $\begin{array}{l}\text { Ibarra-Sanchez et al., } \\
2018\end{array}$ & Curd & 4 & 1.15 & 168 & 0.016 & 0.069 \\
\hline Queso Fresco & $\begin{array}{l}\text { Ibarra-Sanchez et al., } \\
2018\end{array}$ & Curd & 4 & 1.25 & 168 & 0.017 & 0.075 \\
\hline Queso Fresco & $\begin{array}{l}\text { Ibarra-Sanchez et al., } \\
2018\end{array}$ & Curd & 4 & 1.25 & 168 & 0.017 & 0.075 \\
\hline Queso Fresco & $\begin{array}{l}\text { Ibarra-Sanchez et al., } \\
2018\end{array}$ & Curd & 4 & 3.8 & 336 & 0.026 & 0.11 \\
\hline Queso Fresco & Leggett et al., 2012 & Curd & 4 & 3.50 & 480 & 0.017 & 0.073 \\
\hline Queso Fresco & Leggett et al., 2012 & Curd & 10 & 4.00 & 240 & 0.038 & 0.038 \\
\hline Queso Fresco & Leggett et al., 2012 & Curd & 4 & 3.60 & 480 & 0.017 & 0.076 \\
\hline Queso Fresco & Leggett et al., 2012 & Curd & 10 & 4.50 & 288 & 0.036 & 0.036 \\
\hline Queso Fresco & $\begin{array}{l}\text { Lin, Zhang, Doyle, \& } \\
\text { Swaminathan, } 2016\end{array}$ & $\begin{array}{l}\text { Cheese } \\
\text { blend }\end{array}$ & 4 & 2.67 & 336 & 0.018 & 0.080 \\
\hline Queso Fresco & Lin et al., 2016 & $\begin{array}{l}\text { Cheese } \\
\text { blend }\end{array}$ & 4 & 2.07 & 336 & 0.014 & 0.062 \\
\hline Queso Fresco & Lin et al., 2016 & $\begin{array}{l}\text { Cheese } \\
\text { blend }\end{array}$ & 4 & 2.9 & 336 & 0.020 & 0.087 \\
\hline Queso Fresco & Lin et al., 2016 & $\begin{array}{l}\text { Cheese } \\
\text { blend }\end{array}$ & 4 & 2.12 & 336 & 0.015 & 0.064 \\
\hline Queso Fresco & Lin et al., 2016 & $\begin{array}{l}\text { Cheese } \\
\text { blend }\end{array}$ & 12 & 2.91 & 336 & 0.020 & 0.014 \\
\hline Queso Fresco & Lin et al., 2016 & $\begin{array}{l}\text { Cheese } \\
\text { blend }\end{array}$ & 12 & 2.46 & 336 & 0.017 & 0.012 \\
\hline Queso Fresco & Lin et al., 2016 & $\begin{array}{l}\text { Cheese } \\
\text { blend }\end{array}$ & 12 & 3.14 & 336 & 0.022 & 0.016 \\
\hline Queso Fresco & Lin et al., 2016 & $\begin{array}{l}\text { Cheese } \\
\text { blend }\end{array}$ & 12 & 2.58 & 336 & 0.018 & 0.013 \\
\hline Queso Fresco & Lin et al., 2016 & $\begin{array}{l}\text { Cheese } \\
\text { blend }\end{array}$ & 21 & 2.33 & 336 & 0.016 & 0.0042 \\
\hline Queso Fresco & Lin et al., 2016 & $\begin{array}{l}\text { Cheese } \\
\text { blend }\end{array}$ & 21 & 2.38 & 336 & 0.016 & 0.0043 \\
\hline Queso Fresco & Lin et al., 2016 & $\begin{array}{l}\text { Cheese } \\
\text { blend }\end{array}$ & 21 & 2.47 & 336 & 0.017 & 0.0044 \\
\hline Queso Fresco & Lin et al., 2016 & $\begin{array}{l}\text { Cheese } \\
\text { blend }\end{array}$ & 21 & 2.44 & 336 & 0.017 & 0.0044 \\
\hline Queso Fresco & $\begin{array}{l}\text { Lourenço, Kamnetz, } \\
\text { Gadotti, \& Diez- } \\
\text { Gonzalez, } 2017\end{array}$ & Curd & 4 & 4.8 & 336 & 0.033 & 0.14 \\
\hline Queso Fresco & Lourenço et al., 2017 & Curd & 4 & 4.6 & 312 & 0.034 & 0.15 \\
\hline Queso Fresco & Lourenço et al., 2017 & Curd & 4 & 4.4 & 408 & 0.025 & 0.11 \\
\hline Queso Fresco & Lourenço et al., 2017 & Curd & 4 & 3.5 & 264 & 0.031 & 0.13 \\
\hline Queso Fresco & Soni et al., 2010 & Surface & 4 & 3.40 & 312 & 0.025 & 0.11 \\
\hline Queso Fresco & Soni et al., 2012 & Surface & 4 & 3.40 & 504 & 0.016 & 0.068 \\
\hline Queso Fresco & $\begin{array}{l}\text { van Hekken, Tunick, } \\
\text { Leggett, \& Tomasula, } \\
2012\end{array}$ & Surface & 4 & 4.10 & 504 & 0.019 & 0.082 \\
\hline Camembert & $\begin{array}{l}\text { Back, Langford, \& Kroll, } \\
1993\end{array}$ & Milk & $\begin{array}{l}8 \text { on } \\
\text { average } \\
(14 \mathrm{~d} \text { at } \\
13^{\circ} \mathrm{C} \text {, } \\
\text { then at } \\
\left.3{ }^{\circ} \mathrm{C}\right)\end{array}$ & 1.20 & 672 & 0.0041 & 0.0060 \\
\hline Camembert & Back et al., 1993 & Milk & $\begin{array}{l}8 \text { on } \\
\text { average } \\
(14 d \text { at }\end{array}$ & 1.80 & 672 & 0.0062 & 0.0090 \\
\hline
\end{tabular}




\begin{tabular}{|c|c|c|c|c|c|c|c|}
\hline & & & $\begin{array}{l}13^{\circ} \mathrm{C} \text {, } \\
\text { then at } \\
\left.3{ }^{\circ} \mathrm{C}\right)\end{array}$ & & & & \\
\hline Camembert & Back et al., 1993 & Milk & $\begin{array}{l}8 \text { on } \\
\text { average } \\
(14 \mathrm{~d} \text { at } \\
13^{\circ} \mathrm{C} \text {, } \\
\text { then at } \\
\left.3^{\circ} \mathrm{C}\right)\end{array}$ & 3.00 & 672 & 0.010 & 0.015 \\
\hline Camembert & Back et al., 1993 & Milk & $\begin{array}{l}8 \text { on } \\
\text { average } \\
(14 \mathrm{~d} \text { at } \\
13^{\circ} \mathrm{C} \text {, } \\
\text { then at } \\
\left.3^{\circ} \mathrm{C}\right)\end{array}$ & 3.80 & 696 & 0.013 & 0.018 \\
\hline Camembert & Back et al., 1993 & Milk & $\begin{array}{l}8 \text { on } \\
\text { average } \\
(14 \mathrm{~d} \text { at } \\
13^{\circ} \mathrm{C} \text {, } \\
\text { then at } \\
\left.3^{\circ} \mathrm{C}\right)\end{array}$ & -0.50 & 672 & -0.0017 & -0.0025 \\
\hline Camembert & Back et al., 1993 & Milk & $\begin{array}{l}8 \text { on } \\
\text { average } \\
(14 \mathrm{~d} \text { at } \\
13^{\circ} \mathrm{C} \text {, } \\
\text { then at } \\
\left.3^{\circ} \mathrm{C}\right)\end{array}$ & -0.40 & 672 & -0.0014 & -0.0020 \\
\hline Camembert & Back et al., 1993 & Milk & $\begin{array}{l}8 \text { on } \\
\text { average } \\
(14 \mathrm{~d} \text { at } \\
13^{\circ} \mathrm{C} \text {, } \\
\text { then at } \\
\left.3^{\circ} \mathrm{C}\right)\end{array}$ & 0.30 & 672 & 0.0010 & 0.0025 \\
\hline Camembert & Back et al., 1993 & Milk & $\begin{array}{l}8 \text { on } \\
\text { average } \\
(14 \mathrm{~d} \text { at } \\
13^{\circ} \mathrm{C} \text {, } \\
\text { then at } \\
\left.3^{\circ} \mathrm{C}\right)\end{array}$ & 2.40 & 696 & 0.0079 & 0.012 \\
\hline Camembert & Back et al., 1993 & Surface & 3 & 0.70 & 360 & 0.0045 & 0.029 \\
\hline Camembert & Back et al., 1993 & Surface & 6 & 2.20 & 360 & 0.014 & 0.033 \\
\hline Camembert & Back et al., 1993 & Surface & 3 & 1.30 & 360 & 0.0083 & 0.054 \\
\hline Camembert & Back et al., 1993 & Surface & 6 & 1.00 & 192 & 0.012 & 0.028 \\
\hline Camembert & Genigeorgis et al., 1991 & Surface & 30 & 1.75 & 48 & 0.084 & 0.011 \\
\hline Camembert & Genigeorgis et al., 1991 & Surface & 8 & 2.05 & 528 & 0.0089 & 0.013 \\
\hline Camembert & Genigeorgis et al., 1991 & Surface & 4 & 0.64 & 864 & 0.0017 & 0.0075 \\
\hline Camembert & Kapetanakou et al., 2017 & Slices & 7 & 4.70 & 288 & 0.038 & 0.069 \\
\hline Camembert & Lahou et al., 2017 & Cheese rind & 7 & 1.92 & 336 & 0.013 & 0.024 \\
\hline Camembert & Lahou et al., 2017 & Cheese rind & 7 & 1.20 & 336 & 0.0082 & 0.015 \\
\hline Camembert & Lahou et al., 2017 & Cheese rind & 7 & 1.30 & 336 & 0.0089 & 0.016 \\
\hline Camembert & Lahou et al., 2017 & Cheese rind & 14 & 3.55 & 336 & 0.024 & 0.013 \\
\hline Camembert & Lahou et al., 2017 & Cheese rind & 14 & 2.66 & 336 & 0.018 & 0.010 \\
\hline Camembert & Lahou et al., 2017 & Cheese rind & 14 & 2.74 & 336 & 0.019 & 0.010 \\
\hline Camembert & Lahou et al., 2017 & Surface & 7 & 3.82 & 336 & 0.026 & 0.048 \\
\hline Camembert & Lahou et al., 2017 & Surface & 7 & 4.01 & 336 & 0.027 & 0.050 \\
\hline Camembert & Lahou et al., 2017 & Surface & 7 & 1.82 & 336 & 0.012 & 0.023 \\
\hline Camembert & Lahou et al., 2017 & Surface & 14 & 5.46 & 336 & 0.037 & 0.021 \\
\hline Camembert & Lahou et al., 2017 & Surface & 14 & 4.93 & 336 & 0.034 & 0.019 \\
\hline
\end{tabular}




\begin{tabular}{|c|c|c|c|c|c|c|c|}
\hline Camembert & Lahou et al., 2017 & Surface & 14 & 2.82 & 336 & 0.019 & 0.011 \\
\hline Camembert & Larson et al., 1996 & $\begin{array}{l}\text { Cheese } \\
\text { blend }\end{array}$ & 4 & 1.93 & 432 & 0.010 & 0.045 \\
\hline Camembert & Larson et al., 1996 & $\begin{array}{l}\text { Cheese } \\
\text { blend }\end{array}$ & 12 & 3.53 & 264 & 0.031 & 0.022 \\
\hline & $\begin{array}{l}\text { Linton, Mackle, } \\
\text { Upadhyay, Kelly, \& }\end{array}$ & & & & & & \\
\hline Camembert & Patterson, 2008 & Milk & 13 & -0.67 & 336 & -0.0046 & -0.0029 \\
\hline Camembert & Linton et al., 2008 & Milk & 13 & -0.91 & 336 & -0.0062 & -0.0039 \\
\hline Camembert & $\begin{array}{l}\text { Maisnier-Patin et al., } \\
1992\end{array}$ & Milk & 11 & 5.00 & 1008 & 0.011 & 0.010 \\
\hline Camembert & $\begin{array}{l}\text { Sulzer \& Buzze et al., } \\
1991\end{array}$ & Milk & 17 & 4.40 & 1068 & 0.0095 & 0.0037 \\
\hline Camembert & $\begin{array}{l}\text { Sulzer \& Buzze et al., } \\
1991\end{array}$ & Milk & 17 & 4.20 & 936 & 0.010 & 0.0040 \\
\hline Camembert & Wan et al., 1997 & Milk & 15 & 4.36 & 504 & 0.020 & 0.010 \\
\hline Mozzarella & Kapetanakou et al., 2017 & Slices & 7 & 4.40 & 192 & 0.053 & 0.097 \\
\hline Mozzarella & Menon et al., 2001 & Cheese & 7 & 2.07 & 288 & 0.017 & 0.030 \\
\hline Mozzarella & Menon et al., 2001 & Cheese & 30 & 4.51 & 120 & 0.086 & 0.012 \\
\hline Mozzarella & $\begin{array}{l}\text { Stecchini, Aquili, \& } \\
\text { Sarais, } 1995\end{array}$ & Surface & 5 & 4.20 & 504 & 0.019 & 0.060 \\
\hline Cottage & Chen \& Hotchkiss, 1993 & $\begin{array}{l}\text { Cheese } \\
\text { blend }\end{array}$ & 4 & 3.09 & 1512 & 0.0047 & 0.021 \\
\hline Cottage & Chen \& Hotchkiss, 1993 & $\begin{array}{l}\text { Cheese } \\
\text { blend }\end{array}$ & 7 & 2.94 & 384 & 0.018 & 0.032 \\
\hline Cottage & Chen \& Hotchkiss, 1993 & $\begin{array}{l}\text { Cheese } \\
\text { blend }\end{array}$ & 4 & 0.07 & 1512 & 0.00011 & 0.00048 \\
\hline Cottage & Chen \& Hotchkiss, 1993 & $\begin{array}{l}\text { Cheese } \\
\text { blend }\end{array}$ & 7 & 1.27 & 1176 & 0.0025 & 0.0045 \\
\hline Cottage & $\begin{array}{l}\text { El-Ziney \& Debevere, } \\
1998\end{array}$ & $\begin{array}{l}\text { Cheese } \\
\text { blend }\end{array}$ & 7 & 0.40 & 504 & 0.0018 & 0.0033 \\
\hline Cottage & Genigeorgis et al., 1991 & Surface & 30 & -1.95 & 192 & -0.023 & -0.0031 \\
\hline Cottage & Genigeorgis et al., 1991 & Surface & 8 & 0.59 & 432 & 0.0031 & 0.0046 \\
\hline Cottage & Genigeorgis et al., 1991 & Surface & 4 & 0.39 & 576 & 0.0016 & 0.0068 \\
\hline Cottage & Genigeorgis et al., 1991 & Surface & 30 & -1.87 & 192 & -0.022 & -0.0030 \\
\hline Cottage & Genigeorgis et al., 1991 & Surface & 8 & -1.87 & 864 & -0.0050 & -0.0073 \\
\hline Cottage & Genigeorgis et al., 1991 & Surface & 4 & 0.34 & 576 & 0.0014 & 0.0059 \\
\hline Cottage & Genigeorgis et al., 1991 & Surface & 30 & -1.87 & 192 & -0.022 & -0.0030 \\
\hline Cottage & Genigeorgis et al., 1991 & Surface & 8 & 0.42 & 576 & 0.0025 & 0.0025 \\
\hline Cottage & Genigeorgis et al., 1991 & Surface & 4 & 0.41 & 384 & 0.002 & 0.011 \\
\hline Cottage & Genigeorgis et al., 1991 & Surface & 30 & 1.19 & 96 & 0.029 & 0.0038 \\
\hline Cottage & Genigeorgis et al., 1991 & Surface & 8 & 1.13 & 192 & 0.014 & 0.020 \\
\hline Cottage & Genigeorgis et al., 1991 & Surface & 4 & 0.94 & 864 & 0.0025 & 0.011 \\
\hline Cottage & Genigeorgis et al., 1991 & Surface & 30 & -1.87 & 192 & -0.022 & -0.0030 \\
\hline Cottage & Genigeorgis et al., 1991 & Surface & 8 & -1.87 & 192 & -0.022 & -0.033 \\
\hline Cottage & Genigeorgis et al., 1991 & Surface & 4 & -1.87 & 192 & -0.022 & -0.098 \\
\hline Cottage & Kapetanakou et al., 2017 & $\begin{array}{l}\text { Cheese } \\
\text { blend }\end{array}$ & 7 & -0.20 & 240 & -0.0019 & -0.0035 \\
\hline Cottage & Larson et al., 1996 & $\begin{array}{l}\text { Cheese } \\
\text { blend }\end{array}$ & 4 & 2.22 & 672 & 0.0076 & 0.033 \\
\hline Cottage & $\begin{array}{l}\text { McAuliffe, Hill, \& Ross, } \\
1999\end{array}$ & Curd & 4 & -0.35 & 168 & -0.0048 & -0.021 \\
\hline Cottage & McAuliffe et al., 1999 & Curd & 18 & -0.40 & 48 & -0.019 & -0.0067 \\
\hline Cottage & McAuliffe et al., 1999 & Curd & 30 & -3.95 & 72 & -0.13 & -0.017 \\
\hline Cottage & Piccinin \& Shelef, 1995 & $\begin{array}{l}\text { Cheese } \\
\text { blend }\end{array}$ & 5 & -0.75 & 576 & -0.0030 & -0.0094 \\
\hline Cottage & Piccinin \& Shelef, 1995 & $\begin{array}{l}\text { Cheese } \\
\text { blend }\end{array}$ & 5 & -0.08 & 576 & -0.00032 & -0.0010 \\
\hline
\end{tabular}




\begin{tabular}{|c|c|c|c|c|c|c|c|}
\hline Cottage & Piccinin \& Shelef, 1995 & $\begin{array}{l}\text { Cheese } \\
\text { blend }\end{array}$ & 5 & -1.31 & 576 & -0.0052 & -0.016 \\
\hline Cottage & Piccinin \& Shelef, 1995 & $\begin{array}{l}\text { Cheese } \\
\text { blend }\end{array}$ & 5 & -1.52 & 576 & -0.0061 & -0.019 \\
\hline Cottage & Piccinin \& Shelef, 1995 & $\begin{array}{l}\text { Cheese } \\
\text { blend }\end{array}$ & 5 & -0.42 & 576 & -0.0017 & -0.0053 \\
\hline Cottage & Piccinin \& Shelef, 1995 & $\begin{array}{l}\text { Cheese } \\
\text { blend }\end{array}$ & 5 & 0.06 & 576 & 0.00024 & 0.00075 \\
\hline Cottage & Piccinin \& Shelef, 1995 & $\begin{array}{l}\text { Cheese } \\
\text { blend }\end{array}$ & 5 & -0.42 & 576 & -0.0017 & -0.0053 \\
\hline Cottage & Piccinin \& Shelef, 1995 & $\begin{array}{l}\text { Cheese } \\
\text { blend }\end{array}$ & 5 & -0.54 & 576 & -0.0022 & -0.0068 \\
\hline Cottage & Piccinin \& Shelef, 1995 & $\begin{array}{l}\text { Cheese } \\
\text { blend }\end{array}$ & 5 & -0.33 & 576 & -0.0013 & -0.0041 \\
\hline Cottage & Piccinin \& Shelef, 1995 & $\begin{array}{l}\text { Cheese } \\
\text { blend }\end{array}$ & 5 & -0.42 & 576 & -0.0017 & -0.0053 \\
\hline Cottage & $\begin{array}{l}\text { Ryser, Marth, \& Doyle, } \\
1985\end{array}$ & Milk & 3 & 1.04 & 605 & 0.0040 & 0.026 \\
\hline Cottage & Østergaard et al., 2014 & $\begin{array}{l}\text { Cheese } \\
\text { blend }\end{array}$ & 5 & 2.7 & 470 & 0.013 & 0.041 \\
\hline Cottage & Østergaard et al., 2014 & $\begin{array}{l}\text { Cheese } \\
\text { blend }\end{array}$ & 10 & 2.4 & 350 & 0.016 & 0.016 \\
\hline Cottage & Østergaard et al., 2014 & $\begin{array}{l}\text { Cheese } \\
\text { blend }\end{array}$ & 15 & 1.7 & 140 & 0.028 & 0.014 \\
\hline Cottage & Østergaard et al., 2015 & $\begin{array}{l}\text { Cheese } \\
\text { blend }\end{array}$ & 7.5 & 2.10 & 290 & 0.017 & 0.027 \\
\hline Cottage & Østergaard et al., 2015 & $\begin{array}{l}\text { Cheese } \\
\text { blend }\end{array}$ & 7.5 & 1.50 & 150 & 0.023 & 0.038 \\
\hline Cottage & Østergaard et al., 2015 & $\begin{array}{l}\text { Cheese } \\
\text { blend }\end{array}$ & 7.5 & 2.00 & 290 & 0.016 & 0.026 \\
\hline Blue & Back et al., 1993 & Surface & 4 & 0.00 & 336 & 0.00 & 0.000 \\
\hline Blue & Back et al., 1993 & Surface & 8 & 0.00 & 600 & 0.00 & 0.000 \\
\hline Blue & $\begin{array}{l}\text { Bernini, Bottari, Dalzini, } \\
\text { \& Gatti, } 2013\end{array}$ & Surface & 4 & 2.40 & 840 & 0.0066 & 0.029 \\
\hline Blue & Bernini et al., 2013 & Surface & 8 & 3.50 & 1320 & 0.0061 & 0.0089 \\
\hline Blue & Bernini et al., 2013 & Surface & 4 & 0.50 & 1320 & 0.00087 & 0.0038 \\
\hline Blue & Bernini et al., 2013 & Surface & 8 & 2.30 & 1320 & 0.0040 & 0.0059 \\
\hline Blue & Dalzini et al., 2017 & Milk & 4 & 2.2 & 1848 & 0.0027 & 0.012 \\
\hline Blue & Dalzini et al., 2017 & Slices & 8 & 3.40 & 576 & 0.014 & 0.020 \\
\hline Blue & Dalzini et al., 2017 & Slices & 8 & 1.50 & 504 & 0.0069 & 0.010 \\
\hline Blue & Dalzini et al., 2017 & Slices & 8 & 3.10 & 504 & 0.0142 & 0.021 \\
\hline Blue & Dalzini et al., 2017 & Slices & 8 & 3.70 & 1344 & 0.0063 & 0.0093 \\
\hline Blue & Dalzini et al., 2017 & Slices & 8 & 3.90 & 216 & 0.042 & 0.061 \\
\hline Blue & Dalzini et al., 2017 & Slices & 8 & 4.40 & 336 & 0.030 & 0.044 \\
\hline Blue & Genigeorgis et al., 1991 & Surface & 30 & -2.00 & 432 & -0.011 & -0.0014 \\
\hline Blue & Genigeorgis et al., 1991 & Surface & 8 & -2.00 & 432 & -0.011 & -0.016 \\
\hline Blue & Genigeorgis et al., 1991 & Surface & 4 & -2.00 & 864 & -0.0053 & -0.023 \\
\hline Blue & $\begin{array}{l}\text { Papageorgiou \& Marth, } \\
\text { 1989a }\end{array}$ & Milk & 10.5 & -2.80 & 600 & -0.011 & -0.010 \\
\hline Blue & $\begin{array}{l}\text { Papageorgiou \& Marth, } \\
\text { 1989a }\end{array}$ & Milk & 10.5 & -2.80 & 1200 & -0.0054 & -0.0049 \\
\hline Blue & $\begin{array}{l}\text { Papageorgiou \& Marth, } \\
\text { 1989a }\end{array}$ & Milk & 10.5 & -2.50 & 1440 & -0.0040 & -0.0037 \\
\hline Blue & $\begin{array}{l}\text { Papageorgiou \& Marth, } \\
\text { 1989a }\end{array}$ & Milk & 10.5 & -2.50 & 1200 & -0.0048 & -0.0044 \\
\hline Blue & $\begin{array}{l}\text { Papageorgiou \& Marth, } \\
\text { 1989a }\end{array}$ & Milk & 10.5 & -2.70 & 1440 & -0.0043 & -0.0040 \\
\hline
\end{tabular}




\begin{tabular}{|c|c|c|c|c|c|c|c|}
\hline Blue & $\begin{array}{l}\text { Papageorgiou \& Marth, } \\
1989 \text { a }\end{array}$ & Milk & 10.5 & -2.50 & 720 & -0.0080 & -0.0073 \\
\hline Blue & $\begin{array}{l}\text { Schaffer, Tatini, \& Baer, } \\
1995\end{array}$ & Milk & 13 & -2.80 & 720 & -0.0090 & -0.0056 \\
\hline Blue & Schaffer et al., 1995 & Milk & 13 & -4.40 & 1440 & -0.0070 & -0.0044 \\
\hline Blue & $\begin{array}{l}\text { Whitley, Muir, \& Waites, } \\
2000\end{array}$ & Surface & 5 & 0.30 & 1008 & 0.00069 & 0.0021 \\
\hline Feta & Genigeorgis et al., 1991 & Surface & 30 & -2.04 & 96 & -0.049 & -0.0065 \\
\hline Feta & Genigeorgis et al., 1991 & Surface & 8 & -2.04 & 192 & -0.024 & -0.036 \\
\hline Feta & Genigeorgis et al., 1991 & Surface & 4 & -2.04 & 192 & -0.024 & -0.107 \\
\hline Feta & Genigeorgis et al., 1991 & Surface & 30 & -2.04 & 96 & -0.049 & -0.007 \\
\hline Feta & Genigeorgis et al., 1991 & Surface & 8 & -2.04 & 192 & -0.024 & -0.036 \\
\hline Feta & Genigeorgis et al., 1991 & Surface & 4 & -2.04 & 192 & -0.024 & -0.107 \\
\hline Feta & Genigeorgis et al., 1991 & Surface & 30 & -2.04 & 96 & -0.049 & -0.0065 \\
\hline Feta & Genigeorgis et al., 1991 & Surface & 8 & -2.04 & 192 & -0.024 & -0.036 \\
\hline Feta & Genigeorgis et al., 1991 & Surface & 4 & -2.04 & 192 & -0.024 & -0.107 \\
\hline Feta & Genigeorgis et al., 1991 & Surface & 30 & -2.04 & 96 & -0.049 & -0.0065 \\
\hline Feta & Genigeorgis et al., 1991 & Surface & 8 & -2.04 & 192 & -0.024 & -0.036 \\
\hline & $\begin{array}{l}\text { Konteles, Sinanoglou, } \\
\text { Batrinou, \& Sflomos, }\end{array}$ & & & & & & \\
\hline Feta & 2009 & Milk & 4 & -0.40 & 720 & -0.0013 & -0.0056 \\
\hline Feta & Leong et al., 2014 & Slices & 25 & -4.58 & 360 & -0.029 & -0.0055 \\
\hline Feta & Leong et al., 2014 & Slices & 25 & -4.89 & 360 & -0.031 & -0.0059 \\
\hline Feta & $\begin{array}{l}\text { Papageorgiou \& Marth, } \\
\text { 1989b }\end{array}$ & Milk & 4 & -0.80 & 1680 & -0.0011 & -0.0048 \\
\hline Feta & $\begin{array}{l}\text { Papageorgiou \& Marth, } \\
\text { 1989b }\end{array}$ & Milk & 4 & -0.40 & 1680 & -0.00055 & -0.0024 \\
\hline Feta & $\begin{array}{l}\text { Papageorgiou \& Marth, } \\
\text { 1989b }\end{array}$ & Milk & 4 & -1.50 & 2040 & -0.0017 & -0.0074 \\
\hline Feta & $\begin{array}{l}\text { Papageorgiou \& Marth, } \\
\text { 1989b }\end{array}$ & Milk & 4 & -3.00 & 2160 & -0.0032 & -0.014 \\
\hline Feta & $\begin{array}{l}\text { Papageorgiou \& Marth, } \\
\text { 1989b }\end{array}$ & Milk & 4 & -2.80 & 2160 & -0.0030 & -0.013 \\
\hline Feta & $\begin{array}{l}\text { Papageorgiou \& Marth, } \\
\text { 1989b }\end{array}$ & Milk & 4 & -2.80 & 2160 & -0.0030 & -0.013 \\
\hline Cheddar & $\begin{array}{l}\text { Buyong, Kok, \& } \\
\text { Luchansky, } 1998\end{array}$ & Milk & 8 & -1.75 & 168 & -0.0240 & -0.035 \\
\hline Cheddar & Genigeorgis et al., 1991 & Surface & 30 & -1.26 & 96 & -0.030 & -0.0040 \\
\hline Cheddar & Genigeorgis et al., 1991 & Surface & 30 & -2.09 & 168 & -0.029 & -0.0038 \\
\hline Cheddar & Genigeorgis et al., 1991 & Surface & 8 & -2.09 & 720 & -0.0067 & -0.010 \\
\hline Cheddar & Genigeorgis et al., 1991 & Surface & 4 & -2.09 & 720 & -0.0067 & -0.029 \\
\hline Cheddar & Genigeorgis et al., 1991 & Surface & 30 & -0.38 & 96 & -0.0091 & -0.0012 \\
\hline Cheddar & Genigeorgis et al., 1991 & Surface & 8 & -0.06 & 96 & -0.0014 & -0.0021 \\
\hline Cheddar & Genigeorgis et al., 1991 & Surface & 30 & -2.09 & 72 & -0.067 & -0.0089 \\
\hline Cheddar & Genigeorgis et al., 1991 & Surface & 8 & -1.31 & 864 & -0.0035 & -0.0051 \\
\hline Cheddar & Genigeorgis et al., 1991 & Surface & 4 & -2.09 & 864 & -0.0056 & -0.0244 \\
\hline Cheddar & Leong et al., 2014 & Slices & 25 & -0.70 & 360 & -0.0045 & -0.00084 \\
\hline Cheddar & Leong et al., 2014 & Slices & 25 & -0.76 & 360 & -0.0049 & -0.00092 \\
\hline Cheddar & Leong et al., 2014 & Slices & 25 & -0.35 & 360 & -0.0022 & -0.00042 \\
\hline Cheddar & Leong et al., 2014 & Slices & 25 & 0.00 & 360 & 0.00 & 0.0000 \\
\hline Cheddar & $\begin{array}{l}\text { Limjaroen, Ryser, } \\
\text { Lockhart, \& Harte, } 2005\end{array}$ & $\begin{array}{l}\text { Surface } \\
\text { (cubes) }\end{array}$ & 4 & -0.10 & 168 & -0.0014 & -0.0060 \\
\hline Cheddar & Limjaroen et al., 2005 & $\begin{array}{l}\text { Surface } \\
\text { (cubes) }\end{array}$ & 4 & -0.50 & 840 & -0.0014 & -0.0060 \\
\hline Cheddar & Mehta et al., 1994 & Milk & 7 & -0.30 & 288 & -0.0024 & -0.0044 \\
\hline Cheddar & Ryser et al., 1987 & Milk & 13 & -1.40 & 1320 & -0.0024 & -0.0015 \\
\hline Cheddar & Ryser et al., 1987 & Milk & 13 & -1.80 & 3000 & -0.0014 & -0.00087 \\
\hline Cheddar & Ryser et al., 1987 & Milk & 13 & -2.20 & 5400 & -0.00094 & -0.00059 \\
\hline
\end{tabular}




\begin{tabular}{|c|c|c|c|c|c|c|c|}
\hline Cheddar & Ryser et al., 1987 & Milk & 6 & -1.80 & 1680 & -0.0025 & -0.0058 \\
\hline Cheddar & Ryser et al., 1987 & Milk & 6 & -1.45 & 1560 & -0.0021 & -0.0050 \\
\hline Cheddar & Ryser et al., 1987 & Milk & 6 & -2.00 & 3000 & -0.0015 & -0.0036 \\
\hline Cheddar & Ryser et al., 1987 & Milk & 13 & -2.00 & 3720 & -0.0012 & -0.00078 \\
\hline Cheddar & Ryser et al., 1987 & Milk & 13 & -1.70 & 2400 & -0.0016 & -0.0010 \\
\hline Cheddar & Ryser et al., 1987 & Milk & 13 & -0.40 & 4680 & -0.00020 & -0.00012 \\
\hline Cheddar & Ryser et al., 1987 & Milk & 6 & -2.00 & 4320 & -0.0011 & -0.0025 \\
\hline Cheddar & Ryser et al., 1987 & Milk & 6 & -1.50 & 2160 & -0.0016 & -0.0038 \\
\hline Cheddar & Ryser et al., 1987 & Milk & 6 & -1.00 & 8640 & -0.00027 & -0.00063 \\
\hline Cheddar & Schaffer et al., 1995 & Milk & 7 & -2.20 & 2160 & -0.0023 & -0.0043 \\
\hline Cheddar & Schaffer et al., 1995 & Milk & 7 & 0.00 & 2872 & 0.00 & 0.0000 \\
\hline Cheddar & Shrestha et al., 2011 & $\begin{array}{l}\text { Cheese } \\
\text { blend }\end{array}$ & 4 & -0.56 & 1080 & -0.0012 & -0.0052 \\
\hline Cheddar & Shrestha et al., 2011 & $\begin{array}{l}\text { Cheese } \\
\text { blend }\end{array}$ & 4 & -0.40 & 1080 & -0.00085 & -0.0037 \\
\hline Cheddar & Shrestha et al., 2011 & $\begin{array}{l}\text { Cheese } \\
\text { blend }\end{array}$ & 4 & -0.35 & 1080 & -0.00075 & -0.0033 \\
\hline Cheddar & Shrestha et al., 2011 & $\begin{array}{l}\text { Cheese } \\
\text { blend }\end{array}$ & 4 & -0.73 & 1080 & -0.0016 & -0.0068 \\
\hline Cheddar & Shrestha et al., 2011 & $\begin{array}{l}\text { Cheese } \\
\text { blend }\end{array}$ & 10 & -0.55 & 2168 & -0.00058 & -0.00058 \\
\hline Cheddar & Shrestha et al., 2011 & $\begin{array}{l}\text { Cheese } \\
\text { blend }\end{array}$ & 10 & -0.30 & 2168 & -0.00032 & -0.00032 \\
\hline Cheddar & Shrestha et al., 2011 & $\begin{array}{l}\text { Cheese } \\
\text { blend }\end{array}$ & 10 & -0.37 & 2168 & -0.00039 & -0.00039 \\
\hline Cheddar & Shrestha et al., 2011 & $\begin{array}{l}\text { Cheese } \\
\text { blend }\end{array}$ & 10 & -0.76 & 2168 & -0.00081 & -0.00081 \\
\hline Gouda & Leong et al., 2014 & Slices & 25 & -0.51 & 360 & -0.0033 & -0.00061 \\
\hline Gouda & Leong et al., 2014 & Slices & 25 & -0.44 & 360 & -0.0028 & -0.00053 \\
\hline Gouda & Kapetanakou et al., 2017 & Slices & 7 & -0.2 & 1200 & -0.00038 & -0.00070 \\
\hline Gouda & Northolt et al., 1988 & Milk & 13 & -1.07 & 1008 & -0.0025 & -0.0015 \\
\hline Gouda & Northolt et al., 1988 & Milk & 13 & 0.43 & 1008 & 0.0010 & 0.0006 \\
\hline Gouda & $\begin{array}{l}\text { Wemmenhove, } \\
\text { Stampelou, van } \\
\text { Hooijdonk, Zwietering, } \\
\text { \& Wells-Bennik, } 2013 \\
\end{array}$ & Milk & 12.5 & -1.26 & 1008 & -0.0029 & -0.0019 \\
\hline Gouda & $\begin{array}{l}\text { Wemmenhove et al., } \\
2013\end{array}$ & Milk & 12.5 & -0.59 & 1008 & -0.0013 & -0.00091 \\
\hline Gouda & $\begin{array}{l}\text { Wemmenhove et al., } \\
2013\end{array}$ & Milk & 12.5 & -0.45 & 1008 & -0.0010 & -0.00069 \\
\hline Gouda & $\begin{array}{l}\text { Wemmenhove et al., } \\
2013\end{array}$ & Milk & 12.5 & -3.77 & 5846 & -0.0015 & -0.0010 \\
\hline Gouda & $\begin{array}{l}\text { Wemmenhove et al., } \\
2013\end{array}$ & Milk & 12.5 & -1.30 & 1702 & -0.0018 & -0.0012 \\
\hline Gouda & $\begin{array}{l}\text { Wemmenhove et al., } \\
2013\end{array}$ & Milk & 12.5 & -1.54 & 3450 & -0.0010 & -0.00069 \\
\hline Gouda & $\begin{array}{l}\text { Wemmenhove et al., } \\
2013\end{array}$ & Milk & 12.5 & -1.80 & 4704 & -0.00088 & -0.00059 \\
\hline Gouda & $\begin{array}{l}\text { Wemmenhove et al., } \\
2013\end{array}$ & Milk & 12.5 & -0.40 & 4704 & -0.0002 & -0.00013 \\
\hline Gouda & $\begin{array}{l}\text { Wemmenhove et al., } \\
2013\end{array}$ & Milk & 12.5 & -1.00 & 4704 & -0.00049 & -0.00033 \\
\hline Emmental & $\begin{array}{l}\text { Bachmann \& Spahr, } \\
1995\end{array}$ & Milk & 12 & -0.80 & 2160 & -0.00085 & -0.00062 \\
\hline Emmental & Buazzi et al., 1992b & Milk & 7 & -3.04 & 722 & -0.010 & -0.018 \\
\hline Emmental & Buazzi et al., 1992b & Milk & 7 & -3.36 & 722 & -0.011 & -0.020 \\
\hline Emmental & Buazzi et al., 1992b & Milk & 7 & -3.41 & 722 & -0.011 & -0.020 \\
\hline Emmental & Buazzi et al., $1992 b$ & Milk & 24 & -3.04 & 722 & -0.010 & -0.0020 \\
\hline
\end{tabular}




\begin{tabular}{llllllll}
\hline Emmental & Buazzi et al., 1992b & Milk & 24 & -3.36 & 722 & -0.011 & -0.0022 \\
\hline Emmental & Buazzi et al., 1992b & Milk & 24 & -3.41 & 722 & -0.011 & -0.0022 \\
\hline Emmental & Genigeorgis et al., 1991 & Surface & 30 & -2.09 & 168 & -0.029 & -0.0038 \\
\hline Emmental & Genigeorgis et al., 1991 & Surface & 8 & -2.09 & 456 & -0.011 & -0.015 \\
\hline Emmental & Genigeorgis et al., 1991 & Surface & 4 & -2.09 & 864 & -0.0056 & -0.024 \\
\hline Emmental & Leong et al., 2014 & Slices & 25 & -1.20 & 360 & -0.0077 & -0.0014 \\
\hline Emmental & Leong et al., 2014 & Slices & 25 & -0.93 & 360 & -0.0059 & -0.0011 \\
\hline Emmental & Leong et al., 2014 & Slices & 25 & -0.43 & 360 & -0.0028 & -0.00052 \\
\hline Emmental & Leong et al., 2014 & Slices & 25 & -1.83 & 360 & -0.012 & -0.0022 \\
\hline
\end{tabular}




\section{Summary}

Listeria monocytogenes is known as an important bacterial pathogen and is the causative agent of foodborne listeriosis, a disease that can be fatal, especially for people with a weak immune system. L. monocytogenes is a robust bacterium that can be present in ingredients and production environments due to its ability to survive in highly acidic, salty and lowtemperature environments and due to its ability to form biofilms. The pathogen is a particular concern to ready-to-eat (RTE) food products, i.e., food products that do not undergo heat processing prior to consumption. Strict microbiological criteria for L. monocytogenes are applicable to RTE products as specified in regulation (EC) No 2073/2005. Three different categories of RTE products with different criteria for L. monocytogenes are defined therein.

Dutch-type Gouda cheese is a semi-hard cheese that is made from bovine milk that is pasteurized when produced at an industrial scale. It is a RTE food with a $\mathrm{pH}>5.0$ and water activity $\left(a_{w}\right)>0.94$. Without further scientific evidence that the product does not support the growth of L. monocytogenes, it belongs to category 1.2 food products as specified in regulation (EC) No 2073/2005, namely, 'a ready-to-eat food able to support growth of L. monocytogenes'. Category 1.2 products must comply with the criterion 'guarantee that the level does not exceed the limit of $100 \mathrm{cfu} \mathrm{g}^{-1}$ throughout the shelf life $(n=5)^{\prime}$ for products placed on the market during their shelf-life ${ }^{*}$ or with 'absence in $25 \mathrm{~g}(\mathrm{n}=5)$ before the food has left the immediate control of the food business operator, who has produced it $^{\prime * *}$. If a readyto-eat food is unable to support the growth of L. monocytogenes (other than those intended for infants and for special medical purposes) it belongs to category 1.3 and the criterion maximally $100 \mathrm{cfu}^{-1}(\mathrm{n}=5)$ applies. Scientific evidence for no growth potential can be obtained by predictive mathematical modelling, durability tests and/or challenge tests and must be to the satisfaction of the competent authority.

The aims of this study were to establish whether L. monocytogenes can grow in or on Gouda cheese, to investigate the most important factors present in Gouda cheese that determine growth/no growth of L. monocytogenes and the variation of these factors in Gouda, and to provide criteria with respect to the most important growth inhibitors in Gouda cheese that prevent growth of L. monocytogenes.

\footnotetext{
* This criterion applies if the manufacturer is able to demonstrate, to the satisfaction of the competent authority, that the product will not exceed the limit $100 \mathrm{cfu} \mathrm{g}^{-1}$ throughout the shelf-life. The operator may fix intermediate limits during the process that must be low enough to guarantee that the limit of $100 \mathrm{cfu} \mathrm{g}^{-1}$ is not exceeded at the end of the shelf-life.

** This criterion applies to products before they have left the immediate control of the producing food business operator, when he is not able to demonstrate, to the satisfaction of the competent authority, that the product will not exceed the limit of $100 \mathrm{cfu} \mathrm{g}^{-1}$ throughout the shelf-life.
} 
This research comprises two challenge studies investigating the fate of L. monocytogenes in and on Gouda cheese, two studies focusing on the variation in growth inhibition of L. monocytogenes by organic acids and $\mathrm{a}_{\mathrm{w}}$ at conditions relevant to Dutch-type Gouda cheese, and an overall review of the factors that are most important for inhibition of growth of L. monocytogenes in Gouda cheese.

In the first challenge study, cheese milk was artificially contaminated with L. monocytogenes before curd formation. It was demonstrated that L. monocytogenes does not grow in Gouda cheese. No growth of L. monocytogenes was observed during the first eight weeks of ripening, and viable numbers declined significantly between 8 and 52 weeks in a Gouda microcheese system. During curd formation, viable numbers of L. monocytogenes increased by 0.5 log cfu $\mathrm{g}^{-1}$, resulting from entrapment in the curd and removal of whey (Chapter 2).

In the second challenge study, the fate of L. monocytogenes was studied on and within factory-scale Gouda cheeses made from pasteurized cheese milk that had been submerged in artificially contaminated brine and then ripened at $12.5^{\circ} \mathrm{C}$ for up to 26 weeks. The fate of the pathogen in brine was established as well, showing that viable numbers in the brine were stable or decreased during brining. L. monocytogenes was enumerated on the surface of Gouda cheese immediately after brining and during ripening. This showed that transfer of L. monocytogenes from brine to cheese during brining was limited, and that L. monocytogenes was detected in the outer layer of Gouda cheese but not inside the cheese directly after brining or during ripening. Throughout the ripening period, the viable numbers of L. monocytogenes on the outer layer declined significantly (Chapter 3).

Profiles of $\mathrm{NaCl}$ and water and the resulting $a_{w}$ were determined in nature-ripened and foilripened Gouda cheese during brining and ripening to assess the variation in $a_{w}$ in Gouda cheese over time, as input for risk assessments. Immediately after brining, gradients of $\mathrm{NaCl}$ and water were observed throughout both types of cheese. During ripening, these gradients disappeared, except for the water gradient in nature-ripened cheeses. An empirical model was derived for Gouda cheese, in which the $\mathrm{a}_{\mathrm{w}}$ is expressed as a function of the $\mathrm{NaCl}$-in-moisture content, based on the data collected for cheeses with different brining times, at different positions in the cheeses and at different ripening times. Moreover, the effect of a reduced $\mathrm{a}_{\mathrm{w}}$ on inhibition of growth of L. monocytogenes in Gouda cheese was calculated. In addition to the presence of undissociated lactic acid, the reduced $a_{w}$ as seen in Gouda cheese can substantially contribute to inhibition of microbial growth, and even to inactivation of L. monocytogenes when cheeses are brined and nature-ripened for extended periods of time (Chapter 4).

In Chapter 5, the minimal inhibitory concentrations (MICs) of organic acids relevant to cheese for L. monocytogenes are reported. The MICs of undissociated lactic acid for L. monocytogenes were determined for six different strains that were cultured in the presence of different lactate concentrations at $30^{\circ} \mathrm{C}$ and in a pH range of 4.2-5.8. No growth was 
observed at $\mathrm{pH} 4.2$ and 4.4, and the MICs of undissociated lactic acid in the $\mathrm{pH}$ range of 5.25.8 were generally higher than at $\mathrm{pH} 4.6$ for the different L. monocytogenes strains. The average MIC of undissociated lactic acid was 5.0 (SD 1.5) $\mathrm{mM}$ in the $\mathrm{pH}$ range 5.2-5.6. Significant differences in MICs of undissociated lactic acid were found between strains of L. monocytogenes at a given $\mathrm{pH}$. Variations in MICs were mostly due to strain variation. For the strains tested in the $\mathrm{pH}$ range 5.2-5.6, the MICs of undissociated lactic acid were not significantly different at $12{ }^{\circ} \mathrm{C}$ and $30^{\circ} \mathrm{C}$. The MICs of undissociated acetic acid, citric acid, and propionic acid for the six L. monocytogenes strains were also determined, showing average values of 19.0 (SD 6.5) mM, 3.8 (SD 0.9) mM, and 11.0 (SD 6.3) mM, respectively. The MIC values that were established in this study improve the understanding of the growth-inhibiting effect of organic acids for L. monocytogenes, and offer more input data for predictive growth models that incorporate organic acids as growth-inhibiting factors for L. monocytogenes in cheese.

The known factors that are relevant to nature-ripened Gouda cheese were subsequently evaluated for their potential to inhibit growth of L. monocytogenes in this cheese. Factors included $\mathrm{a}_{\mathrm{w}}, \mathrm{pH}$, undissociated acetic and lactic acid, diacetyl, free fatty acids, lactoferrin, nitrate, nitrite and nisin. In addition, the effect of temperature was evaluated. For each factor, the actual concentrations and values relevant to Gouda cheese were obtained and the inhibitory effect of these individual factors on growth of L. monocytogenes was assessed based on literature data or on experimental data if data were not available in the scientific literature. This evaluation revealed that undissociated lactic acid is the primary factor for growth inhibition of L. monocytogenes in Gouda cheese. In a 2-week ripened Gouda cheese, which has a typical total lactic acid content of $1.47 \% \mathrm{w} / \mathrm{w}$, moisture content of $42 \% \mathrm{w} / \mathrm{w}$, and $\mathrm{pH} 5.25$, the concentration of undissociated lactic acid is $10.9 \mathrm{mM}$. Under such conditions, full growth inhibition of L. monocytogenes can be expected. Based on the minimal inhibitory concentrations of undissociated lactic acid for L. monocytogenes of $6.35 \mathrm{mM}$, full growth inhibition of $L$. monocytogenes can be expected in a young Gouda cheese when the total lactic acid concentration is $>0.86 \% \mathrm{w} / \mathrm{w}$ at a $\mathrm{pH}<5.25$, and in a mature Gouda cheese (moisture content of $35 \% \mathrm{w} / \mathrm{w}$ ) when the total lactic acid concentration is $>1.26 \% \mathrm{w} / \mathrm{w}$ at a $\mathrm{pH}<5.5$. In addition to undissociated lactic acid, the $a_{w}$ was identified as a factor that can cause full growth inhibition after prolonged ripening times (Chapter 6).

In the challenge studies that have been performed with L. monocytogenes in Gouda cheese, growth was not supported. The most important factors contributing to growth inhibition were identified as undissociated lactic acid, temperature, $\mathrm{pH}$ and $\mathrm{a}_{\mathrm{w}}$. These four factors determined full growth inhibition of L. monocytogenes during ripening of Gouda cheese. These factors were also the main determinants to correctly predict growth/no growth of $L$. monocytogenes in several other RTE cheeses (e.g. Queso fresco, Camembert, Feta, Cheddar, Ricotta, Mozzarella and Blue cheese). For Gouda, the factors undissociated lactic acid and $a_{w}$ can lead to full growth inhibition. Temperature and $\mathrm{pH}$ only delay growth of L. monocytogenes in Gouda cheese, as 
the critical values for growth of L. monocytogenes are not reached for these factors in this cheese type.

In this thesis, it was concluded that Dutch-type Gouda cheese does not support growth of L. monocytogenes. The assessment of potential inhibitory factors in this cheese revealed the importance of undissociated lactic acid as a growth-inhibiting factor, together with temperature, $\mathrm{pH}$ and $\mathrm{a}_{\mathrm{w}}$. This thesis lends support to categorizing Gouda as a ready-to-eat food product that does not support growth of L. monocytogenes. Furthermore, it is justifiable to include undissociated lactic acid (together with $\mathrm{pH}$ and $\mathrm{a}_{\mathrm{w}}$ ) in future food safety criteria for ready-to-eat products related to absence of growth of $L$. monocytogenes. 


\section{Acknowledgements}

Writing a PhD thesis is not an overnight activity. It is a process in which complex challenges pop up, and for which creativity, consistency and perseverance are required. I hope that the insights from this thesis will be used in the sector, and that the research results will contribute to assurance of food safety of Gouda cheese.

Doing a $\mathrm{PhD}$ research could be perceived as a solitary occupation, however my PhD has enabled me to collaborate with great people whom I would like to thank.

First of all, I would like to thank my co-promotor Marjon Wells-Bennik. You helped me to familiarize quickly at NIZO, taught me a lot about the pathogen, assisted me in setting up the lab trials and improved my scientific writing skills. Furthermore, you gave me the opportunity to work on food safety projects at NIZO in addition to my PhD research.

I would like to direct special thanks to my first promotor Marcel Zwietering. Your focus on the broad picture as well as on all details of the research was certainly helpful. Your critical reflections on my work and ability to challenge people pushed me to develop myself and to further improve the contents of this thesis.

I also want to thank my second promotor, Toon van Hooijdonk. Toon, thank you for underlining the importance of this subject to the dairy industry. You definitely sparked my interest for the dairy industry and cheese technology in general.

Hein van Valenberg and Rijkelt Beumer are acknowledged for their valuable contributions to this work. The colleagues from the Laboratory of Food Microbiology and Food Quality Design, including the Dairy Science and Technology department, I want to thank for the nice meetings and for the pleasant time in the lab.

I would like to thank the reviewers of this thesis. Michiel Kleerebezem, Benno Ter Kuile, JeanChristophe Augustin and Martin Bonestroo, many thanks for putting your time and effort in the evaluation of this work and thesis.

The Dutch Dairy Association (NZO) is acknowledged for sponsoring this project. Alex Hoekstra, Arjan Lobeek, Frank Gielens, Jacco Blankespoor, Koert Mostert, Margreet Hovenkamp, Rien Habraken, Rients Feenstra and Ynte de Vries, thanks for being part of the Begeleidingscommissie Zuivel. It was great to experience the Dutch dairy companies joining forces for the purpose of food safety. Thanks for sharing information, sending me cheeses for chemical characterization and providing me with critical feedback.

I would like thank all my former colleagues from NIZO food research. In particular Martijn Fox, Matthew de Roode and Hein van Lieverloo for working together with the @Risk software as well as Frank Driehuis and Arjen van Asselt for collaborating on NZO projects. I would like to thank Roelie Holleman, Jan de Wit, Elly Lucas, Arjen Wagendorp, Patrick Janssen, Roger Bongers and 
Jacqueline Voorendt for their support in the lab. My students Ioanna Stampelou and Aikaterini Stara are acknowledged for their nice research results generated in the lab. Also I would like to thank my roommates Janny van Gijssel, Stijn van der Veen, Marloes Schepens and Marleen van Ampting, as well as my PhD colleagues Erwin Berendsen, Oylum Erkus, Onur Ercan, Sven Menschel, and later Arla colleagues Elissavet Gkogka, Sander Sieuwerts and Yinghua Xiao, I really appreciated the scientific discussions together with you, as well as all fun activities outside working hours.

Then, thanks a lot to all my friends from Wageningen, Aarhus and Bedford for offering me the necessary distraction from the PhD research: choir concerts, orchestra and musical performances, running competitions, dinners, game nights, city trips and other events.

A special thanks to my paranymphs Yinghua Xiao and Rik Wemmenhove. Xiao, thanks for being around for so many years as a colleague, neighbor and friend. Rik, it's always great to have your down-to-earth opinion on things to put things back into perspective. I want to thank Bart van Heugten for the help with the cover design.

To my parents, Rik, Vera, Dinant and Willem: thanks for your ongoing love and support. 


\section{List of publications}

Wemmenhove, E., Van Valenberg, H.J.F., Van Hooijdonk, A.C.M., Wells-Bennik, M.H.J., Zwietering, M.H. (2018) Factors that inhibit growth of Listeria monocytogenes in nature-ripened Gouda cheese: A major role for undissociated lactic acid. Food Control 84, 413-418.

Wemmenhove, E., Stara, A., Wells-Bennik, M.H.J., Van Hooijdonk, A.C.M., Zwietering, M.H. (2016) How $\mathrm{NaCl}$ and water content determine water activity during ripening of Gouda cheese, and the predicted effect on inhibition of Listeria monocytogenes. Journal of Dairy Science 99, 5192-5201.

Wemmenhove, E., Beumer, R.R., Van Hooijdonk, A.C.M., Zwietering, M.H., Wells-Bennik, M.H.J. (2016) Minimal inhibitory concentrations of undissociated lactic, acetic, citric and propionic acid for Listeria monocytogenes under conditions relevant to cheese. Food Microbiology 58, 63-67.

Wemmenhove, E., Beumer, R.R., Van Hooijdonk, A.C.M., Zwietering, M.H., Wells-Bennik, M.H.J. (2014) The fate of Listeria monocytogenes in brine and Gouda cheese after an artificial contamination during brining: no growth, and inactivation in cheese during ripening. International Dairy Journal, 39, 253-258.

Wemmenhove, E., Stampelou, I., Van Hooijdonk, A.C.M., Zwietering, M.H., Wells-Bennik, M.H.J. (2013) Fate of Listeria monocytogenes in Gouda microcheese: no growth, and substantial inactivation after extended ripening times. International Dairy Journal, 32, 192-198. 


\section{Curriculum vitae}

Ellen Wemmenhove was born in 1985 in Den Ham, The Netherlands. She finished her secondary education (VWO) at Reggesteijn in Nijverdal in 2002. That same year, she moved to Wageningen to do a BSc in Food Technology, followed by an MSc in Food Safety in 2005, focusing on food microbiology and toxicology. After graduating in 2007, Ellen started working as an Assistant Approvals Manager at the Safety and Environmental Assessment Center in Unilever Colworth, United Kingdom. In 2008, she started her PhD in employment of the Dutch Dairy Association (NZO), working as a Scientist at NIZO food research. In 2012 she decided to continue her career in cheese technology by working for Royal FrieslandCampina as a Technology Developer. In 2015, Ellen moved to Denmark to work for Arla Foods, to extend her knowledge on fermentation and cheese technology. Since 2016, she works as a Research Scientist, developing Mozzarella in the Global Cheese team of Arla Foods in Aarhus. 


\section{VLAG graduate school - Overview of completed training activities}

\section{Discipline- specific activities}

Courses:

Basic laboratory pathogens training, NIZO, Ede, NL, 2008

Management of microbiological hazards in foods, VLAG, Wageningen, NL, 2008

Nutrient density of milk, VLAG, Wageningen, NL, 2009

Reaction kinetics in food, VLAG, Wageningen, NL, 2009

Listeria challenge tests, Nieuwsbrief Voedselveiligheid, Maarssen, NL, 2010

Genetics and physiology of food-associated m.o. VLAG, Wageningen, NL, 2010

\section{Conferences/symposia/workshops:}

Food Micro 2008 (oral presentation), ICFMH, Aberdeen, UK, 2008

Safety issues of raw milk cheeses conference, SAFE, Brussels, BE, 2008

Food Micro 2010, ICFMH, Copenhagen, DK, 2010

Workshop Listeria modeling, DTU, Copenhagen, DK, 2010

ICPMF 7, ICPMF, Dublin, IE, 2011

NVVM workshop food microbiology (oral presentation), NVVM, Wageningen, NL, 2012

Food safety \& spoilage seminar NIZO (oral lecture), NIZO, Ede, NL, 2012

Workshop Modeling of Listeria monocytogenes in Gouda cheese (organization and oral lecture), NZO/NIZO,

Ede, NL, 2012

\section{General courses}

VLAG PhD week (Introduction course), VLAG, Wageningen, NL, 2008

Communicative skills, NIZO, Wageningen, NL, 2008

PhD competence assessment, WGS, Wageningen, NL, 2009

Scientific writing, WGS, Wageningen, NL, 2010

Presentation skills, WGS, Wageningen, NL, 2010

Philosophy \& ethics of food science and technology, VLAG, Wageningen, NL, 2011

Communication with the media \& the general public, WGS, Wageningen, NL, 2011

Career perspectives, WGS, Wageningen, NL, 2011

\section{Optional courses}

Preparation of research proposal, WUR, Wageningen, NL, 2008

PhD trip Australia Dairy Science \& Technology, WUR, Wageningen, NL, 2010

TIFN (molecular) microbiology meetings, NIZO, Ede, NL, 2008-2012

Half-yearly meetings of industrial taskforce Listeria in cheese (oral presentations), NIZO, Ede, NL, 2008-

2012 
This thesis was financially supported by the Dutch Dairy Association.

Cover design by Bart van Heugten

Printed by Proefschriftmaken.nl | Digiforce 

